Leila Bagaiolo

\title{
Padrões de Aquisição de Discriminação \\ Condicional durante a Emergência do Controle por Unidades Verbais Mínimas na Leitura em \\ Crianças com Autismo e Desenvolvimento Típico
}

Tese apresentada ao Instituto de Psicologia

da Universidade de São Paulo, para

obtenção do título de DOUTORA em Psicologia

Área de concentração: Psicologia Experimental

Orientação da Profa. Dra. Maria Martha Hübner

São Paulo

2009 


\title{
AUTORIZO A REPRODUÇÃO E DIVULGAÇÃO TOTAL OU PARCIAL DESTE TRABALHO, POR QUALQUER MEIO CONVENCIONAL OU ELETRÔNICO, PARA FINS DE ESTUDO E PESQUISA, DESDE QUE CITADA A FONTE.
}

\author{
Catalogação na publicação \\ Biblioteca Dante Moreira Leite \\ Instituto de Psicologia da Universidade de São Paulo
}

\section{Bagaiolo, Leila.}

Padrões de aquisição de discriminação condicional durante a emergência do controle por unidades verbais mínimas em leitura em crianças com autismo e desenvolvimento típico / Leila Bagaiolo; orientadora Maria Martha Hubner. -- São Paulo, 2009.

$217 \mathrm{p}$.

Tese (Doutorado - Programa de Pós-Graduação em Psicologia. Área de Concentração: Psicologia Experimental) - Instituto de Psicologia da Universidade de São Paulo.

1. Discriminação condicional 2. Equivalência de estímulos
3. Controle do estímulo
4. Leitura
5. Estímulos verbais
6. Autismo

I. Título.

BF319 
Padrões de Aquisição de Discriminação Condicional durante a Emergência do Controle por Unidades Verbais Mínimas na Leitura em Crianças com Autismo e Desenvolvimento Típico

Tese apresentada ao Instituto de Psicologia da Universidade de São Paulo, para obtenção do título de DOUTORA em Psicologia

Área de concentração: Psicologia Experimental Orientação da Profa. Dra. Maria Martha Hübner

Aprovado em:

Banca Examinadora:

Profa. Dra.

Instituição: Assinatura:

Profa. Dra.

Instituição: Assinatura:

Profa. Dra.

Instituição: Assinatura:

Profa. Dra.

Instituição: Assinatura:

Profa. Dra.

Instituição: Assinatura: 
Para Matheus,

com amor (in) condicional $^{2}$ 


\section{AGRADECIMENTOS}

Martha, espero que você também tenha ficado bastante feliz com este trabalho. Obrigada pela reflexão sobre a possibilidade de fazê-lo!!! Obrigada pela colaboração.

Nilza, obrigada por participar de mais essa etapa importante da minha formação. Começamos no TCC e chegamos até aqui! Vamos além.

Paula Debert, suas contribuições (não é de hoje....) são especiais. Obrigada pela disponibilidade sempre.

Às minhas professoras, inspiradoras e primeiras orientadoras: Amália e Téia.

Paula Gioia, sempre querida e perto. Obrigada pelo carinho constante.

Di, obrigada por acreditar e apoiar. Raridade pura.

Matheus, que bom poder aprender e amadurecer com você. lv xx.

Cintia, obrigada pela confiança, amizade e .... mais uma vez começamos e terminamos juntas!

KK, obrigada por compartilhar o cotidiano e fazer dele uma coisa melhor. A festa só está começando ${ }^{2}$.

Jessika, obrigada, obrigada, obrigada! Seu crescimento me orgulha muito; foi um prazer repartir esse trabalho com você; espero repartir outros tantos.

Stephanny, obrigada pela disponibilidade, com empenho, para ajudar a construir esse trabalho.

Ju Godoi, é sempre ótimo contar com você do nosso lado!!! Gradualmente, a confiança e o carinho foram crescendo e hoje você é uma pessoa essencial e especial para mim. 
Pô, vc é uma querida, querida do coração.

Baby Angel Angelíssima, tudo de bom.

Pai e Mãe, obrigada pelo orgulho de vocês.

Renato, você é mais, bem mais que um irmão querido. Amigo.

Raulito e sheilovsky: Família 2, do coração, que me deram um dindo. Obrigada!

D. Fina, obrigada pelo apoio e carinho de sempre.

Olga, Antonio e Raquel: é uma delícia ter vocês como amigos e família.

Mary e Smello, obrigada pela paciência e convivência no "período recluso", no meio da nossa festa. Megablaster!

Wla e Lu, sempre vale pelo interesse e curiosidade constante de vocês. Queridos!

Gu, isto começou lá atrás, com seu apoio. Ainda bem que ficamos juntos ${ }^{2}$.

Fábio e Phila, in memoriam.

E finalmente, agradecimento especial para a participante desta pesquisa e, também, para a sua mãe.

E, a todos que estiveram juntos, um sonoro plágio do Tim Maia e do Matheus:

VALEU!!!!!! 


\section{DUAS ODES}

Quando, Lídia, vier o nosso outono

Com o inverno que há nele, reservemos

Um pensamento, não para a futura

Primavera, que é de outrem,

Nem para o estio, de quem somos mortos,

Senão para que fica do que passa -

$\mathrm{O}$ amarelo actual que as folhas vivem

$\mathrm{E}$ as torna diferentes.

Tênue, como se de Éolo a esquecessem,

A brisa da manhã titila o campo,

E há começo do sol.

Não desejemos, Lídia, nesta hora

Mais sol do que ela, nem mais alta brisa

Que a que é pequena e existe.

Ricardo Reis (Fernando Pessoa) 
BAGAIOLO, L. Padrões de aquisição de discriminação condicional na emergência do controle por unidades verbais mínimas na leitura em crianças com autismo e desenvolvimento típico. 2009. 217 f. Tese (Doutorado) - Instituto de Psicologia, Universidade de São Paulo, São Paulo, 2009.

O Estudo 1 deste trabalho teve como objetivo avaliar, em participantes típicos, possíveis controles de estímulos envolvidos no processo de aquisição do controle por unidades verbais mínimas durante os treinos de discriminação condicional dos estímulos compostos (palavras), e durante os testes que avaliavam deste repertório. O objetivo do Estudo 2 foi realizar uma replicação sistemática dos procedimentos metodológicos e de análise empregados no Estudo 1 com uma participante com autismo e, propor procedimentos individualizados de correção de controle restrito de estímulos. No Estudo 1 foram analisados dados anteriormente coletados, por meio de um programa de ensino de leitura generalizada, de três participantes e, também, foi proposta uma categorização dos pares de estímulos relacionados às respostas dos participantes e os estímulos modelo apresentados, em cada tentativa de erro, em termos da presença de diferenças críticas ou múltiplas nos elementos dos estímulos compostos. No Estudo 2 foi aplicado o programa para a emergência de controles por unidades verbais mínimas e também foi realizada a análise de erros do Estudo 1 que, em parte, auxiliou na introdução de procedimentos específicos e individualizados para a correção de padrões de controle restrito de estímulos. Os resultados do Estudo 1 e 2 apontaram que, de forma geral, os quatro participantes demonstraram aquisição do controle por unidades verbais mínimas, mas foi observada ocorrência de variabilidade no que se refere à predominância de erros envolvendo diferenças críticas ou múltiplas e no que se refere à necessidade de introdução de procedimentos específicos e individualizados para maximizar o repertório de aquisição esperado ou corrigir controles restritos de estímulos.

Palavras-chave: Discriminação Condicional, Equivalência de estímulos, Controle de estímulos, Leitura, Estímulos Verbais, Autismo. 
BAGAIOLO, L. Padrões de Aquisição de Discriminação Condicional durante a Emergência do Controle por Unidades Verbais Mínimas em Leitura. 2009. 217 f. Tese (Doutorado) - Instituto de Psicologia, Universidade de São Paulo, São Paulo, 2009.

Study 1 of this work aimed to evaluate, in children with typical development, possible controls of stimuli involved in the process of acquisition of control by minimal verbal units. Investigation took place during the training sessions of conditional discrimination of compound stimuli (written words), and during the tests that evaluated the emergence of control by minimal verbal units. The purpose of Study 2 was threefold. Firstly, to carry out a systematic replication of the procedures employed in Study 1 with a participant with autism. Secondly, to widen the scope of analysis of Study1. And thirdly, to propose procedures for correction of individual control to restricted stimuli. In Study 1, previously-collected data were analyzed through a program of recombinative reading with three participants. The pairs of stimuli related to the responses of participants and the stimuli model presented in each trial error were categorized. The results were analyzed to see critical and multiple differences of compound stimuli. In Study 2, not only were the same program and categorization applied, but specific and individualized procedures to correct patterns of restricted control of stimuli were introduced. The results of Study 1 and 2 showed that, in general, the four participants demonstrated acquisition of control by minimal verbal units. However, occurrence of variability regarding the prevalence of errors involving multiple or critical differences was observed. There was also variability with regards to the need to introduce specific and individualized procedures to maximize the expected repertoire or correct restricted stimuli control.

Keywords: Conditional Discrimination, Equivalence Relations, Stimulus Control, Reading, Verbal Stimulus, Autism. 


\section{LISTA DE TABELAS}

Tabela 1. Identificação dos participantes por idade, sexo e período de coleta, cujos dados foram publicados originalmente em Matos et al. (2002).

Tabela 2. Distribuição das palavras impressas relativas aos conjuntos de estímulos, apresentados durante o programa EQUIV, formados por palavras ditadas e as respectivas figuras e palavras impressas. .55

Tabela 3. Classificação dos erros e das respectivas combinações entre pares de estímulos que são palavras dissílabas ditadas e impressas (estímulos compostos), relativas ao primeiro conjunto de estímulos, comum aos Participantes 1, 2 e 3. As palavras que formam este conjunto são: BOCA, LOBO, CABO e BOLO. .59

Tabela 4. Classificação dos erros e das respectivas combinações entre pares de estímulos que são palavras dissílabas ditadas e impressas (estímulos compostos), relativas ao segundo conjunto de estímulos, comum aos Participantes 1, 2 e 3. As palavras que formam este conjunto são: CACO, BALA, COCA, BOLA

Tabela 5. Classificação dos erros e das respectivas combinações entre pares de estímulos que são palavras dissílabas ditadas e impressas (estímulos compostos), relativas ao terceiro conjunto de estímulos, comum aos Participantes 1,2 e 3 ( para o Participante 3 foi utilizado outro conjunto de estímulo- ver Tabela 6). As palavras são: BOBO, CALO, LOLO, LOCA.

Tabela 6. Classificação dos erros e das respectivas combinações entre pares de estímulos que são palavras dissílabas ditadas e impressas (estímulos compostos), relativas ao terceiro conjunto de estímulos utilizados apenas com o Participante 3 (para os Participantes 1 e 2 foi utilizado outro conjunto de estímulo - ver Tabela 5). As palavras que formam este conjunto são: BABA, COLO, LOLO, LOCO. 
Tabela 7. Classificação dos erros e das respectivas combinações entre pares de estímulos que são palavras dissílabas ditadas e impressas (estímulos compostos), relativas ao terceiro conjunto de estímulos utilizados apenas com o Participante 3 (os Participante 1 e 2 não foram expostos a um quarto conjunto de estímulos). As palavras que formam este conjunto são: BABO, LOLA, COCO, CACA.

Tabela 8. Distribuição dos tipos de erros dos participantes durante as fases do EQUIV a partir das combinações entre estímulos modelo e estímulos relacionados às respostas dos participantes

TABELA 9. Distribuição da freqüência e dos tipos de erros do Participante 1 nas etapas de Treinos e Testes do programa EQUIV. .71

Tabela 10. Distribuição da freqüência e dos tipos de erros do Participante 2 nas etapas de Treinos e Testes do programa EQUIV. .81

Tabela 11. Distribuição da freqüência e dos tipos de erros do Participante 3 nas etapas de Treinos e Testes do programa EQUIV.

Tabela 12. Distribuição das palavras impressas relativas aos conjuntos de estímulos, apresentados durante o programa, para a Participante 4, formados por palavras ditadas e as respectivas figuras e palavras impressas. 108

Tabela 13. Procedimentos de correção específicos, para P4, frente a dificuldades e controles restritos de estímulos durante o programa EQUIVIUM. 131

Tabela 14. Distribuição dos principais itens potencialmente reforçadores escolhidos por P4 durante o período de coleta de dados. 136

Tabela 15. Distribuição da freqüência e dos tipos de erros da Participante 4 nas etapas de Treinos e Testes do programa EQUIVIUM. 


\section{LISTA DE FIGURAS}

Figura 1. Exemplo de um dos 18 conjuntos de estímulos compostos, positivos e negativos, apresentados durante as condições de treino. Adaptação de Allen e Fuqua (1985)

Figura 2. Distribuição dos tipos de erros emitidos pelo Participante 1 e das respectivas quantidades dos mesmos, ao longo do programa EQUIV para três conjuntos de estímulos. As barras representam as tentativas de treino e os triângulos e as cruzes representam as tentativas de teste.

Figura 3. Distribuição de porcentagens de acerto do Participante 1, nas diferentes fases do programa, para três conjuntos de estímulos diferentes, em diferentes tipos de tarefas.

Figura 4. Distribuição dos tipos de erros emitidos pelo Participante 2 e, das respectivas quantidades dos mesmos, ao longo do programa EQUIV, para três conjuntos de estímulos. As barras representam as tentativas de treino, os triângulos e as cruzes representam as tentativas de teste.

Figura 5. Distribuição das porcentagens de acertos do Participante 2, nas diferentes fases do programa, para três conjuntos de estímulos diferentes.

Figura 6. Distribuição dos tipos de erros emitidos pelo Participante 3 e, das respectivas quantidades dos mesmos, ao longo do programa EQUIV para dois conjuntos de estímulos. As barras representam as tentativas de treino e os triângulos e as cruzes representam as tentativas de teste

Figura 7. Distribuição das porcentagens de acertos do Participante 3, nas diferentes fases do programa, para quatro conjuntos de estímulos diferentes.

Figura 8. Exemplos de figuras utilizadas no primeiro conjunto de estímulos (Conjunto B). 
Figura 9. Exemplos de apresentações de tentativas através do EQUIVIUM. 109

Figura 10. Representação da posição dos estímulos na tela. 110

Figura 11. Diagrama para ilustrar as relações ensinadas e testadas entre os conjuntos de estímulos A, B e C

Figura 12. Seqüência de apresentação das fases no EQUIVIUM

Figura 13. Relação das fases pertencentes ao programa EQUIVIUM: passos, tipos de estímulos utilizados, número e tipo de tentativas previstas, critério de avanço e probabilidade de reforçamento utilizados para a Participante 4

Figura 14. Distribuição do número de acertos e erros da Participante 4, para testagem ABLA 137

Figura 15. Distribuição do número de tentativas apresentadas e do número de tentativas corretas relativas aos desempenhos da Participante 4, em tarefas de discriminação condicional em palavras ditadas e palavras impressas (Treinos AC) e nos Testes de Eqüivalência I, Anagrama I, Testes de Novas Formas Verbais II (BC), para dois conjuntos de estímulos diferentes

Figura 16. Distribuição dos tipos de erros emitidos pela Participante 4 e das respectivas quantidades dos mesmos, ao longo do programa EQUIVIUM, para um conjunto de estímulos. As barras representam tentativas de treino.

Figura 17. Distribuição das porcentagens de acertos da Participante 4, nas diferentes fases do programa, para dois conjuntos de estímulos diferentes 150

Figura 18. Freqüência acumulada do número de erros e acertos realizados pela Participante 4, ao longo das sessões e das diferentes fases do programa EQUIVIUM. 
Figura 19. Relação das fases pertencentes ao programa EQUIVIUM: passos, tipos de estímulos utilizados, número e tipo de tentativas previstas, critério de avanço e probabilidade de reforçamento utilizados para os Participantes 1, 2 e 3

Figura 20. Matriz com erros do Participante 1, nas tentativas do Treino AC, para o primeiro conjunto de estímulos

Figura 21. Matriz com erros do Participante 1, nas tentativas de Treino de Construção (Anagrama I), para o primeiro conjunto de estímulos. 183

Figura 22. Matriz com erros do Participante 1, nas tentativas de Teste de Novas Formas Verbais I (BC/CB), para o segundo conjunto de estímulos.

Figura 23. Matriz com erros do Participante 1, nas tentativas de Treino $\mathrm{A}^{\prime} \mathrm{C}^{\prime}$, para o segundo conjunto de estímulos. 184

Figura 24. Matriz com erros do Participante 1, nas tentativas do Teste de Equivalência II ( $\left.\mathrm{B}^{\prime} \mathrm{C}^{\prime} / \mathrm{C}^{\prime} \mathrm{B}^{\prime}\right)$, para o segundo conjunto de estímulos. 185

Figura 25. Matriz com erros do Participante 1, nas tentativas do Teste de Novas Formas Verbais II (B" $\left.\mathrm{C}^{\prime \prime} / \mathrm{C}^{\prime \prime} \mathrm{B}^{\prime \prime}\right)$, para o terceiro conjunto de estímulos. 186

Figura 26. Matriz com erros do Participante 2, nas tentativas de Treino AC, para o primeiro conjunto de estímulos 187

Figura 27. Matriz com erros do Participante 2, nas tentativas do Testes de Equivalência $\mathrm{I}(\mathrm{BC} / \mathrm{CB})$, para o primeiro conjunto de estímulos 187

Figura 28. Matriz com erros do Participante 2, nas tentativas de Testes de Novas Formas Verbais I ( $\left.\mathrm{B}^{\prime} \mathrm{C}^{\prime} / \mathrm{C}^{\prime} \mathrm{B}^{\prime}\right)$, para o segundo conjunto de estímulos. 188 
Figura 29. Matriz com erros do Participante 2, nas tentativas do Teste de Nomeação Oral II (conjuntos $\mathrm{C}$ e $\mathrm{C}^{\prime}$ ).

Figura 30. Matriz com erros do Participante 2 nas tentativas de Treino $\mathrm{A}^{\prime} \mathrm{C}^{\prime}$, para o segundo conjunto de estímulos.

Figura 31. Matriz com erros do Participante 2, nas tentativas do Teste de Equivalência II $\left(\mathrm{B}^{\prime} \mathrm{C}^{\prime} / \mathrm{C}^{\prime} \mathrm{B}^{\prime}\right)$, para o segundo conjunto de palavras. 192

Figura 32. Matriz com erros do Participante 2, nas tentativas do Testes de Novas Formas Verbais II ( $\left.\mathrm{B}^{\prime \prime} \mathrm{C}^{\prime \prime} / \mathrm{C}^{\prime \prime} \mathrm{B}^{\prime \prime}\right)$, para o terceiro conjunto de estímulos.

Figura 33. Matriz com erros do Participante 2, nas tentativas do Teste de Nomeação Oral III (Conjunto C). 193

Figura 34. Matriz com erros do Participante 2, nas tentativas do Teste de Nomeação Oral III (Conjunto $\mathrm{C}^{\prime}$ )

Figura 35. Matriz com erros do Participante 2, nas tentativas do Teste de Nomeação Oral III Conjunto $\mathrm{C}^{\prime \prime}$ ) 195

Figura 36. Matriz com erros do Participante 3, nas tentativas do Teste de Novas Formas Verbais I ( $\left.\mathrm{B}^{\prime} \mathrm{C}^{\prime} / \mathrm{C}^{\prime} \mathrm{B}^{\prime}\right)$, para o segundo conjunto de estímulos. .196

Figura 37. Matriz com erros do Participante 3, nas tentativas do Teste de Nomeação Oral II (Conjunto C). 198

Figura 38. Matriz com erros do Participante 3, nas tentativas do Teste de Nomeação Oral II (Conjunto $\left.C^{\prime}\right)$ 198

Figura 39. Matriz com erros do Participante 3 nas tentativas de Treino $\mathrm{A}^{\prime} \mathrm{C}^{\prime}$, para o segundo conjunto de palavras.... 
Figura 40. Matriz com erros do Participante 3, nas tentativas de Testes de Equivalência II ( $\left.\mathrm{B}^{\prime} \mathrm{C}^{\prime} / \mathrm{C}^{\prime} \mathrm{B}^{\prime}\right)$, para o segundo conjunto de estímulos 199

Figura 41. Matriz com erros do Participante 3, nas tentativas do Teste de Novas Formas Verbais II $\left(\mathrm{B}^{\prime \prime} \mathrm{C}^{\prime \prime} / \mathrm{C}^{\prime \prime} \mathrm{B}^{\prime \prime}\right)$ para o terceiro conjunto de estímulos. .200

Figura 41. Matriz com erros do Participante 4, nas tentativas do Treino AC, para o primeiro conjunto de estímulos 217 


\section{SUMÁRIO}

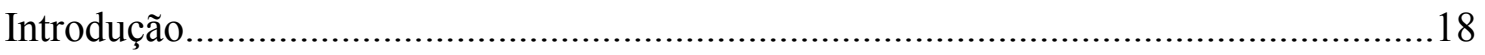

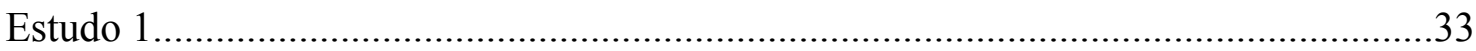

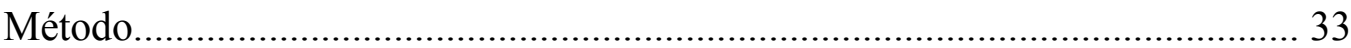

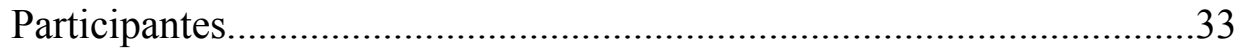

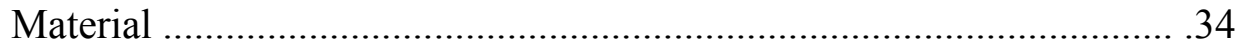

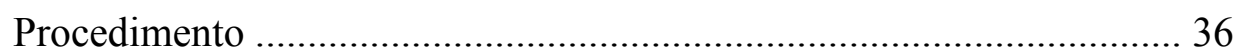

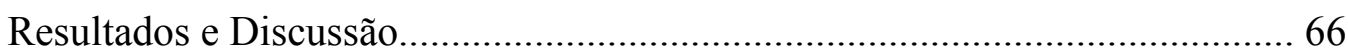

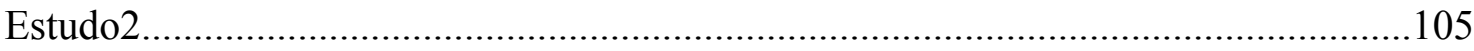

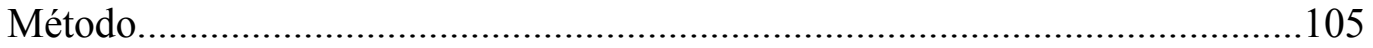

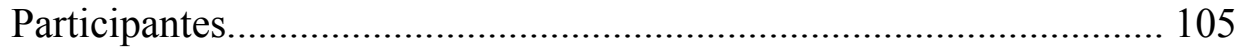

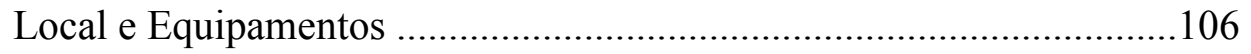

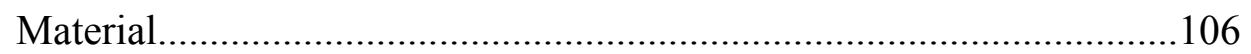

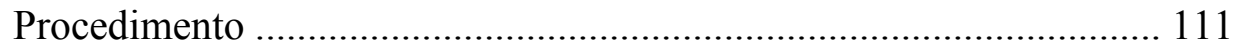

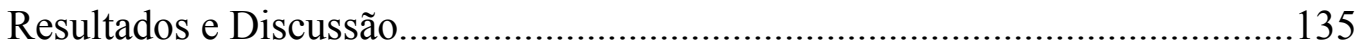

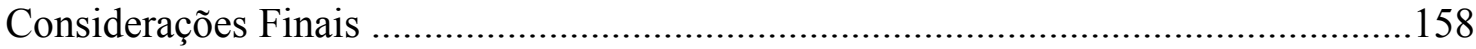

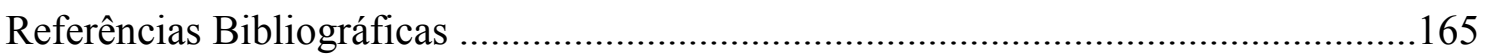

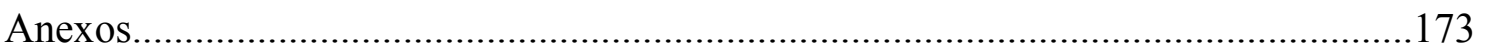


A investigação experimental do comportamento de ler, na Análise do Comportamento, requer como eixo fundamental a noção skinneriana de comportamento operante; a formulação deste conceito está, por sua vez, intrinsecamente relacionada com a noção de probabilidade:

Os estímulos agem continuamente sobre o organismo, mas sua conexão funcional com o comportamento operante não é a mesma que no reflexo. $\mathrm{O}$ comportamento operante, em resumo, é emitido e não eliciado. Precisa ter esta propriedade para que esta noção de probabilidade de resposta tenha sentido. (Skinner, 1953/ 1998, p. 118)

Diferente do comportamento reflexo, no qual um estímulo antecedente provoca invariavelmente a emissão de uma determinada resposta, no comportamento operante é preciso descrever uma contingência de três termos por meio da qual se demonstra que um determinado estímulo antecedente é ocasião para a emissão de uma determinada resposta que, por sua vez, será seguida de reforço: "Descrevemos a contingência dizendo que um estímulo (a luz) é a ocasião na qual uma resposta (estirar o pescoço) é seguida por reforço (com alimento). ... O processo através do qual isso acontece denomina-se discriminação." (Skinner; 1953/1998, p. 119).

Assim, quando uma discriminação é estabelecida, é possível aumentar ou diminuir a probabilidade de uma determinada resposta, por meio da manipulação do estímulo discriminativo; enquanto este é ocasião para a emissão de uma resposta, não é ocasião para a emissão de outras respostas, que não são seguidas por reforço.

De modo diferencial em relação à discriminação simples (demonstrada por meio da contingência de três termos), na discriminação condicional a função dos estímulos discriminativos altera-se dependendo dos contextos nos quais eles estão presentes, ou seja, a função do estímulo discriminativo é alterada pela presença ou não de outros 
estímulos, denominados condicionais. Como apontam Cumming e Berryman (1965), enquanto na discriminação simples ou simultânea o estímulo discriminativo tem uma relação invariante com o reforçamento ou extinção de uma resposta, na discriminação condicional há uma restrição da contingência de reforçamento por algum aspecto específico do estímulo condicional, que funciona como um seletor de discriminações. Para os autores, uma discriminação condicional é demonstrada quando um estímulo condicional (um estímulo discriminativo de segunda ordem) exerce controle sobre os estímulos discriminativos de primeira ordem, que controlam a resposta por meio da presença ou ausência do reforço.

Estudos sobre discriminação condicional geralmente empregam um tipo de procedimento denominado como escolha de acordo com o modelo (Matching-tosample), que comumente é abreviado como MTS (Cumming \& Berryman, 1965). Neste procedimento, uma tríplice contingência - estímulo antecedente, resposta, estímulo conseqüente - estaria sob controle de um estímulo condicional; assim, a discriminação condicional envolveria uma contingência de quatro termos, como descrito mais tarde por Sidman e Tailby (1982), na qual é a relação entre os dois estímulos (condicional e discriminativo) que controla a relação resposta-reforço.

No procedimento de MTS um estímulo condicional é denominado estímulo modelo e os estímulos discriminativos são denominados estímulos de escolha. Durante o procedimento, o estímulo modelo é apresentado em cada tentativa e, geralmente, é exigida uma resposta de observação do sujeito (por exemplo, tocar ou apontar) em relação ao estímulo modelo; na mesma tentativa, dois ou mais estímulos são apresentados como escolhas, mas apenas um deles é designado como escolha correto; a escolha desse estímulo será reforçada e respostas a outros estímulos não serão acompanhadas de reforço. Em uma tentativa de MTS os estímulos modelo e os de 
escolha podem ser apresentados de forma simultânea, com todos os estímulos juntos ou pode ocorrer um intervalo entre a apresentação do estímulo modelo, a resposta de observação e a retirada do estímulo modelo e, então, a apresentação dos estímulos de escolha, o que é denominado como MTS com atraso zero.

O procedimento de MTS pode ser denominado como de identidade, no qual os estímulos modelo e de escolha têm uma relação de similaridade física entre si; outro tipo de MTS pode ser o arbitrário ou simbólico (Cumming \& Berryman, 1965); aqui a especificação entre os estímulos modelo e de escolha é arbitrária, ou seja, não há similaridade física entre eles. É exatamente essa relação arbitrária entre os estímulos presentes em uma dada discriminação condicional, que permite o estudo de comportamentos complexos como, por exemplo, o da leitura, conforme ressalta Hübner (1990):

A possibilidade de estudar o fenômeno da leitura com procedimentos de discriminação condicional surgiu com os estudos em 'MTS to sample simbólico' onde os estímulos-modelo e de escolha não são idênticos fisicamente: sua relação é arbitrária e, portanto, o fenômeno em estudo passa a ser 'simbólico' (tais como são, por exemplo, as relações entre a grafia das palavras e o seu significado: um código arbitrário, que varia de língua para língua (pp. 10-11).

A análise experimental dos processos envolvidos no comportamento de ler tem um importante marco: o experimento de Sidman, de 1971. Neste histórico estudo, que utilizou o procedimento de MTS, foi realizado o primeiro experimento na área, que posteriormente passou a ser identificada como de equivalência de estímulos; o experimento tinha como estímulos palavras ditadas e as respectivas figuras e palavras impressas. O objetivo final era testar se após o treino direto destas relações emergeria a leitura com compreensão. 
O participante deste experimento tinha 17 anos e era descrito como severamente retardado. Primeiramente foram realizados pré-testes, os "testes de controle de linha de base", para verificar os pareamentos que o participante já realizava. Verificou-se que ele era capaz de emparelhar vinte figuras e seus respectivos nomes ditados, bem como nomeava estas vinte figuras; porém, o participante não realizava o emparelhamento das respectivas palavras impressas com seus nomes ditados e, também, não era capaz de nomear as vinte palavras impressas.

A partir dos resultados do Pré-Teste, Sidman (1971) realizou um treino com o objetivo de estabelecer a aquisição de discriminações condicionais entre as vinte palavras impressas e os respectivos nomes ditados. Durante as tentativas de treino, uma palavra era apresentada oralmente como modelo e, após o participante tocar uma janela central, oito estímulos de escolha (palavras impressas) eram apresentados; um deles correspondia ao estímulo modelo.

Após o treino, Sidman (1971) realizou outra série de testes, os Pós-Testes, nos quais verificou se o participante era capaz de combinar as figuras com as respectivas palavras impressas, as palavras impressas com as respectivas figuras e nomear em voz alta as palavras impressas, ou seja, comportamentos emergentes, que não foram explicitamente ensinados anteriormente. A conclusão do autor foi que, a partir do repertório do participante anteriormente à etapa de treino (combinar figuras com palavras ditadas e nomear figuras) e do treino de discriminações condicionais entre palavras ditadas e as respectivas palavras impressas, foi possível observar a emergência de dois novos comportamentos: pareamento de palavras escritas e respectivas figuras e nomeação oral de palavras impressas.

Conforme apontado por Hübner (1990, 2006) este artigo de Sidman (1971) pode ser considerado histórico em termos de experimentos sobre leitura a partir da utilização 
do procedimento de MTS; além disso, a autora ressalta a importância deste experimento como precursor de estudos posteriores denominados como Equivalência de Estímulos, termo proposto por Sidman e Tailby, em 1982. De acordo com estes autores, o processo de aquisição de discriminações condicionais pode gerar, além de relações condicionais entre estímulos, relações de equivalência. Ao ensinar para um participante, por exemplo, relações condicionais envolvendo três grupos de estímulos (A1, A2, A3, B1, B2, B3, C1, C2, C3), treina-se o mesmo a selecionar um determinado estímulo de escolha (B1) condicionalmente à presença de um determinado estímulo modelo (A1) e, a selecionar outro estímulo de escolha (C1) perante o mesmo estímulo modelo (A1), sendo que apenas estas respostas são consistentemente reforçadas; de forma contrária, perante o estímulo modelo $\mathrm{A} 1$, respostas de seleção a outros estímulos de escolha (como B2, B3, C2, C3) não são seguidas de reforço. Após este treino, o participante pode aprender outras sete relações, sem treino específico, a saber: A1A1; B1B1; C1C1; $\mathrm{B} 1 \mathrm{~A} 1 ; \mathrm{C} 1 \mathrm{~A} 1 ; \mathrm{B} 1 \mathrm{C} 1 ; \mathrm{C} 1 \mathrm{~B} 1$.

Sidman e Tailby (1982) trouxeram da matemática, mais especificamente da teoria dos conjuntos, as três propriedades básicas (Reflexividade, Simetria e Transitividade) para descrever as relações emergentes, derivadas de contingências de reforçamento, que além de resultar em discriminações condicionais, resultam também em novas discriminações emergentes verificadas em testes padrões (Sidman, 2000). As propriedades são:

- Reflexividade: após o treino de discriminações condicionais, por exemplo, das relações A1B1 e A1C1, é verificado que, durante os testes, quando o estímulo modelo A1 é apresentado o estímulo de escolha idêntico A1 é escolhido e não A2 ou A3; perante A2 deve ser escolhido A2 e não A1 ou A3 e, assim por diante. O mesmo desempenho pode ser esperado para os estímulos B1, B2, B3 e C1, C2 e C3. 
- Simetria: Após o treino de discriminações condicionais, por exemplo, das relações A1B1 e A1C1 é verificada a emergência da relação inversa, ou seja, se A1B1, então B1A1 e, se A1C1, então C1A1. Assim, na presença do estímulo modelo B1, deve ser escolhido o estímulo de escolha A1 e não A2 ou A3 e, na presença do estímulo modelo $\mathrm{C} 1$ deve ser escolhido novamente $\mathrm{A} 1$ e não $\mathrm{A} 2$ ou $\mathrm{A} 3$. O mesmo desempenho, em situação de teste, deve ser esperado para as respostas relativas aos estímulos modelos B2 e C2 (escolha do estímulo de escolha A2 e não A1 ou A3) e aos estímulos modelos B3 e C3 (seleção do estímulo de escolha A3 e não A1 ou A2).

- Transitividade: Se estabelecidas, por exemplo, as relações A1B1 (se A1 então B1) e A1C1 (se A1 então C1) a relação de transitividade seria a emergência da relação B1C1 (se B1, então C1); assim, após o ensino de A1B1 e de $\mathrm{A} 1 \mathrm{C} 1$, espera-se que a relação B1C1 emirja, por transitividade. Assim, na situação de teste, perante o estímulo modelo B1, deve ser selecionado o estímulo de escolha $\mathrm{C} 1$ e não $\mathrm{C} 2$ ou $\mathrm{C} 3$, do mesmo modo que perante os estímulos modelos B2 e B3 devem ser selecionados, respectivamente, os estímulos comparações C2 e C3 (e não $\mathrm{C} 1$ ou C3 perante $\mathrm{C} 2$, tampouco $\mathrm{C} 1$ ou $\mathrm{C} 2$ perante $\mathrm{C} 3$ ). Também é pré-requisito para uma determinada classe de estímulo ser definida como equivalente a emergência da relação de equivalência, classificada então como a simetria da transitividade (no exemplo citado acima, a emergência da relação C1B1); perante o estímulo modelo $\mathrm{C} 1$, deve ser selecionado o estímulo de escolha $\mathrm{B} 1$ e não $\mathrm{B} 2$ ou $\mathrm{B} 3$, sendo que o mesmo raciocínio deve ser estendido para as seleções dos estímulos de escolha perante os estímulos modelos C2 e C3.

A noção de equivalência de estímulos, trazida para a Análise Experimental do Comportamento, configurou-se como um modelo experimental de análise da leitura com compreensão. Desta perspectiva, após o treino das relações condicionais AC 
(palavra ditada/palavra impressa) e AB (palavra ditada/figura) a emergência de relações que não são ensinadas diretamente pode ocorrer, como a relação simultânea de simetria e transitividade - BC e CB). Sidman e Tailby (1982) apontam que esta relação de equivalência entre palavras ditadas e impressas e seus respectivos referenciais pictográficos (figuras) configuram a obtenção de relações simbólicas a partir de treinos de relações condicionais, já que as palavras impressas simbolizando os respectivos desenhos designariam uma leitura com compreensão.

O desenvolvimento de repertórios tão adaptativos socialmente como a escrita e leitura é um tema de extrema relevância e que vem sido discutido e estudado experimentalmente por analistas do comportamento (Sidman, 1971; Sidman, 1982; Lee \& Pegler, 1982; de Rose, Souza, Rossito, \& de Rose, 1989; Hübner, 1990; Matos \& Hübner, 1992; de Rose, de Souza, \& Hanna, 1996; Matos, Hübner, \& Peres, 1997; Matos, Hübner, Serra, Basaglia e Avanzi, 2002; Bagaiolo \& Micheletto, 2004; Andréa \& Micheletto, 2005; de Souza \& de Rose, 2006; Hübner, 2006).

Do ponto de vista conceitual, o comportamento de ler foi amplamente analisado por Skinner, em 1957, no livro Verbal Behavior. A leitura foi descrita pelo autor com um operante verbal no qual a resposta verbal vocal (manifesta ou encoberta) tanto é controlada por um estímulo antecedente escrito (textual) como por uma conseqüência reforçadora generalizada. Skinner hipotetizou ainda, em 1957, que a partir do aprendizado de unidades maiores da língua (palavras) um repertório maior formado por unidades menores (letras/sílabas) poderia emergir; assim, o aprendizado de novas palavras ocorreria por recombinação de sílabas e/ou letras de palavras anteriormente aprendidas.

A partir das descobertas de Sidman e Tailby (1982) e das considerações de Skinner (1957) sobre o desenvolvimento do comportamento de ler, mais 
especificamente a emergência da leitura com compreensão e com recombinação de unidades menores, um grupo de pesquisadoras (Matos et al., 2002) relatou um conjunto de trabalhos sistemáticos para a investigação sobre a emergência de leitura recombinativa $^{1}$, com ênfase em analisar como se dá o processo de aquisição de leitura sob controle das unidades menores do que a palavra, verificando procedimentos que maximizem a aquisição desse controle. Para tanto, foram propostas modificações em relação ao procedimento inicial de Sidman, 1971: a partir do ensino das relações condicionais entre um primeiro grupo de quatro palavras simples ditadas e suas respectivas figuras (relação $\mathrm{AB}$ ) e palavras impressas (relação $\mathrm{AC}$ ), testou-se a emergência das relações entre palavras e figuras (relação CB) e vice-versa (relação BC); se essas últimas duas relações emergissem, as sílabas das palavras anteriormente ensinadas eram fragmentadas e, a partir da recombinação destas sílabas já ensinadas, quatro novas palavras eram formadas em um segundo grupo de palavras simples. Porém, para este novo grupo de palavras era ensinada apenas a nova relação condicional $\left(\mathrm{A}^{\prime} \mathrm{B}^{\prime}\right)$, a relação $\mathrm{A}^{\prime} \mathrm{C}^{\prime}$ não era ensinada diretamente. Testavam-se as relações $\mathrm{B}^{\prime} \mathrm{C}^{\prime} \mathrm{e}$ C'B'; etapa esta denominada de 'Leitura recombinativa com compreensão'.

Conforme apontado pelas autoras, esta alteração no procedimento gerou uma economia no processo de aquisição por unidades verbais menores, já que a leitura recombinativa ocorreu sem os treinos adicionais de cada nova palavra; os treinos adicionais para cada nova palavra conferiam um caráter de morosidade a este processo. De acordo com as autoras: "o repertório de novas palavras passíveis de serem lidas será tão grande quanto o das possíveis combinações das unidades aprendidas" (Matos et al., 2002).

\footnotetext{
${ }^{1}$ Neste trabalho os termos Leitura Recombinativa, Controle por unidades verbais mínimas e Controle por unidades menores do que a palavra serão empregados como sinônimos. É importante destacar que a Leitura recombinativa requer o estabelecimento do Controle por unidades verbais mínimas ou Controle por unidades menores que a palavra (Alessi, 1987 e Matos, Avanzi e McIllvane, 2006).
} 
É necessário ressaltar que durante o processo de aprendizagem de leitura pode ocorrer um fenômeno chamado controle restrito de estímulos, ou seja, o aprendiz ficar sob controle de apenas um componente da palavra que está sendo ensinada, que pode ser a sílaba ou a letra (Birnie-Selwyn \& Guerin, 1997). Assim, se durante a aprendizagem da palavra BOLO o aprendiz responde prioritariamente sob controle da sílaba BO e se esse controle se estabelecer, o aprendizado da palavra BOCA, por exemplo, ficará impossibilitado; o aprendiz continuará a responder BOLO diante BOCA.

Reynolds (1961), por meio de um experimento básico com participantes infrahumanos (dois pombos privados de alimento), demonstrou o processo denominado como controle restrito. Para tanto, ele utilizou dois estímulos compostos; um deles era um triângulo branco sobre um fundo vermelho e outro era um círculo branco sobre um fundo verde. Esses estímulos eram apresentados em uma caixa experimental por meio da iluminação de um disco e os participantes eram reforçados diferencialmente com alimento ao bicar o disco. Os treinos foram realizados com o procedimento de discriminação sucessiva; por três minutos o disco era iluminado com o triângulo branco em fundo vermelho e as respostas de bicar eram conseqüenciadas; por mais três minutos o disco era iluminado com o círculo branco sobre fundo verde e as respostas não eram conseqüenciadas; assim, cada sessão continha 30 ciclos de um esquema múltiplo de dois componentes que ocorriam alternadamente.

Os resultados apontaram que durante o treino discriminativo os participantes comportaram-se diferencialmente a depender dos componentes dos estímulos que eram apresentados; assim, houve uma alta freqüência de bicar no triângulo branco com fundo vermelho e baixa freqüência de bicar quando o círculo branco sobre fundo verde estava iluminado. 
Após o treino discriminativo (realizado durante seis sessões), foi realizado um teste no qual os componentes dos dois estímulos (triângulo, círculo, fundo branco e fundo vermelho) foram apresentados separadamente; não houve reforçamento para nenhuma resposta. Durante o teste foi observado que o comportamento dos participantes ficou sob controle de aspectos distintos do estímulo discriminativo: enquanto um deles apresentou maior freqüência de respostas perante o triângulo, o outro respondeu de forma preponderante frente à apresentação do estímulo vermelho. Estes resultados mostram que um organismo, no caso, o pombo, pode atentar para apenas uma parte de um determinado estímulo; assim, o atentar a um estímulo ocorre quando o responder está sob controle daquele estímulo ou parte dele, como no caso do experimento de Reynolds (1961).

O fenômeno denominado como controle restrito de estímulos tem sido relacionado freqüentemente com a população portadora de autismo ${ }^{2}$. A partir do início da década de 70, um grupo de pesquisadores desenvolveu pesquisas para analisar este comportamento com grupos de crianças com autismo, com retardo e com desenvolvimento típico a partir da utilização de estímulos compostos (Lovass \& Schreibman, 1971; Lovaas, Schreibman, Koegel \& Rehm, 1971; Koegel \& Schreibman, 1977). A principal hipótese destes autores era de que crianças portadoras de autismo tinham uma tendência importante em responder a um número limitado de 'dicas' no ambiente, o que poderia contribuir diretamente para a falha em vários campos do desenvolvimento desta população, como, por exemplo, na comunicação, comportamento social, generalização de comportamentos adquiridos para novas situações, utilização de dicas variadas no aprendizado e dificuldade geral em aprender novos comportamentos (Loovas, Koegel, \& Schreibman, 1979).

\footnotetext{
${ }^{2}$ Os manuais médicos de classificação de doenças, CID 10 e DSM IV, caracterizam o transtorno autista com um transtorno do desenvolvimento, caracterizado por um desenvolvimento alterado nas interações sociais, na comunicação e na variabilidade comportamental, manifestado até os três anos de idade.
} 
Loovas et al. (1979), em um artigo de revisão sobre pesquisas realizadas por analistas do comportamento e relacionadas ao tema do controle restrito com autismo, enfatizaram que o enfoque das mesmas era estudar como ocorre o controle restrito de estímulos, e como isso pode afetar e alterar o desenvolvimento considerado atípico, por meio do processo de aprendizagem da criança portadora de autismo com os ambientes a que é exposta. Esta é uma posição importante que prioriza estudar as relações operantes organismo-ambiente, inversa e contraposta a uma visão que busca a causa do comportamento dentro do organismo, independente da relação com o meio.

Um primeiro estudo relacionado a este tema foi o de Lovaas et al. (1971). Os pesquisadores ensinaram cinco crianças com autismo, cinco crianças com retardo e um grupo controle de cinco crianças típicas a responderem a um estímulo composto por três elementos, sendo eles: visual (luz vermelha, intensidade de 150-W), auditivo (som de 63 decibéis) e tátil (“jato de ar" na panturrilha esquerda do participante). Além desses três componentes (visual, auditivo e tátil) era apresentada também uma dica temporal, já que o estímulo composto era apresentado em um intervalo de cinco segundos, a cada vinte segundos; assim, o participante poderia obter reforçamento por pressionar a barra em função do tempo passado em relação ao último reforçamento, mais do que sob controle das outras três dicas.

Durante o início da etapa de treino, a tarefa principal era a resposta de pressão à barra frente ao estímulo composto (formado pelos componentes visual, auditivo e tátil) apresentado durante 10 segundos ou até o participante pressionar a barra. Tais respostas eram reforçadas. $\mathrm{Na}$ ausência do estímulo composto (intervalo de 20 segundos), o pressionar à barra não era conseqüenciado. Quando o participante respondia ao estímulo composto em três apresentações sucessivas, a duração do período do mesmo diminuía gradualmente, em unidades de um segundo, até atingir o intervalo de cinco segundos. 
Após a discriminação deste estímulo complexo ter se tornado estável durante o treino, ou seja, o participante emitir pelo menos $90 \%$ das respostas de pressão à barra, dentro do intervalo de apresentação do estímulo composto (cinco segundos), durante duas sessões consecutivas, testes foram realizados com a apresentação separada de cada componente do estímulo (visual, tátil e auditivo), com o objetivo de avaliar qual deles tinha adquirido controle funcional.

Durante as tentativas de testes, os componentes eram apresentados, de forma randômica e intercalada, com tentativas de treino (nas quais os componentes eram apresentados novamente de forma simultânea); cada tentativa de teste devia ser precedida e seguida por, no mínimo, uma tentativa de treino e não podia ocorrer mais do que três tentativas de treino em seguida. Durante as sessões de teste, as respostas corretas eram reforçadas. As crianças com autismo e com retardo passavam por dez sessões de testes e as crianças com desenvolvimento típico acabavam esta fase após a realização de duas sessões sucessivas com 100\% de respostas corretas para cada componente. Os resultados apontaram que as crianças com diagnóstico de autismo responderam de forma seletiva a apenas um dos componentes do estímulo composto, sendo que três delas responderam ao componente auditivo, duas responderam ao componente visual e nenhuma delas respondeu ao componente tátil; o grupo de crianças típicas respondeu igualmente a cada um dos componentes apresentados separadamente; as crianças com retardo não responderam a todos os componentes, mas preferencialmente a dois componentes. Os autores discutem este dado a partir da análise de que crianças portadoras de autismo apresentam uma dificuldade maior em responder a múltiplos elementos ou dicas de um estímulo composto em relação à quantidade mais do que à qualidade dos mesmos, já que durante a sessão de testes com a apresentação separada dos elementos do composto, a atenção foi seletiva em relação a apenas um dos 
elementos, independente da modalidade sensorial (no caso, os participantes respondiam ou apenas para a modalidades auditiva ou para a modalidade visual, já que nenhum deles respondeu ao estímulo tátil); eles denominaram este fenômeno como "stimulus overselectivity”, que pode ser traduzido como superseletividade de estímulos e que, no presente trabalho, está sendo padronizado com o termo controle restrito de estímulos.Um segundo estudo, com o objetivo de continuar investigando o processo de controle restrito, foi conduzido por Lovaas e Schereibman (1971) que replicaram o estudo de Lovaas et al. (1971), mas com a utilização de estímulos compostos formados por apenas dois componentes (os mesmos auditivos e visuais já descritos), já que os autores hipotetizaram que três modalidades de componentes poderia ter sido inadequado e poderia induzir a criança com autismo a selecionar apenas um dos componentes. Foram selecionados apenas dois grupos de participantes: seis crianças típicas e nove crianças com autismo. Como no estudo anterior, os participantes eram reforçados quando pressionavam a barra na presença do estímulo complexo envolvendo a apresentação simultânea de um componente auditivo e um componente visual; após esta discriminação ter sido estabelecida, os componentes eram apresentados separadamente em situação de teste.

Os resultados apontaram que o grupo de seis crianças típicas não apresentou sinais de controle restrito de estímulos, já que responderam igualmente aos dois componentes do estímulo composto, quando apresentados separadamente na situação de teste. Já o grupo de crianças autistas apresentou algumas especificidades diferentes do estudo anterior, no qual todos os participantes apresentaram controle restrito. Quatro, das nove crianças deste grupo, apresentaram controle restrito por um dos componentes do estímulo composto (duas responderam predominantemente ao componente visual e duas ao auditivo), porém duas delas mostraram respostas a ambos os componentes 
durante a fase inicial do teste, mas perderam estas respostas durante o teste, mantendo o controle restrito pelo componente predominante no início desta fase de teste; duas outras crianças autistas mostraram controle restrito apenas na parte inicial do teste; durante o teste, entretanto, gradualmente passaram a responder sob controle dos dois componentes do estímulo composto; outra criança autista mostrou controle restrito primeiramente por um dos componentes (visual), mas no decorrer do teste passou a responder preponderantemente para o outro componente (auditivo); duas crianças deste grupo não demonstraram controle restrito por um dos componentes do estímulo composto.

Os autores discutem estes resultados relacionando a menor ocorrência de controle restrito com o menor número de componentes do estímulo composto (dois) em relação ao estudo anterior, que envolvia três componentes. Além disso, os mesmos discutem que mudanças no procedimento de ensino podem gerar possibilidades de aprendizagem, específicas para indivíduos portadores de autismo, mesmo com estímulos compostos.

Koegel e Schereibman (1971) também conduziram um estudo com o objetivo principal de avaliar se crianças com desenvolvimento atípico têm a possibilidade de responder a estímulos compostos, com dicas múltiplas; participaram deste estudo quatro crianças com autismo e quatro crianças com desenvolvimento típico.

Em uma primeira etapa, os participantes aprenderam a responder separadamente a cada um dos elementos do estímulo composto: auditivo - som de 63 decibéis ou visual - luz vermelha, intensidade de $150-\mathrm{W}$. A resposta a ser realizada pelo participante, como nos dois experimentos anteriores, deveria ser a de pressionar a barra; mas neste experimento esta resposta deveria ocorrer diante da apresentação de um dos dois componentes separadamente. Após atingir o critério de avanço $(90 \%$ ou mais de 
tentativas corretas durante uma sessão de treino) em relação a um dos elementos, os participantes passavam pelo mesmo treino com o outro elemento do estímulo composto. Em uma etapa posterior, denominada pelos autores como "Treino de discriminação condicional de dicas múltiplas”, os participantes eram apresentados a sessões similares em termos de parâmetros experimentais à etapa anterior, mas com três tipos de tentativas: com elemento apenas auditivo, com elemento apenas visual e com os dois elementos conjuntamente (estímulo composto); os estímulos eram apresentados randomicamente de forma que não ocorria mais do que três tentativas seguidas com elementos do composto apresentados separadamente e não mais do que duas tentativas consecutivas com o mesmo elemento. Nesta etapa o responder nas tentativas nas quais os elementos eram apresentados separadamente não era reforçado; o elemento do estímulo composto (auditivo ou visual) permanecia na tela por cinco segundos independente de eventuais respostas dos participantes. Apenas respostas dos participantes nas tentativas nas quais o estímulo composto era apresentado eram reforçadas, o que foi caracterizado como um treino de discriminação condicional. $\mathrm{O}$ critério para se considerar que a discriminação havia sido adquirida era a realização de dois blocos de testes consecutivos com $0 \%$ de resposta para os elementos em separado (visual ou auditivo) e $100 \%$ de respostas nas tentativas de apresentação dos estímulos compostos.

A aquisição de discriminação condicional, ou seja, o responder diferenciado ao estímulo composto e não aos elementos apresentados separadamente, foi avaliada pelo exame das curvas de extinção a partir dos dados das respostas dos participantes aos elementos compostos separadamente que, por sua vez, não eram reforçadas na etapa de "Treino de discriminação condicional de dicas múltiplas". Os quatro participantes autistas aprenderam a discriminar o estímulo composto de seus componentes, já que os 
mesmos pararam de responder aos componentes separadamente da mesma forma que os participantes que formavam o grupo de quatro crianças típicas; a diferença entre os grupos foi o número de tentativas para alcançar este critério de discriminação. Para três crianças com autismo, essa aquisição ocorreu apenas depois de muitas tentativas (um participante precisou de 990 tentativas e os outros dois de 870 e 480 tentativas); por outro lado, a quarta criança deste grupo precisou de 210 tentativas. O número de tentativas necessárias para adquirir o mesmo repertório pelas crianças típicas foi similar ao da última criança autista citada (dois participantes necessitaram de 360 tentativas, uma precisou de 120 e outra de 90 tentativas).

Além do número de tentativas necessárias para o aprendizado da discriminação do estímulo composto, mais complexo, outra diferença consistente entre os dois grupos foi o modo como este processo ocorreu; enquanto que para as quatro crianças típicas as respostas à apresentação dos elementos separadamente, durante os testes, extinguiam-se simultaneamente, para as quatro crianças autistas as respostas a um dos dois elementos apresentados separadamente continuava a ocorrer mesmo em esquema de extinção, ou seja, mesmo cessando o responder a um dos elementos, a dificuldade em cessar a resposta ao outro elemento denota o controle restrito de estímulo, o que provavelmente gerou a demora em adquirir a discriminação pelo estímulo composto; esta é a principal discussão dos autores, ou seja, que indivíduos com autismo aprendem a responder a estímulos compostos (complexos) de forma diferenciada, como por exemplo, neste experimento aqui descrito, no qual eles precisaram, em sua maioria, de um determinado número de tentativas com elementos do composto em esquema de extinção para romper o controle restrito e responder a todos os elementos do estímulo composto simultaneamente. 
Diferentemente da principal discussão derivada dos experimentos anteriores (tanto do estudo de Lovaas et al. quanto o de Lovaas \& Schereibman, ambos de 1971) de que o controle restrito de estímulos ocorria durante o processo de aprendizado de crianças com autismo, os autores deste estudo discutem os resultados alcançados em relação ao tratamento para indivíduos com autismo, ou seja, é possível desenvolver arranjos experimentais que auxiliem a prevenção ou a correção de controle restrito de estímulos com esta população. Koegel e Schreibman (1977) ressaltam que estratégias que auxiliem autistas a responder a múltiplas dicas (estímulos compostos) acarretam algumas vantagens e destacam três delas; primeiramente, as situações cotidianas de aprendizagem não são predominantemente formadas por apenas um tipo de dica; segundo, se a criança aprende a responder a dicas múltiplas, é mais provável que ela se beneficie de procedimentos de ensino já disponíveis que requerem este tipo de respostas e, por último, ressaltam o fato de que se a criança com autismo pode responder a dicas múltiplas de forma geral, ela pode vir a responder ao ambiente de forma similar as crianças com desenvolvimento típico.

Allen e Fuqua (1985) também afirmam que indivíduos com desenvolvimento atípico (pertencentes ao espectro do autismo, com retardo e/ou com atraso de linguagem) tendem a falhar em responder a todos os elementos de estímulos compostos. Os autores concordam que esta tendência a um controle restrito na aprendizagem de estímulos, como ressaltado acima, influencia diretamente na aprendizagem e afirmam que a continuidade de desenvolvimento de procedimentos que investiguem a prevenção ou redução deste fenômeno tem derivações importantes para o contexto educacional e clínico; estes autores também ressaltam que mudanças no arranjo experimental podem auxiliar na correção do fenômeno do controle restrito; postura esta que corrobora a concepção de analistas do comportamento de que o controle restrito de estímulos não 
seja uma característica do indivíduo per si. Para tanto, eles desenvolveram dois experimentos para avaliar o efeito da similaridade dos estímulos sobre a ocorrência de controle restrito de estímulos; a hipótese dos autores é que se os estímulos de escolha negativos fossem minimamente diferentes do estímulo de escolha positivo, a probabilidade de redução de controle de estímulos aumentaria, já que o participante não tenderia a realizar as respostas de discriminação baseadas em outros aspectos do estímulo que não aqueles especificados pelo experimentador.

Participaram do primeiro experimento três crianças, com retardo, que foram ensinadas a selecionar estímulos compostos positivos $(\mathrm{S}+)$ que consistiam de dois elementos (situados verticalmente e separadamente, ora acima ora abaixo), sendo que um dos elementos era uma forma geométrica e outro elemento era uma linha horizontal ou um ponto. Os $\mathrm{S}+$ apareciam, em tentativas de treino ou teste, com estímulos negativos $\mathrm{S}^{-}$que diferiam daqueles quanto ao grau de similaridade em relação à forma e posição (localização espacial); um exemplo de um conjunto destes estímulos compostos pode ser visualizado na Figura 1.

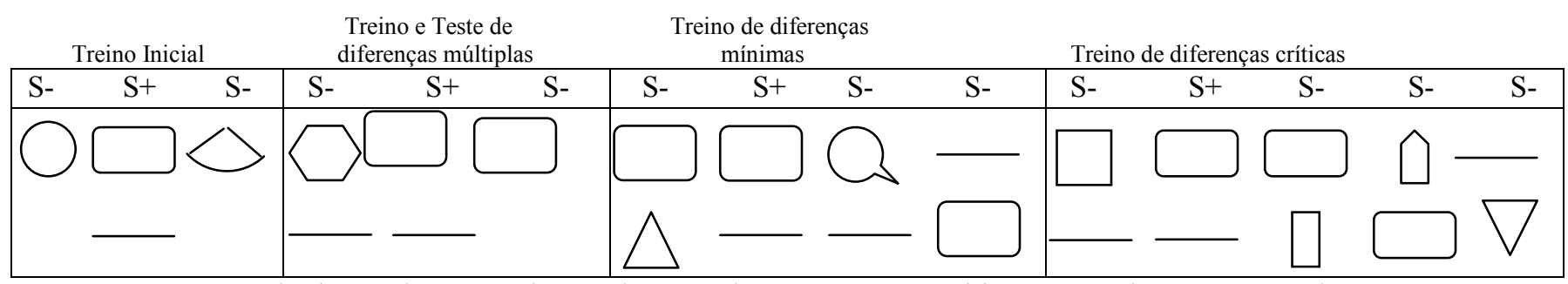

Figura 1. Exemplo de um dos 18 conjuntos de estímulos compostos, positivos e negativos, apresentados durante as condições de treino. Adaptação de Allen e Fuqua (1985).

Foi construído um total de 18 conjuntos de estímulos; estes conjuntos seguiam a padronização do exemplo de conjunto de estímulos presentes na Figura 1, com variações relativas ao tipo de figura geométrica e substituições de linhas por pontos. Tais conjuntos de estímulos eram apresentados em cartões (havia cartões com os $\mathrm{S}+\mathrm{e}$ os S-, separadamente); os mesmos foram divididos em quatro grandes grupos e 
nomeados pelos autores como serão citados abaixo; um exemplo destes conjuntos pode ser visualizado na Figura 1:

a) Conjuntos de estímulos "Treino inicial": Os conjuntos de estímulos deste tipo consistiam dos $\mathrm{S}+$ (combinação de forma geométrica com linha horizontal ou ponto) apresentados com dois $\mathrm{S}$ - formados apenas por uma forma geométrica (diferente do $\mathrm{S}+$ ) que variava de tipo e posição por entre os 18 conjuntos de estímulos; na Figura 1, na primeira coluna, há um exemplo de um conjunto de estímulos do tipo "Treino Inicial”.

b) Conjuntos de estímulos “Treino e Teste de diferenças múltiplas”: Como pode ser visto na segunda coluna da Figura 1, um dos dois S- possuía apenas um elemento e este era igual ao composto positivo, a forma geométrica (situada na mesma posição); o outro $\mathrm{S}^{-}$possuía uma nova forma geométrica combinada com linha ou ponto igual ao $\mathrm{S}+$, também situados na mesma posição, ou seja, os dois $\mathrm{S}^{-}$tinham um elemento idêntico ao $\mathrm{S}+$ composto e na mesma posição que a configuração do composto. Este conjunto de estímulos foi denominado como "Diferenças Múltiplas" porque os S- diferiam de vários modos do $\mathrm{S}+$, ou seja, o número de elementos diferia e o formato da forma geométrica também.

c) Conjuntos de estímulos "Teste de diferenças mínimas": Um exemplo deste tipo de conjunto de estímulos pode ser encontrado na terceira coluna da Figura 1. Os conjuntos de estímulos pertencentes a esta categoria tinham três novos S-; dois deles continha um novo formato de forma geométrica combinado com outro elemento do S+, o terceiro S- era formado com os mesmos elementos do $\mathrm{S}+$, em arranjo vertical invertido. Este conjunto recebeu tal denominação dos autores porque, segundo eles, os S- diferiam em características mínimas do $\mathrm{S}+$, isto é, orientação dos estímulos ou mudança no formato de um dos elementos. 
d) Conjuntos de estímulos "Treino de diferenças críticas": Um exemplo deste conjunto de estímulos também pode ser visualizado na quarta coluna da Figura 1. Para o conjunto de estímulos deste tipo foram construídos quatro novos S-, sendo que dois deles eram compostos com uma nova forma geométrica combinada com uma forma geométrica idêntica a um dos elementos do $\mathrm{S}+$ (mesmo formato e mesma posição) e ou outros dois S- continham uma nova forma geométrica combinada com uma das formas geométricas do $\mathrm{S}+$, com mudança da posição. Os autores ressaltam que este conjunto de estímulos foi denominado "Treino com diferenças múltiplas" porque os Sdiferenciavam-se de forma crítica do S-, ou seja, em apenas uma dimensão; assim, a atenção a ambos, forma geométrica e orientação era crítica para que pudesse vir a ocorrer uma discriminação com acurácia.

Todos os participantes passavam por duas condições de treino, sendo elas: Treino de diferenças múltiplas e Treino de diferenças críticas, sequencialmente; foi utilizada uma linha de base múltipla para demonstração do controle experimental. A parte inicial do procedimento era comum para as duas condições; primeiramente era realizado o Treino Inicial para ensinar a discriminação do estímulo composto positivo $(\mathrm{S}+)$ de um dos conjuntos, do grupo de dezoito conjuntos de estímulos (ver exemplo na primeira coluna da Figura 1). A escolha do estímulo composto correto $(\mathrm{S}+)$ era reforçada ${ }^{3}$ e as respostas incorretas (escolha de S-) eram seguidas pela verbalização "não" e os estímulos eram retirados; o Treino inicial era considerado completo quando o participante atingia $90 \%$ de acertos em vinte tentativas consecutivas, com o $\mathrm{S}+$ do conjunto de estímulos que estava sendo apresentado. A partir deste ponto do procedimento as condições tinham características diferentes:

- Treino com diferenças múltiplas:

\footnotetext{
${ }^{3}$ Durante o Treino Inicial o esquema de reforçamento mudou gradualmente de um esquema de reforçamento contínuo para um esquema de razão variável; o objetivo desta mudança foi preparar os participantes para as tentativas de teste posteriores, que não seriam realizadas em extinção.
} 
Nesta condição, após o participante terminar o Treino Inicial era apresentado o Teste com diferenças múltiplas, como medida do controle de estímulos resultante do Treino inicial. Um exemplo do conjunto de estímulos apresentados neste teste pode ser visto na segunda coluna da Figura 1; é importante ressaltar que durante as tentativas de teste não havia reforçamento. Durante esta etapa, se o participante não atingisse $90 \%$ de acertos em 20 tentativas consecutivas, o mesmo era apresentado ao esquema de treino com estes mesmo estímulos (Treino com múltiplas diferenças) com o objetivo de estabelecer a discriminação condicional do $\mathrm{S}+$ com os $\mathrm{S}$ - deste conjunto de diferenças múltiplas; este treino era realizado até o participante alcançar o critério de $90 \%$ de respostas corretas em 20 tentativas consecutivas. Quando este critério era alcançado, o participante era exposto ao Teste de diferenças mínimas (um exemplo de um conjunto de estímulos deste tipo pode ser visualizado a terceira coluna da Figura 1) para ser verificado se o Treino com diferenças múltiplas foi tinha sido efetivo em ensinar o participante a responder às características especificadas no $\mathrm{S}+$.

Por outro lado, se o participante alcançasse o critério de $90 \%$ de acerto em 20 tentativas consecutivas durante o Teste com diferenças múltiplas (apresentado após o Treino Inicial), o Treino com diferenças múltiplas não era realizado e havia a apresentação do Teste de diferenças mínimas. Assim, o Teste de diferenças mínimas era apresentado quando: 1 . O participante alcançava $90 \%$ de acertos no Teste de diferenças múltipla (realizado logo após o Treino inicial) ou 2. O participante alcançava 90\% de acertos no Treino com diferenças múltiplas.

Este procedimento era repetido com um novo conjunto de estímulos até o participante alcançar o critério de avanço em ambos os testes (Teste de diferenças múltiplas e Teste de diferenças críticas) com dois conjuntos de estímulos consecutivamente.- Treino com diferenças críticas: 
Nesta condição, que vinha em seguida à condição anterior (Treino com diferenças múltiplas) o Treino Inicial também ocorria e era o mesmo, com outros conjuntos de estímulos (também selecionados do grupo de 18 conjuntos de estímulos). Quando o participante atingia 90\% de acertos em 20 tentativas consecutivas, o mesmo era exposto ao Teste de diferenças mínimas (ver exemplo de conjunto de estímulos na terceira coluna da Figura 1), como medida do controle de estímulos resultante do Treino inicial. Nas tentativas de teste não ocorria reforçamento.

Se o participante não atingisse $90 \%$ de acertos em 20 tentativas consecutivas durante esta etapa (Teste de diferenças mínimas), o mesmo era apresentado ao Treino de diferenças críticas (um exemplo de um conjunto de estímulos deste tipo pode ser visualizado na quarta coluna da Figura 1) até alcançar o critério de $90 \%$ de respostas corretas em 20 tentativas consecutivas. Quando este critério era alcançado, o participante era exposto novamente ao Teste de diferenças mínimas com o objetivo de avaliar se ocorreu um aumento no controle de estímulos, devido ao Treino com diferenças críticas, em relação à discriminação do $\mathrm{S}+$ do conjunto de estímulos de diferenças mínimas.

Por outro lado, se o participante alcançasse o critério de $90 \%$ de acerto, em 20 tentativas consecutivas, durante o Teste com diferenças mínimas (apresentado após o Treino Inicial), ele começava um novo Treino inicial com um novo conjunto de estímulos. Este procedimento era repetido com um novo conjunto de estímulos até o participante alcançar o critério de avanço no Teste de mínimas com dois conjuntos de estímulos consecutivamente.

Assim, todos os participantes passavam pelo Teste com diferenças mínimas nas duas condições; segundo os autores, o desempenho neste tipo de teste poderia ser um indicativo de que o mostra se o participante conseguiu discriminar o estímulo composto 
positivo programado pelo experimentador, sem ficar sob controle dos elementos do S+ presentes nos estímulos negativos. Os resultados apontaram que a condição de Treino com diferenças críticas foi mais efetiva, em prevenir e eliminar controle restrito de estímulos, do que a condição de Treino com diferenças múltiplas, já que a média total do número de tentativas utilizadas pelos participantes para atingir o critério de $90 \%$ de acerto, em 20 tentativas consecutivas, nos Testes de diferenças mínimas foi menor. Durante a condição de Treino com diferenças críticas os três participantes utilizaram as médias de 40, 29 e 30 tentativas para atingir o critério referido acima, em cada conjunto de estímulos; já na condição com de Treino com diferenças críticas as médias para atingir este mesmo critério para os três participantes foram de 35, 26, 25 para cada conjunto de estímulos. Também foi possível observar que os participantes passaram por um número menor de conjunto de estímulos para atingir o critério $(90 \%$ de acertos nos Testes de diferenças mínimas) durante a condição de Treino de diferenças críticas do que na condição Treino com diferenças múltiplas.

Para garantir que esse desempenho tenha melhorado em função da segunda condição(Treino com diferenças críticas) e não por conta da história experimental que os participantes passaram durante o procedimento, os autores fizeram um segundo experimento com outros três participantes com retardo, com outros conjuntos de estímulos e apenas com a condição de Treino com diferenças críticas. Os desempenhos dos participantes replicaram os resultados do Experimento I, ou seja, as médias de tentativas por conjunto de estímulos foram de 26,25 e 30 ; o tipo e o número de estímulos utilizados foi similar ao utilizado pelos participantes do Experimento I, durante a segunda condição de treino (Treino com diferenças críticas).Allen e Fuqua (1985) concluem que o procedimento de Treino com diferenças críticas contém estratégias, relativas aos arranjos dos elementos dos estímulos compostos, que 
favorecem a ocorrência de uma discriminação acurada permitindo que comportamento de discriminação do participante não se estabeleça sob controle de elementos do estímulo composto positivo presentes nos estímulos compostos negativos e sim, se estabeleça sob controle de todos os elementos do estímulo composto positivo. Assim, os autores afirmam que arranjos experimentais deste tipo, presentes no Treino com diferenças críticas, podem auxiliar na diminuição de controle restrito de estímulos.

Birnie-Selwyn e Guerin (1997) também ressaltam a importância na manipulação dos estímulos a serem ensinados com o objetivo de prevenir e remediar controle restrito de estímulos. Os autores ressaltam que este fenômeno não ocorreria apenas com autistas e indivíduos com desenvolvimento atípico e/ou com retardo, mas com a população típica também; o que poderia influenciar é a complexidade presente nos estímulos, como no caso das tarefas de leitura e escrita; para investigar essa hipótese eles sugeriram utilizar comportamento de soletrar palavras que continham duas ou mais consoantes em seqüência (este tipo de seqüência de letras é chamado em inglês de consonant clusters, ex.: $\boldsymbol{S H O W ) . ~ E l e s ~ r e s s a l t a m ~ q u e ~ u m ~ d o s ~ e r r o s ~ m a i s ~ c o m u n s ~ d a s ~}$ crianças ao soletrar palavras é quando as consoantes estão em seqüência; elas tendem a ficar sob controle apenas da primeira consoante da seqüência, e ao invés de soletrar $S$ $H-O-W$, existe uma tendência de soletrar $S-O-W$, o que seria indicativo de controle restrito de estímulos por apenas uma parte de um estímulo composto.

Participaram do estudo seis crianças típicas que foram apresentadas ao ensino de discriminação de palavras em duas condições diferentes, de diferenças múltiplas e diferenças críticas, conforme proposto por Allen e Fuqua (1985); o objetivo principal era avaliar se as duas condições de treino produziriam efeitos diversos no processo de construção das palavras. Para tanto, os autores desenvolveram um conjunto de 24 palavras, sendo que todas elas tinham quatro letras: duas consoantes iniciais, uma vogal 
e uma consoante final; as mesmas palavras eram usadas em ambas as condições de treino (diferenças críticas e diferenças múltiplas). A manipulação das semelhanças e diferenças nas duas condições de treino estava presente na escolha das palavras apresentadas como estímulos de escolha; na condição de diferenças críticas os estímulos de escolha negativos eram minimamente diferentes do estímulo modelo (a palavra correta ditada) e de escolha correto (palavra impressa correspondente à palavra ditada), por exemplo: quando a palavra correta era $S N O W$, um dos estímulos de escolha incorretos era $S L O W$ (só a segunda consoante é diferente) e ou outro era $S N A P$ (vogal e consoante final diferentes). Na condição de diferenças múltiplas, os estímulos de escolha incorretos eram completamente diferentes do estímulo modelo e escolha correspondente. Por exemplo, quando a palavra correta era $S N O W$, os estímulos de escolha eram NICE e REST.

Primeiramente os participantes eram expostos a um teste inicial no qual soletravam, oralmente, as 24 palavras do conjunto de estímulos desenvolvido pelo autores; não havia reforçamento. Palavras soletradas corretamente não eram incluídas nas duas condições experimentais posteriormente; as respostas corretas variaram de duas a nove palavras, do conjunto de 24 palavras, sendo que estas respostas corretas estavam distribuídas ente os seis participantes. Após este teste inicial havia um treino preliminar cujo objetivo era ensinar o participante responder adequadamente à manipulação do mouse para a tarefa de compor palavras e selecionar palavras (estímulos de escolha), por meio da seleção de letras na tela do computador; todas as fases (treinos e teste) eram realizadas no computador.

Após as duas etapas descritas acima o treino propriamente dito era iniciado. Os participantes eram expostos a 30 tentativas de treino com seis palavras que continham diferenças críticas e diferenças múltiplas, ou seja, as duas condições de treino ocorriam 
durante uma mesma sessão de treino randomicamente e cada palavra era treinada cinco vezes; também é importante ressaltar que a apresentação dos estímulos, a resposta requerida do participante e o esquema de reforçamento eram comuns às duas condições de treino. Em cada sessão de treino eram ensinadas seis palavras; três delas eram relativas à condição com diferenças críticas e as outras três delas eram relativas à condição com diferenças múltiplas; metade dos participantes, durante todo o treino, era exposta às primeiras 12 palavras do conjunto total de 24 palavras e, os outros três participantes eram expostos às últimas 12 palavras.

Durante as duas condições de treino de discriminação condicional (tanto com diferenças críticas quanto com diferenças mínimas) os participantes deveriam selecionar dentre as palavras apresentadas como estímulos de escolha àquela correspondente à palavra ditada, que era o estímulo modelo; assim, por exemplo, quando o estímulo modelo auditivo $S N O W$ era apresentado, apenas a resposta de seleção do estímulo de escolha era reforçada, diferentemente das respostas de seleção aos estímulos de escolha negativos $S L O W$ e $S N A P$, que não eram reforçadas. Desta maneira, as respostas corretas eram seguidas de reforçamento que podia ser cinco diferentes estímulos visuais apresentados na tela do computador; as respostas incorretas eram seguidas pela apresentação da tela do computador sem nenhuma imagem, na cor negra, por três segundos.

Após o treino de discriminação condicional entre seis palavras ditadas e impressas, nas duas condições de treino, os participantes eram expostos imediatamente a um teste de construção de palavras no qual era avaliada a transferência de controle das letras isoladas para a composição de palavras inteiras; neste teste, os participantes deveriam compor a palavra ditada selecionado quatro letras dentre seis disponíveis. As palavras eram as mesmas que estavam sendo apresentadas na condição de treino 
anterior; não havia reforço (após respostas corretas) ou tela negra (após respostas incorretas) nesta etapa. Quando o participante alcançava o critério de construir uma palavra correta durante o teste citado acima, em três sessões consecutivas, a palavra era retirada e outra palavra era incluída no programa até o participante passar pelo treino de 12 palavras.Resultados indicaram que o treino com diferenças múltiplas favoreceu a etapa de treino de discriminação condicional entre palavras ditadas e palavras impressas. A média de porcentagem de tentativas corretas durante o treino com diferenças críticas variou de 84 a 92\%, enquanto no treino com diferenças múltiplas variou de 94 a $100 \%$.

Porém, no teste de construção de palavras que exigia a observação de cada uma das letras disponíveis, os participantes obtiveram escores mais elevados em relação a este desempenho durante a condição de diferenças críticas; foi necessário um menor número de sessões para encontrar o critério proposto pelos experimentadores, que era construir uma palavra corretamente durante por três sessões consecutivas. Durante a condição de diferenças críticas, os participantes precisaram de uma média de sessões que variou de 3.7 a 5.4; durante o treino com diferenças múltiplas a média das sessões para a atingir o critério variou entre 5.3 a 11.7. Também ocorreram diferenças no teste de construção de palavras durante as duas condições: ocorreram mais erros na colocação de consoantes em seqüência (consonanst clusters) durante a condição de diferenças múltiplas (79 erros de um total de 109 erros deste tipo - 73\%) do que na condição de diferenças críticas (30 erros de um total de 109 - 27\%).

Os resultados apontaram que a condição de diferenças críticas presente no treino de discriminação condicional foi mais efetiva em reduzir a quantidade de erros durante a construção das palavras, pois favoreceu uma discriminação mais acurada em relação a cada elemento do estímulo composto. Além disso, favoreceu que erros de construção de 
consoantes em seqüência, que caracterizam um controle restrito de estímulos, fossem minimizados, o que tem uma implicação direta com programas de educação e de alfabetização.

Uma das implicações da análise do controle restrito de estímulos para o ensino de leitura reside na escolha dos estímulos compostos (palavras) que deveriam compor os primeiros passos de um programa de ensino, por exemplo; trata-se de um desafio para o educador ou experimentador que delineiam procedimentos para o ensino e aquisição do controle por unidades verbais mínimas.

Hübner (1990), por exemplo, no planejamento das primeiras três palavras a serem ensinadas com crianças pré-escolares e não alfabetizadas, escolheu as palavras BOCA, BOLA e BOTA, com o objetivo de prevenir o controle pela primeira sílaba; entretanto, ocorreu que as crianças ficaram sob controle restrito das letras C, L e T. Com base nesses dados, novos conjuntos de palavras foram elaborados, permanecendo o desafio de reduzir controles espúrios (ou restritos) pelos estímulos compostos apresentados.

Neste sentido Matos et al. (2002) ressaltaram que o problema do controle restrito de estímulos pode ser minimizado com o ensino de conjuntos de estímulos planejados e a repetição sistemática de unidades menores (sílabas ou letras) que compõem as palavras que estão sendo treinadas durante o estabelecimento de discriminações condicionais; este treino favorece que o aprendiz esteja sob controle de todas as unidades relevantes do estímulo composto, ou seja, a palavra: “... as palavras cuja composição permitem um controle de estímulos parcial ou superseletividade impedem o funcionamento destas estratégias. Portanto, uma análise estrutural dos estímulos a serem utilizados deve ser feita antes de sua seleção.” (p. 301). 
As estratégias desenvolvidas por este grupo de pesquisadoras visavam que o processo de aquisição de discriminações condicionais, entre palavras ditadas e suas respectivas figuras e correlatos impressos propiciassem a recombinação das unidades menores, gerando a leitura recombinativa e, assim, um repertório do comportamento de ler mais extenso e eficiente. Para tanto, as autoras introduziram diferentes procedimentos de ensino que pudessem aumentar a probabilidade do aprendiz estabelecer controle discriminativo pelas unidades menores; o objetivo era identificar as variáveis responsáveis pelo desempenho com menor variabilidade nos testes de leitura recombinativa. Os procedimentos foram testados em estudos diferentes e envolveram: oralização fluente e escandida das palavras aprendidas após os testes de equivalência, oralização fluente e escandida das palavras durante a aquisição de pré-requisitos e anagrama silábico das palavras sem oralização simultânea e com oralização fluente e escandida das palavras.

Primeiramente era realizada uma série de tentativas de treino para o estabelecimento de relações condicionais entre palavras ditadas e as respectivas figuras (Treino $\mathrm{AB}$ ) e palavras escritas (Treino $\mathrm{AC}$ ); esta primeira etapa era formada pelos seguintes estímulos: Conjunto A, formado pelas palavras ditadas: "boca", "bolo", "lobo", "cabo"; Conjunto B, formado pelas figuras de boca, bolo, lobo, cabo e Conjunto C, formado pelas palavras impressas: BOCA, BOLO, LOBO, CABO ${ }^{4}$. Após estes treinos iniciais, eram realizados Testes de Equivalência (Testes BC e CB). Se ocorresse critério de emergência nos Testes de Equivalência, as palavras do conjunto $\mathrm{C}$ eram fragmentadas e apresentadas de forma recombinada em novas palavras escritas $\left(\mathrm{C}^{\prime}\right)$ :

\footnotetext{
${ }^{4}$ No presente estudo será utilizada a grafia proposta por Matos et al. para designar palavras ditadas (que serão escritas entre aspas), figuras (que serão escritas em itálico) e palavras impressas (que serão escritas em caixa alta).
} 
LOCA $^{5}$, BOBO, LOLO, CALO; estas novas palavras novas eram apresentadas na situação de teste de equivalência com as respectivas figuras (conjunto B': figuras de louca, bobo, lolo, calo) denominado como Teste de Leitura Recombinativa com Compreensão.

Um primeiro estudo (Estudo I) consistiu em aplicar este procedimento geral assim como descrito acima, com nove participantes; os resultados apontaram que os índices de acerto nos testes de leitura recombinativa ficaram ao nível do acaso, entre 20 a $40 \%$.

Outros dois estudos empregaram a oralização fluente e escandida das palavras, introduzidas após os testes de equivalência e antes dos testes de leitura recombinativa. $\mathrm{O}$ estudo com uso de oralização fluente (Estudo II) foi aplicado com quatro participantes, após os testes de equivalência e anteriormente aos testes de leitura recombinativa; o experimentador dizia o nome de uma palavra diante de seu correlato impresso e solicitava que a criança o repetisse, e retirava de modo gradual o modelo oral ao longo das tentativas; a tarefa começava com o operante ecóico e terminava com o operante textual. Tal procedimento mostrou-se insuficiente para produzir leitura recombinativa, já que o índice de acertos variou entre $20 \%$ a $40 \%$.

O estudo com oralização escandida das palavras de treino (Estudo III) também foi aplicado com quatro participantes, após os testes de equivalência e anteriormente aos testes de leitura recombinativa. No caso da oralização escandida, deveria ocorrer um espaçamento maior entre as sílabas da palavra impressa oralizada, sendo que este espaçamento também era gradualmente removido. Os resultados foram similares aos de oralização fluente, mas um participante, em um total de quatro, mostrou leitura recombinativa, alcançando $90 \%$ de acerto.

\footnotetext{
${ }^{5}$ Segundo as autoras, aqui a palavra "louca" foi representada textualmente com o ô fechado ("lôca") por necessidade metodológica. Foi uma licença ortográfica para fins de pesquisa, para não introduzir uma dificuldade adicional à constituição dos estímulos experimentais.
} 
Em um quarto estudo (Estudo IV) também foi utilizada a oralização fluente, mas durante a fase de treino, nas quais ocorriam os pareamentos entre palavra ditada e a respectiva palavra impressa. Foi aplicado com treze participantes; neste caso, era ditada uma palavra à criança e era solicitado que a criança repetisse o que havia sido dito e, então, apontasse a palavra impressa correspondente. Os resultados obtidos foram melhores em relação aos dois estudos anteriores; mais da metade dos participantes (sete deles) superou os $75 \%$ de acertos nos testes de leitura recombinativa.

Em outro estudo (Estudo V), o mesmo procedimento descrito acima foi introduzido durante a aquisição de pré-requisitos (relações $\mathrm{AB}$ e AC) e foi aplicado com doze crianças; porém, a oralização da palavra era escandida (a palavra ditada era apresentada pelo experimentador de forma escandida e assim devia ser ecoada pela criança). Os resultados apontaram que um terço dos participantes apresentou porcentagens de acerto maiores que $75 \%$ em leitura recombinativa.

Outro procedimento foi testado pelo grupo de Matos et al. (2002): a introdução do anagrama silábico sem oralização (Estudo VI), após a realização dos testes de equivalência, com quatro participantes; neste procedimento a criança fazia uma cópia do modelo impresso de uma palavra por meio de unidades menores, no caso, sílabas impressas sobre tijolinhos de madeira, os anagramas. Este procedimento foi realizado após os testes de equivalência e produziu todos os resultados com índices abaixo de 40\% de acerto (ao nível do acaso) em relação à leitura recombinativa.

No Estudo VII o anagrama silábico, introduzido após os testes de equivalência, foi acompanhado da solicitação da oralização fluente da palavra impressa e das sílabas envolvidas nas tentativas com anagrama; este estudo foi aplicado com nove crianças e foi verificado um aumento expressivo nos testes de leitura recombinativa: mais da metade das crianças mostrou resultados acima de $75 \%$ de acertos nos testes de leitura 
recombinativa, embora os autores apontem para uma grande variabilidade entres os desempenhos dos participantes (30 a 100\% de acertos entre os diferentes participantes).

Por fim, no Estudo VIII, aplicado com onze participantes, juntamente com o procedimento de anagrama silábico após os testes de equivalência, foi realizado um treino explícito de oralização escandida das sílabas, que era realizado simultaneamente ao anagrama. Neste estudo os resultados foram os melhores no conjunto de oito estudos; dois terços das crianças atingiram índices de acertos superiores a 75\%.

Os estudos de Matos et al. (2002) até aqui descritos (Estudos I a VIII) foram sempre aplicados com crianças de desenvolvimento típico; tais estudos indicaram variáveis determinantes dos desempenhos em leitura recombinativa, que se resumem a procedimentos que maximizaram a discriminação das sílabas, seja pela oralização das mesmas, no que foi denominado "oralização escandida", seja pela manipulação manual das sílabas por meio do anagrama. O processo de aprendizagem que culminou no controle preciso pelas unidades verbais mínimas palavra foi analisado dando-se ênfase aos procedimentos especiais descritos nos diferentes estudos.

No presente estudo foram analisados dados já coletados de três participantes que participaram do Estudo VIII de Matos et (2002), descrito anteriormente. A principal análise dos dados destes três participantes, que já haviam sido coletados, foi avaliar quais os possíveis controles de estímulos envolvidos no processo de aquisição do controle por unidades verbais mínimas, já durante todo o processo de aprendizado do repertório de leitura e não apenas no testes; assim, foram analisados todos os erros destes participantes durante os treinos de discriminação condicional dos estímulos compostos (palavras escritas), ou seja, nos Treinos $\mathrm{AB}$ e $\mathrm{AC}$ e não somente durante os testes que avaliavam a emergência do controle por unidades verbais mínimas, como foi 
feito nos estudos da área, especificamente nos estudos descritos em Matos et al. (2002) e no estudo de Hübner, Faggiani, Leite, Coelho e Bagaiolo (2007).

Neste último estudo (Hübner et al., 2007) também foram analisados os dados de seis participantes do Estudo VIII de Matos et al. (2002), que não foram os mesmos analisados no presente trabalho, e foi detectado que para os seis participantes, quando havia a ocorrência de erros nos testes de recombinação de sílabas, a preponderância dos mesmos estava relacionada a um extremado grau de semelhança entre os componentes dos estímulos compostos envolvidos nas respostas dos participantes, tais como: uma única letra como elemento diferente entre os estímulos ou duas sílabas em comum, situadas em posição invertida; os estímulos envolvidos nestes erros foram categorizados como contendo diferenças críticas.

Ressalte-se que na análise de erros foi empregada, como um dos modelos de categorização, a sistematização feita por Allen e Fuqua (1985) e também utilizada por Birnie-Selwyn e Guerin (1997), já descrita neste trabalho. Foi analisada qual a relação entre os estímulos relacionados às respostas dos participantes e o estímulo modelo apresentado, em cada tentativa com resposta incorreta, em termos da presença de diferenças críticas ou múltiplas nos elementos destes estímulos compostos, como já salientado por Hübner et al. (2007); os estímulos foram aqueles que vêm sendo propostos desde Hübner (1990) e que foram utilizados por Matos et al. (2002).

Além dessa análise em termos de diferenças críticas ou múltiplas, baseada em Allen e Fuqua (1985) e Birnie-Selwyn e Guerin (1997), elaborou-se também, como ficará claro adiante, na seção de Método, uma análise de caráter descritivo da composição numérica das palavras, em termos de sílabas e letras comuns, que os estímulos relacionados às respostas dos participantes e os estímulos modelo apresentados compartilhavam. 
Considerou-se relevante analisar todo o processo de aquisição do controle por unidades mínimas, buscando-se identificar nuances nos controles de estímulos estabelecidos, em três participantes dos estudos de Matos et al. (2002), que levaram à aquisição deste complexo operante com êxito, empregando novas categorias de análise do que aquelas empregadas nos Estudos de Matos et al. (2002). Este foi o principal objetivo do Estudo 1, deste trabalho.

Foi, ainda, objetivo do presente estudo, realizar uma replicação sistemática (Sidman, 1960) do Estudo VIII, em uma participante com desenvolvimento atípico, diagnosticada como pertencente ao espectro de autismo; pretendeu-se comparar os processos de aquisição do controle por unidades mínimas em indivíduos com desenvolvimento típico com a participante diagnosticada como pertencente ao espectro do autismo. No estudo com participante autista (Estudo 2) foi utilizado o mesmo procedimento do Estudo 1, bem como a análise de erros também já realizada baseada em Allen \& Fuqua (1985) e Birnie-Selwyn \& Guerin (1997); a partir desse instrumental de análise e da detecção de controles restritos de estímulos, durante a replicação com a participante autista, foram indicados e planejados procedimentos específicos de correção para eliminar controles espúrios.

A aplicação deste procedimento (Hübner, 1990; Matos \& Hübner, 1992; Matos \& Hübner, 1998 e Matos et al., 2002), desenvolvido para estabelecer a emergência do controle por unidades verbais mínimas, que vêm alcançando resultados positivos desde Hübner (1990), agora com participantes portadores de autismo, pode ser considerado importante, pois como já salientado anteriormente, esta população pode tender a apresentar controle restrito de estímulos durante a aprendizagem de discriminação de estímulos compostos (Lovass \& Schreibman, 1971; Lovaas et al., 1971; Koegel \& Wilhelm, 1973 e Allen \& Fuqua, 1985). Tais controles restritos podem afetar o 
estabelecimento do controle por unidades verbais mínimas e, por conseguinte, o estabelecimento do comportamento de ler. Tal comportamento é adaptativo, como um repertório verbal alternativo e/ou complementar, para esta população, portadora deste distúrbio - o autismo, que tem como uma das características principais a dificuldade em adquirir, manter e expandir o comportamento verbal em toda a sua extensão, complexidade e funcionalidade. 


\section{Estudo 1}

A partir das conclusões apresentadas no trabalho Hübner et al. (2007) que apontou os tipos de combinações entre estímulos modelo e aqueles relacionados às respostas de seis participantes, que geraram mais erros durante os testes de recombinação de sílabas já treinadas, com o procedimento descrito por Matos et al. (2002), Estudo VIII e, também, dos trabalhos de Allen e Fuqua (1985) e Birnie-Selwyn e Guerin (1997), que manipularam, analisaram e categorizaram diversas combinações entre estímulos modelo e de escolha com o objetivo de prevenir ou eliminar possíveis controles restritos de estímulos durante o processo de aprendizagem envolvendo estímulos compostos, pretendeu-se avaliar:

1) se conclusões sobre os tipos de erros preponderantes demonstrados por Hübner et al. (2007) seriam generalizados para os participantes analisados no presente Estudo (Participantes 1, 2 e 3);

2) se os padrões de erros demonstrados por Hübner et al. (2007) ocorriam durante todas as fases do programa e não apenas durante os testes;

3) qual(is) erro(s) e dificuldade(s) era(m) preponderante(s) nos comportamentos de cada um dos participantes analisados durante todo o processo de aquisição do controle por unidades verbais mínimas, processo esse que envolveria a análise dos treinos das relações pré-requisitos $\mathrm{AB}$ e $\mathrm{AC}$.

\section{Método}

\section{Participantes}

Foram analisados os dados já coletados de três participantes que fizeram parte do projeto de Pesquisa em Equivalência e Unidades Verbais Mínimas, que está relatado em 
Matos et al. (2002), mais especificamente, no Estudo VIII (p 300). Na Tabela 1 é possível identificar a idade, o sexo e o período de coleta de dados para estes três participantes. Eles foram escolhidos aleatoriamente; o único critério de escolha era o de que eles houvessem participado do experimento descrito em Matos et al. (2002), no Estudo VIII.

TABELA 1

Identificação dos participantes por idade, sexo e período de coleta, cujos dados foram publicados originalmente em Matos et al. ( 2002).

\begin{tabular}{cccc}
\hline Participantes & Idade & Sexo & Período de coleta \\
\hline Participante 1 & 5 anos e 7 meses & Masculino & Abril a Junho/2001 \\
Participante 2 & 5 anos e 8 meses & Masculino & Abril a Junho/2001 \\
Participante 3 & 5 anos e 6 meses & Masculino & Setembro a Novembro/2002 \\
\hline
\end{tabular}

\section{Material}

É importante destacar que a descrição do material utilizado na coleta com estes três participantes obedece a uma descrição padrão que vem sido publicada em, por exemplo, Hübner (1990), Saraiva (2000), Matos et al. (2002) e Gomes (2007).

A Tabela 2 apresenta as palavras impressas, presentes nas relações condicionais (diretamente ensinadas ou não) relacionadas aos estímulos envolvidos no programa: palavras impressas (C), figuras correspondentes (B) e respectivas palavras ditadas (A). Para os Participantes 1 e 2 foram empregados três conjuntos de estímulos (A, B e C; A', $\mathrm{B}^{\prime}$ e $\mathrm{C}^{\prime}$ e $\mathrm{A}^{\prime \prime}, \mathrm{B}^{\prime \prime}$ e $\mathrm{C}^{\prime \prime}$ ); para o Participante 3 foi utilizado um quarto conjunto de estímulos $\left(\mathrm{A}^{\prime \prime \prime}, \mathrm{B}^{\prime \prime \prime}\right.$ e $\left.\mathrm{C}^{\prime \prime \prime}\right)$, sendo que o terceiro conjunto também diferia daquele apresentado aos Participantes 1 e 2. Assim, os Participantes 1, 2 e 3 compartilharam apenas o primeiro e o segundo conjuntos, como é possível verificar na Tabela 2. 
TABELA 2

Distribuição das palavras impressas relativas aos conjuntos de estímulos, apresentados durante o programa EQUIV ${ }^{6}$, formados por palavras ditadas e as respectivas figuras e palavras impressas.

\begin{tabular}{ccccc}
\hline & Conjunto C & Conjunto C $^{\prime}$ & Conjunto C $^{\prime \prime}$ & Conjunto C" $^{\text {"r }}$ \\
\hline Participantes 1 e 2 & BOCA & COCA & LOLO & - \\
& BOLO & CACO & BOBO & \\
& CABO & BOLA & CALO & \\
& LOBO & BALA & LOCA & BABO \\
\hline Participante 3 & Idem acima & Idem acima & LOLO & LOLA \\
& & & BABA & CACA \\
& & & COLO & COCO \\
\hline
\end{tabular}

O material utilizado para a análise dos dados de P1, P2 e P3 durante os treinos e testes para a aquisição do controle por unidades verbais mínimas foram os relatórios impressos gerados automaticamente por meio do programa EQUIV; tal material foi cedido pelo Laboratório de Estudos de Operantes Verbais - LEOV, coordenado pela Professora Dra. Maria Martha Hübner, no Instituto de Psicologia da Universidade de São Paulo.

Nestes relatórios estavam impressos os resultados relativos a todas as tentativas que os participantes realizaram durante o programa, na seqüencia de apresentação do mesmo; os dados consultados neste material eram:

$\checkmark$ Número e porcentagem de acertos e erros por fase e por passo.

$\checkmark$ Matriz de resposta, indicando o número e porcentagem de acertos para cada estímulo de escolha em relação ao estímulo modelo apresentado, ou seja, a cada

\footnotetext{
${ }^{6}$ EQUIV é o software por meio do qual foram coletados os dados nos trabalhos de Saraiva (2000), Matos et al. (2002) e Gomes (2007), por exemplo.
} 
tentativa, quais estímulos o participante pareou corretamente ou não e, em caso de erro, que estímulo escolheu (Mackay e Sidman, 1984).

$\checkmark$ Latência de resposta entre a apresentação do estímulo modelo e a resposta ao estímulo de escolha.

\section{Procedimento}

\section{Análise e classificação de erros}

Primeiramente foi realizada uma análise dos conjuntos de estímulos aos quais os participantes P1, P2 e P3 foram expostos, com o objetivo de classificar os possíveis erros em cada uma das variadas combinações entre os pares estímulos compostos empregados naquele estudo, durante a execução das variadas fases de treinos e testes de todo o programa EQUIV: palavras ditadas e impressas, formadas por duas sílabas. Para tanto, foi desenvolvido um modelo de tabela para auxiliar nesta classificação, nas diversas tentativas de MTS, tanto na condição de treino de discriminações condicionais (Treinos AC), quanto nas condições de Teste (Testes de Equivalência e Testes de Novas Formas Verbais), nas tentativas de Testes de Nomeação Oral e nas Tentativas de Anagrama $^{7}$ e 8 .

Estas classificações possibilitaram categorizar os erros como contendo diferenças críticas DC ou diferenças múltiplas (Allen \& Fuqua, 1985; Birnie-Selwin \& Guerin, 1997) a partir das considerações de Hübner et al. (2007) sobre os dados encontrados em relação à preponderância de tipos de erros, para os seis sujeitos naquele

\footnotetext{
${ }^{7}$ Um modelo inicial destas tabelas foi desenvolvido pelos alunos do Programa de Pós-Graduação em Psicologia Experimental, que desenvolvem estudos na área de Controle por Unidades Mínimas, sob orientação da Professora Doutora Maria Martha Costa Hübner.

${ }^{8}$ Para uma consulta das etapas de treinos e testes do programa EQUIV, consultar o Anexo 1, Figura 19; para uma consulta mais detalhada e específica em relação aos procedimentos do EQUIV, as sugestões dos trabalhos que devem ser consultados são: Saraiva (2000), Matos et al. (2002) e Gomes (2007).
} 
neste estudo. Estas classificações podem ser encontradas nas Tabelas 3, 4, 5, 6 e 7, as quais contém três classificações principais:

1. Número de letras existentes em comum entre os estímulos apresentados como modelo e os estímulos relacionados às possíveis respostas incorretas dos participantes, abreviado como LC (letras em comum). Por exemplo: as palavras CABO e BOCA têm quatro letras em comum (B, O, C, A), como pode ser verificado na Tabela 3.

2. Número de sílabas existentes em comum entre os estímulos modelo e os estímulos relacionados às possíveis respostas incorretas dos participantes, abreviado como SC (sílabas em comum). Por exemplo: CACO e COCA têm duas sílabas em comum, como pode ser verificado na Tabela 4.

3. Posição das letras ou sílabas em comum, ou seja, quais as posições dos componentes (letras ou sílabas) que estão iguais nos dois estímulos compostos apresentados (modelo e estímulos os estímulos relacionados às possíveis respostas incorretas dos participantes); a posição dos componentes em comum pode ocorrer tanto em situações em que as letras/sílabas estão na mesma posição (abreviado como PC posição em comum) ou quando as mesmas estão em posição invertida (abreviado como PI - posição invertida). Por exemplo: as palavras LOCA e LOLO, têm em comum as letras L e O e, portanto a sílaba LO em posição comum (verificar na Tabela 5) e as palavras LOCO e COLO têm as duas sílabas LO e CO em comum (verificar na Tabela $6)$.

Estas classificações possibilitaram categorizar os erros e identificar as variadas combinações entre os elementos (letras e sílabas) dos pares de estímulos envolvidos; foi possível notar a partir desta análise dos conjuntos de estímulos que as combinações são variadas, algumas delas são combinações nas quais os estímulos modelo e aqueles relacionados às respostas incorretas do participante são muito similares e as diferenças 
entre os mesmos são muito sutis, conforme as indicações de Hübner et al. (2007) que apontou que a maioria dos erros dos resultados encontrados naquele trabalho ocorreu quando a diferença entre os estímulos compostos eram muito sutis (como em BOCA e CABO, por exemplo, ou como em BALA e BOLA, como pode ser visualizado nas Tabelas 3 e 4, respectivamente). Erros para os estímulos que contém diferenças muito sutis (ou seja, que têm muita semelhança) entre os componentes (letras e sílabas) que formam os estímulos compostos (palavras) seriam aqueles em que as palavras relacionadas têm quatro ou três letras em comum (4LC ou 3LC) e duas sílabas em comum (2SC) em posição invertida (PI) como, por exemplo, BOCA e CABO / LOBO e BOLO (Tabelas 3 e 4, respectivamente); erros formados por combinação de palavras que têm tanto três letras em comum (3LC), quanto as três letras na mesma posição, como BALA e BOLA (Tabela 4), também foram classificadas como contendo diferenças críticas ou sutis (DC), conforme nomenclatura proposta por Allen e Fuqua (1985) e Birnie-Selwyn e Guerin (1997).

O restante dos erros resultantes das combinações entre os demais estímulos compostos (palavras) foi classificado como apresentando menor grau de semelhança entre os componentes (sílabas e letras) que os formam. Essas categorizações são, por exemplo, duas letras em comum (2LC) e na posição comum (PC) entre as palavras envolvidas no erro, como BOCA e BOLO ou LOBO e CABO ou ainda duas letras em comum, mas em posição invertida, como BOLO e CABO (tais exemplos podem ser visualizados na Tabela 3); também são exemplos de erros que conteriam diferenças múltiplas (DM) - (Allen \& Fuqua, 1985 e Birnie-Selwyn e Guerin, 1997) aqueles em que as palavras relacionadas têm apenas uma letra em comum (1LC), como COCO e CACA (Tabela 7) ou também nenhuma letra em posição comum (0LC), como BABA e LOLO (Tabela 6). 
TABELA 3

Classificação dos erros e das respectivas combinações entre pares de estímulos, que são palavras dissílabas ditadas e impressas (estímulos compostos), relativas ao primeiro conjunto de estímulos, comum aos Participantes 1, 2 e 3. As palavras que formam este conjunto são: BOCA, LOBO, CABO, BOLO.

\begin{tabular}{|c|c|c|c|c|c|}
\hline $\begin{array}{l}\text { Estímulos } \\
\text { modelo }\end{array}$ & $\begin{array}{c}\text { Estímulos } \\
\text { relacionados } \\
\text { às possíveis } \\
\text { respostas } \\
\text { incorretas dos } \\
\text { participantes }\end{array}$ & $\begin{array}{c}\text { Classificação 1: } \\
\text { Letras em comum } \\
\text { (LC) }\end{array}$ & $\begin{array}{c}\text { Classificação 2: } \\
\text { Sílabas em comum } \\
\text { (SC) }\end{array}$ & $\begin{array}{c}\text { Classificação 3: } \\
\text { Posição das letras ou } \\
\text { sílabas em comum } \\
\text { (Posição em comum } \\
\text { - PC ou Posição } \\
\text { invertida - PI) }\end{array}$ & $\begin{array}{c}\text { Erros com } \\
\text { diferenças } \\
\text { críticas (DC) ou } \\
\text { diferenças } \\
\text { múltilplas (DM) }\end{array}$ \\
\hline \multirow{3}{*}{ BOCA } & $\mathrm{LOBO}\left(\mathrm{S}^{-}\right)^{9}$ & $2 \mathrm{LC}$ & $1 \mathrm{SC}$ & PI & $\mathrm{DM}$ \\
\hline & BOLO $\left(\mathrm{S}^{-}\right)$ & $2 \mathrm{LC}$ & $1 \mathrm{SC}$ & $\operatorname{PC}\left(1^{\mathrm{a}}, 2^{\mathrm{a}}\right)$ & $\mathrm{DM}$ \\
\hline & $\mathrm{CABO}\left(\mathrm{S}^{-}\right)$ & $4 \mathrm{LC}$ & $2 \mathrm{SC}$ & PI & $\mathrm{DC}$ \\
\hline \multirow{3}{*}{ LOBO } & $\mathrm{BOCA}\left(\mathrm{S}^{-}\right)$ & $2 \mathrm{LC}$ & $1 \mathrm{SC}$ & PI & $\mathrm{DM}$ \\
\hline & $\mathrm{BOLO}\left(\mathrm{S}^{-}\right)$ & $3 \mathrm{LC}$ & $2 \mathrm{SC}$ & PI & $\mathrm{DC}$ \\
\hline & $\mathrm{CABO}\left(\mathrm{S}^{-}\right)$ & $2 \mathrm{LC}$ & $1 \mathrm{SC}$ & $\operatorname{PC}\left(3^{\mathrm{a}}, 4^{\mathrm{a}}\right)$ & $\mathrm{DM}$ \\
\hline \multirow{3}{*}{ BOLO } & BOCA $\left(\mathrm{S}^{-}\right)$ & $2 \mathrm{LC}$ & $1 \mathrm{SC}$ & $\mathrm{PC}\left(1^{\mathrm{a}}, 2^{\mathrm{a}}\right)$ & $\overline{\mathrm{DM}}$ \\
\hline & $\mathrm{LOBO}\left(\mathrm{S}^{-}\right)$ & $3 \mathrm{LC}$ & $2 \mathrm{SC}$ & PI & DC \\
\hline & $\mathrm{CABO}\left(\mathrm{S}^{-}\right)$ & $2 \mathrm{LC}$ & $1 \mathrm{SC}$ & PI & $\mathrm{DM}$ \\
\hline \multirow{3}{*}{$\mathrm{CABO}$} & BOCA $\left(\mathrm{S}^{-}\right)$ & $4 \mathrm{LC}$ & $2 \mathrm{SC}$ & PI & $\overline{\mathrm{DC}}$ \\
\hline & LOBO $\left(\mathrm{S}^{-}\right)$ & $2 \mathrm{LC}$ & $1 \mathrm{SC}$ & $\operatorname{PC}\left(3^{\mathrm{a}}, 4^{\mathrm{a}}\right)$ & $\mathrm{DM}$ \\
\hline & $\mathrm{BOLO}\left(\mathrm{S}^{-}\right)$ & $2 \mathrm{LC}$ & $1 \mathrm{SC}$ & PI & DM \\
\hline
\end{tabular}

${ }^{9}$ A abreviação $\mathrm{S}^{-}$significa que este estímulo comparação é negativo, ou seja, não corresponde ao estímulo modelo apresentado nas tentativas de MTS. 
TABELA 4

Classificação dos erros e das respectivas combinações entre pares de estímulos, que são palavras dissílabas ditadas e impressas (estímulos compostos), relativas ao segundo conjunto de estímulos, comum aos Participantes 1, 2 e 3. As palavras que formam este conjunto são: CACO, BALA, COCA, BOLA.

\begin{tabular}{|c|c|c|c|c|c|}
\hline $\begin{array}{c}\text { Estímulos } \\
\text { modelo }\end{array}$ & $\begin{array}{c}\text { Estímulos } \\
\text { relacionados às } \\
\text { possíveis } \\
\text { respostas } \\
\text { incorretas dos } \\
\text { participantes }\end{array}$ & $\begin{array}{l}\text { Classificação 1: } \\
\text { letras em comum } \\
\text { (LC) }\end{array}$ & $\begin{array}{c}\text { Classificação 2: } \\
\text { sílabas em comum } \\
\text { (SC) }\end{array}$ & $\begin{array}{c}\text { Classificação 3: } \\
\text { posição das letras } \\
\text { ou sílabas em } \\
\text { comum } \\
\text { (Posição em } \\
\text { comum - PC ou } \\
\text { Posição invertida - } \\
\text { PI) }\end{array}$ & $\begin{array}{c}\text { Erros com } \\
\text { diferenças } \\
\text { críticas (DC) ou } \\
\text { diferenças } \\
\text { múltiplas (DM) }\end{array}$ \\
\hline \multirow{3}{*}{ BALA } & BOLA $\left(\mathrm{S}^{-}\right)$ & $3 \mathrm{LC}$ & $1 \mathrm{SC}$ & $\mathrm{PC}\left(1^{\mathrm{a}}, 3^{\mathrm{a}}, 4^{\mathrm{a}}\right)$ & $\mathrm{DC}$ \\
\hline & $\operatorname{COCA}\left(\mathrm{S}^{-}\right)$ & $1 \mathrm{LC}$ & 0SC & $\mathrm{PC}\left(4^{\mathrm{a}}\right)$ & $\mathrm{DM}$ \\
\hline & $\mathrm{CACO}\left(\mathrm{S}^{-}\right)$ & $1 \mathrm{LC}$ & OSC & $\mathrm{PC}\left(2^{\mathrm{a}}\right)$ & $\mathrm{DM}$ \\
\hline \multirow{3}{*}{ BOLA } & BALA $\left(\mathrm{S}^{-}\right)$ & $3 \mathrm{LC}$ & $1 \mathrm{SC}$ & $\mathrm{PC}\left(1^{\mathrm{a}}, 3^{\mathrm{a}}, 4^{\mathrm{a}}\right)$ & $\mathrm{DC}$ \\
\hline & $\mathrm{COCA}\left(\mathrm{S}^{-}\right)$ & 2LC & 0SC & $\mathrm{PC}\left(2^{\mathrm{a}}, 4^{\mathrm{a}}\right)$ & $\mathrm{DM}$ \\
\hline & $\mathrm{CACO}\left(\mathrm{S}^{-}\right)$ & $2 \mathrm{LC}$ & oSC & - & $\mathrm{DM}$ \\
\hline \multirow{3}{*}{ COCA } & BALA $\left(\mathrm{S}^{-}\right)$ & $1 \mathrm{LC}$ & $0 \mathrm{SC}$ & $\mathrm{PC}\left(4^{\mathrm{a}}\right)$ & $\overline{\mathrm{DM}}$ \\
\hline & BOLA $\left(\mathrm{S}^{-}\right)$ & $2 \mathrm{LC}$ & OSC & $\mathrm{PC}\left(2^{\mathrm{a}}, 4^{\mathrm{a}}\right)$ & $\mathrm{DM}$ \\
\hline & $\mathrm{CACO}\left(\mathrm{S}^{-}\right)$ & $3 \mathrm{LC}$ & $2 \mathrm{SC}$ & PI & DC \\
\hline \multirow{3}{*}{$\mathrm{CACO}$} & BALA $\left(\mathrm{S}^{-}\right)$ & $1 \mathrm{LC}$ & $0 \mathrm{SC}$ & $\mathrm{PC}\left(2^{\mathrm{a}}\right)$ & $\mathrm{DM}$ \\
\hline & $\operatorname{BOLA}\left(\mathrm{S}^{-}\right)$ & $2 \mathrm{LC}$ & oSC & - & $\mathrm{DM}$ \\
\hline & $\operatorname{COCA}\left(\mathrm{S}^{-}\right)$ & $3 \mathrm{LC}$ & $2 \mathrm{SC}$ & PI & $\mathrm{DC}$ \\
\hline
\end{tabular}


TABELA 5

Classificação dos erros e das respectivas combinações entre pares de estímulos, que são palavras dissílabas ditadas e impressas (estímulos compostos), relativas ao terceiro conjunto de estímulos, comum aos Participantes 1 e 2 (para o Participante 3 foi utilizado outro conjunto de estímulo - ver Tabela 6). As palavras que formam este conjunto são: BOBO, CALO, LOLO, LOCA.

\begin{tabular}{|c|c|c|c|c|c|}
\hline \multirow[t]{2}{*}{$\begin{array}{c}\text { Estímulos } \\
\text { modelo }\end{array}$} & $\begin{array}{c}\text { Estímulos } \\
\text { relacionados às } \\
\text { possíveis } \\
\text { respostas } \\
\text { incorretas dos } \\
\text { participantes }\end{array}$ & $\begin{array}{l}\text { Classificação 1: } \\
\text { letras em comum } \\
\text { (LC) }\end{array}$ & $\begin{array}{c}\text { Classificação 2: } \\
\text { sílabas em comum } \\
\text { (SC) }\end{array}$ & $\begin{array}{c}\text { Classificação 3: } \\
\text { posição das } \\
\text { letras ou sílabas } \\
\text { em comum } \\
\text { (Posição em } \\
\text { comum - PC ou } \\
\text { Posição } \\
\text { invertida - PI) }\end{array}$ & $\begin{array}{c}\text { Erros com } \\
\text { diferenças } \\
\text { críticas (DC) ou } \\
\text { diferenças } \\
\text { múltiplas (DM) }\end{array}$ \\
\hline & CALO $\left(\mathrm{S}^{-}\right)$ & $3 \mathrm{LC}$ & $2 \mathrm{SC}$ & PI & $\mathrm{DC}$ \\
\hline \multirow[t]{3}{*}{ LOCA } & $\operatorname{LOLO}\left(\mathrm{S}^{-}\right)$ & $2 \mathrm{LC}$ & $1 \mathrm{SC}$ & $\operatorname{PC}\left(1^{\mathrm{a}}, 2^{\mathrm{a}}\right)$ & DM \\
\hline & $\mathrm{BOBO}\left(\mathrm{S}^{-}\right)$ & $1 \mathrm{LC}$ & OSC & $\mathrm{PC}\left(2^{\mathrm{a}}\right)$ & $\mathrm{DM}$ \\
\hline & LOCA $\left(\mathrm{S}^{-}\right)$ & $3 \mathrm{LC}$ & $2 \mathrm{SC}$ & PI & $\mathrm{DC}$ \\
\hline \multirow[t]{3}{*}{ CALO } & $\operatorname{LOLO}\left(\mathrm{S}^{-}\right)$ & $2 \mathrm{LC}$ & $1 \mathrm{SC}$ & $\operatorname{PC}\left(3^{a}, 4^{a}\right)$ & $\mathrm{DM}$ \\
\hline & $\mathrm{BOBO}\left(\mathrm{S}^{-}\right)$ & $1 \mathrm{LC}$ & OSC & $\mathrm{PC}\left(4^{\mathrm{a}}\right)$ & $\mathrm{DM}$ \\
\hline & LOCA $\left(\mathrm{S}^{-}\right)$ & $2 \mathrm{LC}$ & $1 \mathrm{SC}$ & $\mathrm{PC}\left(1^{\mathrm{a}}, 2^{\mathrm{a}}\right)$ & $\mathrm{DM}$ \\
\hline \multirow[t]{3}{*}{ LOLO } & $\mathrm{CALO}\left(\mathrm{S}^{-}\right)$ & $2 \mathrm{LC}$ & $1 \mathrm{SC}$ & $\operatorname{PC}\left(3^{\mathrm{a}}, 4^{\mathrm{a}}\right)$ & $\mathrm{DM}$ \\
\hline & $\mathrm{BOBO}\left(\mathrm{S}^{-}\right)$ & $1 \mathrm{LC}$ & OSC & $\operatorname{PC}\left(2^{\mathrm{a}}, 4^{\mathrm{a}}\right)$ & $\mathrm{DM}$ \\
\hline & $\operatorname{LOCA}\left(\mathrm{S}^{-}\right)$ & $1 \mathrm{LC}$ & OSC & $\mathrm{PC}\left(2^{\mathrm{a}}\right)$ & $\mathrm{DM}$ \\
\hline \multirow[t]{2}{*}{ BOBO } & $\mathrm{CALO}\left(\mathrm{S}^{-}\right)$ & $1 \mathrm{LC}$ & OSC & $\operatorname{PC}\left(4^{a}\right)$ & $\mathrm{DM}$ \\
\hline & $\operatorname{LOLO}\left(\mathrm{S}^{-}\right)$ & $1 \mathrm{LC}$ & OSC & $\operatorname{PC}\left(2^{\mathrm{a}}, 4^{\mathrm{a}}\right)$ & DM \\
\hline
\end{tabular}




\section{TABELA 6}

Classificação dos erros e das respectivas combinações entre pares de estímulos, que são palavras dissílabas ditadas e impressas (estímulos compostos), relativas ao terceiro conjunto de estímulos utilizado com o Participante 3 (para os Participantes 1 e 2 foi utilizado outro conjunto de estímulo). As palavras que formam este conjunto são: BABA, COLO, LOLO, LOCO.

\begin{tabular}{|c|c|c|c|c|c|}
\hline $\begin{array}{c}\text { Estímulos } \\
\text { modelo }\end{array}$ & $\begin{array}{c}\text { Estímulos } \\
\text { relacionados às } \\
\text { possíveis } \\
\text { respostas } \\
\text { incorretas dos } \\
\text { participantes }\end{array}$ & $\begin{array}{l}\text { Classificação 1: } \\
\text { letras em comum } \\
\text { (LC) }\end{array}$ & $\begin{array}{c}\text { Classificação 2: } \\
\text { sílabas em comum } \\
\text { (SC) }\end{array}$ & $\begin{array}{c}\text { Classificação 3: } \\
\text { posição das } \\
\text { letras ou sílabas } \\
\text { em comum } \\
\text { (Posição em } \\
\text { comum - PC ou } \\
\text { Posição } \\
\text { invertida - PI) }\end{array}$ & $\begin{array}{c}\text { Erros com } \\
\text { diferenças } \\
\text { críticas (DC) ou } \\
\text { com diferenças } \\
\text { múltiplas (DM) }\end{array}$ \\
\hline \multirow{3}{*}{ BABA } & LOLO $\left(\mathrm{S}^{-}\right)$ & 0LC & $0 \mathrm{SC}$ & - & $\overline{\mathrm{DM}}$ \\
\hline & $\operatorname{LOCO}\left(\mathrm{S}^{-}\right)$ & OLC & OSC & - & DM \\
\hline & $\operatorname{COLO}\left(\mathrm{S}^{-}\right)$ & 0LC & 0SC & - & $\mathrm{DM}$ \\
\hline \multirow{3}{*}{ LOLO } & BABA (S') & 0LC & OSC & - & DM \\
\hline & $\operatorname{LOCO}\left(\mathrm{S}^{-}\right)$ & $2 \mathrm{LC}$ & $1 \mathrm{SC}$ & $\operatorname{PC}\left(1^{\mathrm{a}}, 2^{\mathrm{a}}, 4^{\mathrm{a}}\right)$ & $\mathrm{DC}$ \\
\hline & $\operatorname{COLO}\left(\mathrm{S}^{-}\right)$ & $2 \mathrm{LC}$ & $1 \mathrm{SC}$ & $\mathrm{PC}\left(3^{\mathrm{a}}, 4^{\mathrm{a}}\right)$ & DM \\
\hline \multirow{3}{*}{ LOCO } & BABA (S') & 0LC & 0SC & - & $\mathrm{DM}$ \\
\hline & LOLO $\left(\mathrm{S}^{-}\right)$ & $2 \mathrm{LC}$ & $1 \mathrm{SC}$ & $\mathrm{PC}\left(1^{\mathrm{a}}, 2^{\mathrm{a}}, 4^{\mathrm{a}}\right)$ & $\mathrm{DC}$ \\
\hline & $\operatorname{COLO}\left(\mathrm{S}^{-}\right)$ & $3 \mathrm{LC}$ & $2 \mathrm{SC}$ & PI & $\mathrm{DC}$ \\
\hline \multirow{3}{*}{ COLO } & BABA $\left(\mathrm{S}^{-}\right)$ & OLC & OSC & - & $\mathrm{DM}$ \\
\hline & $\operatorname{LOLO}\left(\mathrm{S}^{-}\right)$ & $2 \mathrm{LC}$ & $1 \mathrm{SC}$ & $\mathrm{PC}\left(3^{\mathrm{a}}, 4^{\mathrm{a}}\right)$ & DM \\
\hline & $\operatorname{LOCO}\left(\mathrm{S}^{-}\right)$ & $3 \mathrm{LC}$ & $2 \mathrm{SC}$ & PI & $\mathrm{DC}$ \\
\hline
\end{tabular}




\section{TABELA 7}

Classificação dos erros e das respectivas combinações entre pares de estímulos, que são palavras dissílabas ditadas e impressas (estímulos compostos), relativas ao quarto conjunto de estímulos utilizados apenas com o Participante 3 (os Participantes 1 e 2 não foram expostos a um quarto conjunto de estímulos). As palavras que formam este conjunto são: BABO, LOLA, COCO, CACA.

\begin{tabular}{|c|c|c|c|c|c|}
\hline $\begin{array}{c}\text { Estímulos } \\
\text { modelo }\end{array}$ & $\begin{array}{c}\text { Estímulos } \\
\text { relacionados } \\
\text { às possíveis } \\
\text { respostas } \\
\text { incorretas dos } \\
\text { participantes }\end{array}$ & $\begin{array}{l}\text { Classificação 1: } \\
\text { letras em comum } \\
\text { (LC) }\end{array}$ & $\begin{array}{l}\text { Classificação 2: } \\
\text { sílabas em } \\
\text { comum } \\
\text { (SC) }\end{array}$ & $\begin{array}{l}\text { Classificação 3: } \\
\text { posição das } \\
\text { letras ou sílabas } \\
\text { em comum } \\
\text { (Posição em } \\
\text { comum - PC ou } \\
\text { Posição } \\
\text { invertida - PI) }\end{array}$ & $\begin{array}{c}\text { Erros com } \\
\text { diferenças } \\
\text { críticas }(\mathrm{DC}) \text { ou } \\
\text { com diferenças } \\
\text { múltiplas (DM) }\end{array}$ \\
\hline \multirow{3}{*}{ BABO } & $\operatorname{LOLA}\left(\mathrm{S}^{-}\right)$ & $2 \mathrm{LC}$ & $0 \mathrm{SC}$ & - & DM \\
\hline & $\operatorname{COCO}\left(\mathrm{S}^{-}\right)$ & $1 \mathrm{LC}$ & OSC & $\operatorname{PC}\left(4^{a}\right)$ & DM \\
\hline & $\mathrm{CACA}\left(\mathrm{S}^{-}\right)$ & $1 \mathrm{LP}$ & OSC & $\mathrm{PC}\left(2^{\mathrm{a}}\right)$ & DM \\
\hline \multirow{3}{*}{ LOLA } & $\mathrm{BABO}\left(\mathrm{S}^{-}\right)$ & $2 \mathrm{LC}$ & 0SC & - & $\mathrm{DM}$ \\
\hline & $\operatorname{COCO}\left(\mathrm{S}^{-}\right)$ & $1 \mathrm{LC}$ & OSC & $\operatorname{PC}\left(2^{a}\right)$ & DM \\
\hline & $\mathrm{CACA}\left(\mathrm{S}^{-}\right)$ & $1 \mathrm{LC}$ & OSC & $\mathrm{PC}\left(4^{\mathrm{a}}\right)$ & $\mathrm{DM}$ \\
\hline \multirow{3}{*}{$\mathrm{COCO}$} & $\mathrm{BABO}\left(\mathrm{S}^{-}\right)$ & $1 \mathrm{LC}$ & $0 \mathrm{SC}$ & $\mathrm{PC}\left(4^{\mathrm{a}}\right)$ & $\mathrm{DM}$ \\
\hline & $\operatorname{LOLA}\left(\mathrm{S}^{-}\right)$ & $1 \mathrm{LC}$ & OSC & $\operatorname{PC}\left(2^{a}\right)$ & $\mathrm{DM}$ \\
\hline & $\mathrm{CACA}\left(\mathrm{S}^{-}\right)$ & $1 \mathrm{LC}$ & OSC & $\operatorname{PC}\left(1^{\mathrm{a}}, 3^{\mathrm{a}}\right)$ & DM \\
\hline \multirow{3}{*}{ CACA } & $\mathrm{BABO}\left(\mathrm{S}^{-}\right)$ & $1 \mathrm{LC}$ & 0SC & $\mathrm{PC}\left(2^{\mathrm{a}}\right)$ & $\mathrm{DM}$ \\
\hline & $\operatorname{LOLA}\left(\mathrm{S}^{-}\right)$ & $1 \mathrm{LC}$ & OSC & $\operatorname{PC}\left(4^{a}\right)$ & DM \\
\hline & $\operatorname{COCO}\left(\mathrm{S}^{-}\right)$ & $1 \mathrm{LC}$ & OSC & $\operatorname{PC}\left(1^{\mathrm{a}}, 3^{\mathrm{a}}\right)$ & DM \\
\hline
\end{tabular}


Com a classificação dos conjuntos de estímulos realizada, foi desenvolvido um trabalho com os dados dos participantes P1, P2 e P3 que se submeteram ao programa EQUIV, com o objetivo de sistematizar os erros de cada um dos participantes, mapeando e apontando o processo de aquisição do controle por unidades verbais mínimas por meio da análise dos erros, durante toda a execução das fases do programa. Os dados principais para esta análise individualizada estão relacionados às escolhas e respostas de cada um dos participantes, quando ocorreram erros; para tanto, foram utilizadas os dados presentes nas matrizes dos registros de P1, P2 e P3 e esquematizados em novas matrizes apresentadas no Anexo 2, nas quais é possível observar a freqüência de erros, nas diferentes fases do programa, a saber:

- Treinos: Treinos de discriminação condicional $\mathrm{AC}, \mathrm{A}^{\prime} \mathrm{C}^{\prime}, \mathrm{A}^{\prime \prime} \mathrm{C}^{\prime \prime}$; este último apenas para o Participante 3 e Treinos de construção com anagramas ${ }^{10}$.

- Testes: 1. Testes de Equivalência (Testes $\mathrm{BC} / \mathrm{CB}^{11}$ e ${ }^{12}, \mathrm{~B}^{\prime} \mathrm{C}^{\prime} / \mathrm{C}^{\prime} \mathrm{B}^{\prime}$, $\mathrm{B}^{\prime \prime} \mathrm{C}^{\prime \prime} / \mathrm{C}^{\prime \prime} \mathrm{B}^{\prime \prime}$, realizados após o treino direto entre palavras ditadas e palavras impressas [Treinos AC]), 2. Testes de Novas Formas Verbais (testes $\mathrm{B}^{\prime} \mathrm{C}^{\prime} / \mathrm{C}^{\prime} \mathrm{B}^{\prime}$, $\mathrm{B}^{\prime \prime} \mathrm{C}^{\prime \prime} / \mathrm{C}^{\prime \prime} \mathrm{B}^{\prime \prime}, \mathrm{B}^{\prime \prime \prime} \mathrm{C}^{\prime \prime \prime} / \mathrm{C}^{\prime \prime \prime} \mathrm{B}^{\prime \prime \prime}$, este último apenas para $\mathrm{P}$, realizados após o treino entre palavras ditadas e respectivas figuras [Treinos $\mathrm{A}^{\prime} \mathrm{B}^{\prime}$ e $\mathrm{A}^{\prime \prime} \mathrm{B}^{\prime \prime}$ - este último também apenas para P3] sem o treino direto entre palavras ditadas e palavras impressas) e 3. Testes de Nomeação das palavras impressas realizados em dois momentos diferentes do

\footnotetext{
${ }^{10}$ Para uma consulta das etapas de treinos e testes do programa EQUIV, consultar o Anexo 1, Figura 19; além disso, os trabalhos que devem ser consultados em relação aos procedimentos do EQUIV são: Saraiva (2000), Matos et al. (2002) e Gomes (2007)..

${ }^{11}$ No caso deste estudo, tentativas do tipo BC (tanto nos Testes de Equivalência quanto nos Testes de Novas Formas Verbais) são aquelas em que os estímulos modelos são formados por figuras e os estímulos de escolha são formados por palavras impressas.

12 Os erros desta fase (CB) não foram incluídos nesta classificação porque os estímulos de escolha positivos e negativos, formados por figuras, não tem uma divisão clara e uniforme dos elementos destes supostos estímulos compostos (figuras). Já os estímulos compostos formados por palavras impressas ditadas/oralizadas (que compõe os estímulos de escolha negativos e positivos em tentativas do tipo AC, $\mathrm{BC}$ e, também, as tentativas de nomeação e de anagrama) são formados pelos elementos identificados neste trabalho como letras e sílabas e, portanto, foram comparados entre si, diferentemente das figuras.
} 
programa (no início, na metade, aproximadamente, e no final); os erros ocorridos no primeiro Teste de Nomeação, que foi a primeira fase do programa, não foram contabilizados aqui, pois foram realizados a título de 'Pré-Teste' e foram comuns a todos os participantes.

Nas fases de treino e teste nas quais não ocorreu nenhum erro não foi feita nenhuma matriz; todos os erros realizados por P1, P2 e P3 durante o programa estão sistematizados no Anexo 2.

Após a classificação dos erros que podem ocorrer durante a execução do programa EQUIV (para todos os conjuntos de estímulos) e, após a tabulação dos erros de cada participante em matrizes de respostas, foi desenvolvido um modelo de tabela, para cada participante, no qual os erros foram organizados obedecendo à seqüência do programa. Para cada uma das fases, os erros foram dispostos em ordem decrescente, ou seja, primeiro foram dispostos os tipos de erros que ocorreram em maior número, em cada fase do programa. Esta sistematização foi realizada para uma melhor visualização das possíveis dificuldades individuais de cada participante, em cada fase do programa, com o objetivo específico de entender quais controles de estímulos estavam presentes durante a aquisição do processo de controle por unidades mínimas, desde as fases de treino. 
Primeiramente será apresentado um resumo das diversas combinações entre os estímulos compostos, para as quais foi observada a ocorrência de erros, como pode ser visto na seção de Método, deste estudo, nas Tabelas 3, 4, 5, 6 e 7. No presente trabalho, tal como já descrito no Método, os conjunto de estímulos (estímulos modelo e estímulos relacionados às respostas dos participantes) foram descritos e classificados comparativamente, quanto ao número de sílabas e letras em comum e quanto à posição das mesmas nas diversas tentativas de MTS (Treinos AB, Treinos AC, Testes de Equivalência e Testes de Novas Formais Verbais), bem como nas tarefas de construção (Anagrama) e tarefas de nomeação (Testes de Nomeação Oral) ${ }^{13}$.Na Tabela 8, a seguir, pode ser encontrada a categorização resumida destes erros. Na primeira parte da Tabela 8 (acima da linha horizontal destacada) estão dispostos os tipos de erros de P1, P2 e P3 derivados de combinações que foram categorizadas como contendo diferenças críticas DC - (Allen \& Fuqua, 1985; Birnie-Selwin \& Guerin, 1997), já que há muita semelhança entre os estímulos modelos e os estímulos relacionados às respostas dos participantes (Hübner, 2007). Seguem as categorias:

- Combinações com quatro letras em comum (4LC/2SC/PI): São combinações entre pares de estímulos que têm quatro letras e duas sílabas em comum (4LC/2SC) em posição invertida (PI), essa situação pode ser verificada na combinação entre as palavras BOCA/CABO. As letras em comum são: $\mathrm{B}, \mathrm{O}, \mathrm{C}, \mathrm{A}$; as sílabas em comum são $\mathrm{BO}$ e CA em posição invertida.

\footnotetext{
${ }^{13}$ Para uma consulta das etapas de treinos e testes do programa EQUIV, consultar o Anexo 1, Figura 19; para uma consulta mais detalhada e específica em relação aos procedimentos do EQUIV, as sugestões dos trabalhos que devem ser consultados são: Saraiva (2000), Matos et al. (2002) e Gomes (2007).
} 
TABELA 8

Distribuição dos tipos de erros dos participantes durante as fases do EQUIV a partir das combinações entre estímulos modelo e estímulos relacionados às respostas dos participantes.

\begin{tabular}{|c|c|c|c|c|c|}
\hline $\begin{array}{c}\text { Classificação 1: } \\
\text { letras em } \\
\text { comum (LC) }\end{array}$ & $\begin{array}{l}\text { Classificação 2: } \\
\text { sílabas em } \\
\text { comum } \\
\text { (SC) }\end{array}$ & $\begin{array}{l}\text { Classificação 3: } \\
\text { posição das letras } \\
\text { em comum (PC) } \\
\text { ou sílabas em } \\
\text { posição invertida } \\
\text { (PI) }\end{array}$ & $\begin{array}{c}\text { Exemplos de } \\
\text { estímulos modelo } \\
\text { (palavras ditadas } \\
\text { ou impressas) }\end{array}$ & $\begin{array}{l}\text { Erros (Exemplos } \\
\text { de estímulos } \\
\text { relacionados às } \\
\text { respostas dos } \\
\text { participantes) }\end{array}$ & $\begin{array}{c}\text { Erros com } \\
\text { diferenças críticas } \\
\text { (DC) ou diferenças } \\
\text { múltilplas (DM) }\end{array}$ \\
\hline $4 \mathrm{LC}$ & $2 \mathrm{SC}$ & PI & BOCA & $\mathrm{CABO}$ & $\mathrm{DC}$ \\
\hline $3 \mathrm{LC}$ & $2 \mathrm{SC}$ & PI & CACO & COCA & $\mathrm{DC}$ \\
\hline $3 \mathrm{LC}$ & $1 \mathrm{SC}$ & $\operatorname{PC}\left(1^{\mathrm{a}}, 3^{\mathrm{a}}, 4^{\mathrm{a}}\right)$ & BALA & BOLA & $\mathrm{DC}$ \\
\hline $3 \mathrm{LC}$ & $1 \mathrm{SC}$ & $\operatorname{PC}\left(1^{\mathrm{a}}, 2^{\mathrm{a}}, 4^{\mathrm{a}}\right)$ & BOLA & BOCA & $\mathrm{DC}$ \\
\hline $2 \mathrm{LC}$ & $1 \mathrm{SC}$ & $\operatorname{PC}\left(1^{\mathrm{a}}, 2^{\mathrm{a}}, 4^{\mathrm{a}}\right)$ & LOLO & LOCO & $\mathrm{DC}$ \\
\hline $2 \mathrm{LC}$ & $1 \mathrm{SC}$ & $\operatorname{PC}\left(2^{\mathrm{a}}, 3^{\mathrm{a}}, 4^{\mathrm{a}}\right)$ & COLO & LOLO & $\mathrm{DC}$ \\
\hline $2 \mathrm{LC}$ & $1 \mathrm{SC}$ & $\overline{P I}$ & BOLO & $\overline{\mathrm{CABO}}$ & $\overline{\mathrm{DM}}$ \\
\hline $2 \mathrm{LC}$ & $1 \mathrm{SC}$ & $\operatorname{PC}\left(1^{\mathrm{a}}, 2^{\mathrm{a}}\right)$ & BOCA & BOLO & DM \\
\hline $2 \mathrm{LC}$ & $1 \mathrm{SC}$ & $\operatorname{PC}\left(3^{\mathrm{a}}, 4^{\mathrm{a}}\right)$ & LOBO & CABO & DM \\
\hline $2 \mathrm{LC}$ & OSC & - & $\mathrm{BABO}$ & LOLA & $\mathrm{DM}$ \\
\hline $1 \mathrm{LC}$ & OSC & $\operatorname{PC}\left(1^{\mathrm{a}}, 3^{\mathrm{a}}\right)$ & $\mathrm{COCO}$ & CACA & DM \\
\hline $1 \mathrm{LC}$ & OSC & $\operatorname{PC}\left(2^{\mathrm{a}}, 4^{\mathrm{a}}\right)$ & LOLO & BOBO & DM \\
\hline $1 \mathrm{LC}$ & OSC & $\mathrm{PC}\left(2^{\mathrm{a}}\right)$ & BALA & CACO & DM \\
\hline $1 \mathrm{LC}$ & OSC & $\operatorname{PC}\left(4^{a}\right)$ & BALA & COCA & $\mathrm{DM}$ \\
\hline OLC & OSC & - & BABA & LOLO & DM \\
\hline
\end{tabular}

- Combinações com três letras em comum:

a. (3LC/2SC/PI): Combinações realizadas pelos participantes entre os pares de estímulos que possuem três letras e duas sílabas em comum, mas em posição invertida (3LC/2SC/PI); um exemplo desta combinação são as palavras CACO e COCA. As letras em comum são C (que ocorre duas vezes nas duas palavras), A, O; as sílabas em comum são CA e CO em posição invertida. 
b. (3LC/1SC, com três letras na mesma posição): Combinações entre pares de estímulos que têm três letras em comum (3LC), na mesma posição $\left(1^{\mathrm{a}}\right.$., $3^{\mathrm{a}}$ e $\left.4^{\mathrm{a}}\right)$ e, também, uma sílaba em comum (1SC). Como pode ser verificado na Tabela 4, p. 60, seção de Método deste estudo, a única combinação de erros deste tipo foi observada entre as palavras BALA e BOLA (B, L e A em comum nas posições $1^{\mathrm{a}}$., $3^{\mathrm{a}}$. e $4^{\mathrm{a}}$ e a sílaba LA em comum); porém, o Participante 2, no Teste de Nomeação Oral II (ver Anexo 1, Figura 19) diante da palavra impressa BOLA falou BOCA três vezes, o que traz uma nova combinação para esta categoria de erros que têm três letras em comum e na mesma posição, já que as letras em comum são: $\mathrm{B}, \mathrm{O}, \mathrm{A}$ e a posição em comum é $1^{\mathrm{a}}$. $2^{\mathrm{a}}, 4^{\mathrm{a}}$.

- Combinações com duas letras em comum (2LC/1SC, com três letras na mesma posição): São combinações entre palavras que têm duas letras em comum (mas que se repetem duas vezes na mesma palavra), uma sílaba em comum e três letras na mesma posição. Há dois exemplos de respostas que envolvem estas combinações: 1. LOLO e LOCO, que têm três letras em comum na posição $1^{\mathrm{a}}, 2^{\mathrm{a}}$ e $4^{\mathrm{a}}$ e 2 . COLO e LOLO, que têm três letras em comum na posição $2^{\mathrm{a}}, 3^{\mathrm{a}} \cdot 4^{\mathrm{a}}$.

O restante dos estímulos compostos foi agrupado como pertencente às combinações entre estímulos com poucas semelhanças/diferenças sutis, pois apresentam menor grau de semelhança entre os componentes (Hübner, 2007); tais exemplos foram denominados como contendo diferenças múltiplas - DM (Allen \& Fuqua, 1985; BirnieSelwin \& Guerin, 1997). Eles podem ser encontrados na segunda parte da Tabela 8 (abaixo da linha horizontal destacada); as categorizações deste tipo são:

- Combinações com duas letras em comum:

a. (2LC/1SC/PI): Combinações que possuem duas letras e uma sílaba em comum em posição invertida (2LC/1SC/PI); um exemplo desta combinação são as 
palavras BOLO e CABO. As letras em comum são B e O; a sílaba em comum é BO, em posição invertida.

b. (2LC/1SC, com duas letras na mesma posição): São combinações entre pares de estímulos que têm duas letras e uma sílaba em comum e, também, duas letras na mesma posição. Há dois exemplos de combinações para esta categoria de erros: 1. BOCA e BOLO, que têm duas letras em comum na posição $1^{\mathrm{a}}$. e $2^{\mathrm{a}}$ e 2 . LOBO e CABO, que têm duas letras em comum na posição $3^{\mathrm{a}}$. e $4^{\mathrm{a}}$.

c. (2LC/0SC e sem letras na mesma posição): São combinações entre pares de estímulos que têm apenas duas letras em comum, mas nenhuma sílaba em comum e sem letras na mesma posição. Há um exemplo deste tipo de combinação na Tabela 7 , da Seção de Método deste estudo: BABO e LOLA, que têm duas letras em comum (A e O), mas não na mesma posição e, também, não possuem nenhuma sílaba em comum.

- Combinações com uma letra em comum:

a. (1LC/0SC, com duas letras na mesma posição): São combinações entre pares de estímulos que têm duas letras em comum (mas que se repetem duas vezes na mesma palavra), nenhuma sílaba em comum e duas letras na mesma posição. Há dois exemplos de combinações para esta categoria de erros: 1 . COCO e CACA, que têm a letra $\mathrm{C}$ em comum nas posições $1^{\mathrm{a}}$. e $3^{\mathrm{a}}$ e 2 . BOLO e BOBO, que têm a letra $\mathrm{B}$ em comum nas direções $3^{\mathrm{a}}$. e $4^{\mathrm{a}}$.

b. (1LC/0SC, com uma letra na mesma posição): São combinações entre pares de estímulos que têm uma letra em comum, nenhuma sílaba em comum e uma letra na mesma posição. Há dois exemplos de combinações para esta categoria de erros: 1 . BALA e CACO, que têm a letra A em comum na $2^{\text {a }}$. posição e 2. BOLA e COCA, que têm a letra $\mathrm{O}$ em comum na $4^{\mathrm{a}}$. posição. 
- Combinações com nenhuma letra e sílaba em comum (0LC/0SC/-): São

combinações que não possuem nenhuma letra e sílaba em comum, como por exemplo, BABA e LOLO.

Com o objetivo de realizar uma análise de possíveis controles de estímulos envolvidos durante os processos de aquisição de discriminação condicional e de controle por unidades mínimas, foi realizada uma análise qualitativa dos erros de cada um dos participantes durante todas as fases de treinos e testes do programa EQUIV explicitadas na seção de Método, deste estudo. As Tabelas 9, 10 e 11 apresentam esta análise a partir dos erros de P1, P2 e P3, respectivamente; nestas tabelas, a disposição dos erros obedece a sua ocorrência na ordem/seqüência de execução do programa e, também, os erros foram organizados em ordem decrescente de freqüência, ou seja, dos mais freqüentes para os menos freqüentes; a consulta e tabulação de tais dados pôde ser feita a partir das matrizes de respostas apresentadas no Anexo 2.

Participante 1

Para o Participante 1 estas matrizes estão sistematizadas nas Figuras 20 a 25; para o Participante 2, nas Figuras 26 a 35 e, para o Participante 3, nas Figuras 36 a 41, no Anexo 2.

O Participante 1, como pode ser verificado na Tabela 9, teve a maioria de seus erros concentrados logo no primeiro treino de discriminações condicionais palavra ditada/palavra impressa com o primeiro conjunto de estímulos, o Treino $\mathrm{AC}^{14}: 31$ erros, sendo que na continuidade do programa esse número de erros foi diminuindo gradualmente. No treino de construção com anagramas, o Treino de Anagrama I, P1 realizou apenas dois erros e continuou até o final do programa realizando um erro, no

\footnotetext{
${ }^{14}$ Para uma consulta das fases e suas características e seqüênciação no programa EQUIV, consultar o Anexo 1, Figura 19.
} 
máximo, em cada uma das fases listadas a seguir, como pode ser verificado na Tabela 9: Teste de Novas Formas Verbais I, Treino A'C', Teste de Equivalência II e Teste de Novas Formas Verbais II.

A partir destes dados gerais, uma consideração aqui vale ser realizada: parece que P1, já durante seu primeiro treino de discriminações condicionais entre palavras ditadas/palavras impressas (Treino AC) usufruiu do esquema do procedimento adotado nesta fase, ou seja, em cada passo deste treino havia a introdução gradual do número de estímulos de escolha e o critério de avanço era de $100 \%$ de acertos de um passo para o outro, sendo que havia um número de passos suficientes para que houvesse combinações entre todas as quatro palavras deste primeiro conjunto de estímulos (Hübner, 1990), como pode ser verificado no Anexo 1, Figura 19; a proposta deste procedimento específico, para o treino de discriminações condicionais palavra ditada/palavra impressa durante o programa, era de auxiliar o participante na aquisição gradual dos controles exatos pelos componentes das palavras. Se essa discriminação pelos componentes das palavras ocorre desde o primeiro Treino AC (Fase 6) é possível supor que o participante continue no programa com probabilidade de alcance de altas taxas de acertos.

Quanto à característica dos erros, como também é possível observar na Tabela 9, durante todo o primeiro Treino AC, este participante realizou 31 erros, sendo que quatorze deles tinham uma sílaba ('bo') em comum, na mesma posição entre os estímulos modelo e os estímulos de escolha negativos (em doze deles, a sílaba 'bo' estava na primeira posição em comum e em dois deles esta sílaba estava na segunda posição); tais erros tinham duas letras ou uma sílaba em comum, na primeira ou segunda posições, em relação aos estímulos modelo e de escolhas $\left(2 \mathrm{LC} / 1 \mathrm{SC}, 1^{\mathrm{a}}\right.$ e $2^{\mathrm{a}}$ ou $3^{\mathrm{a}}$ e $4^{\mathrm{a}}$. em PC), exemplos: "boca"/CABO e "cabo"/LOBO. P1 também realizou oito 
erros com estímulos de escolhas negativos que tinham a sílaba 'bo' em comum com o estímulo modelo mas em posição invertida em relação ao mesmo, como por exemplo, "bolo"/CABO (2LC/1SC, em PI). Além disso, também fez nove erros com a sílaba 'bo' nos estímulos de escolha na posição invertida em relação em relação ao estímulo modelo, como por exemplo, "lobo"/BOLO, mas neste caso os estímulos modelo e comparação envolvidos nestas tentativas tinham duas sílabas em comum e não apenas uma 4LC ou 3LC/2SC em PI).

Pelo fato de terem ocorrido quatorze erros de P1 com a sílaba 'bo' em posições comuns nos estímulos modelo e nos estímulos de escolha, poder-se-ia supor um controle restrito de estímulos pela posição, neste momento do aprendizado do participante, ou seja, no Treino AC. Por outro lado, há indicativos de que não ocorreu o controle restrito pela posição, já que $\mathrm{P} 1$ respondeu dezessete vezes para estímulos de escolha negativos que continham a sílaba 'bo' em posição invertida em relação à posição que esta sílaba ocupa no estímulo modelo. Também é importante notar que destes dezessete erros com a sílaba 'bo' em posição invertida, nove escolhas deste tipo poderiam ter sido realizadas também sob controle da sílaba 'lo' ou 'ca' (no caso, quando ocorreram as combinações 'lobo/bolo' e 'boca/cabo', respectivamente), que supostamente seriam combinações que envolvem grande semelhança entre o par estímulo modelo e de escolha negativo, já que têm quatro ou três letras em comum e, também, duas sílabas em comum, apenas alterando a posição das mesmas.

A Figura 2 apresenta a distribuição dos tipos de erros e da freqüência de ocorrência dos mesmos durante diversas fases do programa EQUIV: nos Treinos AC e $\mathrm{A}^{\prime} \mathrm{C}^{\prime}$, nos Testes de Equivalência I e II e nos Testes de Novas Formas Verbais I e II. Nesta figura é possível verificar o desempenho de P1 no Treino AC, descrito no parágrafo anterior, que mostra uma alta incidência de erros (no início do Treino AC), 


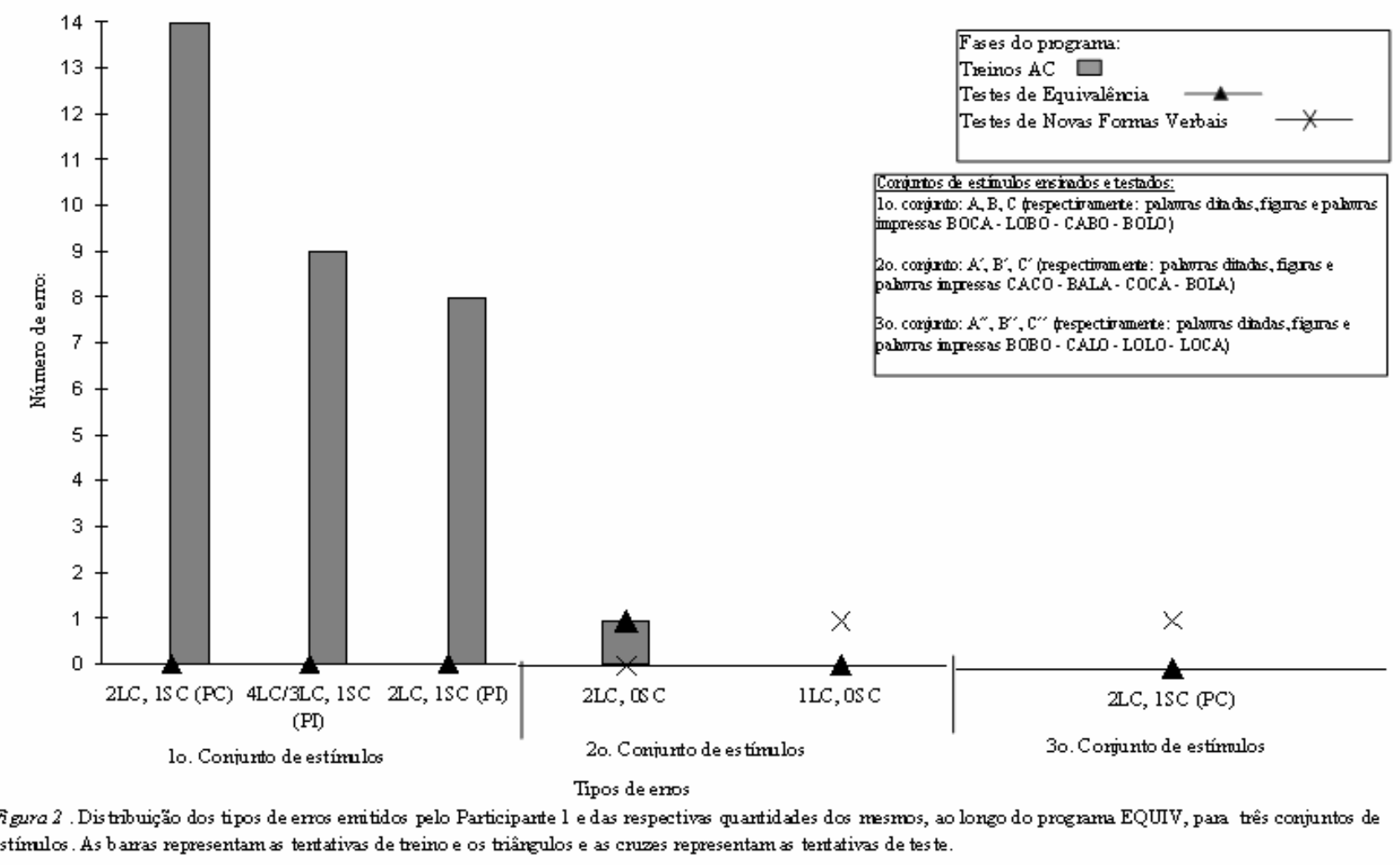

em relação ao restante de seu desempenho no programa. Importante notar novamente, entretanto, que de acordo com os critérios de aprendizagem do programa, P1 só poderia passar para as fases posteriores ao Treino AC se houvesse atingido 100\% de acertos; tais erros, então, se referem a momentos anteriores ao alcance deste critério.

Também é possível verificar na Figura 2, quanto ao desempenho de P1, que durante as tentativas do Treino AC, em que houve ocorrência de erros, este participante parecia fazer escolhas sob controle de estímulo relativo à sílaba 'bo', tal como já apontado, independente da mesma estar em posição invertida (PI) ou em posições comuns (PC) ao estímulo modelo e ao estímulo de escolha. É importante destacar que neste primeiro conjunto de estímulos todas as palavras têm a sílaba 'bo' em comum, ou em posição invertida ou na mesma posição, o que pode ter contribuído para a ocorrência destas respostas de P1. Vale ressaltar que esta repetição sistemática dos elementos nas palavras, em posições diferentes foi planejada para evitar que o participante 
estabelecesse possíveis padrões de controle restrito tanto em relação a elementos isolados que eram recombinados no conjunto de palavras, quanto em relação à posição dos estímulos (Hübner, 1990 \& Matos, et al., 1992).

Considerando este fato, o de todos os estímulos deste primeiro conjunto terem a sílaba 'bo' e considerando a suposição de que tal sílaba tenha exercido um controle sistemático sobre a resposta de P1, é possível entender a alta incidência de erros deste participante, neste momento do programa. Uma possível interpretação, no caso deste participante, é que o controle pela unidade mínima estava se instalando, já no Treino AC (com o primeiro conjunto de estímulos), iniciando-se pela sílaba 'bo'; essa suposição ganha sustentabilidade perante o desempenho posterior de P1 no programa, no qual ele passa a acumular altos índices de acertos, o que também pode demonstrar que este possível padrão (preponderante, pela sílaba 'bo') não continuou durante a seqüência do programa.

Vale ressaltar que no Teste de Novas Formas Verbais I, com o segundo conjunto de estímulos, este participante não escolheu nenhum estímulo negativo que continha a letra 'bo'; ele escolheu estímulo negativo BALA diante de caco (Tabela 9), mas poderia ter realizado erros escolhendo a palavra impressa 'bola', caso ainda estivesse sob controle restrito da sílaba 'bo' na tarefa de seleção de novas palavras, que foram montadas a partir da combinação de sílabas e letras apresentadas no primeiro conjunto de estímulos. Este erro que ocorreu no Teste de Novas Formas Verbais I, com o segundo conjunto de estímulos, pode ser verificado na Figura 2, onde é possível verificar que a combinação entre estímulo modelo e de escolha, neste erro, não tinha sílabas em comum e sim apenas uma letra (1LC na segunda posição). Ainda na Tabela 9 é possível observar que o Participante 1 realizou mais dois erros que continham a sílaba 'bo' nos dois estímulos de escolha negativos escolhidos, tanto no Treino $\mathrm{A}^{\prime} \mathrm{C}^{\prime}$ (estímulo 
modelo "caco"/estímulo de escolha BOLA) quanto no Teste de Equivalência II (estímulo modelo "caco"/estímulo de escolha BOLA), com o segundo conjunto de estímulos; mas estes erros parecem ser irrelevantes para demonstrar um possível ressurgimento de controle restrito, já que os respectivos estímulos modelos não tinham a sílaba 'bo' em nenhuma posição (apenas tinham as letras em comum, mas não em posições coincidentes, como também pode ser verificado na Figura 2) e, além disso, em todas as outras tentativas as escolhas do Participante 1 ocorriam com a relação esperada entre o estímulo modelo e o estímulo de escolha positivo.

Vale ressaltar que o erro ocorrido durante o Teste de Novas Formas Verbais II, com o terceiro conjunto de estímulos, não continha nenhum elemento 'bo', pois o estímulo de escolha negativo escolhido foi LOCA e tinha sílaba 'lo' em comum com o estímulo modelo (ver Tabela 9), sendo que P1 poderia ter escolhido o estímulo de escolha negativo BOBO. Ainda vale ressaltar que no Teste de Nomeação Oral III não teve ocorrência de nenhum erro.

Os erros tabulados na Tabela 9 permitiram verificar que a dificuldade para P1 não foi preponderante em relação às combinações entre pares de estímulos que tinham sido pré-categorizadas como combinações em que os estímulos envolvidos tinham diferenças muito sutis entre os mesmo, ou seja, tinham um grau considerável de semelhança (como pode ser verificado na Tabela 3 ), que foram denominadas como diferenças críticas (Allen \& Fuqua, 1985; Birnie-Selwin \& Guerin, 1997). Na Figura 2 é possível verificar que dos 37 erros realizados por P1 durante todo o programa EQUIV, apenas nove continham uma combinação do tipo 4LC/3LC, 2SC em posição invertida. O restante dos erros estava incluído na categoria de combinações com diferenças múltiplas. Vale retomar que no Treino AC, no qual houve um número maior e relevante 
de erros, a dificuldade foi com a sílaba 'bo', independente da posição em que a mesma estava.

Por um lado, os dados do Participante 1 são similares aos demonstrados por Hübner et al. (2007) no que se refere ao fato de que naquele estudo, cinco de seis participantes, que passaram pelo mesmo procedimento (Matos et al, 2002; Estudo VIII) parecem ter alcançado o controle por unidades na leitura durante o treino de discriminações condicionais auditivo-visuais, já que alcançavam a fase de Teste de Novas Formas Verbais demonstrando pouca ocorrência de erros. Por outro lado, a maioria dos erros dos participantes do trabalho de Hübner et al. (2007), nas fases de testes, eram relativos à combinações de pares de estímulos que tinham diferenças muito sutis entre seus componentes (diferenças críticas, segundo Allen \& Fuqua, 1985 e Birnie-Selwin \& Guerin, 1997), como foi categorizado e pode ser verificado na Tabela 4, p. 60; os erros que P1 demonstrou durante os testes não foram derivados de combinações de elementos entre pares de estímulos que não tinham diferenças tão sutis entre eles, como pode ser verificado na Figura 2.

Uma questão importante a ser destacada é como o desempenho de P1 mudou durante a seqüência do programa e que as respostas do mesmo passaram a ficar sob controle das unidades verbais mínimas relevantes, como é possível observar na Figura 2; o programa foi eficiente em instalar o controle pelas unidades mínimas; os erros apresentados por P1, logo no início, quando todas as palavras apresentavam o elemento 'bo' em comum desapareceram; tal interpretação mostra-se pertinente já que P1 continuou sem um acúmulo de erros nos testes, principalmente nos dois Testes de Novas Formas Verbais I e II, que ocorreram com os segundo e terceiro conjuntos de estímulos, os quais são a medida de que houve a aquisição do controle por unidades verbais mínimas (letras/sílabas), desempenho que seria afetado caso estivesse ocorrendo 
algum controle restrito de estímulos; deste modo, é possível afirmar que ocorreu a leitura recombinativa ou generalizada ao longo do programa, já que P1 identificou letras e sílabas (elementos do estímulos compostos - palavras) aprendidas em situação de treino em outras posições de outros estímulos compostos (novas palavras formadas por recombinação de letras e sílabas anteriores), em situação de teste, sem reforçamento.

Ainda é importante considerar que os procedimentos planejados no programa EQUIV para a aquisição de controle por unidades verbais mínimas foram suficientes para este participante, ou seja, a Topografia de Controle de Estímulos planejada para a emergência deste tipo de repertório tornou-se coerente com a Topografia de Controle de Estímulos demonstrada por P1 para atingir tal repertório (McIlvane \& Dube, 1992; Mcllvane, Serna, Dube \& Stromer, 2000).

Outra questão importante é quanto à emergência do comportamento textual verificado por meio dos Testes de Nomeação Oral II e III. A Figura 3 é uma representação esquemática realizada com o objetivo de mostrar esse processo; nela, é possível observar a porcentagem de acertos do Participante 1 nas tarefas de treino de discriminação condicional entre palavras ditadas/palavras impressas (Treinos AC e $\mathrm{A}^{\prime} \mathrm{C}^{\prime}$ ), tarefas de construção de palavras (Anagrama I e II) e as tarefas relativas ao comportamento textual não ensinadas diretamente (Testes de Nomeação Oral II e III), ou seja, por meio da Figura 3 pretende-se mostrar se o repertório de comportamento textual emergiu sem o treino direto do mesmo e, sim, com treinos de seleção e de construção de palavras. Como neste caso, pretendeu-se averiguar se ocorriam acertos 


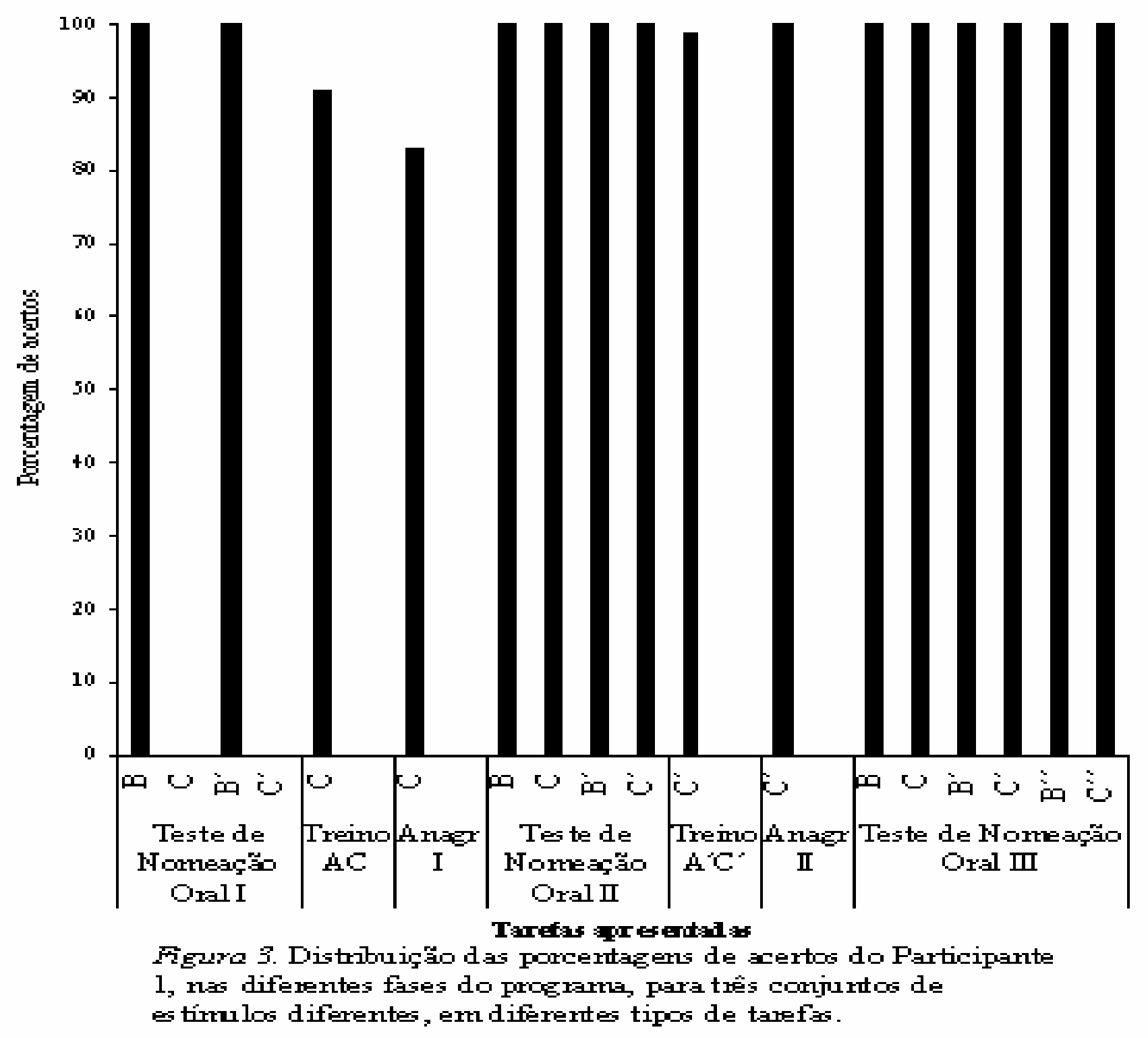

em relação ao repertório de comportamento textual e não foi enfatizada a análise dos erros nesta relação aqui destacada, optou-se por realizar uma figura com porcentagens de acertos, que desse um panorama geral da aquisição dos repertórios investigados no estudo.

Como é possível observar na Figura 3, no Teste de Nomeação Oral I, P1 não nomeou nenhuma palavra impressa corretamente, mas após as tarefas de seleção com o treino de discriminação condicional palavra ditada/palavra impressa (Treino AC, para o primeiro conjunto de conjunto de estímulos) e, após as tarefas de construção 
(Treino de Anagrama I), P1 nomeou tanto as palavras do primeiro conjunto de estímulos (C - com as quais ele já havia passado pelos treinos anteriores de seleção e de construção [este último, similar à escrita]) quanto as do segundo conjunto de estímulos, as quais este participante não tinha realizado nenhum treino prévio. As palavras eram recombinações das unidades verbais mínimas (letras/sílabas) do primeiro conjunto de estímulos. Este desempenho aponta que o operante verbal envolvendo comportamento textual emergiu com treinos prévios que não envolviam este operante especificamente, indicando que pode ter ocorrido uma indução indireta de um novo comportamento, a partir de contingências de reforçamento relacionadas a classes de comportamentos envolvendo respostas de seleção e de construção, tal como apontado por Lee e Pegler (1982).

Ainda vale ressaltar que este desempenho de P1 manteve-se também para o terceiro conjunto de estímulos, já que o participante nomeou corretamente todas as palavras deste conjunto $\left(\mathrm{C}^{\prime \prime}\right)$ sem o treino prévio de seleção (Treino $\mathrm{A}^{\prime \prime} \mathrm{C}^{\prime \prime}$ ) e sem nenhum treino envolvendo o operante verbal de comportamento textual. Pode-se dizer que, para as palavras impressas apresentadas neste programa, P1 demonstrou o comportamento textual de forma emergente.

\section{Participante 2}

Em relação ao Participante 2, diferentemente do Participante 1, o mesmo realizou menos erros durante o primeiro treino de discriminações condicionais entre palavras ditadas/palavra escritas, o Treino $\mathrm{AC}^{15}$ : apenas nove erros; esta informação pode ser verificada na Tabela 10 (que mostra a distribuição da freqüência e dos tipos de erros realizados por P2 durantes as fases do programa EQUIV).

\footnotetext{
${ }^{15}$ Para uma consulta das fases e suas características e seqüênciação no programa EQUIV, consultar o Anexo 1, Figura 19.
} 
Ainda na Tabela 10, é possível verificar que os erros que ocorreram em maior número (oito), durante o Treino $\mathrm{AC}$, foram derivados de combinações entre estímulos modelo e de comparação negativos com a sílaba 'bo' em comum e na mesma posição em relação ao estímulo modelo (ex.: "boca"/BOLO) - 2LC, 1SC, PI. Apenas um de nove erros ocorreu com a sílaba 'bo' do estímulo de escolha em posição invertida em relação ao estímulo modelo e, ainda, com dois elementos em comum 'bo' e 'lo' (ex.: "lobo"/BOLO - 2LC, 2SC em PI); tais dados também podem ser verificados na Figura 4, que apresenta a distribuição dos tipos deerros e da freqüência de ocorrência dos mesmos nos Treinos $\mathrm{AC}$ e $\mathrm{A}^{\prime} \mathrm{C}^{\prime}$, nos Testes de Equivalência I e II e nos Testes de Novas Formas Verbais I e II.

Porém, no Teste de Equivalência I, que ocorreu logo na seqüência do programa, este possível padrão de controle restrito de estímulos pela posição do elemento na palavra parece não ter continuado a ocorrer nas escolhas de $\mathrm{P} 2$; como pode ser conferido na Tabela 10 e na Figura 4. O Participante 2, nesta fase, realizou quatro erros, dos quais três deles não foram para palavras que tinham um elemento na mesma posição entre os pares de estímulos relacionados; eles foram para estímulos com elementos em posição invertida (sílaba 'bo'), sendo que dois deles (a metade) não tinham apenas a sílaba 'bo' em comum e em posição invertida entre os pares de estímulos envolvidos, mas tinham duas sílabas em comum (ex.: boca- "boca"/BOCA - 4LC, 2SC em PI). Tais tipos de erros auxiliam na interpretação de que não havia, nas escolhas de P2, uma preponderância em relação à posição em que a sílaba 'bo' ocupava entre os pares de estímulos envolvidos, nesta fase de teste. Apenas um erro ocorreu com uma sílaba em comum ('bo'), na mesma posição entre o par de estímulos envolvidos (boca"boca"/BOLO, com duas letras em comum, na primeira e segunda posição). 


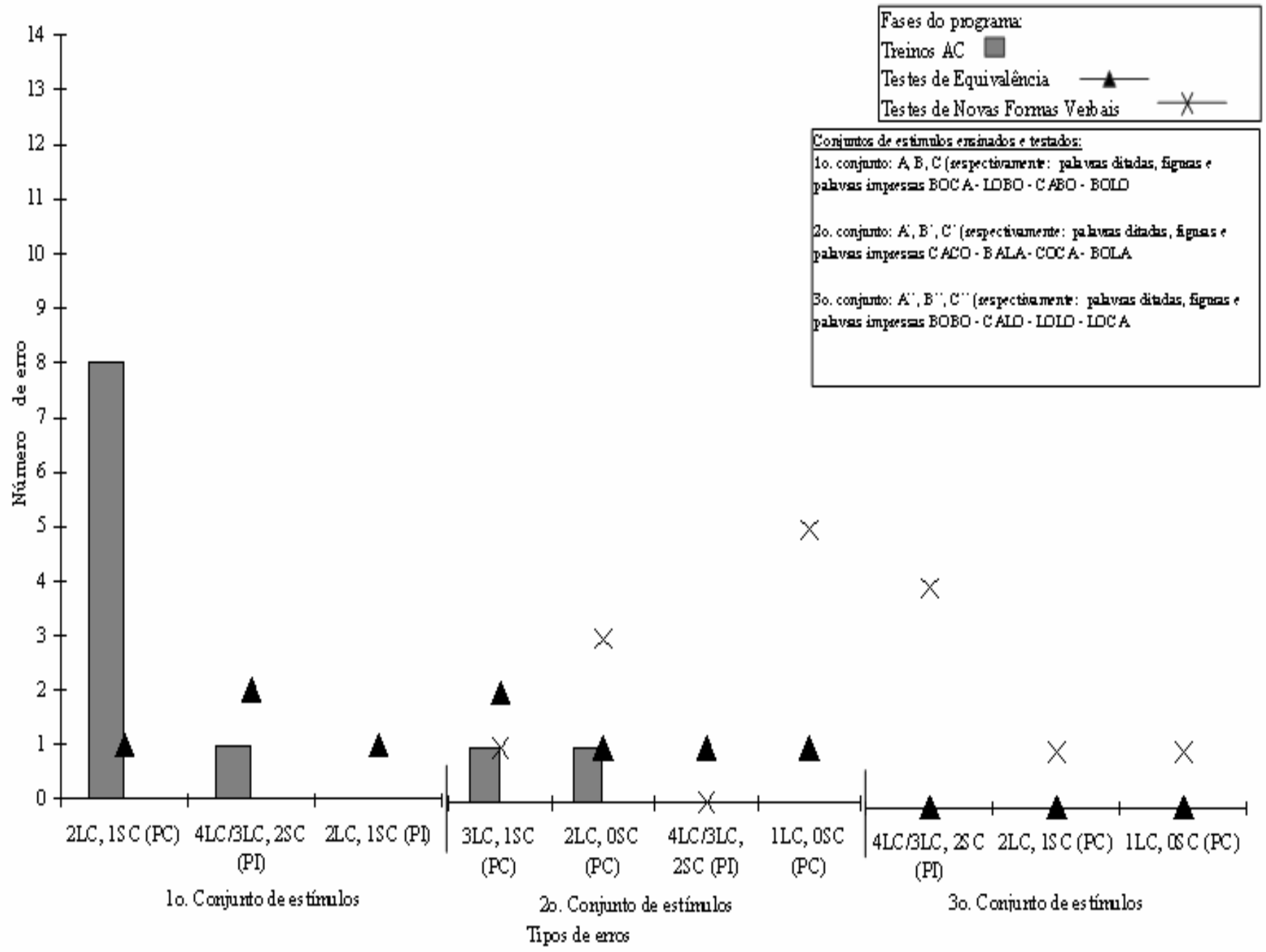

Figura 4. Distribuição dos tipos de enos enritidos pelo Participante 2 e das res pectivas quantidades dos mesmos, ao longo do programa EQUV, para três ornjurtos de estímulos. As banas representam as tentativas de trino e os triângulos e as cruzs representam as tentativas de teste.

Como pode ser observado na Figura 4, no desempenho representado para o primeiro conjunto de estímulos, $\mathrm{P} 2$ exibiu uma mudança em relação à ocorrência de erros importante, já que mudou de um padrão de erros que ocorreu com maior freqüência (preponderância com a repetição da sílaba 'bo' na mesma posição entre os pares de estímulos) durante o Treino $\mathrm{AC}$, para erros que não mostraram nenhum tipo de preponderância em relação à posição durante o Teste de Equivalência I. Destes quatro erros, três deles estão relacionados à inversão de sílabas entre os estímulos modelos e os estímulos relacionados às escolhas do participante, o que pode mostrar um padrão inverso ao que foi comentado em relação ao treino anterior (possível controle restrito pela posição). 
No Teste de Novas Formas Verbais I, já com o segundo conjunto de estímulos, também continuou a ocorrência de erros (nove erros), embora no Treino de Anagrama I anterior, que exige uma resposta de construção com cópia, não tenha havido a ocorrência de nenhum erro, como ser observado na Tabela 10. Dos cinco dos erros ocorridos nesta fase, Teste de Novas Formas Verbais I, praticamente nenhum estava relacionado à palavras que tinham sílabas em comum nos pares de estímulos envolvidos nestes erros (apenas uma letra em comum e em posição comum entre os estímulos modelo e de comparação negativos; ex.: caco-"caco"/BALA - 1LC, PC) e três deles tinham duas letras em comum, mas sem sílabas em comum (ex.: coca-"coca"/BOLA 2LC, na $2^{\mathrm{a}}$ e $4^{\mathrm{a}}$ posições). É importante ressaltar que os pares de estímulos envolvidos nesses oito erros ocorridos durante o Teste de Novas Formas Verbais I tinham muitas diferenças entre os elementos, ou seja, tinham preferencialmente Diferenças Múltiplas (Allen \& Fuqua, 1985; Birnie-Selwin \& Guerin, 1997), dificultando a identificação de algum controle restrito de estímulos.

Esta dificuldade de P2 durante o Teste de Novas Formas Verbais, pode ser decorrente de seu desempenho durante o Treino AC. Se naquele treino o participante não atingiu um grau de discriminação acurada entre os elementos dos compostos (sílabas/letras), mesmo com critério de avanço de 100\% a cada passo do Treino AC e, também, no Teste de Equivalência (critério de 100\% acertos para avanço no programa), o acúmulo de erros pode continuar durante a seqüência do programa e, neste caso, sem algum padrão específico de controle restrito de estímulo que pareceu ser preponderante.

Vale ressaltar que nesta fase, no Teste de Novas Formas Verbais, é a fase na qual o participante é testado em relação ao processo de aquisição de controle por unidades mínimas em função da apresentação de recombinações dos elementos (sílabas e letras) supostamente aprendidas anteriormente, em situação de treino. Tanto os 
critérios de avanço de $100 \%$ planejados para cada passo do Treino AC (Fase 6), para maximizar o aprendizado do controle pelos elementos (sílabas e letras), quanto a repetição sistemática dos elementos nas palavras do primeiro conjunto de estímulos, em posições diferentes, como proposto no programa para evitar que o participante estabeleça possíveis padrões de controle restrito em relação a elementos isolados que não tinham sido recombinados anteriormente em situação de treino e, evite controle restrito por posição. Tais características do programa parecem ter auxiliado P2 no processo de aquisição do controle por unidades mínimas, já que perante 96 tentativas totais de apresentação de tentativas deste tipo, ele realizou apenas nove erros.

Durante o Teste de Nomeação Oral II, realizado com os dois primeiros conjuntos de estímulos, como pode ser verificado na Tabela 10, P2 acertou todas as tentativas com as palavras impressas do primeiro conjunto de estímulos, mas acumulou três erros, com palavras do segundo conjunto de estímulos, que tinham três letras em comum e na mesma posição entre os pares de estímulos envolvidos (BOLA, como estímulo modelo e "boca", como resposta oral de P2), nomeando-as com as palavras do primeiro conjunto ("boca" para BOLA e "cabo" para COCA). Este tipo de teste, o Teste de Nomeação Oral, é relativo ao comportamento textual e não ao de seleção, como anteriormente e, parece ter ocorrido uma possível dificuldade na discriminação e recombinação dos elementos (letra e sílabas) e P1 emitiu um comportamento textual para a leitura de palavras impressas do segundo conjunto de estímulos com palavras do primeiro conjunto de estímulos, com as quais ele tinha maior familiaridade, pois já havia realizado o treino específico de discriminação condicional palavra ditada/palavra impressa (Treino AC) com as mesmas, o que ainda não havia ocorrido com as palavras do segundo conjunto de estímulos na fase do Teste de Nomeação Oral II. 
Durante o Treino $\mathrm{A}^{\prime} \mathrm{C}^{\prime}$, que é o treino direto de discriminações condicionais entre palavras ditadas/palavras escritas para o segundo conjunto de estímulos, P2 realizou erros, mas em menor freqüência, em comparação ao seu desempenho no primeiro treino deste tipo, no início do programa (Treino AC); naquele treino, como descrito anteriormente, foram nove erros e neste Treino $\mathrm{A}^{\prime} \mathrm{C}^{\prime}$ foram apenas dois erros, como pode ser verificado na Tabela 10. Nestes dois erros P2 parece ter demonstrado ainda alguma dificuldade na discriminação dos elementos, mais especificamente, as letras, já que os erros ocorreram em combinações nas quais os estímulos de escolha negativos e os modelos tinham como característica principal o fato de terem letras em comum ("bola"/BALA - três letras iguais em posição comum [3LC - $1^{\mathrm{a}}$., $\left.3^{\mathrm{a}}, 4^{\mathrm{a}}\right]$ ) e "bola"/COCA - duas letras iguais em posição comum [2LC - 2a $4^{\mathrm{a}}$ ), como pode ser verificado na Tabela 10 e na Figura 4.

Durante o Teste de Equivalência II, ainda com o segundo conjunto de estímulos, parece ter ocorrido um padrão similar de dificuldades durante a ocorrência de erros, que pode ter começado a prevalecer desde o Teste de Novas Formas Verbais I, ou seja, alguma dificuldade na discriminação dos elementos (sílabas e letras) parece ter ocorrido nesta fase de Teste de Equivalência II também, como pode ser verificado na Figura 4 e na Tabela 10. Dos cinco erros que ocorreram nesta fase, quatro deles foram com pares de estímulos com semelhança nas letras em posição comum; em dois erros P2 repetiu uma mesma escolha em que os estímulos modelo e de escolha tinham três letras em comum (bola-"bola"/BALA [3LC $\left.-1^{\mathrm{a}}, 3^{\mathrm{a}}, 4^{\mathrm{a}}\right]$ ) e os outros dois erros foram com estímulos com duas e uma letra em comum (coca-"coca"/BOLA e bala-"bala"/caco, respectivemente $\left[2 \mathrm{LC}-2^{\mathrm{a}}, 4^{\mathrm{a}}\right]$ ); apenas um erro foi com palavras que tinham sílabas em comum, mas em posição invertida em relação ao estímulo modelo e a resposta do 
participante (diante da figura coca, apresentada juntamente com a palavra falada "coca", P2 selecionou a palavra impressa CACO [2SC em $\mathrm{PI}])$.

No segundo treino de construção (Anagrama II) não foi observada nenhuma ocorrência de erro, mas durante o Teste de Novas Formas Verbais II ocorreram cinco erros (quatro a menos do que durante o primeiro teste deste tipo - o Teste de Novas Formas Verbais I), como pode ser verificado na Tabela 10. Diferentemente dos erros preponderantes na fase de Teste de Novas Formas Verbais I e Teste de Equivalência II, dos cinco erros de P2 nesta fase do programa, quatro deles tinham o elemento sílaba, como maior grau de semelhança entre os pares de estímulos envolvidos (loca"loca"/CALO, calo-"calo"/LOCA [3LC, 2SC em PI] e loca-"loca"/LOLO [2LC, 1SC em $\left.\mathrm{PC}-2^{\mathrm{a}}, 4^{\mathrm{a}}.\right]$ ), como é possível conferir na Figura 4. Tal tipo de erro pode configurar uma aquisição de controle pela sílaba, mais do que pela letra. Apenas um dos cinco erros na fase Teste de Novas Formas Verbais II foi para palavras com apenas uma letra em comum entre o par de estímulos envolvidos (lolo-“lolo"/BOBO [1LC, nas posições comuns $2^{\mathrm{a}}$ e $\left.\left.4^{\mathrm{a}}\right]\right)$.

Nesta fase que é mais complexa, de Testes de Novas Formas Verbais, neste momento avançado do programa (Teste de Novas Formas Verbais II, realizado com o terceiro conjunto de estímulos), estes erros de P2 descritos acima, sob controle de sílabas em posição invertida, podem apontar que este participante tenha iniciado um processo de aquisição sob controle de unidades mínimas em que a discriminação da recombinação das mesmas pode ter começado a ser mais sistemático; porém, para avaliar esta suposição, seria necessário verificar o desempenho de P2 em fases subseqüentes. Uma possibilidade seria a aplicação de mais um conjunto de estímulos para verificar se estes erros ocorridos durante o Teste de Novas Formas Verbais II, com duas sílabas em comum e em posição invertida (4LC, PI) entre os pares de estímulos 
envolvidos, demonstrassem que P2 estivesse discriminando com maior acurácia os elementos (sílabas) das palavras que contém um grau de semelhança categorizado como contendo diferenças críticas (Allen \& Fuqua, 1985; Birnie-Selwin \& Guerin, 1997), diferentemente dos erros anteriores como os exibidos nas fases de Teste de Equivalência I (primeiro conjunto de estímulos), Teste de Equivalência II e Teste de Novas Formas Verbais I (ambos com o segundo conjunto de estímulos) em que os pares de estímulos tinham apenas algumas letras em comum, com diferenças múltiplas entre seus elementos, o que poderia ser indicativo de uma discriminação com menos acurácia para as sílabas.

$\mathrm{Na}$ última fase do programa, o Teste de Nomeação Oral III, que estava relacionado ao comportamento textual de $\mathrm{P} 2$ frente aos três conjuntos de estímulos e às respectivas palavras impressas do mesmo, o participante realizou nove erros. Como pode ser verificado na Tabela 10 , frente a uma tentativa com palavra impressa do primeiro conjunto (BOLO), frente a três tentativas com palavra impressa do segundo conjunto (BOLA) e frente a três tentativas com palavras impressas do terceiro conjunto (CALO/BOBO), o participante disse "Não sei", o que inviabilizou uma análise mais detalhada da resposta deste participante em relação a pares de estímulos. Nos outros dois erros que ocorreram durante o Teste de Nomeação Oral III, P2 diante da palavra impressa BALA, emitiu a verbalização "bola" uma vez e, diante da palavra impressa LOCA emitiu a verbalização "loco" uma vez, sendo que esta palavra não havia sido apresentada para este participante em nenhum dos três conjuntos de estímulos, como pode ser verificado na Tabela 2, p. 55 (que mostra quais estímulos e em que seqüência os mesmos foram utilizados no estudo).

Quanto a este último resultado no Teste de Nomeação Oral III, é importante ressaltar que, diferentemente de P1, que mostrou um desempenho emergente em relação 
ao comportamento textual de $100 \%$ de acertos, para os três conjuntos de estímulos mesmo sem o ensino direto deste, mas sim a partir de contingências de reforçamento relacionadas a classes de comportamentos envolvendo respostas de seleção e de construção (Lee \& Pegler, 1982), P2 não realizou estes mesmos índices de acertos. Este desempenho de P2 pode ser verificado na Figura 5, que apresenta as porcentagens de acertos nas tarefas de discriminação condicional entre palavras ditadas/palavras impressas (Treinos $\mathrm{AC}$ e $\mathrm{A}^{\prime} \mathrm{C}^{\prime}$ ), tarefas de construção de palavras (Anagrama I e II) e as tarefas relativas ao comportamento textual não ensinadas diretamente (Testes de Nomeação Oral I, II e III).

Na Figura 5 é possível verificar que P2 alcançou 88\% de acertos, para as palavras do primeiro conjunto de estímulos, $67 \%$ de acertos para as palavras do segundo conjunto de estímulos e $50 \%$ para as palavras do terceiro conjunto de estímulos. Embora, P2 tenha alcançado um índice de acertos acima de 50\% para os dois primeiros conjuntos de estímulos, é importante ressaltar que no Teste de Nomeação Oral II, ele havia alcançado $100 \%$ e $83 \%$ para estes dois conjuntos, como é possível verificar na Figura 5; assim, ele deixou de acumular acertos em relação à emergência do comportamento textual. Uma possível hipótese é quanto a uma possível dificuldade do Participante 2 ter mantido-se engajado nesta última etapa do programa, em situação de teste sem reforçamento; vale retomar, como pode ser verificado na Tabela 10 , que de nove erros acumulados durante o Teste de Nomeação III, em sete deles P2 verbalizou "Não sei", o que também poderia ser interpretado como um comportamento de esquiva da tarefa.

Por fim, vale frisar que P2, conforme pode ser verificado na Figura 4, acumulou erros durante todo o programa, mas erros que, também seus erros durante as fases de treino entre palavras ditadas/palavras escritas (Treinos AC) diminuíram entre a 


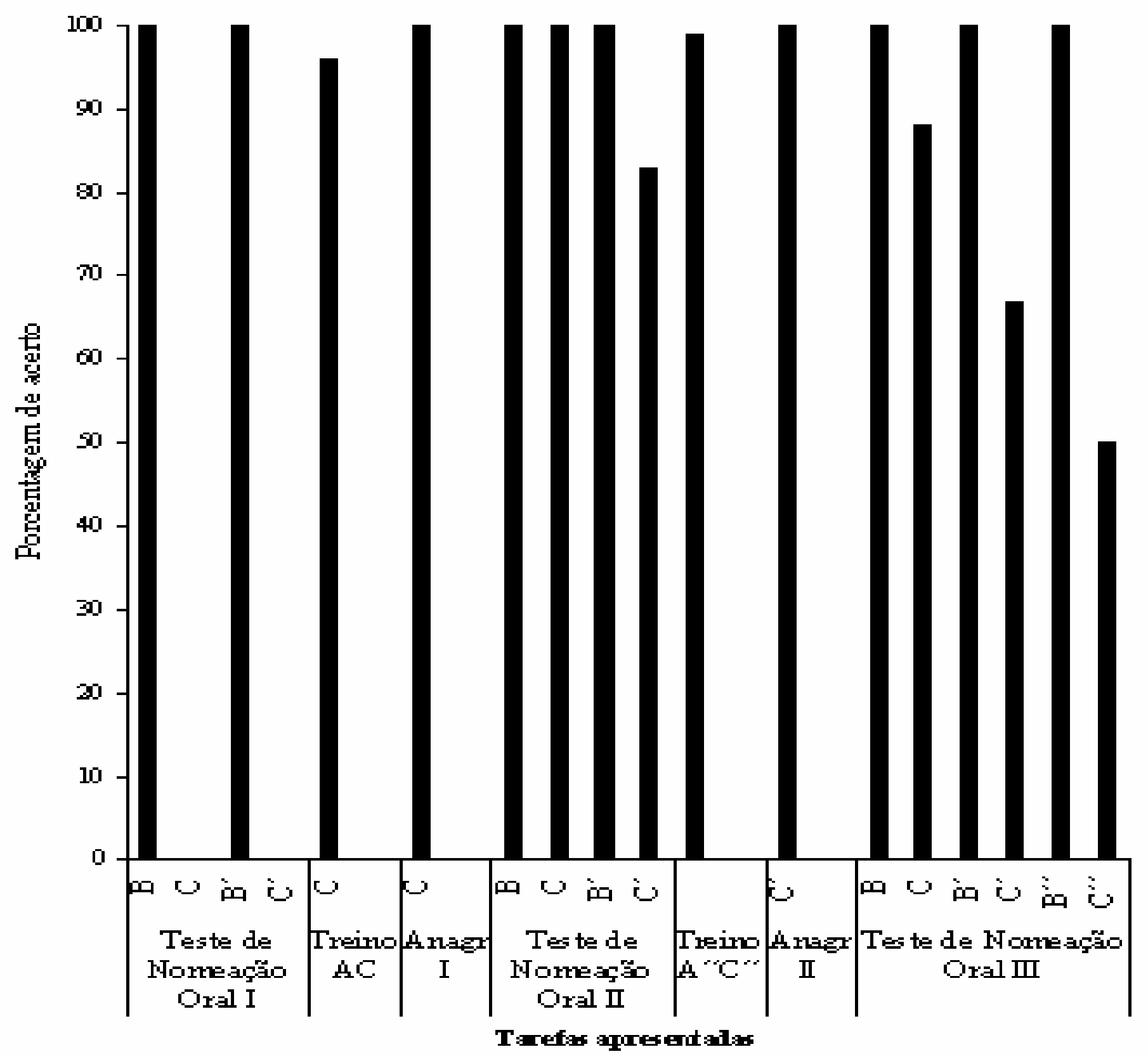

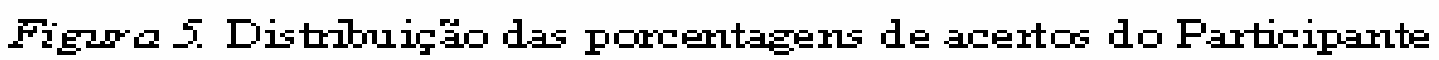
2 ma diferentes fases do prograrm, fara tres aorinutas de E tirrulos diferentes.

aplicação do primeiro e do segundo conjunto de estímulos, de nove para dois erros. Nas situações de testes, mais especificamente nos Teste de Equivalência e de Nomeação 
Oral, não é possível observar esse padrão de diminuição do número total de erros, o que também pode estar relacionado ao fato de não ocorrer reforçamento durante os testes.

Também vale ressaltar que nos poucos erros observados no Teste de Novas Formas Verbais II, com o terceiro conjunto de estímulos, pode ser verificado um padrão entre os estímulos modelo e os estímulos negativos relacionados às respostas de P2 que foram categorizados como contendo Diferenças Críticas (2SC em posição invertida) e que podem ser um indicativo de que P2 estivesse estabelecendo uma discriminação ainda mais acurada das sílabas, que são elementos dos estímulos compostos (palavras) importantes de serem discriminados separadamente para que o processo de controle por unidades verbais mínimas ocorra de forma esperada com, pelo menos, o universo de palavras apresentadas durante o programa.

\section{Participante 3}

O Participante 3, diferentemente dos Participantes 1 e 3 não apresentou nenhum erro nas fases de Treino AC, de Teste de Equivalência I e de Treino de Anagrama I, como é possível observar na Tabela 11, que mostra a distribuição da freqüência e dos tipos de erros realizados por P2 durantes as fases do programa EQUIV; P3 só foi apresentar erros durante o Teste de Novas Formas Verbais I, que mostra-se um ambiente mais complexo pois, o participante entra em contato com novas palavras recombinadas a partir dos elementos (letras/sílabas) do primeiro grupo e com menor densidade de reforçamento, já que os testes são aplicados sem reforçamento.

Na Tabela 11 e na Figura 6, que apresenta a distribuição dos tipos de erros e da freqüência de ocorrência dos mesmos no Teste de Nomeação Oral II, Treino A ' C' (para o segundo conjunto de estímulos), nos Testes de Equivalência II (para o segundo conjunto de estímulos) e nos Testes de Novas Formas Verbais II e III (respectivamente: 
Fases 18A e 18B, para o terceiro conjunto de estímulos e Fases 23A e 23 B; esta apenas aplicado para P3), é possível observar que os erros mais recorrentes de P3 durante o Teste de Novas Formas Verbais I, com o segundo conjunto de estímulos, nas tentativas $\mathrm{BC}$, foram seis erros em que a semelhança entre os pares de estímulos era de apenas uma letra em comum entre o estímulo de comparação negativo (ex.: BALA) e o modelo (ex.: coca/"coca"), sendo que nestas seis tentativas a letra A era o elemento em comum; tais erram estão dentro da categorização denominada como Diferenças Múltiplas (Allen \& Fuqua, 1985; Birnie-Selwin \& Guerin, 1997).

Mas, ainda na mesma fase de Teste de Novas Formas Verbais I, como também pode ser verificado na Tabela 11 e na Figura 6, P3 realizou cinco erros em que os pares de estímulos tinham maior semelhança em termos de elementos em comum: o estímulo de escolha negativo escolhido nestas tentativas (BALA) tinha três letras em comum e na mesma posição que o modelo (bola/“bola”), configurando uma combinação entre pares de estímulos do tipo 3LC, PC. O Participante 3 também realizou três erros em que os pares de estímulos envolvidos tinham três letras e duas sílabas em comum; assim, por ex., o estímulo de comparação negativo COCA tinha três letras e duas sílabas em comum, em posição invertida com o modelo caco/"caco". Nestes erros P3 tanto pode ter ficado sob controle das sílabas iguais, mas em posição invertida, como também sob controle restrito do estímulo composto (palavra) com um todo, ou seja, sob controle da semelhança geral entre as duas palavras, o que parece ser parecido com as escolhas que fez nos cinco erros apontados acima, que tinham três letras em comum e na mesma posição entre os pares de estímulos envolvidos. Estes oito tipos de erros (3LC, 1SC/PC e 3LC, 2SC/PI) aqui descritos são categorizados como contendo diferenças críticas (DF) - (Allen \& Fuqua, 1985; Birnie-Selwin \& Guerin, 1997). Nos Testes de Novas Formas Verbais I, P3 poderia ter demonstrado que estava sob controle de cada elemento do 


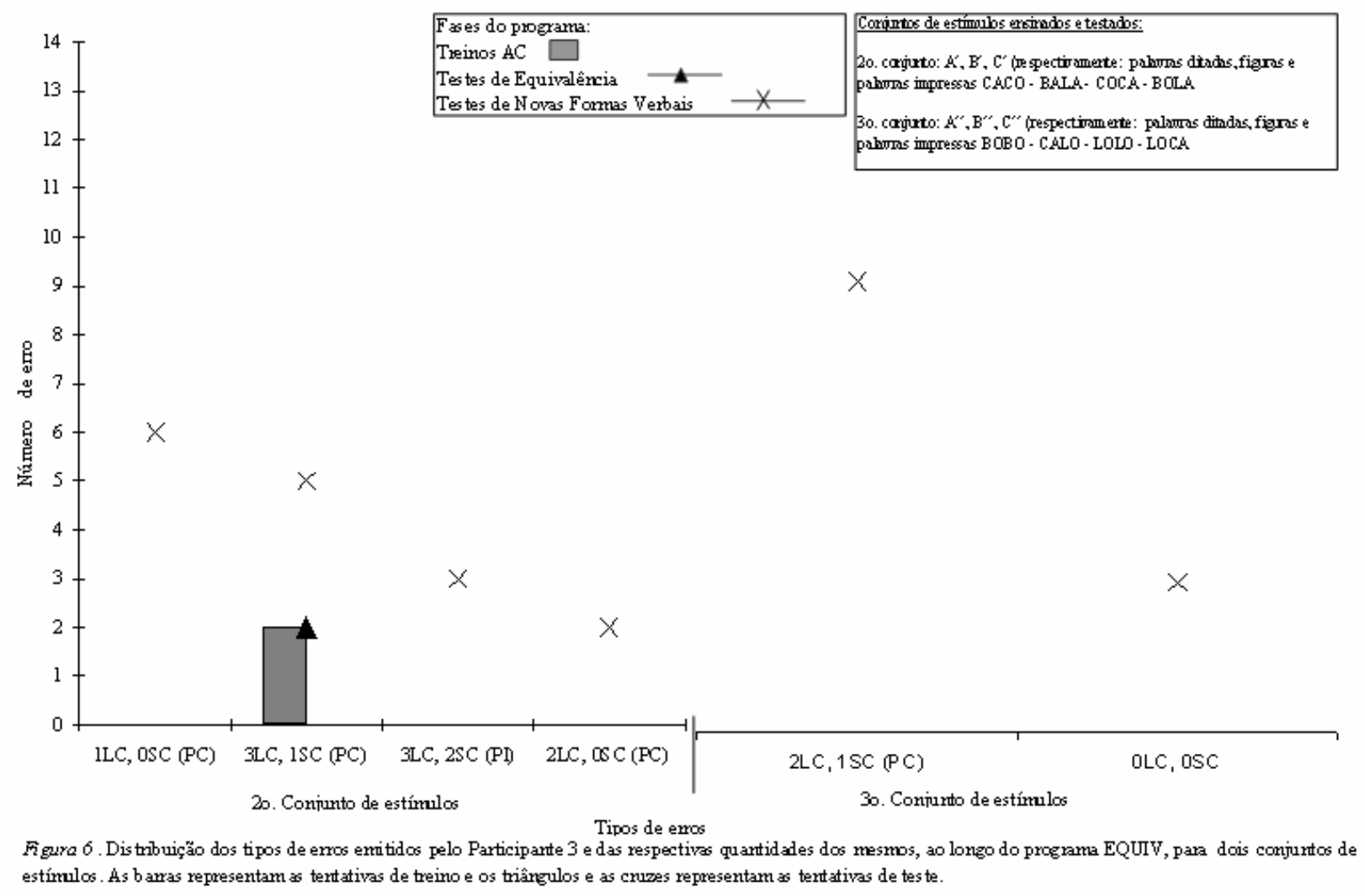

estímulo composto e poderia recombiná-los em novas palavras, pois havia obtido um desempenho anterior com $100 \%$ de acertos, tanto no treino de discriminações condicionais para o primeiro conjunto de estímulos (Treino AC) quanto nos Teste de Equivalência I, também relativo a este conjunto de estímulos. Entretanto, o acúmulo de erros de P3 no Teste de Novas Formas Verbais I é um demonstrativo de que P3 possa ter feito suas escolhas, naquele teste, por meio da discriminação da palavra inteira e não sob controle de elementos que são recombináveis; por exemplo: frente ao estímulo modelo figura boca disponibilizado juntamente com o estímulo auditivo "boca", ele escolheu a palavra impressa COCA. Durante o Teste de Novas Formas Verbais I não ocorreu um padrão de erros preponderante, ou sob controle restrito de um dos elementos (sílaba ou letra) ou sob controle restrito de posição (verificar na Figura 6). De qualquer forma, pode-se afirmar que o processo de aquisição do controle por unidades mínimas não tenha ocorrido neste momento do programa (Teste de Novas Formas Verbais I). 
Na próxima fase, que foi o Teste de Nomeação Oral II, no qual novamente havia os dois primeiros conjuntos de estímulos sendo apresentados em tarefas de comportamento textual, $\mathrm{P} 3$ realizou cinco erros em 24 tentativas disponibilizadas, sendo que em três deles o pareamento feito foi com palavras que tinham três letras em comum e na mesma posição (na resposta oral do participante "coca" e diante do estímulo modelo BOCA. Ainda durante o Teste de Nomeação Oral II, P3 também fez dois erros em que os pares de estímulos envolvidos tinham quatro ou três letras em comum e, também, duas sílabas em comum e em posição invertida, como pode ser conferido na Tabela 11; assim, por ex., diante do modelo (palavra impressa) BOCA, a resposta oral de P3 foi "coca". Nestes dois erros analisados em conjunto, P3 tanto pode ter ficado sob controle da inversão de sílabas iguais (CA), mas em posição invertida, mostrando que ele estaria mais sob controle da sílaba, quanto também pode estar exibindo um controle restrito do estímulo composto (palavra) como um todo (BOCA e COCA seriam iguais para P3, pela semelhança inteira da palavra), o que parece coerente com os erros ocorridos durante o Treino $\mathrm{A}^{\prime} \mathrm{C}^{\prime}$, Teste de Equivalência II e Teste de Novas Formas Verbais II, como será comentado a seguir.

Na Tabela 11 e na Figura 6 é possível verificar que no Treino $\mathrm{A}^{\prime} \mathrm{C}^{\prime}$ e Teste de Equivalência II, com o segundo conjunto de estímulos, P3 realizou três erros, no total das duas fases, totalmente iguais; tais erros (3LC/1SC em PI - ex.: frente ao estímulo modelo auditivo "bola", a escolha é a palavra impressa BALA) demonstram que existe um grau de semelhança considerável entre os pares de estímulos. Tais erros fortalecem a hipótese de que P3 parece demonstrar um possível padrão de discriminação condicional sob controle do composto como um todo e não de seus elementos.

Como pode ser verificado na Tabela 11, durante o Teste de Novas Formas Verbais II, realizado com o terceiro conjunto de estímulos, P3 demonstrou doze erros 
diante de 24 tentativas disponibilizadas, sendo que nove deles também seguiam o mesmo padrão preponderante nas fases anteriores; na Tabela 11 e, também na Figura 6, pode ser verificado como os erros desta fase foram para estímulos que compartilhavam duas letras iguais ( $\mathrm{L}$ e O), que se repetiam na mesma palavra impressa. No caso desses nove erros, as palavras eram: COLO, LOLO e LOCO. É importante verificar que as relações estabelecidas por P3 entre os nove pares de estímulos envolvidos nos erros durante o Teste de Novas Formas Verbais II, como já foi comentado, parece seguir o padrão de controle restrito pelo estímulo composto como todo, ou seja, pela semelhança geral entre as palavras e não sob controle dos elementos das palavras como sílabas/letras.

Foi apenas a partir do terceiro treino de discriminação condicional (Treino $\mathrm{A}^{\prime \prime} \mathrm{C}^{\prime \prime}$ - Fase 20; realizada apenas com P3) que este participante não apresentou mais erros, conseguindo recombinar elementos dos estímulos compostos e realizar a leitura de novas palavras não ensinadas anteriormente, demonstrado no Teste de Novas Formas Verbais III (Fases 23A e 23B, também realizadas apenas com P3).

Como ressaltado anteriormente, a emergência do comportamento textual é verificada por meio dos Testes de Nomeação Oral II e Teste de Nomeação Oral III. Na Figura 7 há uma representação esquemática realizada com o objetivo de mostrar esse processo para P3; nela, é possível observar a porcentagem de acertos do Participante 3 nas tarefas de treino de discriminação condicional entre palavras ditadas/palavras impressas (Treinos $\mathrm{AC}$ e $\mathrm{A}^{\prime} \mathrm{C}^{\prime}$ ), tarefas de construção de palavras (Anagrama I e II) e as tarefas relativas ao comportamento textual não ensinadas diretamente).

Como é possível observar na Figura 7, no Teste de Nomeação Oral I, P3 não nomeou nenhuma palavra impressa corretamente, mas após as tarefas de seleção com o treino de discriminação condicional palavra ditada/palavra impressa (Treino AC) para o 
primeiro conjunto de conjunto de estímulos) e após as tarefas de construção (Treino de Anagrama I), P3 nomeou corretamente todas as palavras do primeiro conjunto de estímulos (C - com as quais ele já havia passado pelos treinos anteriores de seleção e de construção [este último, similar à escrita]), demonstrando a emergência deste repertório relativo ao comportamento textual sem o ensino direto deste operante.

Quanto às palavras impressas do segundo conjunto de estímulos $\left(\mathrm{C}^{\prime}\right)$, para as quais este participante não havia realizado nenhum treino prévio específico, houve ocorrência de erros (mas P3 obteve 83\% de acertos). Vale ressaltar que as palavras do segundo conjunto de estímulos eram recombinações das unidades verbais mínimas (letras/sílabas) do primeiro conjunto de estímulos. Tal desempenho revela que P3 já demonstrava o comportamento de ler sob controle parcial das unidades menores do que a palavra. Além disso, também é importante destacar, como pode ser verificado na Figura 7, que no Teste de Nomeação Oral III (Fase 24, apenas para P3), o último do programa, este participante atingiu o critério de $100 \%$ de acertos na nomeação dos quatro conjuntos de estímulos a que foi apresentado, sendo que com as palavras do quarto conjunto de estímulos $\left(\mathrm{C}^{\prime \prime \prime}\right)$, P3 não havia passado pelo treino de discriminação condicional auditivo-visual.

Tal como destacado para P1, este desempenho aponta que o operante verbal envolvendo comportamento textual emergiu com treinos prévios que não envolviam este operante especificamente, indicando que para P3 também pode ter ocorrido uma indução indireta de um novo comportamento a partir de contingências de reforçamento relacionadas a classes de comportamentos envolvendo respostas de seleção e de construção, tal como apontado por Lee e Pegler (1982). Como destacado anteriormente, para P2 essa a emergência do comportamento textual não foi alcançado. 


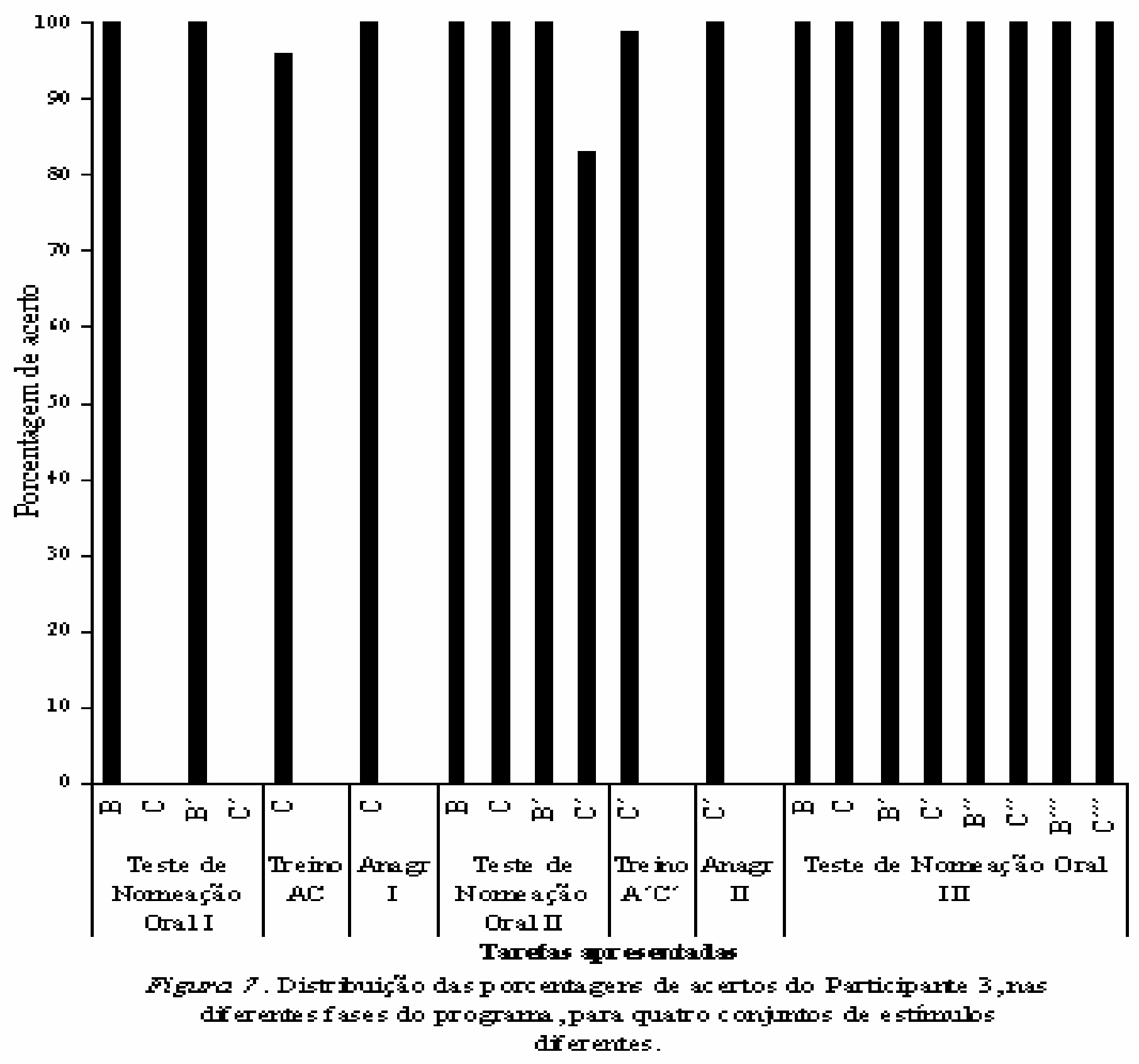

Em relação à análise dos dados demonstrados por Hübner et al. (2007) já relacionados anteriormente com os resultados de $\mathrm{P} 1$ e com os quais foram apontadas similaridades quanto ao padrão de aquisição do processo de controle por unidades mínimas, é relevante fazê-la também para os Participantes 2 e 3.

Os dados demonstrados a partir do desempenho de P2 também demonstraram semelhança com aqueles descritos por Hübner et al. (2007), no qual seis de cinco participantes, que passaram pelo mesmo procedimento (Matos et al, 2002; Estudo VIII) 
alcançaram o controle por unidades na leitura durante o treino de discriminações condicionais auditivo-visuais, já que alcançavam a fase de Teste de Novas Formas Verbais demonstrando pouca ocorrência de erros; P2, como foi ressaltado anteriormente, acumulou erros de forma paulatina durante todo o programa EQUIV e, parece ter alcançado o controle por unidades mínimas, demonstrando poucos erros nos Testes de Novas Formais Verbais I (96 tentativas e nove erros) e Teste de Novas Formas Verbais II (48 tentativas e cinco erros).

O Participante 3 também alcançou o controle por unidades verbais mínimas, mas tal desempenho não foi demonstrado em nenhum dos dois primeiros Testes de Novas Formas Verbais a que foi submetido, como ocorreu com P1 e com os seis participantes do estudo de Hübner et al. (2007); P3 alcançou este repertório mais tardiamente no programa, quando foi ensinado um quarto conjunto de estímulos. Para os participantes de Hübner et al. (2007) não foi necessário ensinar este quarto conjunto de estímulos; o controle por unidades mínimas já havia sido demonstrado.

É importante ressaltar que P3 demonstrou acumular tipos de erros similares aos tipos de erros demonstrados pelos participantes do trabalho de Hübner et al. (2007), nas fases de testes. Tais erros eram relativos às combinações de pares de estímulos que tinham diferenças muito sutis entre seus componentes (diferenças críticas - Allen \& Fuqua, 1985; Birnie-Selwin \& Guerin, 1997), como foi categorizado e pode ser verificado na Tabela 8, p. 67; os erros que P3 demonstrou durante os testes foram apresentados em pares de estímulos que tinham diferenças sutis entre eles, mais especificamente, os pares de estímulos que tinham três letras em comum (na palavra escolhida pelo estímulo modelo).

Uma questão que está presente em todo este trabalho e que impulsionou o levantamento de dados aqui apresentados, foi a análise dos conjuntos de estímulos 
apresentados e as respostas dos participantes aos mesmos, primando por identificar possíveis padrões de controles restritos de estímulos, para cada participante, em todas as fases do programa.

Durante a análise de dados dos Participantes 1, 2 e 3, uma problematização teórica esteve presente, como fio condutor: se a Topografia de Controle de Estímulos (McIlvane \& Dube, 1992; McIlvane, Serna, Dube \& Stromer, 2000) planejada para a aquisição do controle por unidades verbais mínimas era coerente com a Topografia de Controle de Estímulos exibida em cada participante durante todas as etapas que auxiliam na emergência deste repertório.

Para P1, como ressaltado anteriormente, concluiu-se que sim. Para o Participante 3, alguns questionamentos são pertinentes. Sem procedimentos específicos (ou especiais e extras ao programa EQUIV) P3 adquiriu o controle por unidades verbais mínimas e a leitura generalizada ou recombinativa, mas para tanto, parece que a exposição a um quarto conjunto de estímulos foi uma variável importante; a introdução de um procedimento específico, durante o programa, poderia ser uma variável para melhorar o desempenho do participante, já que a análise aqui realizada auxiliou na identificação de que no Teste de Novas Formas Verbais I a discriminação pelos elementos não havia ocorrido de forma satisfatória e que a maioria dos erros estava relacionada a um padrão de escolha dos estímulos modelos com três letras iguais e na mesma posição que o modelo, ou seja, que P3 supostamente pudesse estar fazendo suas escolhas sob controle do estímulo composto inteiro e não de seus elementos.

Procedimentos especiais foram descritos em documento interno do Laboratório de Estudos de Operantes Verbais - LEOV, coordenado pela Professora Dra. Maria Martha Hübner, no Instituto de Psicologia da Universidade de São Paulo, para fins de treinamento de auxiliares de pesquisa. No caso de P3, poderia ser adicionado uma fase 
de treino de construção por anagramas silábico anterior e posterior à fase de treino de pré-requisitos Treino $\mathrm{A}^{\prime} \mathrm{C}^{\prime}$, com a retirada gradual do modelo visual para auxiliar a transferência do controle de estímulos da dica das sílabas impressas, para a discriminação auditivo-visual de cada sílaba, o que poderia auxiliar na maximização do controle por unidades mínimas. Outro questionamento que poderia ser pertinente é quanto ao esquema de reforçamento; P3 mostrou um padrão de concentração de erros durante os testes, maior do que nas etapas de treino. Tal efeito pode também ser derivado do procedimento de extinção, que mesmo com o Treino $\mathrm{AB}$ e $\mathrm{AC}$, realizado de forma conjunta e em tentativas intercalas às de teste, não tenha mantido a atenção do participante para a tarefa. Desse ponto de vista, um esquema de reforçamento em que P3 continuasse a ser reforçado por outros comportamentos que não o das respostas nos Testes de Equivalência e de Novas Formas Verbais poderia ser interessante.

Quanto ao Participante 2, que acumulou erros ao longo de todo o programa, que alcançou a emergência do controle por unidades mínimas, mas com a ocorrência de alguns erros e, teve uma diminuição de acertos em relação ao repertório de comportamento textual no final do programa, uma questão pode ser apontada: com a ampliação do programa, com mais um grupo de estímulos (como P3), o mesmo alcançaria a emergência dos repertórios esperados mais robustamente?

De qualquer forma, a idéia é buscar, de forma mais eficiente possível, manipular os arranjos experimentais para auxiliar a emergência esperada; desta forma, também poderia ser sugerido o treino antecipado de anagrama descrito acima para P3, porém antes do Teste de Novas Formas Verbais I, já que P2 exibiu erros durante o Teste de Equivalência I, diferentemente de P1 e P3 que não demonstraram erros neste tipo de teste. 
Além disso, como P2 demonstrou uma queda de desempenho em relação ao comportamento textual no Teste de Nomeação Oral III e, já no Teste de Nomeação Oral II, ele mostrou uma dificuldade com este repertório nomeando palavras do segundo conjunto de estímulos com o nome das palavras do segundo conjunto de estímulos, poderia ser realizado um treino adicional e antecipado com introdução e retirada gradual da dica ecóica, anteriormente ao Teste de Nomeação Oral III.

A possibilidade de analisar os desempenhos dos participantes durante e após os treinos de discriminação condicional entre palavras ditadas e palavras impressas e, também, durante os testes, buscando identificar padrões diferenciais ou não de aquisição de discriminações condicionais e a existência de eventuais controles restritos de estímulos é uma forma individualizada de, talvez, se necessário, alterar alguns aspectos do procedimento que podem ser positivos tanto para um participante específico ou para outros participantes que vierem a exibir padrões similares.

Com a análise dos desempenhos de P1, P2 e P3 aqui apresentada, verificou-se a existência de padrões variados nos controles de estímulos estabelecidos durante a aquisição do controle por unidades mínimas. Diante de procedimentos experimentais e controlados, como aqueles envolvidos no EQUIV, com rigores sistemáticos nos treinos dos experimentadores (tal como descrito nas publicações de Matos et al., 2002; Matos \& Hübner, 1992; Matos et al., 1997) é possível supor que as topografias de controle de estímulos desenvolvidas pelos participantes não sejam derivadas necessariamente do “inadequado" planejamento experimental, mas talvez da interação entre o procedimento e os repertórios prévios dos participantes, uma vez que o ensino é de palavras familiares (em termos auditivos) aos participantes.

A variabilidade inter-sujeitos nos dados de resultados relativos ao processo de aquisição por unidades mínimas vêm sido amplamente discutido e, também, têm sido 
propostas estratégias para realizar alterações experimentais no procedimento que auxilie a diminuição desta variabilidade (Malheiros, 2002; Matos et al, 2002; Gomes, 2007; Leite, 2008) e, o estabelecimento de parâmetros experimentais é de extrema relevância; mas, também, como ressaltado anteriormente, a variabilidade experimental que não é explicada pode ser gerada pela falta de coerência entre a topografia de controle de estímulos que o experimentador programou e a topografia de controle de estímulos exibida pelo participante (McIlvane \& Dube, 1992; McIlvane, Serna, Dube \& Stromer, 2000).

Assim, como proposto neste trabalho, frente à variabilidade inter-sujeitos observada, o manejo de procedimentos individualizados é fundamental para aumentar a coerência entre as topografias de controles de estímulos entre o planejamento do pesquisador e o comportamento do participante. Neste sentido, em relação ao Participante 1 foi discutido que embora o mesmo tenha possivelmente demonstrado inicialmente um controle restrito pela sílaba 'bo' relacionada a escolhas denominadas aqui de diferenças críticas (DC - Allen \& Fuqua, 1985; Birnie-Selwin \& Guerin, 1997), as contingências já planejadas no programa EQUIV foram suficientes para diminuir esta dificuldade e o participante atingir o controle por unidades verbais mínimas.

Já, para o Participante 2 foram indicados alguns procedimentos especiais. É importante lembrar que P2 não demonstrou um padrão específico de erros, que estes mostravam uma preponderância em escolhas categorizadas como Diferenças Múltiplas (DM) - (Allen \& Fuqua, 1985; Birnie-Selwin \& Guerin, 1997) e que se acumularam durante todo o programa, inclusive no último teste de Novas Formas Verbais; além disso, a emergência do comportamento textual não ocorreu de forma completa como para P1 e P3. 
O Participante 3 demonstrou um possível controle restrito pela palavra com um todo e não uma discriminação relativa aos elementos principalmente durante os dois primeiros Testes de Novas Formas Verbais; a preponderância destes erros está relacionada a uma combinação entre pares de estímulos categorizada como diferença crítica - DF (Allen \& Fuqua, 1985; Birnie-Selwin \& Guerin, 1997), na qual preponderantemente três letras em comum estavam localizadas sempre na mesma posição entre as palavras escolhidas. Para P3, que demonstrou uma aquisição de controle por unidades mínimas tardiamente no programa (apenas com o quarto conjunto de estímulos) e concentração de ocorrência de erros nos testes, também foram propostos procedimentos especiais com o objetivo de maximizar com ainda maior eficácia a coerência de topografia de controle de estímulos entre as contingências planejadas pelo pesquisador e as demonstradas pelo participante.

A continuidade deste trabalho será a coleta de dados com o mesmo procedimento aplicado com P1, P2 e P3, com um participante portador de autismo, que como foi amplamente ressaltado pode exibir uma tendência a demonstrar controle restrito de estímulos durante a aprendizagem de discriminação de estímulos compostos (Lovass \& Schreibman, 1971; Lovaas e cols., 1971; Koegel \& Wilhelm, 1973 e Allen \& Fuqua, 1985); portanto, a aplicação deste procedimento e da análise e discussões aqui apresentados pode ser de fundamental importância para a extensão do uso dos mesmos com uma população com déficits comportamentais importantes, como a de autistas. 


\section{Estudo 2}

O Estudo 2 teve como um dos objetivos realizar uma replicação sistemática (Sidman, 1960) do estudo de Matos et al. (2002), mais especificamente o Estudo VIII (p. 300), com uma participante diagnosticada com autismo. Para tanto, foram necessárias algumas adaptações gerais dos procedimentos originalmente empregados no EQUIV, principalmente em relação à retirada de instruções verbais e alterações nos esquemas de reforçamento durante as tentativas de treino e teste.

Também foi objetivo do Estudo 2 estender a análise realizada no Estudo 1, no qual foi desenvolvido um procedimento para analisar as diferentes combinações entre pares de estímulos (tanto em tarefas de treino e teste em MTS, como tarefas de nomeação e de construção por anagramas) em relação ao grau de semelhança que havia entre os mesmos, ou seja, foi analisado o número de sílabas e letras em comum, bem como a posição dos mesmos nos diversos pares de estímulos (Tabela 8, Estudo 1, p. 67) também foi analisado a relação dessas diferentes combinações entre estímulos com possíveis padrões de controle restrito de estímulos durante o processo de aquisição de controle por unidades verbais mínimas, o que também possibilitou a realização de procedimentos específicos de correção, quando fez-se necessário.

\section{Método}

\section{Participante}

No Estudo 2 foram coletados dados com uma participante, do sexo feminino, diagnosticada com autismo: P4, que tem a idade de 14 anos e um mês. P4 foi selecionada de uma clínica particular na cidade de São Paulo, que atende crianças com desenvolvimento atípico, na abordagem comportamental. 
P4 freqüenta uma escola da rede pública, porém em uma sala especial, com indivíduos com desenvolvimento atípico, mas com diagnósticos variados. A participante apresenta um repertório verbal muito reduzido e emite respostas ecóicas freqüentemente; também se observa alta freqüência de comportamentos estereotipados, principalmente ecolalia $^{16}$. Atualmente, a intervenção comportamental tem como uma das principais estratégias o treino de comunicação por meio de figuras; ainda vale ressaltar que P4 não havia passado por programas de alfabetização anteriormente.

A mãe de P4 assinou um Termo de Consentimento Livre e Esclarecido para que a mesma pudesse participar da pesquisa ${ }^{17}$.

\section{Local e Equipamentos}

As sessões experimentais foram conduzidas em uma sala organizada para a coleta de dados; havia um computador, duas cadeiras, uma mesa e uma filmadora Sony Ericcson (DCR - TRV 250).

\section{Material}

Teste de preferência de estímulos (De Leon \& Iwata, 1996)

- Itens (brinquedos e/ou atividades) que, segundo os dados coletados com o Teste de Preferência de Estímulos, eram estímulos potencialmente reforçadores para P4.

- Folha de Registro do Teste de Preferência de Estímulos (Anexo 4)

ABLA - Assesment of Basic Learning Abilities Test (Kerr, Meyerson, \& Flora, 1977)

\footnotetext{
${ }^{16}$ Por ecolalia entende-se a resposta de repetir sons do ambiente, sem função de comunicação social.

${ }^{17}$ Ver Anexo 3.
} 
- Duas latas de papelão amarelas na forma de um cilindro com aproximadamente $15 \mathrm{~cm}$ de diâmetro e $17 \mathrm{~cm}$ de altura

- Uma caixa vermelha de papelão na forma de um cubo com aproximadamente $14 \mathrm{~cm}$ X $14 \mathrm{~cm}$ X 10cm;

- Uma peça de lego verde tridimensional - com aproximadamente - com aproximadamente $6 \mathrm{~cm}$ X $2,5 \mathrm{~cm}$ X $3 \mathrm{~cm}$;

- Um cilindro de madeira amarelo com aproximadamente $9 \mathrm{~cm}$ de altura e $3 \mathrm{~cm}$ de diâmetro;

- Um cubo vermelho com aproximadamente $5 \mathrm{~cm}$ X $5 \mathrm{~cm}$ X 5cm;

- Folhas de registro para registrar as respostas emitidas por P4 nas tentativas de teste (Anexo 5).

\section{EQUIVIUM $^{18}$}

O EQUIVIUM é um programa de ensino e teste informatizados planejados para o desenvolvimento do repertório de aquisição de leitura por meio de procedimentos de equivalência de estímulos e foi iniciado a partir da tese de doutorado de Hübner (1990), apresentada ao Instituto de Psicologia da Universidade de São Paulo. O material e os procedimentos básicos incluídos no programa foram apresentados por meio do software EQUIVIUM (Baldani \& Piccolo, 2008) ${ }^{19}$ especialmente construído para essa finalidade.

A Tabela 12 apresenta as palavras impressas, presentes nas relações condicionais (diretamente ensinadas ou não) relacionadas aos estímulos envolvidos no programa: palavras impressas (C), figuras correspondentes (B) e respectivas palavras ditadas (A).

\footnotetext{
${ }^{18}$ A descrição do Procedimento no presente trabalho obedece a uma descrição padrão dos estudos de Hübner (1990), Saraiva (2000), Matos et al. (2002) e Gomes (2007), com as alterações necessárias para a coleta com participantes com diagnóstico de autismo.

${ }^{19}$ O software EQUIVIUM é derivado de um software anterior, o EQUIV, também construído com a finalidade de coleta de dados em de aquisição de leitura por meio de procedimentos de equivalência de estímulos (Pimentel, 1996; Pimentel, Hübner, \& Matos, 1997).
} 


\section{TABELA 12}

Distribuição das palavras impressas relativas aos conjuntos de estímulos, apresentados durante o programa, para a Participante 4, formados por palavras ditadas e as respectivas figuras e palavras impressas.

\begin{tabular}{|c|c|}
\hline Conjunto $\mathrm{C}$ & Conjunto $\mathrm{C}^{\prime}$ \\
\hline BOCA & $\mathrm{CACO}$ \\
\hline LOBO & BALA \\
\hline $\mathrm{CABO}$ & BOLA \\
\hline BOLO & COCA \\
\hline
\end{tabular}

O Conjunto de Palavras Escritas (C) era formado por palavras dissílabas, compostas por sílabas simples (do tipo consoante-vogal-consoante-vogal), apresentadas em letras maiúsculas, fonte Arial, tamanho 49, em cor preta e em negrito. Na Tabela 12 foram apresentadas as palavras e figuras empregadas de forma padrão, como pode ser verificado no estudo de Matos et al. (2002): no primeiro conjunto A, B, C (respectivamente: palavras ditadas, figuras e palavras impressas BOCA - LOBO - CABO - BOLO) e no segundo conjunto A', B', C' (respectivamente: palavras ditadas, figuras e palavras impressas CACO - BALA - COCA - BOLA); assim, P4 foi submetida a treinos e testes apenas com o primeiro e segundo conjunto de estímulos.

Na Figura 8 há exemplos das quatro figuras relacionadas ao primeiro conjunto de estímulos. Por meio da execução do programa EQUIVIUM era exibido no monitor de vídeo, em uma tela de fundo preto, as configurações de estímulos programadas para casa fase específica. Como pode ser verificado na Figura 9, a qual mostra diferentes tipos de tentativas no EQUIVIUM, os estímulos visuais (cores, palavras escritas e figuras) eram apresentados em retângulos de $5 \mathrm{~cm}$ X $6 \mathrm{~cm}$ (chamados "janelas"), sendo que aqueles do conjunto de cores, utilizados em um pré-treino, ocupavam toda extensão da janela; os do conjunto de palavras escritas eram exibidos sobre um fundo amarelo e os do conjunto de 


\begin{tabular}{|ll|}
\hline Figuras & Palavras impressas relacionadas \\
\hline & BOCA \\
& BOLO \\
\hline
\end{tabular}

Figura 8. Exemplos de figuras utilizadas no primeiro conjunto de estímulos (Conjunto B).

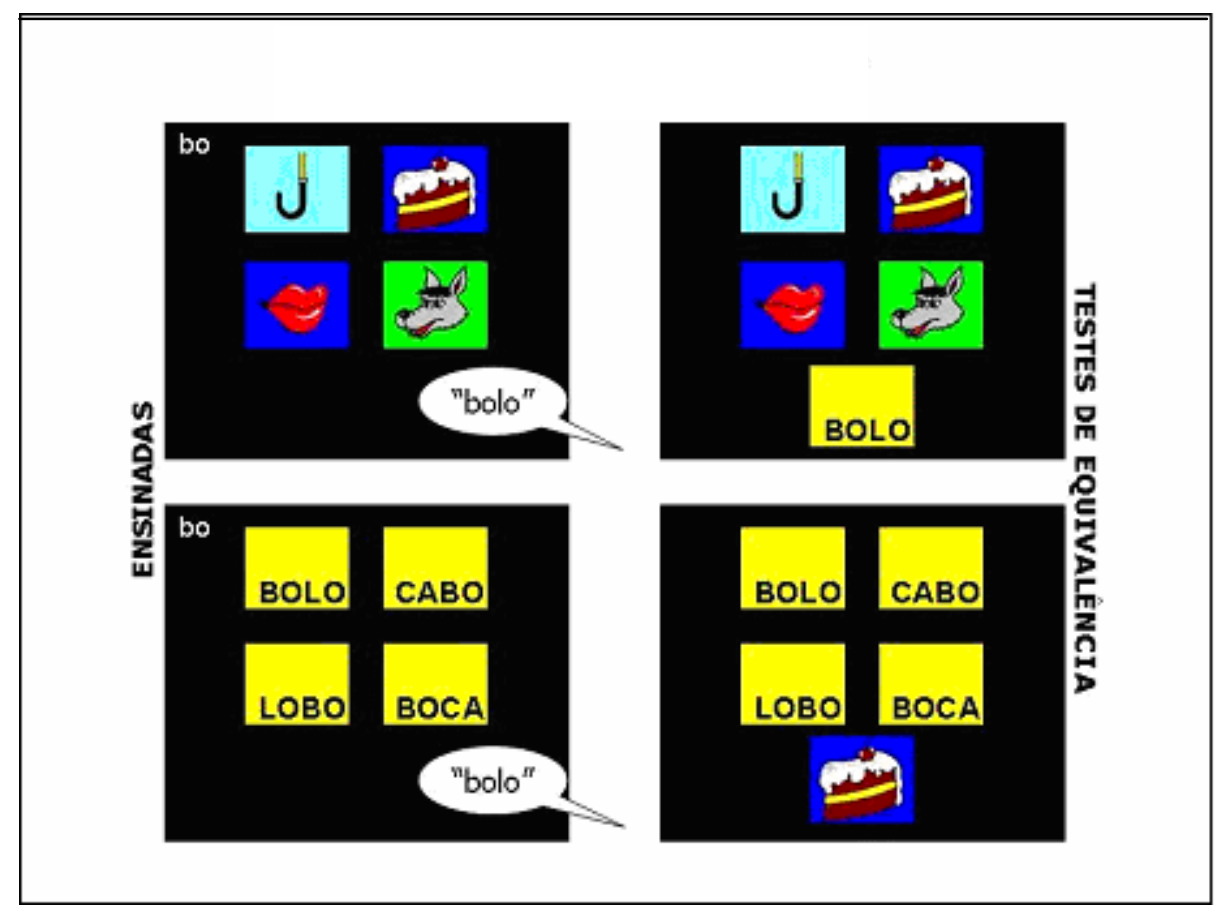

Figura 9. Exemplos de apresentações de tentativas através do EQUIVIUM. 
figuras apareciam sobre fundos de cores amarelas, verdes, azuis claros ou azuis escuros; a escolha das cores presentes no fundo das figuras foi realizada de forma aleatória, não havendo alguma relação entre aquelas cores e as figuras. O estímulo modelo era sempre apresentado na parte inferior central da tela, na janela identificada como de número 5, como pode ser verificado na Figura 10. Caso o estímulo modelo fosse uma palavra ditada, a janela aparecia vazia (preenchida com a cor branca) e o estímulo modelo auditivo correspondente era liberado por meio do sistema de som do computador utilizado na coleta.

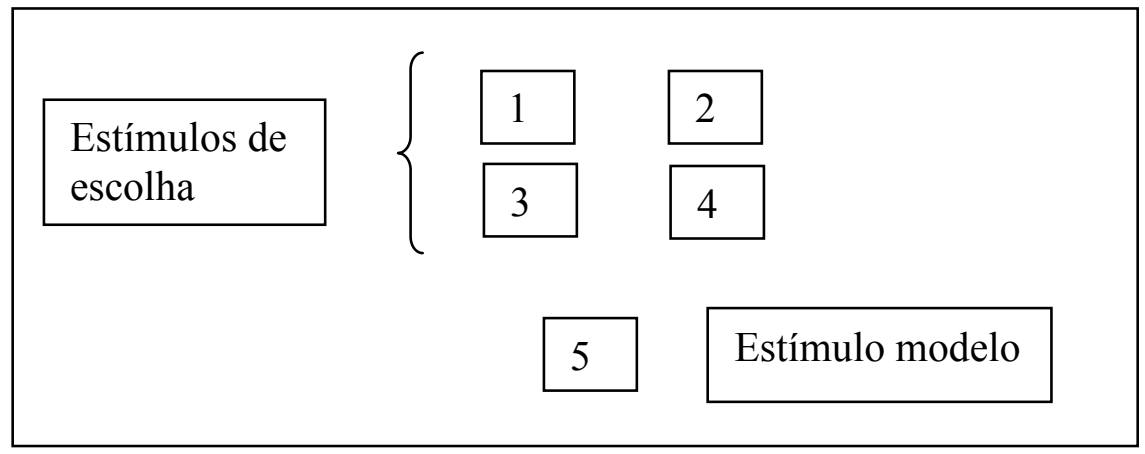

Figura 10. Representação da posição dos estímulos na tela.

Os estímulos de escolha ocupavam aleatoriamente as posições nas janelas de $1 \mathrm{a}$ 4; assim, a localização dos estímulos de escolha podia variar de acordo com as posições das janelas numeradas de 1 a 4, conforme esquematizado na Figura 10. Nas fases de Testes de Nomeação Oral (CD), onde não havia estímulos de escolha, a posição relativa ao estímulo modelo visual ficava em branco. 


\section{Procedimento}

Teste de preferência de estímulos (De Leon \& Iwata, 1996)

Foram realizados Testes de Preferência de Estímulos conforme proposto por De Leon e Iwata (1996), com estímulos múltiplos e sem reposição. Este teste era realizado semanalmente, sempre no primeiro dia de coleta da semana, com o objetivo de monitorar quais eram os possíveis reforçadores para P4.

Em cada sessão de teste a experimentadora selecionava sete itens que, segundo relato da aplicadora dos programas relativos à intervenção comportamental de $\mathrm{P} 4$, eram potencialmente preferidos desta participante; é importante ressaltar que não foram realizados Testes de Preferência com itens comestíveis e sim com brinquedos e/ou atividades.

Os sete itens eram disponibilizados em cima da mesa, com uma distância entre eles de $10 \mathrm{~cm}$ aproximadamente; a ordem de apresentação dos mesmos em cada testagem era aleatória. A experimentadora perguntava: "Qual você quer?" e esperava-se que a participante pegasse um dos estímulos apresentados; alguns tipos de aproximação física em relação aos itens (pegar, tocar, apontar) eram considerados com uma resposta de escolha ao item potencialmente reforçador.

Após pegar o primeiro item (primeira tentativa de escolha), P4 podia manipulá-lo por até 30 segundos e, então, a experimentadora bloqueava o acesso ao item. Tais itens, após terem sido escolhidos, não eram repostos na mesa para as próximas tentativas; deste modo, a cada tentativa, havia um item a menos à mesa. A cada tentativa de escolha a ordem dos estímulos era modificada; a experimentadora movia o primeiro item da última posição situação à sua esquerda para a primeira posição situada à sua direita. Este procedimento prosseguia até a participante não realizar mais nenhuma resposta de 
escolha em até 30 segundos desde o início da tentativa ou até todos os estímulos serem escolhidos.

O primeiro item escolhido pela participante era considerado como potencialmente reforçador (preferência), o segundo item escolhido era o segundo preferido e, assim por diante. Todas as respostas foram registradas em folhas de registro especialmente planejadas para este tipo de teste (Ver Anexo 4).

Os dois primeiros itens escolhidos eram utilizados nas sessões experimentais durante as sessões de realização do programa Equivium.

ABLA - Assesment of Basic Learning Abilities Test (Kerr et al., 1977)

O ABLA é composto por seis níveis de tarefas: Imitação Simples; Discriminação de Posição; Discriminação Visual; Discriminação de Escolha de Acordo com o Modelo; Discriminação Auditiva e Discriminação Auditivo-Visual. A aplicação do teste é realizada com o objetivo de averiguar a facilidade/dificuldade de pessoas com desenvolvimento atípico aprenderem as discriminações pontuadas acima, que são organizadas de forma hierárquica. O objetivo, com a aplicação do teste, foi o de identificar o repertório de entrada de P4 em tarefas de discriminações condicionais auditivo/visuais e visuais/visuais e, também, a depender dos resultados desta participante, após a aplicação do EQUIVIUM, poderia ser uma medida do aprendizado da mesma por meio deste programa.

As tarefas eram apresentadas da seguinte maneira:

Nível 1 (Imitação): A experimentadora colocava um objeto num recipiente e pedia para a participante fazer igual.

Nível 2 (Discriminação de Posição): Uma caixa vermelha e uma lata amarela eram apresentadas sempre na mesma posição; era requerido que a participante colocasse, 
consistentemente, um pedaço de espuma verde no recipiente da esquerda quando a experimentador dizia: "Coloque-a dentro".

Nível 3 (Discriminação Visual): Uma caixa vermelha e uma lata amarela eram apresentadas aleatoriamente (variando entre as posições direita e esquerda); era requerido que a participante colocasse um pedaço de espuma verde na lata amarela quando a experimentadora dizia: "Coloque-a dentro".

Nível 4 (Discriminação de escolha de acordo com o modelo): Era requerido que a participante, frente à apresentação da lata amarela e da caixa vermelha em posições direita e esquerda aleatoriamente alternadas, colocasse dentro da lata amarela um cilindro amarelo e da caixa vermelha um cubo vermelho. O cubo e o cilindro também são aleatoriamente apresentados.

Nível 5 (Discriminação Auditiva): Era requerido que a participante, frente à apresentação da lata amarela e da caixa vermelha em posições fixas, colocasse dentro da lata amarela uma espuma verde quando a experimentadora dizia: "lata amarela" (com entonação rápida e alta) e, também, colocasse a espuma verde dentro da caixa vermelha quando a experimentadora dizia: "caixa vermelha” (com entonação baixa e lenta).

Níveis 6 (Discriminação Auditivo-visual): Idem ao nível 5, mas ocorria a apresentação aleatória da posição (direita e esquerda) dos recipientes.

Para a aplicação do ABLA, no presente trabalho, foi replicado o trabalho de Guilhardi (2003).

\section{Pré-Teste ABLA:}

O Pré-Teste ocorria antes de iniciar a testagem de cada uma das tarefas do teste ABLA. Assim, existia um Pré-Teste da tarefa de imitação simples, um Pré-Teste da 
tarefa de discriminação de posição, e assim por diante, intercalados com a testagem propriamente dita da tarefa.

O Pré-Teste consistia na execução dos seguintes passos:

a. Os objetos de testagem utilizados em cada tarefa do ABLA eram colocados sobre a mesa, diante da participante.

b. Uma tentativa de demonstração da tarefa era então realizada: a experimentadora emitia a resposta esperada na tarefa, enquanto verbalizava uma instrução. Por exemplo: “Quando eu disser 'onde é que isso vai?', isto vai aqui”. A experimentadora então completava, ela mesma, a tarefa: por exemplo, pegava o objeto de testagem (cubo vermelho) e o colocava na caixa vermelha.

c. Uma tentativa com ajuda física: após a primeira demonstração, a experimentadora rearranjava os objetos sobre a mesa e iniciava uma nova tentativa. Após a instrução a experimentadora direcionava fisicamente as mãos da participante para que a mesma emitisse a resposta esperada, enquanto verbalizava: "Vamos fazer juntos... onde é que isso vai? Isto vai aqui”. Se a participante emitisse a resposta correta, com a ajuda da experimentadora, ele era elogiada.

d. Uma tentativa de resposta independente: a experimentadora oferecia à participante uma oportunidade de responder, com os mesmos materiais, sem ajuda, enquanto verbalizava, após a instrução: “Agora, tente você sozinha”. Se a participante emitisse a resposta correta, de maneira independente, ele era elogiado e iniciava-se a testagem, propriamente dita. Se a participante não emitisse nenhuma resposta em um intervalo de 10 segundos, repetia-se a instrução verbal.

e. Registro das respostas emitidas nas tentativas de resposta independente (experimentadora). 
Se a participante errasse (apontasse/pegasse outro objeto que não o esperado na tarefa) ou se fizesse outra coisa, que não emitir a resposta correta (não iniciasse a atividade, levantasse da mesa, jogasse os objetos no chão etc.) reiniciava-se o procedimento em " $\mathrm{a}$ ".

Se a participante não emitisse uma única resposta independente neste Pré-Teste, após oito tentativas de resposta independente, a testagem do ABLA era finalizada.

A testagem da tarefa só era iniciada se e quando a participante realizasse o passo d., ou seja, se ela realizasse a tarefa de maneira correta independentemente. Acertos eram consequenciados por elogios e pelo item reforçador iniciado no teste de preferência de estímulos.

As tentativas de resposta independentes emitidas neste Pré-Teste eram registradas na mesma folha de registro do teste ABLA (Anexo 5). Coube à experimentadora identificar quais tentativas eram de Pré-Teste e quais tentativas eram de teste.

\section{Teste ABLA:}

Apenas na primeira tentativa de cada tarefa testada seguia os seguintes passos:

a. Colocava os objetos de testagem sobre a mesa diante da participante;

b. Oferecia uma tentativa de demonstração da tarefa e dizia: "Quando eu disser onde é que isso vai, isso vai aqui.” A experimentadora completava, ele mesma, a tarefa: por exemplo, pegava o objeto de testagem e o colocava na caixa vermelha. A única exceção era a tarefa de nível 6, na qual, antes dessa instrução, a experimentadora verbalizava também "caixa vermelha" ou "lata amarela".

c. Oferecia uma oportunidade de resposta independente;

d. Registrava as respostas emitidas nas tentativas de resposta independente. 
Nas tentativas subseqüentes a experimentadora apenas seguia os passo a., c. e d., descritos acima.

- Conseqüências para acerto e erro no teste ABLA:

Todas as respostas corretas eram consequenciadas com elogio e com um dos itens mais preferidos em esquema de CRF (reforçamento contínuo a cada resposta da participante). Quando havia erro nas tentativas de resposta independente (no pré-teste ou no teste), a experimentadora realizava o procedimento de correção que consistia na apresentação consecutiva de uma tentativa de demonstração, uma tentativa com ajuda física e uma tentativa independente. O procedimento de correção era repetido até que a participante emitisse uma resposta correta e independente, quando se passava à tentativa seguinte, ou era repetido até que a participante atingisse o critério de reprovação.

Cada tarefa do ABLA era apresentada por várias tentativas: mínimo de oito e máximo de 40, até atingir o critério de aprovação/reprovação.

O critério de aprovação em um nível do teste ABLA era a emissão de oito respostas corretas consecutivas (não incluindo respostas corretas emitidas durante o procedimento de correção). Assim, para cada tarefa do ABLA, a participante deveria realizar oito tentativas seguidas de maneira correta. Se a participante errasse em alguma tentativa, a contagem era reiniciada. Atingido o critério de aprovação, a participante passava a ser testada na tarefa seguinte.

O critério de reprovação em um nível era a ocorrência de oito erros, consecutivos ou não, incluindo os erros envolvidos no procedimento de correção (oportunidade de resposta independente). Assim, se durante a testagem de uma tarefa eram totalizadas oito tentativas erradas, o critério de reprovação era atingido e o teste era finalizado. O desempenho no ABLA foi sempre representado pelo último nível no qual a participante apresentou oito respostas consecutivas corretas. 


\section{EQUIVIUM}

As relações $\mathrm{AB}$ e $\mathrm{AC}$, ambas ensinadas, referiam-se respectivamente à seleção de uma figura diante de um estímulo oral ditado e à seleção de uma palavra impressa diante de um estímulo oral ditado. A seleção de uma palavra diante de uma figura (relação BC) e vice versa (relação $\mathrm{CB}$ ) eram relações testadas ao longo do procedimento; a esquematização deste procedimento pode ser vista na Figura 11.

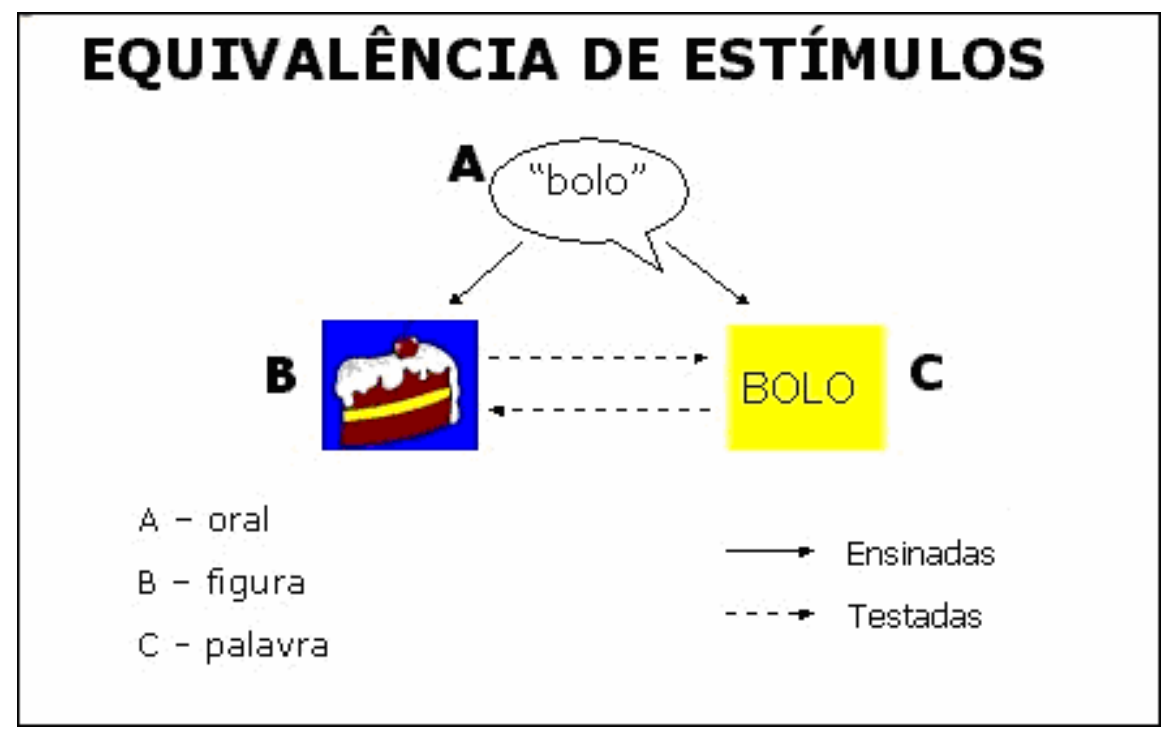

Figura 11. Diagrama para ilustrar as relações ensinadas e testadas entre os conjuntos de estímulos A, $\mathrm{B}$ e C.

As respostas corretas eram conseqüenciadas a cada tentativa: pelo computador, com estímulo(s) auditivo(s) agradável(eis) para a participante (para P4 este estímulo era o som de bater palmas) e, pela experimentadora, com elogios e uma ficha; ao final da sessão, o estímulo tido com preferido no teste de reforçadores podia ser usufruído por mais tempo, exceto para as fases de Testes (conforme descrição pormenorizada adiante $)^{20}$; no caso de P4, foi utilizado um Esquema de Reforço de Razão Fixa de três respostas (FR3), já que depois que esta participante realizava três acertos e acumulava

\footnotetext{
${ }^{20}$ No programa original (ver Hübner, 1990; Saraiva, 2000, Matos et al., 2002, \& Gomes, 2007) as respostas eram consequenciadas com três notas musicais a cada tentativa de acerto e, ao final da sessão, o computador estava programado para tocar um trecho da música "Parabéns para você".
} 
três fichas, as mesmas eram trocadas pelo item que havia sido escolhido no Teste de Reforçadores como potencialmente reforçado.

No programa original desenvolvido para crianças com desenvolvimento típico, durante as tentativas de teste realizadas em extinção, as fichas entregadas e trocadas por brinquedos preferidos no final da sessão. Esse procedimento chama-se "ONE-SHOT" (Galvão, Calcagno \& Sidman, 1992); porém, como este esquema de entrega e troca de fichas apenas no final de uma sessão (de aproximadamente 40 minutos) não mantém, de forma geral, o responder da participante com desenvolvimento atípico engajado nas tarefas, optou-se por um esquema de reforçamento que auxiliasse a participante a manterse na tarefa, ou seja, P4 realizava tentativas de teste em extinção intercaladas com tentativas de repertórios que a mesma já conhecia e eram diferentes dos repertórios aqui testadas e, assim, ela prosseguia recebendo reforços.

O software EQUIVIUM também estava programado para fazer o registro automático dos seguintes dados:

$\checkmark$ Número e porcentagem de acertos e erros por fase e por passo.

$\checkmark$ Matriz de resposta, indicando o número e porcentagem de acertos para cada estímulo de escolha, em relação ao estímulo modelo apresentado (ou seja, a cada tentativa, quais estímulos a participante pareou corretamente ou não e, em caso de erro, que estímulo escolheu).

$\checkmark$ Latência de resposta entre a apresentação do estímulo - modelo e a resposta ao estímulo de escolha

Para registrar a resposta da participante nas fases que envolvessem estímulos modelo e de escolha, era sempre pressionado o botão esquerdo do mouse em cima do estímulo modelo e, logo em seguida, em cima do estímulo de escolha apontado pela participante naquela tentativa. Durante os Testes de Nomeação Oral (CD) o 
procedimento para registrar a resposta da participante era: usar a tecla 1 para acertos e a tecla 3 para os erros e, em seguida, anotar em um protocolo específico e a transcrição exata da resposta emitida pela participante diante do estímulo apresentado.

O EQUIVIUM é constituído de cinco tipos básicos de procedimentos: Pré-Teste, Pré-Treino, Treinos, Anagrama, Testes e Pós-Teste, como pode ser verificado na Figura 12, a qual apresenta a seqüência de fases do EQUIVIUM.

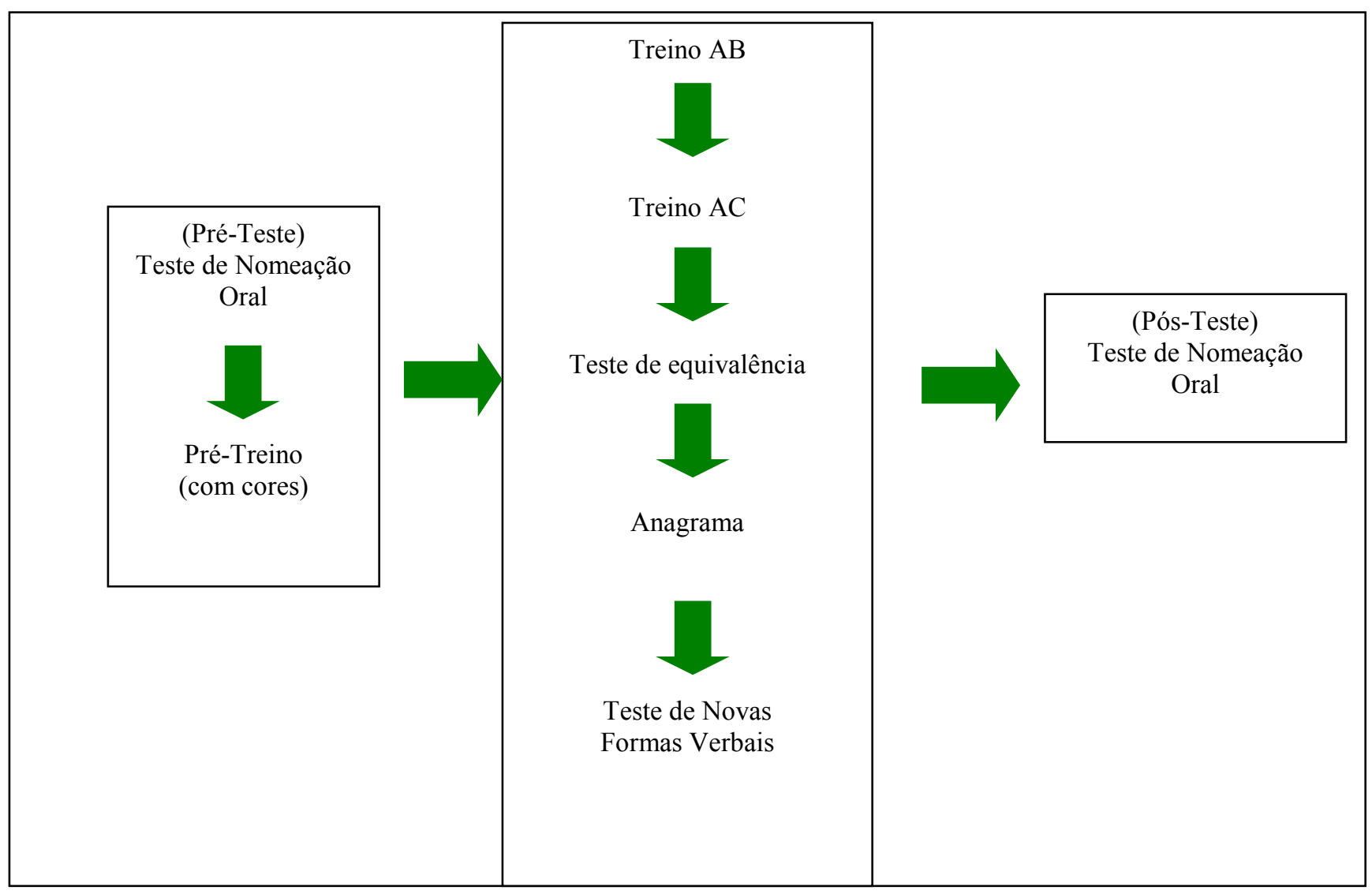

Figura 12. Seqüência de apresentação das fases no EQUIVIUM.

O Pré-Teste era a Fase 1 - Teste de Nomeação Oral I; uma visualização mais detalhada de todas as fases do programa EQUIVIUM e dos respectivos procedimentos pode ser verificada na Figura 13, que contém uma relação de todas as fases pertencentes ao programa EQUIVIUM: passos, tipos de estímulos utilizados, número e tipo de tentativas previstas, critério de avanço e probabilidade de reforçamento. 
O objetivo do Pré-Teste era verificar se a participante lia as palavras que seriam ensinadas (ver Tabela 12). O Pré-Teste (Fase 1 - Teste de Nomeação Oral I), como pode ser verificado na Figura 13, era composto por 48 tentativas, distribuídas em dois tipos, de acordo com a natureza dos estímulos que apareciam na parte central inferior da tela: figuras ou palavras. Nesta fase foram testados o primeiro e segundo conjunto de estímulos.

Durante esta fase, quando aparecia uma figura ou palavra na tela do computador era dito à participante: “Qual o nome dessa figura?” ou “O que está escrito?”,21. Para P4, especificamente, durante o procedimento foi retirada esta instrução; desta forma a experimentadora passou a não disponibilizar nenhuma instrução, pois a participante ecoava a instrução muito freqüentemente.

Ainda nesta fase, para as tentativas que envolviam figuras, se a participante acertasse, era elogiada, ganhava uma ficha e era acionada a tecla 1 do teclado (acerto); se a participante errasse, era dito o nome da figura e requerido que a mesma repetisse o nome correto da figura; após essa nomeação correta P4 era elogiada e recebia um ficha. Era apertada a tecla 3 do teclado (erro).

Para as tentativas que envolviam estímulos palavras, se a participante não lesse era apertada a tecla 3 do teclado (erro). Caso a participante lesse, ganhava uma ficha e a tecla 1 do teclado era acionada (acerto), mas a participante não era elogiada. Entretanto, para que o responder da participante não entrasse em extinção e a mesma aprendesse a nomear

\footnotetext{
${ }^{21}$ No programa original (ver Hübner, 1990; Saraiva, 2000, Matos et al., 2002, \& Gomes, 2007) o(a) experimentador(a) disponibilizava a seguinte instrução: "Quero saber se você sabe o nome de algumas figuras se você não souber, eu vou ensinar. Quero saber também se você lê algumas palavras e letras; se você não souber, mais tarde eu vou ensiná-lo a ler" e, após a figura ou palavra impressa aparecer na tela, o(a) experimentador(a) perguntava: "Qual o nome dessa figura?" ou "O que está escrito?"
} 


\begin{tabular}{|c|l||l|l||l|}
\hline \multicolumn{3}{|c|}{ SUMÁRIO DE PROCEDIMENTOS } \\
\hline \hline Passos & Natureza do Estímulo & $\begin{array}{l}\text { Número de } \\
\text { Tentativas }\end{array}$ & Tipo de Tentativas & Critério \\
\hline
\end{tabular}

FASE 1: Teste de Nomeação Oral I.

\begin{tabular}{|l|l|l||l||l|l|}
\hline & 1 FIGURA & 12 & 3BOCA-3BOLO-3LOBO-3CABO & $100 \%$ \\
\hline \hline 1 IMPRESSA & 12 & 3 BOCA-3BOLO-3LOBO-3CABO & - \\
\hline 1 FIGURA & 12 & 3 BALA-3CACO-3BOLA-3COCA & 1.0 \\
\hline \hline 1 IMPRESSA & 12 & 3BALA-3CACO-3BOLA-3COCA & - \\
\hline
\end{tabular}

FASE $5^{22} \mathrm{e}^{23}$ : Treino da Relação Pré-Requisito AB para o $1^{\circ}$ Conjunto.

\begin{tabular}{|l|l|l||l||l|l|l|}
\hline & 1ORAL-4FIGURA & 16 & 4BOCA-4BOLO-4LOBO-4CACO & $100 \%$ \\
\hline
\end{tabular}

FASE 6: Treino da Relação Pré-Requisito AC para o $1^{\circ}$ Conjunto.

\begin{tabular}{|c|c|c|c|c|c|}
\hline 6A & 1ORAL-1IMPRESSA & 3 & 3BOCA & $100 \%$ & 1.0 \\
\hline 6B & 1ORAL-2IMPRESSA & 6 & 3BOCA-3LOBO & $100 \%$ & 1.0 \\
\hline $6 \mathrm{C}$ & 1ORAL-2IMPRESSA & 6 & 3BOCA-3BOLO & $100 \%$ & 1.0 \\
\hline 6D & 1ORAL-2IMPRESSA & 6 & 3BOLO-3CABO & $100 \%$ & 1.0 \\
\hline $6 \mathrm{E}$ & 1ORAL-2IMPRESSA & 6 & 3LOBO-3CABO & $100 \%$ & 1.0 \\
\hline $6 \mathrm{~F}$ & 1ORAL-2IMPRESSA & 8 & 4BOCA-4CABO & $100 \%$ & 1.0 \\
\hline $6 G$ & 1ORAL-2IMPRESSA & 8 & 4BOLO-4LOBO & $100 \%$ & 1.0 \\
\hline $6 \mathrm{H}$ & 1ORAL-3IMPRESSA & 12 & 4BOCA-4CABO-4BOLO & $100 \%$ & 1.0 \\
\hline $6 I$ & 1ORAL-3IMPRESSA & 12 & 4BOLO-4LOBO-4BOCA & $100 \%$ & 1.0 \\
\hline $6 \mathrm{~J}$ & 1ORAL-3IMPRESSA & 12 & 4BOCA-4LOBO-4CABO & $100 \%$ & 1.0 \\
\hline 6L & 1ORAL-3IMPRESSA & 12 & 4BOLO-4CABO-4LOBO & $100 \%$ & 1.0 \\
\hline $6 M$ & 1ORAL-4IMPRESSA & 24 & 6BOCA-6BOLO-6LOBO-6CABO & $100 \%$ & 1.0 \\
\hline
\end{tabular}

FASE 8A ${ }^{24}$ : Teste Combinado de Equivalência I para o $1^{\circ}$ Conjunto: BC/CB.

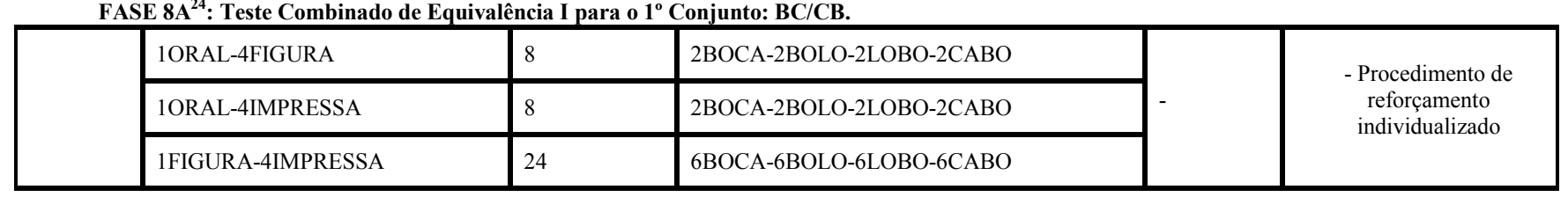

${ }^{22}$ No programa original EQUIVIUM, há a Fase 2 - Pré-Treino de Cores (como pode ser verificado no Anexo 1, Figura 19); o objetivo desta fase é familiarizar o participante com as condições experimentais, experimentador(a), instruções, material, reforçadores e ritmo de trabalho, modelando a resposta em tentativas de MTS; com P4 não foi realizada esta fase.

${ }^{23}$ Entre as Fases 2 e 5 não houve um seqüenciamento direto, pois as fases 3 e 4 foram canceladas ao longo do procedimento (Hübner \& Matos, 1992).

${ }^{24}$ No programa original EQUIVIUM, existem as Fase 7A e 7B (como pode ser verificado no Anexo 1, Figura 19); durante estas fases, há tentativas de Treino $\mathrm{AB}$ e $\mathrm{AC}$ intercaladas com e sem reforçamento. $\mathrm{O}$ objetivo é misturar habilidades já aprendidas (discriminações $\mathrm{AB}$ e $\mathrm{AC}$ ), tornando o ambiente mais complexo e preparando o participante para a situação de teste que vem em seqüência. Para P4 estas fases não foram realizadas. 
FASE 8B: Teste Combinado de Equivalência I para o $1^{\circ}$ Conjunto: CB.

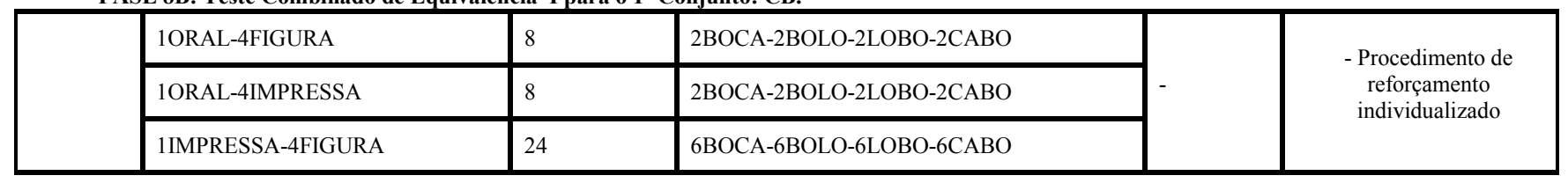

FASE 8C: Teste Combinado de Equivalência I para o $1^{\circ}$ Conjunto: CB.

\begin{tabular}{||l||l|l|l||l|}
\hline \multicolumn{1}{||}{} & 1ORAL-4FIGURA & 8 & 2BOCA-2BOLO-2LOBO-2CABO \\
\cline { 2 - 5 } & 1ORAL-4IMPRESSA & 8 & 2BOCA-2BOLO-2LOBO-2CABO \\
\cline { 2 - 5 } & 1FIGURA-4IMPRESSA & 12 & 3BOCA-3BOLO-3LOBO-3CABO \\
\cline { 2 - 5 } & 1IMPRESSA-4FIGURA & 12 & 3BOCA-3BOLO-3LOBO-3CABO & $\begin{array}{c}\text { Procedimento de } \\
\text { individualizado }\end{array}$ \\
\hline
\end{tabular}

FASE 9: Anagrama I

\begin{tabular}{|l||l|l|l||l|}
\hline FASE 9: Anagrama I & 12 & 3BOCA-3BOLO-3LOBO-3CABO & $100 \%$ \\
\hline
\end{tabular}

FASE 10: Treino da Relação Pré-Requisito A'B' para o $2^{\circ}$ Conjunto.

\begin{tabular}{|l|l|l|l||l|l|}
\hline \hline & 1ORAL-4FIGURA & 16 & 4BALA-4CACO-4BOLA-4COCA & $100 \%$ & 1.0 \\
\hline
\end{tabular}

FASE 11A: Teste das Novas Formas Verbais I para o $2^{\circ}$ Conjunto: $B^{\prime} C^{\prime}$.

\begin{tabular}{||l||l|l|l||l|}
\hline \multicolumn{1}{||l|}{ 1ORAL-4FIGURA } & 8 & 2BOCA-2BOLO-2LOBO-2CABO \\
\cline { 2 - 5 } & 1ORAL-4IMPRESSA & 8 & 2BOCA-2BOLO-2LOBO-2CABO & - \\
\cline { 2 - 5 } & 1FIGURA-4IMPRESSA & 24 & 6BALA-6CACO-6BOLA-6COCA & $\begin{array}{c}\text { reforçamento } \\
\text { individualizado }\end{array}$ \\
\hline
\end{tabular}

FASE 11B: Teste das Novas Formas Verbais I para o $2^{\circ}$ Conjunto: $C^{\prime} B$ '.

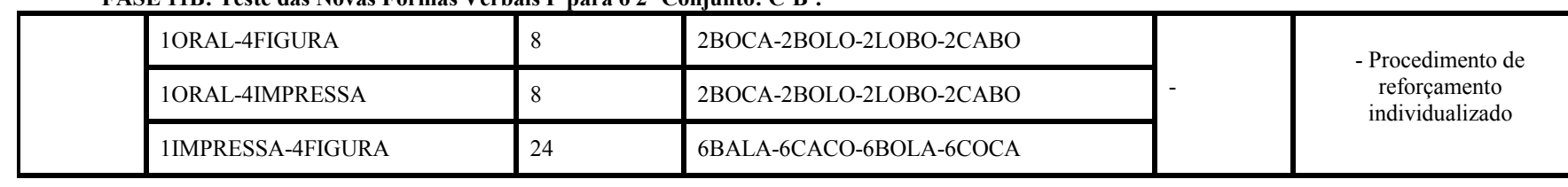

FASE 12: Teste de Nomeação Oral II.

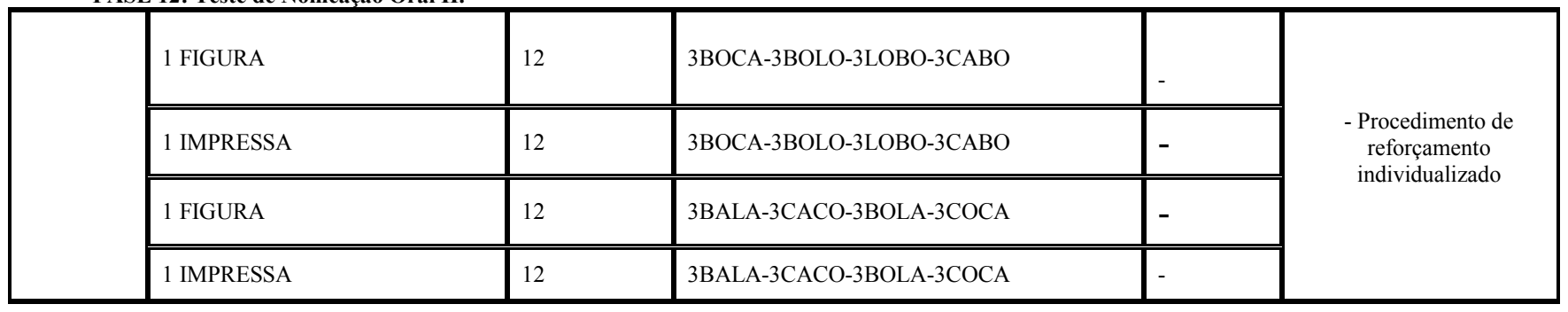

Figura 13. Relação das fases pertencentes ao programa EQUVIUM: passos, tipos de estímulos utilizados, número e tipo de tentativas previstas, critério de avanço e probabilidade de reforçamento utilizados para a Participante 4.

as figuras, a nomeação correta das mesmas era reforçada com um elogio da experimentadora e com o som de aplausos emitido a partir do computador. 
Para este tipo de fase (Testes de Nomeação Oral I, II e III), havia uma folha de registro manual, onde a experimentadora registrava as respostas incorretas ditas pela participante frente aos estímulos apresentados.

As fases de Treino eram compostas por dois tipos de tentativas: o Treino AB, que ensinava o pareamento de palavras ditadas (A) com suas figuras correspondentes (B) e o Treino AC, que ensinava o pareamento da oralização das palavras (A) com seus correspondentes escritos (C). Durante todas as fases de treino, as respostas corretas dos participantes eram conseqüenciadas com elogio, som indicativo de acerto emitido pelo computador (aplauso) e fichas; para P4, foi mantido o esquema de reforçamento FR3 durante todo o programa.

Levando-se em conta a complexidade da tarefa durante o Treino AC e, a tentativa de realizar um procedimento de aprendizagem sem erro, aplicou-se um procedimento de fading in dos estímulos de escolha em 12 passos (ver Figura 13), por meio do qual o nível de dificuldade da tarefa era aumentado gradualmente. Iniciava-se com um estímulo de escolha e, já no passo seguinte, um segundo estímulo era adicionado às tentativas. Os passos se sucediam até que todas as combinações possíveis entre dois estímulos de escolha daquele conjunto houvessem sido apresentadas. Em seguida, um terceiro estímulo de escolha passava a ser apresentado nas tentativas e essa configuração também se mantinha até que todas as combinações possíveis entre três estímulos de escolha para aquele conjunto tivessem sido apresentadas. Então, finalmente, quatro estímulos de escolha eram apresentados na tela.

Ainda nas fases de treinos, os erros da participante implicavam em uma repetição automática de todo o bloco de tentativas daquele passo, até que o critério de $100 \%$ de acerto fosse atingido. Havia um procedimento específico para erros recorrentes: os erros eram registrados e quando estes eram consecutivos, após a ocorrência de três deles, em 
qualquer passo, apresentava-se o modelo na próxima tentativa (a experimentadora tocava com o dedo no espaço do estímulo modelo, dizia o nome do mesmo [figura ou palavra impressa] e, depois, apontava o estímulo de escolha correspondente) ${ }^{25}$; se os erros iniciais fossem não-consecutivos, o mesmo procedimento era aplicado após a ocorrência de cinco erros desse tipo. Após estes procedimentos, caso a participante errasse novamente no mesmo passo (mesmo que não consecutivamente), era apresentado novamente o modelo na próxima tentativa. Depois de três apresentações de modelo nesse passo, o mesmo era encerrado e voltava-se ao anterior. Ao retornar ao passo crítico, a fase era iniciada com a apresentação do modelo.

Segue abaixo descrição pormenorizada das fases de treino com tentativas do Treino AB - Fase 5 (pareamento palavra ditada-figura) apresentadas durante a aplicação do EQUIVIUM:

A Fase 5: Treino da Relação Pré-Requisito AB para o primeiro conjunto de estímulos era o pareamento dos nomes ditados "boca", "lobo", "cabo" e "bolo" com as figuras correspondentes. O objetivo dessa fase era ensinar a participante a selecionar a figura diante do nome ditado correspondente. Como é possível observar na Figura 13, esta fase era composta por 16 tentativas, quatro com cada uma das figuras e o critério para terminá-la era de $100 \%$ de acertos.

Na primeira tentativa era dado o modelo à criança: o computador liberava o áudio com o nome de uma das figuras dos quadradinhos de cima e a experimentadora escolhia a figura relacionada ao áudio ${ }^{26}$.

\footnotetext{
${ }^{25}$ No programa original (ver Hübner, 1990; Saraiva, 2000, Matos et al., 2002, \& Gomes, 2007), apresentar o modelo significava que era lido para a participante cada uma das palavras que apareciam na tela, apontando-as com o dedo, sem tocar na tela e a criança deveria oralizar cada palavra.

${ }^{26}$ No programa original (ver Hübner, 1990; Saraiva, 2000, Matos et al., 2002, \& Gomes, 2007) era explicado à criança: "Agora você vai por o dedinho no quadradinho de baixo e prestar atenção no nome que eu vou dizer. Eu vou dizer o nome de cada uma das figuras que estão nos quadradinhos de cima. Depois você deve escolher o quadradinho que tiver a figura que eu falei. Toda vez que você acertar o
} 
A Fase 6, Treino da Relação Pré-Requisito AC (verificar na Figura 13), era realizado para o primeiro conjunto de estímulos com o pareamento dos nomes ditados "boca", "lobo", "cabo" e "bolo" e as respectivas palavras escritas. O objetivo dessa fase era ensinar a participante a selecionar a palavra escrita diante do nome ditado correspondente. Diante da primeira tela deste passo apresentava-se à participante uma tentativa de demonstração (modelo) igual àquela apresentada na primeira tentativa do Treino AB, como descrito acima. Toda vez que a participante acertava, ganhava uma ficha, muitos elogios e o computador emitia sons de aplausos. Após o acúmulo de três fichas, trocavam-se as mesmas pelo brinquedo desejado ${ }^{27}$.

Nas tentativas posteriores à de demonstração era emitido o som do estímulo modelo (A) e, se a opção pelo estímulo de escolha impresso (C) da participante fosse incorreta, era teclado o comando que indicava o erro e as tentativas continuavam. Se a escolha do estímulo de escolha impresso (C) pela participante fosse correta, conseqüenciava-se com elogio e ficha. Como é possível averiguar na Figura 13, esta fase era composta por doze passos que introduziam gradualmente uma nova palavra ou um novo par de palavras. Toda sessão começava pelo último passo onde a participante havia atingido $100 \%$ de acertos e esse era o critério também em cada passo para seguir adiante.

Os testes relativos aos pareamentos visuais/visuais entre figuras e palavras impressas e, entre palavras impressas e figuras constituíam-se em dois tipos: os de Equivalência e o denominado de Teste de Novas Formas Verbais. Como ressaltado anteriormente, no programa original os testes são realizados em extinção, como pode ser verificado no Anexo 1, Figura 19; porém, para P4 e, participantes com autismo de forma

computador vai tocar uma musiquinha, você vai ganhar uma ficha, eu vou ficar contente e vamos trocar as fichas por brinquedos".

27 No programa original (ver Hübner, 1990; Saraiva, 2000, Matos et al., 2002, \& Gomes, 2007) era disponibilizada a mesma instrução relativa à primeira tentativa do Treino $\mathrm{AB}$, mas o(a) experimentador(a) substituía o uso do nome figura por palavra, já que tratava-se do Treino AC. 
geral, esta contingência sem reforçamento tende a gerar aumento significativo de comportamentos disruptivos, como, por exemplo, aumento de respostas de estereotipia e diminuição de respostas de atenção para a tarefa, o que prejudica muito o desempenho. Assim, nas situações de teste, para P4, foi adotado um esquema de reforçamento alternativo no qual duas tentativas relativas ao programa eram realizadas sem reforçamento e, uma ou duas tentativas com reforçamento era intercaladas, mas com tarefas que P4 já havia aprendido anteriormente.

O primeiro tipo de teste, o Teste de Equivalência I (BC/CB) - Fases $8 \mathrm{~A}$ e 8B, tinha por objetivo verificar se a partir das relações condicionais aprendidas $\mathrm{AB}$ e $\mathrm{AC}$, a participante seria capaz de demonstrar, sem treino direto, as relações $\mathrm{BC}$ e $\mathrm{CB}$, que indicariam compreensão de leitura. Em outras palavras, verificava-se se os pareamentos do som de palavras as respectivas figuras e palavras impressas eram suficientes para que a participante também apresentasse, sem treino específico para tal, os pareamentos das figuras com os respectivos nomes escritos e vice-versa. Segue abaixo a descrição detalhada desses testes:

Na Fase 8A - Teste Combinado de Equivalência I - BC, para o primeiro conjunto de estímulos (ver Figura 13), eram disponibilizadas dois tipos de tentativas (tentativas $\mathrm{AB}$ e $\mathrm{AC}$, combinadas com tentativas $\mathrm{BC}$ ); assim, eram disponibilizadas dois tipos de tentativas de demonstração, a depender do tipo de tarefa apresentada ${ }^{28}$ :

- Na primeira tentativa do tipo AB e AC: o mesmo modelo já descrito acima para os Treinos $\mathrm{AB}$ e AC.

\footnotetext{
${ }^{28}$ No programa original (ver Hübner, 1990; Saraiva, 2000, Matos et al., 2002, \& Gomes, 2007) era dito à criança: "Nessa fase também vão aparecer figuras e palavras. Você vai prestar atenção no nome que eu vou dizer, escolher o quadradinho que tem a figura ou a palavra que eu disse. Mas há uma novidade: é que às vezes vai aparecer uma figura nesse quadradinho de baixo e você vai escolher o nome da figura nos quadradinhos de cima e aí eu não vou falar nada. O computador não vai tocar musiquinha quando você acertar. Eu vou ficar contando quantas vezes você acertou e vou dar as fichas todas no final. Se você acertar tudo você vai ganhar um prêmio especial".
} 
- Na primeira tentativa do tipo BC: a experimentadora apontava para o estímulo modelo e, logo após, para o estímulo de escolha relacionado.

Essa fase era composta por 40 tentativas: duas com cada uma das figuras e palavras nos quadrados superiores da tela e o quadrado inferior central vazio (tentativas de $\mathrm{AB}$ e $\mathrm{AC}$ combinadas ao Teste de Equivalência), seis com cada uma das palavras nos quadrados superiores da tela e o quadrado inferior central da tela com uma das figuras correspondentes às palavras (tentativas $\mathrm{BC})$.

A Fase 8B - Teste Combinado de Equivalência I - CB, para o primeiro conjunto de estímulos, era o complemento da fase $8 \mathrm{~A}$. O procedimento e o número de tentativas eram os mesmos da fase anterior, só que as tentativas BC eram substituídas por tentativas CB (pareamento da palavra impressa com a figura correspondente).

O critério para terminar este bloco de testes (fases 8A e 8B) também era de $100 \%$ acertos. Caso o critério não fosse atingido na primeira tentativa, o mesmo era repetido e só depois de atingido o critério a participante poderia ir para a Fase $8 \mathrm{C}$ e, depois, para a Fase 9 - Anagrama I. A Fase 8C - Teste Combinado de Equivalência I (BC/CB) para o primeiro conjunto de estímulos: era complementar às Fases $8 \mathrm{~A}$ e $8 \mathrm{~B}$. Como é possível verificar na Figura 13, esse teste mesclava tentativas dos testes $\mathrm{BC}$ com tentativas dos testes CB com o objetivo principal de averiguar se a participante mantinha o desempenho de $100 \%$ de acertos em um contexto mais complexo.

O segundo tipo de teste, o Teste de Novas Formas Verbais - Fases 11A e 11B (ver Figura 13) verificava a emergência da leitura sob controle de unidades mínimas (letras e sílabas) treinadas anteriormente. Nesse teste, novas palavras eram apresentadas à participante (palavras do segundo conjunto de estímulos [ver Tabela 12, p. 108] que eram derivadas das ensinadas no primeiro conjunto de estímulos) e ela devia pareá-las com as 
figuras correspondentes, indicando assim, a emergência do repertório de controle por unidades mínimas.

A forma de apresentação e reforçamento durante as tentativas das fases de Testes de Novas Formas Verbais I (Fases 11A e 11B) eram iguais às tentativas dos Testes de Equivalência (Fases 8A, 8B e 8C); porém, no Testes de Novas Formas Verbais I não havia critério de $100 \%$ de avanço para a continuidade da participante no programa ${ }^{29}$.

Após o Teste de Equivalência I foi aplicado o procedimento de construção por anagramas (Anagrama I) tal procedimento consistia em cópia por construção das palavras, com oralização das palavras e das sílabas. Os estudos anteriores do grupo de Matos et al. (2002) identificaram esse procedimento como um dos melhores para gerar a aquisição do controle por unidades mínimas.

$\mathrm{Na}$ aplicação do procedimento da fase de Anagrama I, treinava-se a participante a discriminar palavras escritas, de acordo com modelo oral ditado. A experimentadora e a participante sentavam-se lado a lado, em frente ao computador ${ }^{30}$; na parte inferior da tela do computador, a cada tentativa, havia uma das palavras do primeiro conjunto de estímulos que estavam sendo ensinadas (BOCA - CABO - BOLO - LOBO) junto com seis sílabas distribuídas aleatoriamente: $\mathrm{BO}, \mathrm{CA}, \mathrm{LO}, \mathrm{MA}$ e TA, para que a participante selecionasse uma das sílabas e construísse a palavra. Na parte superior da tela do computador, havia quatro quadradinhos onde deveriam ser encaixadas as sílabas correspondentes ao modelo. Primeiramente, a experimentadora, perguntava o que estava escrito e, caso a participante acertasse, era conseqüenciada oralmente com elogios e com uma ficha..

\footnotetext{
${ }^{29}$ No programa original, as instruções e o esquema de reforçamento nos Testes de Novas Formas Verbais eram os iguais aqueles utilizados nos Testes de Equivalência, como pode ser verificado no Anexo 1, Figura 19.

${ }^{30}$ No programa original a tarefa de construção por anagramas era realizada com as sílabas coladas em pedaços de madeira, já que esta fase não estava inserida no software EQUIV.
} 
Se a participante errasse, era apresentado o modelo, logo após pedia-se à participante que pegasse o primeiro "pedacinho" da palavra; ao achá-lo e colocá-lo sob o primeiro quadradinho onde deveria ser encaixada a sílaba da palavra exposta, era requerido que a participante oralizasse a sílaba e, se acertasse, era conseqüenciada oralmente com elogios e com uma ficha que seria trocada por um objeto de interesse, após três respostas em uma série. Se a participante errasse, era apresentado o modelo; pedia-se então para a participante achar o segundo "pedacinho" e o procedimento era o mesmo da primeira sílaba. Por último, pedia-se a oralização da palavra inteira novamente. O critério de desempenho era acertar três vezes consecutivas cada palavra e a sílaba apresentada.

O Pós-teste era a Fase 12 - Teste de Nomeação Oral II; o objetivo era verificar se diante da palavra, sílaba ou letra impressa (C) a participante era capaz de emitir o correspondente textual correspondente (D). Em outras palavras, o objetivo era avaliar se a participante era capaz de nomear (ler) todas as palavras, sílabas e letras dos conjuntos de envolvidos durante a aplicação do EQUIVIUM, como pode ser verificado na Figura 13. Também era avaliada a nomeação das figuras envolvidas nos conjuntos de estímulos. O esquema de reforçamento durante o Teste de Nomeação Oral II era o mesmo utilizado durante as fases de Teste de Equivalência I (Fases 8A e 8B) e Teste de Novas Formas Verbais I (Fases 11A e 11B).

Na maioria das fases do Equivium, o critério de mudança para a fase seguinte era o de $100 \%$ de acertos e o tempo de sessão era de aproximadamente 40 minutos, em média. Nem sempre a participante atingiu o critério em 40 minutos. Assim, se estivesse próximo de alcançá-lo, prolongava-se o tempo de sessão e se estivesse longe de alcançálo, encerrava-se a sessão após 30 minutos, aproximadamente. A sessão seguinte era 
sempre iniciada pela última fase na qual a participante havia atingido o critério de aprendizagem (100\% de acertos).

Após as sessões com a participante, com o Equivium, eram anotados no "Diário de Coleta" dados adicionais como, por exemplo, a data, o horário de início e término da sessão, o número de pontos alcançados, as fases realizadas, o reforçador escolhido, comentários feitos pela participante, comportamentos estereotipados (por ex.: balançar as pernas, ecolalia verbal, estereotipias motoras e/ou com objetos) ou disruptivos (por ex.: tentar pegar as fichas, levantar da mesa, emitir hetero ou auto-agressão). Também era anotado caso a participante precisasse de modelo para emissão do comportamento textual nas tentativas AC.

\section{Procedimentos de correção específicos}

Além de realizar uma replicação sistemática de Matos et al. (2002) com uma participante com desenvolvimento atípico, mais especificamente diagnosticada com autismo (P4), também foi objetivo do Estudo 2 propor procedimentos de correção individualizados que auxiliassem na continuidade do programa. A partir da análise dos dados desta participante, sessão a sessão, e a partir da análise de dificuldades específicas ou detecção de possíveis controles restritos de estímulos foram propostos procedimentos de correção individualizados para P4.

$\mathrm{Na}$ Tabela 13 estão descritos todos os procedimentos aplicados diante de cada dificuldade específica de P4. Na sessão 2 (Teste de Nomeação Oral I) foi proposto como procedimento de correção específico, a disponibilização da dica ecóica com o atraso gradual de cinco a dez segundos (prompt delay); acrescentava-se um segundo de atraso a cada sessão.

Na sessão 6, após o início do Treino $\mathrm{AB}$ (que foi iniciado na sessão 5), a experimentadora disponibilizou ajuda física para auxiliar a resposta de P4 apontar para 
o estímulo modelo em branco (resposta de observação) e, ajuda gestual como modelo após cada tentativa na qual ocorria erro. Na sessão 7 (Treino $\mathrm{AB}$ ), foi continuada a disponibilização da ajuda física para manter a resposta de apontar para o estímulo modelo em branco (resposta de observação), mas agora a disponibilização do modelo (ajuda gestual) passou a ser disponibilizada apenas para lobo, após cada tentativa incorreta. Ainda, na sessão 8, a experimentadora continuou a disponibilizar ajuda física para a resposta de apontar para estímulo modelo em branco (resposta de observação) e, a disponibilização do modelo (ajuda gestual), passou a ser disponibilizada apenas para lobo antes da participante realizar a reposta de escolha. Para as sessões 9 e 10, foram utilizados os mesmo procedimentos específicos de correção que na sessão 8.

Ainda no Treino $\mathrm{AB}$, na sessão 11, foi introduzido o último procedimento específico de correção: fading in do número de estímulos de escolha negativos, que é o procedimento padrão de ensino do programa, para a fase posterior (Treino AC). Assim, na sessão 11, do Treino AB, treinou-se o pareamento de um estímulo modelo auditivo com um estímulo de escolha positivo, no passo 1; no passo 2 treinou-se o pareamento de um estímulo modelo auditivo com dois estímulos de escolha, um positivo e um negativo; no passo 3 foi apresentado mais um estímulo de escolha negativo (um estímulo de escolha positivo e dois estímulos de escolha negativos); no passo 4, foi acrescentado mais um estímulo de escolha negativo (um estímulo de escolha positivo e três) estímulos de escolha negativos).

Para o Treino AC, foram necessários três procedimentos específicos de correção. Sessão 20: disponibilização da ajuda física para resposta de observação de todos os estímulos de escolha presentes na tela do computador, seguida da resposta independente; sessão 21: disponibilização da dica gestual antes da participante realizar a resposta de escolha dos estímulos; sessão 24: disponibilização dos estímulos de escolha, 
em papel, na mesa, em frente ao computador, sendo que P4 foi ensinada a selecionar (com ajuda gestual), após a emissão do estímulo modelo auditivo, o estímulo visual impresso correspondente (estímulo de escolha positivo). Imediatamente depois, P4 deveria parear este estímulo visual (em papel) com o estímulo de escolha similar na tela do computador. Este procedimento de correção foi utilizado até o final do Treino AC.

Para as seguintes fases: Teste de Equivalência I, Anagrama I, Treino A’B' e Teste de Novas Formas Verbais I, não foi fez necessária a introdução de procedimentos de correção específicos.

Validação por Consenso das Respostas emitidas pelos participantes e do Procedimento

As sessões experimentais foram conduzidas por quatro profissionais: dois experimentadores principais e dois experimentadores coadjuvantes. A cada sessão experimental estavam presentes um experimentador principal e um experimentador coadjuvante. Os experimentadores principais (sendo um deles, a autora da presente pesquisa) executavam e registravam os procedimentos descritos desta pesquisa. Os experimentadores coadjuvantes filmavam (quando fosse o caso) e observavam as sessões experimentais. No entanto, as imagens foram observadas e analisadas pela equipe de profissionais da mesma maneira que as demais sessões filmadas.

Foram filmadas e analisadas $50 \%$ das sessões experimentais. Semanalmente cada filmagem era observada, analisada e registrada pela equipe de experimentadores. Nesse encontro era feito a fidedignidade dos registros realizados pelo experimentador principal.

Pelas filmagens pode-se avaliar que:

1. As respostas emitidas pelos participantes foram emitidas tal e qual as registradas pelo experimentador, com concordância de $100 \%$. 
2. O procedimento realizado pelo experimentador realizado foi fiel ao procedimento descrito em $95 \%$ das sessões filmadas.

A análise acima apresentada revela que o procedimento foi fidedigno ao descrito na sessão de método. 
Primeiramente serão apresentados os dados relativos aos testes de possíveis itens reforçadores, aos quais $\mathrm{P} 4$ foi exposta no início de todas as semanas nas quais os dados foram coletados; a importância das informações constantemente obtidas por meio da aplicação deste tipo de testagem era fornecer itens que seriam potenciais reforçadores e, assim, aumentar a probabilidade do engajamento e a permanência da participante nas atividades propostas.

A Tabela 14 mostra as duas primeiras escolhas realizadas pela Participante 4; na primeira coluna da tabela apresentam-se as semanas nas quais foram realizadas sessões de coleta de dados, sendo que no primeiro dia da semana era feito o teste de possíveis reforçadores; na segunda coluna apresenta-se o primeiro item escolhido pela participante e, na terceira coluna, apresenta-se o segundo item escolhido pela participante.

Os dois itens tidos como preferidos nos resultados do teste de reforçadores foram usados também durante a testagem do ABLA e durante todo o programa EQUIVIUM. Como é possível verificar na Tabela 14, dos nove testes realizados com P4, em sete deles ela escolheu DVDs da Xuxa, embora a experimentadora sempre colocasse outras opções, como DVDs de música sertaneja (já que a mesma tinha informações de que a participante ouvia este tipo de música, com muita freqüência), mas a participante, neste ambiente da coleta dados, não fez estas escolhas; as duas únicas vezes que ela variou, em relação à escolha do DVD da Xuxa, foi na escolha de bolinha de sabão e boneca. Quanto ao segundo item de escolha, invariavelmente, ela escolheu quebra-cabeça dos temas trenzinho e cachorro, embora houvesse variação de tema e de atividade nos sete itens dispostos. 
TABELA 14

Distribuição dos principais itens potencialmente reforçadores escolhidos por P4 durante o período de coleta de dados.

\begin{tabular}{lll}
\hline \multicolumn{1}{c}{ Semanas } & \multicolumn{1}{c}{ Primeiro item escolhido } & \multicolumn{1}{c}{ Segundo item escolhido } \\
\hline $1^{\circ}$ semana - 24 a 28/11/08 & DVD Xuxa 2 - Tema: Festa & Quebra-cabeça (cachorro)- 20 peças \\
$2^{\circ}$ semana - 1 a 5/12/08 & DVD Xuxa 5 - Tema: Circo & Quebra-cabeça (cachorro)- 20 peças \\
$3^{\circ}$ semana - 8 a 12/12/08 & DVD Xuxa 5 - Tema: Circo & Quebra-cabeça (trenzinho)-20 peças \\
$4^{\circ}$ semana - 15 a 19/12/08 & Boneca & Quebra-cabeça (cachorro)- 20 peças \\
$5^{\circ}$ semana - 22 e 23/12/08 & DVD Xuxa 2 - Tema: Festa & Quebra-cabeça (cachorro)- 20 peças \\
$6^{\circ}$ semana - 7 a 9/01/09 & Bolinha de sabão & Quebra-cabeça (cachorro)- 20 peças \\
$7^{\circ}$ semana - 12 a 16/01/09 & DVD Xuxa 2 - Tema: Festa & Quebra-cabeça (cachorro)- 20 peças \\
$8^{\circ}$ semana - 19 a 23/01/09 & DVD Xuxa 5 - Tema: Circo & Quebra-cabeça (trenzinho)-20 peças \\
$9^{\circ}$ semana - 26 a 30/01/09 & DVD Xuxa 2 - Tema: Festa & Quebra-cabeça (cachorro)- 20 peças \\
\hline
\end{tabular}

\section{ABLA}

A testagem ABLA foi aplicada antes do início da coleta de dados, com o programa EQUIVIUM e o objetivo era obter resultados do repertório inicial da Participante 4 em relação ao seu desempenho em tarefas de discriminação condicional auditivo-visual e visual-visual e, também, em relação à avaliação da facilidade/dificuldade da participante nestas tarefas.

A Figura 14 apresenta a distribuição dos acertos e erros, da Participante 4, em três níveis do teste ABLA. Como é possível verificar na figura, no nível 1, era avaliado o repertório de Imitação Simples, ou seja, a experimentadora colocava um objeto em um recipiente e pedia a P4 para fazer o mesmo. Diante dessa tarefa, a participante demonstrou duas respostas incorretas, mas demonstrou oito respostas corretas consecutivas; com tal desempenho (oito respostas corretas consecutivas) ela atingiu o critério de aprovação no nível 1. 


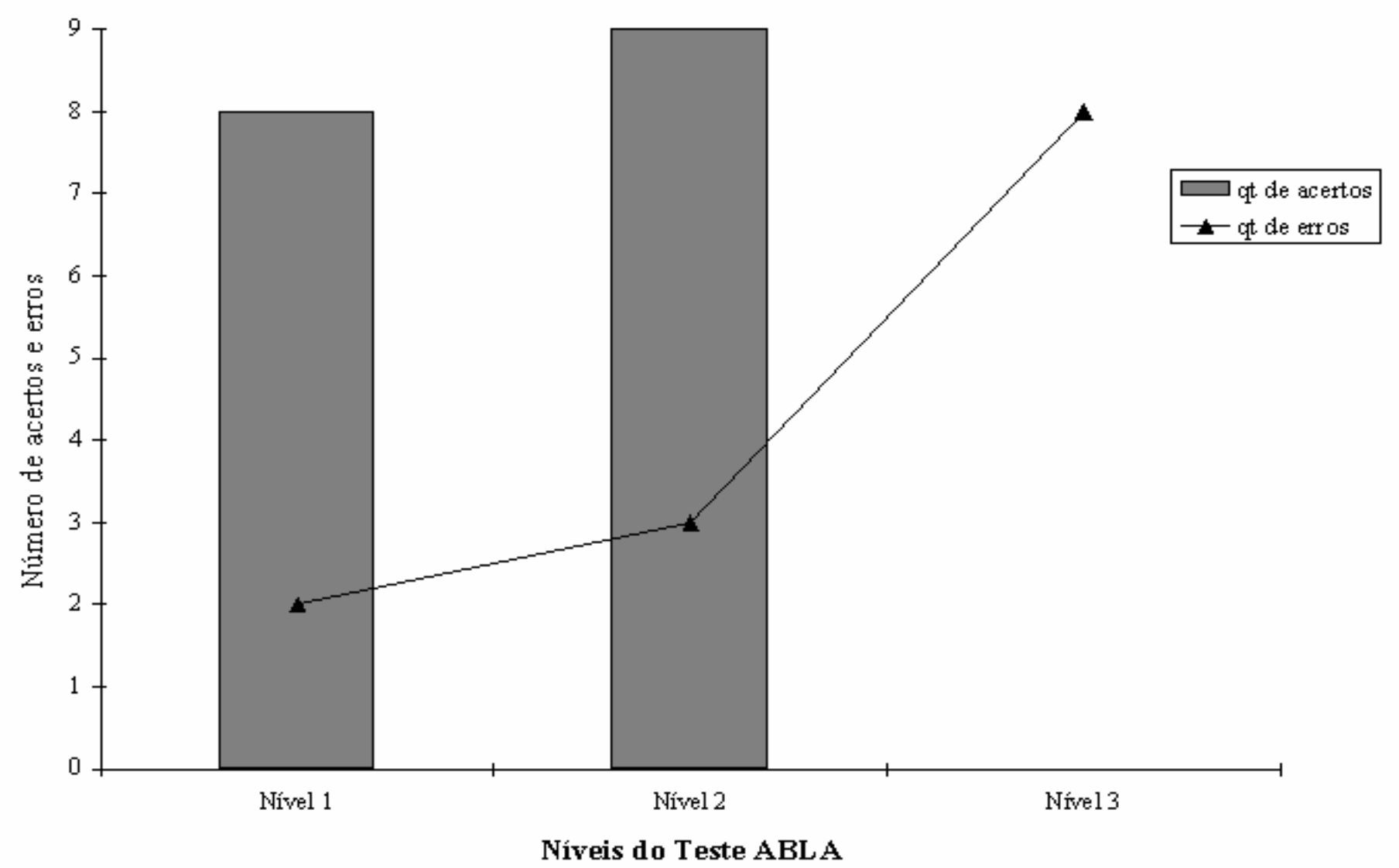

Figura 14 - Distribuição de números de acertos e erros da Participante 4, para testagem ABLA

No nível 2 era avaliado o repertório de Discriminação de Posição; havia uma lata vermelha e uma caixa amarela, sempre na mesma posição e era requerido que P4 colocasse um pedaço de espuma verde no recipiente da esquerda (no caso, foi a caixa vermelha). Como pode ser verificado na Figura 14, frente a esta tarefa P4 realizou doze tentativas no total, sendo que ocorreram três erros não consecutivos e oito acertos consecutivos; assim, o critério de avanço foi atingido.

No nível 3, que avaliava o repertório de Discriminação Visual, foi observada a ocorrência de oito erros consecutivos e, assim, a participante atingiu o critério de reprovação (oito erros consecutivos ou não); tal desempenho pode ser verificado na Figura 14. Nesta tarefa, P4 deveria colocar uma espuma verde dentro de uma lata amarela que sempre era apresentada ao lado de uma caixa vermelha, em posições 
aleatórias; durante as oito tentativas, mesmo com os procedimentos de correção, ela colocava a espuma dentro caixa vermelha.

Na testagem ABLA, o desempenho é representado pelo último nível no qual o participante atinge o critério de avanço (oito respostas consecutivas). Assim, P4 teve seu desempenho registrado no nível 2 - Discriminação de Posição; tal resultado aponta que esta participante demonstraria dificuldade na aquisição de discriminações auditivovisuais (nível 6), já que o desempenho que a mesma alcançou envolvia controles de estímulos mais simples.

Após a realização do Teste ABLA, foi iniciada a coleta com o programa EQUIVIUM. Na Figura 15 estão apresentados os resultados relativos à quantidade de tentativas e freqüência de acertos, obtidos pela Participante 4, durante todas as fases de treino e teste do programacom os primeiro e segundo conjunto de estímulos aos quais a participante foi submetida. É importante ressaltar que este tipo de figura foi desenvolvido para $\mathrm{P} 4$ porque os dados da mesma são inéditos e referem-se à coleta realizada neste trabalho, diferentemente dos Participantes 1, 2 e 3, cujos dados já foram publicados (Matos et al., 2002), com representação esquemática similar à referida figura (Figura 15).

Na Figura 15 o número total de tentativas disponibilizadas em cada tipo de treino e teste está representado pelas barras e, também, pelos números situados acima das mesmas; as tentativas corretas estão representadas por marcas (losangos pretos) situadas dentro das barras; os números exatos das tentativas corretas estão indicados ao lado dos losangos pretos. Quando o número de tentativas disponibilizadas e o número de tentativas corretas são coincidentes, há uma indicação relativa ao número exato das mesmas. 


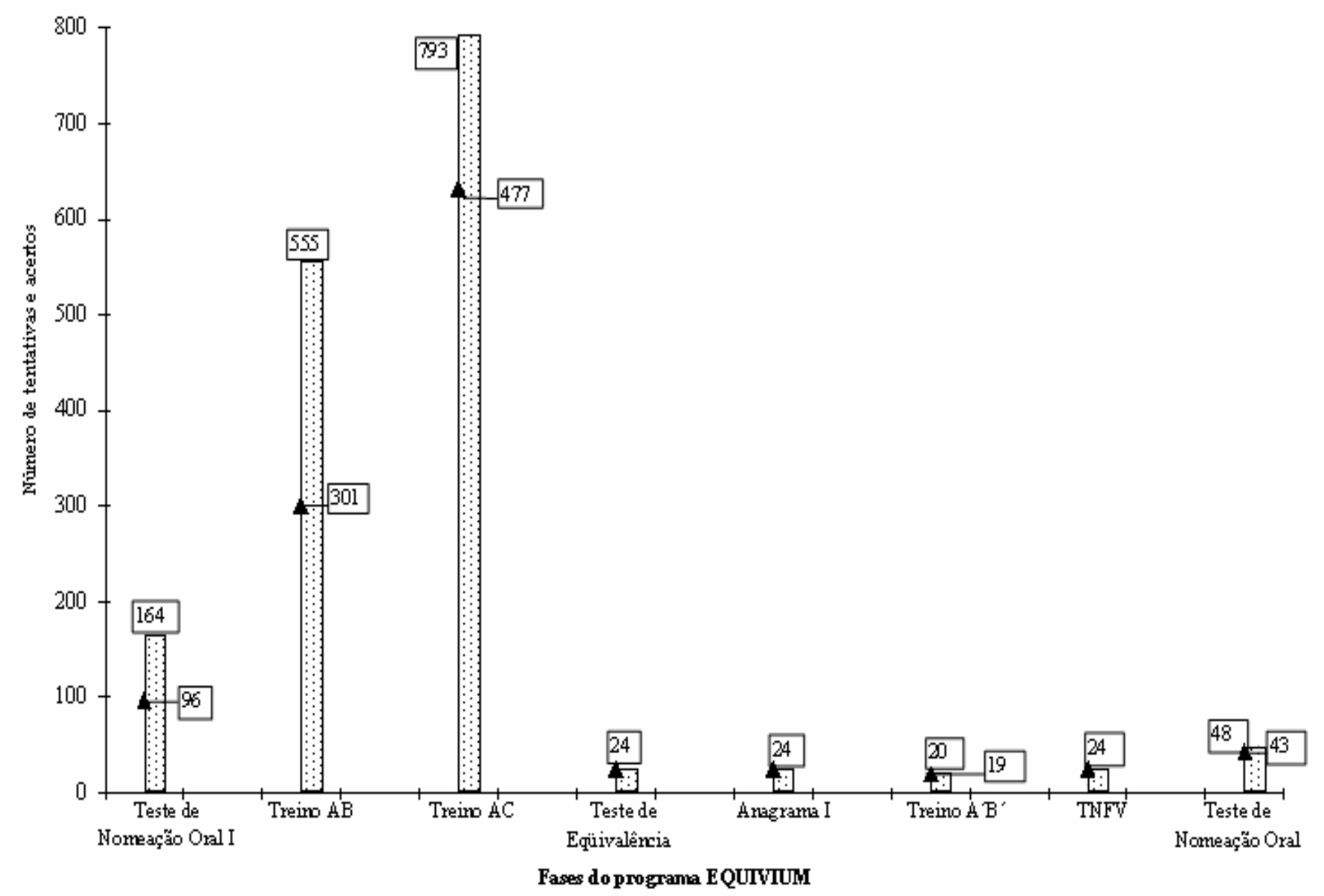

Figura 15. Dis tribuição do rúmero de tertativas apresertadas e do rúmero de tertativas conetas relativas aos desermenhos da Participante 4, em tarefas de discriminação condicional em palawas ditadas e palawas impres sas (Treinos AC) e nos Testes de Equivalência I Anagrama I Testes de Novas Fomas Verbais II (BC), para dois conjuntos de es tímulos diferentes.

A primeira fase do programa EQUIVIUM (Teste de Nomeação Oral I) era composta por tarefas de nomeação das figuras e das respectivas palavras que seriam ensinadas durante o decorrer do procedimento. No caso de P4 foram testados os estímulos do primeiro e do segundo conjunto; os objetivos principais desta fase eram ensinar o nome das figuras e averiguar se a participante sabia emitir o comportamento textual em relação às palavras escritas, repertório este que inviabilizaria a continuidade da mesma neste estudo.

Foi verificado que P4 leu uma das palavras impressas do segundo conjunto de estímulos (COCA) duas vezes; esta participante costuma emitir o comportamento de 
beber o refrigerante que tem este nome com alta freqüência, segundo relato verbal de sua mãe e observação da experimentadora. É comum vê-la olhar ou apontar para a lata do refrigerante e verbalizar: "coca"; desta forma, foi considerado que P4 não emitia o comportamento textual em relação às outras palavras que foram testadas e, assim, prosseguiu-se com ela no programa.

O desempenho de P4, na primeira fase (Teste de Nomeação Oral I), nas tarefas de nomeação de figuras e palavras impressas (representadas pelo primeiro histograma), pode ser verificado na Figura 15; foram apresentadas, no total, 164 tentativas de tentativas relativas às figuras e palavras impressas do primeiro e segundo conjunto de estímulos, das quais 96 foram corretas. Primeiramente, é importante ressaltar que as palavras escritas não eram treinadas, apenas testadas; desta forma, foram apresentadas 24 tentativas com palavras impressas dos primeiro e segundo conjunto de estímulos e P4 acertou uma delas, em duas tentativas (COCA).

O restante das tentativas (140) foi de treino das figuras dos primeiro e segundo conjuntos de estímulos, sendo que destas 140 tentativas P4 emitiu 94 respostas corretas, ou seja, realizou 46 erros para atingir o critério de avanço de $100 \%$ de acertos em três blocos de apresentação de cada um dos dois conjuntos de figuras. Com o critério de avanço alcançado nesta fase, $\mathrm{P} 4$ continuou no programa sendo submetida ao primeiro treino de discriminações condicionais entre palavras ditadas/figuras, para o primeiro conjunto de estímulos, o Treino $\mathrm{AB}^{31}$.

Na Figura 15 é possível observar o desempenho da participante nas tarefas de emparelhamento entre palavras ditadas e figuras do primeiro conjunto (Treino $\mathrm{AB}$ ). $\mathrm{O}$ critério de avanço nesta fase era de $100 \%$ de acertos em quatro apresentações do bloco

\footnotetext{
${ }^{31}$ Como descrito na seção de Método, deste estudo, entre o Teste de Nomeação Oral I e o Treino AB, havia o Pré-Treino de Cores, o qual não foi aplicado com P4 por conta da premência na coleta de dados. É importante destacar ainda que ocorreram problemas técnicos com o software utilizado neste momento da coleta.De qualquer forma, o Teste ABLA identificou que P4 apresentava o matching de identidade, tal como treinado na Fase de Pré- Treino.
} 
de quatro figuras deste primeiro conjunto; para alcançar tal critério foram disponibilizadas 555 tentativas para $\mathrm{P} 4$, sendo que a mesma realizou 301 acertos e, conseqüentemente, acumulou 254 erros nesta fase de aquisição de pré-requisitos em relação ao repertório de discriminação condicional entre palavras ditadas e figuras, colocando em risco a possibilidade de avanço no programa, mas P4 atingiu o critério de $100 \%$ de acertos, com procedimentos específicos, descritos adiante.

A próxima fase foi o treino de discriminações condicionais entre as palavras ditadas e impressas do primeiro conjunto de estímulos (Treino AC). Nesta fase, foram disponibilizadas 793 tentativas de treino, sendo que P4 realizou 477 acertos e, portanto, 316 erros; é importante ressaltar que nesta fase o critério de avanço era relativo a cada passo de fading in dos estímulos de escolha incorretos. O objetivo deste procedimento era de auxiliar o participante na aquisição gradual dos controles exatos pelos componentes das palavras.

Atingido o critério de avanço no Treino AC, a participante foi exposta ao primeiro Teste de Equivalência no programa (Teste de Equivalência I), no qual eram testadas as relações emergentes $\mathrm{BC} / \mathrm{CB}$ para o primeiro conjunto de estímulos. Como pode ser verificado na Figura 15, nesta fase P4 alcançou o critério de $100 \%$ de avanço sem nenhuma ocorrência de erros, demonstrando a emergência dos desempenhos testados, ou seja, a relação de simetria e transitividade $\mathrm{BC} / \mathrm{CB}$.

O mesmo desempenho de $100 \%$ de acertos também ocorreu na próxima fase do programa ao qual P4 foi submetida, o treino de construção por anagramas (Anagrama I); nesta fase, o critério de avanço também era de $100 \%$ de acertos. Tal desempenho de P4 também pode ser conferido na Figura 15.

Até este momento do programa, P4 havia demonstrado que as palavras ditadas, as figuras e as palavras impressas do primeiro conjunto de estímulos haviam se tornado 
equivalentes, bem como a emitir o comportamento análogo à escrita diante das palavra ditadas, deste mesmo conjunto.

Após o Teste de Equivalência I e após a fase de Anagrama I, P4 realizou um novo treino entre palavras ditadas e figuras, para o segundo conjunto de estímulos (Treino $\mathrm{A}^{\prime} \mathrm{B}^{\prime}$ ). Como pode ser verificado na Figura 15, foram apresentadas vinte tentativas, sendo que P4 acertou dezenove delase acumulou apenas um erro; o critério de avanço nesta fase também era de $100 \%$ de acertos; aqui vale ressaltar a diferença de desempenho desta participante em relação à primeira vez que este tipo de tarefa foi aplicado no Treino AB, para o primeiro conjunto de estímulos. O Treino A 'B', como ressaltado anteriormente, é realizado com estímulos (palavras ditadas e figuras) do segundo conjunto de estímulos, que são formados por meio da recombinação de elementos (sílabas e letras) do primeiro conjunto de estímulos; por conta dessas características, esse treino $\left(\mathrm{A}^{\prime} \mathrm{B}^{\prime}\right)$ é pré-requisito para a próxima fase do programa, o Teste de Novas Formais I, no qual é testado o repertório de emergência de novas formas verbais sem o ensino direto das palavras impressas correspondentes às figuras ensinadas no Treino A'B'.

Na Figura 15 é possível verificar o repertório de P4 no Teste de Novas Formas Verbais I. A Participante 4 não realizou nenhum erro, atingindo $100 \%$ de acertos, o que demonstra que com este novo conjunto de estímulos, o segundo, houve a emergência do controle por unidades mínimas. Tal tipo de desempenho é positivamente surpreendente, quando comparado àqueles encontrados nos estudos anteriores do grupo (Matos et al., 2002; Gomes, 2007 e Leite, 2008). Outro dado importante, em termos de emergência de repertório, é relativo à última fase do programa a qual P4 foi submetida: o Teste de Nomeação Oral II; neste teste foi avaliado o repertório de $\mathrm{P} 4$ em relação à nomeação das figuras dos primeiro e segundo conjuntos e, também, o repertório de 
comportamento textual para as palavras impressas destes mesmos conjuntos de estímulos.

Na figura 15 é possível verificar o desempenho de P4 no Teste de Nomeação Oral I. Foram disponibilizadas 48 tentativas e a participante errou cinco delas. Do total de tentativas (48), 24 eram relativas às figuras e 24 eram relativas às palavras impressas. P4 errou a nomeação de três figuras do primeiro conjunto e não emitiu o comportamento textual esperado para uma palavra impressa do primeiro conjunto e para uma do segundo conjunto. Vale ressaltar aqui que o desempenho mostrado na última testagem, tanto de nomeação de figuras quanto em relação às palavras impressas, foi bastante diverso daquele realizado no início do programa: o Teste de Nomeação Oral I.

Além desta análise geral e quantitativa representada na Figura 15, para o desempenho de $\mathrm{P} 4$, é importante ressaltar que também foi realizada a análise qualitativa apresentada previamente no Estudo 1, com o mesmo objetivo lá descrito, ou seja, identificar possíveis padrões de controle restrito de estímulos durante os processos de aquisição de discriminação condicional e de controle por unidades mínimas. Para tanto, tal como foi conduzido com os Participantes 1, 2 e 3, cada um dos erros emitidos pela Participante 4, durante as diversas fases de treinos e testes do programa EQUIVIUM, foram categorizados a partir das combinações dos estímulos relacionados às respostas de P4 nas tentativas em que houve erros e os estímulos apresentados para a mesma durante estas tentativas.

Assim, com base na categorização apresentada na Tabela 8, Estudo 1, p. 67, os pares de estímulos envolvidos nos erros de P4 foram analisados relação ao grau de semelhança que havia entre os mesmos (número de sílabas e letras em comum e suas posições). Quando as combinações entre os estímulos modelos e os estímulos relacionados às respostas dos participantes tinham diferenças muito sutis (Hübner, 
2007) os mesmo foram categorizadas como contendo diferenças críticas - DC - (Allen \& Fuqua, 1985; Birnie-Selwin \& Guerin, 1997); mas quando as combinações entre estímulos tinham poucas semelhanças/diferenças sutis, pois apresentam pouca semelhança entre os componentes (Hübner, 2007), as mesmas foram denominadas como contendo diferenças múltiplas - DM (Allen \& Fuqua, 1985; Birnie-Selwin \& Guerin, 1997).

$\mathrm{Na}$ Tabela 15 pode ser verificada esta análise a partir dos erros de P4. Nesta tabela, a disposição dos erros obedece a sua ocorrência na ordem/seqüência de execução do programa e, também, os erros foram organizados em ordem decrescente de freqüência, ou seja, dos mais freqüentes para os menos freqüentes. A consulta e tabulação de tais dados pôde ser feita a partir das matrizes de respostas apresentadas no Anexo 6, sistematizadas nas Figuras de 41 e 42.

Quanto à característica dos erros, como é possível verificar na Tabela 15, do total de erros observados na fase de Treino AC (316), 233 foram resultantes de combinações em que havia quatro letras e duas sílabas em comum e em posição de sílabas invertidas em relação às do estímulo modelo (4LC/2SC em PI); tais erros eram relativos às combinações de pares de estímulos que tinham diferenças muito sutis entre seus componentes, ou seja, DC - diferenças críticas (Allen \& Fuqua, 1985; BirnieSelwin \& Guerin, 1997). 
Dentre os erros com diferenças críticas (4LC/2SC em PI) destacados acima, como preponderantes (233), durante o Treino AC, a maioria deles (201) foi relacionada às palavras BOLO e LOBO, sendo que as mesmas aparecem tanto como estímulo modelo como estímulo de escolha negativo (ver Tabela 15). Menos preponderantes, mas parte desta categoria de combinações entre pares de estímulos,foram os 32 erros envolvendo as palavras BOCA e CABO; as mesmas também ocorrem, nestas tentativas de erros, como estímulo modelo e como estímulo de escolha negativo (ver Tabela 15).

Como pode ser verificado na Tabela 15 e na Figura 16, que apresenta a distribuição dos tipos de erros e da freqüência dos mesmos no programa EQUIVIUM Para P4 também foi observada no Treino AC a ocorrência de 59 erros relacionados à outra combinação de pares de estímulos, classificada como 2LC/1SC e PI, ou seja, o estímulo de escolha negativo que tem duas letras/uma sílaba em comum e na posição invertida em relação ao estímulo modelo; exemplos deste tipo de combinação foi "boca"/LOBO e "cabo"/BOLO. Esta combinação entre pares de estímulos foi categorizada como contendo diferenças pouco sutis entre os elementos que os compõe (diferenças múltiplas - DM), como proposto por Allen e Fuqua, 1985; Birnie-Selwin e Guerin, 1997); além disso, é possível observar que a sílaba 'bo', em todos estes 59 erros, era o elemento comum entre os pares de estímulos envolvidos, mesmo em posições invertidas.

E, ainda em relação ao Treino AC, na Tabela 15 e na Figura16 podem ser verificados outros dezesseis erros do tipo que têm duas letras/uma sílaba em posição comum (2LC/1SC em PC) entre os estímulos modelo apresentados e os estímulos de escolha negativos selecionados pela participante; exemplo: "cabo"/LOBO e "bolo"/BOCA. Esta combinação entre pares de estímulos também foi categorizada como contendo diferenças pouco sutis entre os elementos que os compõe (diferenças 


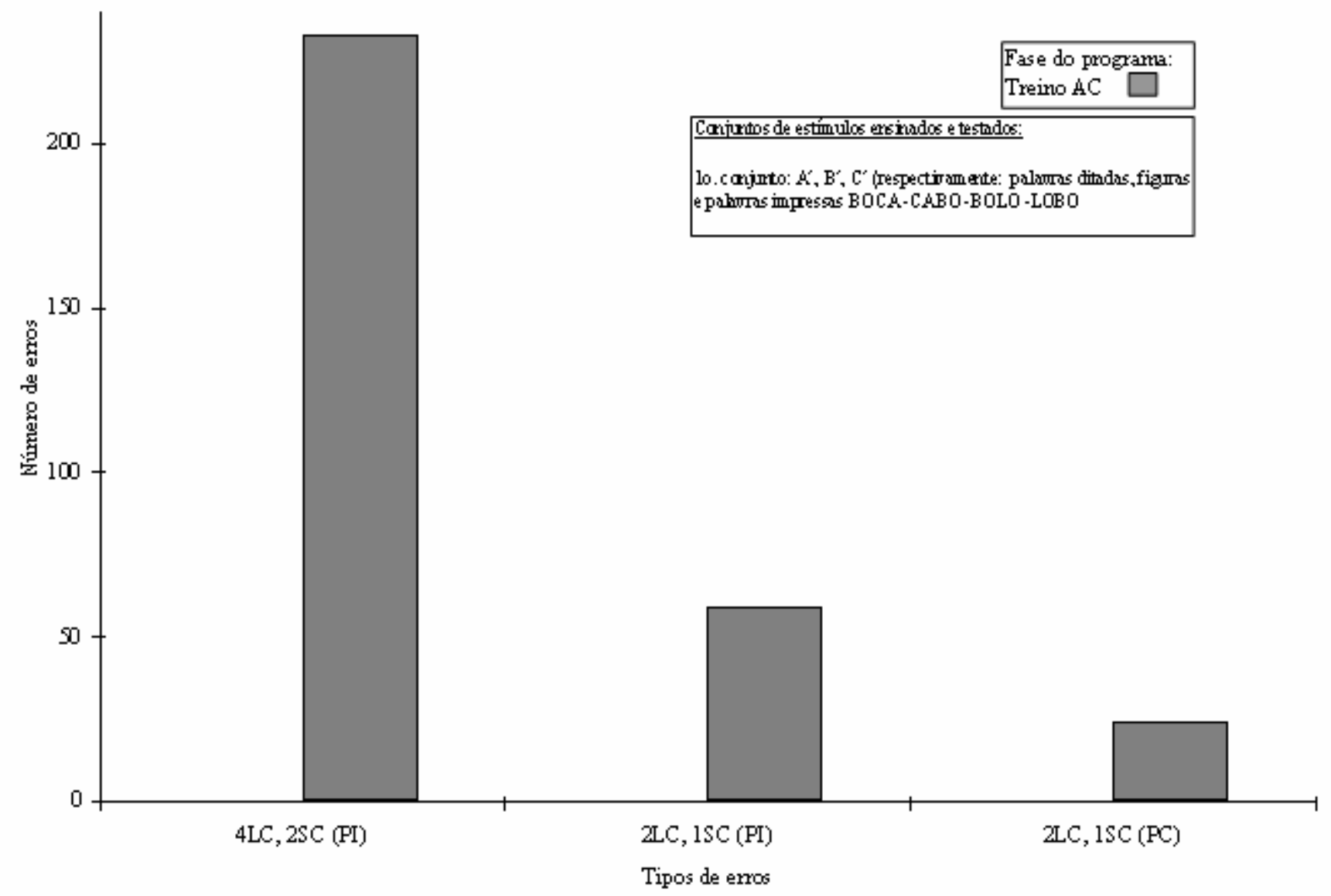

Figua 16 . Distribuição dos tipos de enros entitidos pela Participante 4 e das res pectivas quantidades dos mesmos, ao longo do programa EQUV IJM, para um conjunto de estínulos. As barras representam tertativas de treino.

múltiplas - DM), como proposto por Allen e Fuqua, 1985; Birnie-Selwin e Guerin, 1997). Além disso, para esta categoria também foi possível observar que a sílaba 'bo', nestes 16 erros, era o elemento comum entre os pares de estímulos envolvidos, e ocupava sempre a mesma posição.

Assim, apenas por meio da análise dos erros, com diferenças críticas, preponderantes em freqüência (233, do total de 316 erros no Treino AC) e com base nas palavras para as quais os erros ocorreram (201 erros envolvendo a combinação BOLO/LOBO do total de 233 erros categorizados como 4LC, 2SC em PI), não é plausível supor que P4 estivesse emitindo suas respostas de seleção apenas sob controle restrito da sílaba 'bo' ou 'lo', durante estas tentativas. Ambas as sílabas pareciam controlar as respostas de P4. Por outro lado, a análise da ocorrência dos outros 83 erros 
categorizados como contendo diferenças múltiplas (59 erros categorizados como 2LC/1SC em PI e 24 erros categorizados como 2LC/1SC em PC), evidenciou uma possível preferência pela sílaba 'bo', nestas tentativas.

De qualquer forma, é importante destacar que P4 não demonstrou um controle restrito indesejável, durante o treino $\mathrm{AC}$, como preferência por posição ou alguma letra específica; até em relação à sílaba 'bo' é arriscado, com esses dados, supor um controle restrito pela mesma. Considerando-se que houve dificuldades de aprendizagem no contexto de aquisição de discriminações condicionais (para as quais foram propostos procedimentos de correção específicos, descritos adiante), como já era previsto pelo desempenho da participante no Teste ABLA, pode-se supor que P4 parecia fazer escolhas já sob controle da discriminação de sílabas, o que é um repertório pré-requisito para a emergência do controle por unidades mínimas.

É importante retomar que neste primeiro conjunto de estímulos todas as palavras têm a sílaba 'bo' em comum, ou em posição invertida ou na mesma posição. Hübner (1990) e Matos et al. (1992) discutiram a importância da repetição sistemática dos elementos nas palavras e em posições diferentes para evitar que o participante estabeleça possíveis padrões de controle restrito tanto em relação a elementos isolados, quanto em relação à posição dos estímulos. Como destacado para os participantes típicos do Estudo 1 ( $\mathrm{P} 1, \mathrm{P} 2$ e P3), P4 também parece ter se beneficiado destas estratégias experimentais para a prevenção de controle restrito de estímulos em relação aos elementos que formavam os estímulos compostos (palavras ditadas e impressas).

Esta suposição parece ser fundada, quando se examina os testes de Equivalência I ou Teste de Novas Formas Verbais I, para os quais houve índices de 100\% de acertos, como é possível verificar na Tabela 15 e, também, na Figura 16 (que apresenta erros de 
P4), pela ausência de pontos na própria figura, que está composta por barras que representam os erros em tentativas de treino.

O desempenho perfeito nos Testes de Novas Formas Verbais I merece destaque, pois eles são a medida de que houve a aquisição do controle por unidades verbais mínimas (letras/sílabas), desempenho este que não emergeria caso estivesse ocorrendo algum controle restrito de estímulos; deste modo, é possível afirmar que ocorreu a leitura recombinativa ou generalizada com os estímulos dos primeiro e segundo conjuntos, já que esta participante identificou letras e sílabas (elementos dos estímulos compostos - palavras) aprendidas em situação de treino, em outras posições de outros estímulos compostos (novas palavras formadas por recombinação de letras e sílabas anteriores), em situação de teste, sem reforçamento.

Outra questão importante, derivada das fases de treino deste programa, é a emergência do comportamento textual verificado por meio do Teste de Nomeação Oral II. Como destacado anteriormente para os Participantes 1, 2 e 3, a Participante 4 também mostrou um desempenho emergente para o comportamento textual mesmo sem o ensino direto deste, mas sim a partir de contingências de reforçamento relacionadas a classes de comportamentos envolvendo respostas de seleção e de construção (Lee \& Pegler, 1982); o único desempenho direto de nomeação ensinado foram os nomes das figuras, durante o Teste de Nomeação Oral I, com dica ecóica.

Este desempenho de P4 pode ser verificado na Figura 17, que contém uma representação esquemática das tarefas de discriminação condicional entre palavras ditadas/palavras impressas (Treino AC), tarefa de construção de palavras (Anagrama I) e as tarefas relativas ao comportamento textual não ensinadas diretamente (Teste de Nomeação Oral II). Na Figura 17 é possível verificar como, por meio dos treinos de seleção e construção por anagramas, P4 mostrou um desempenho emergente do 


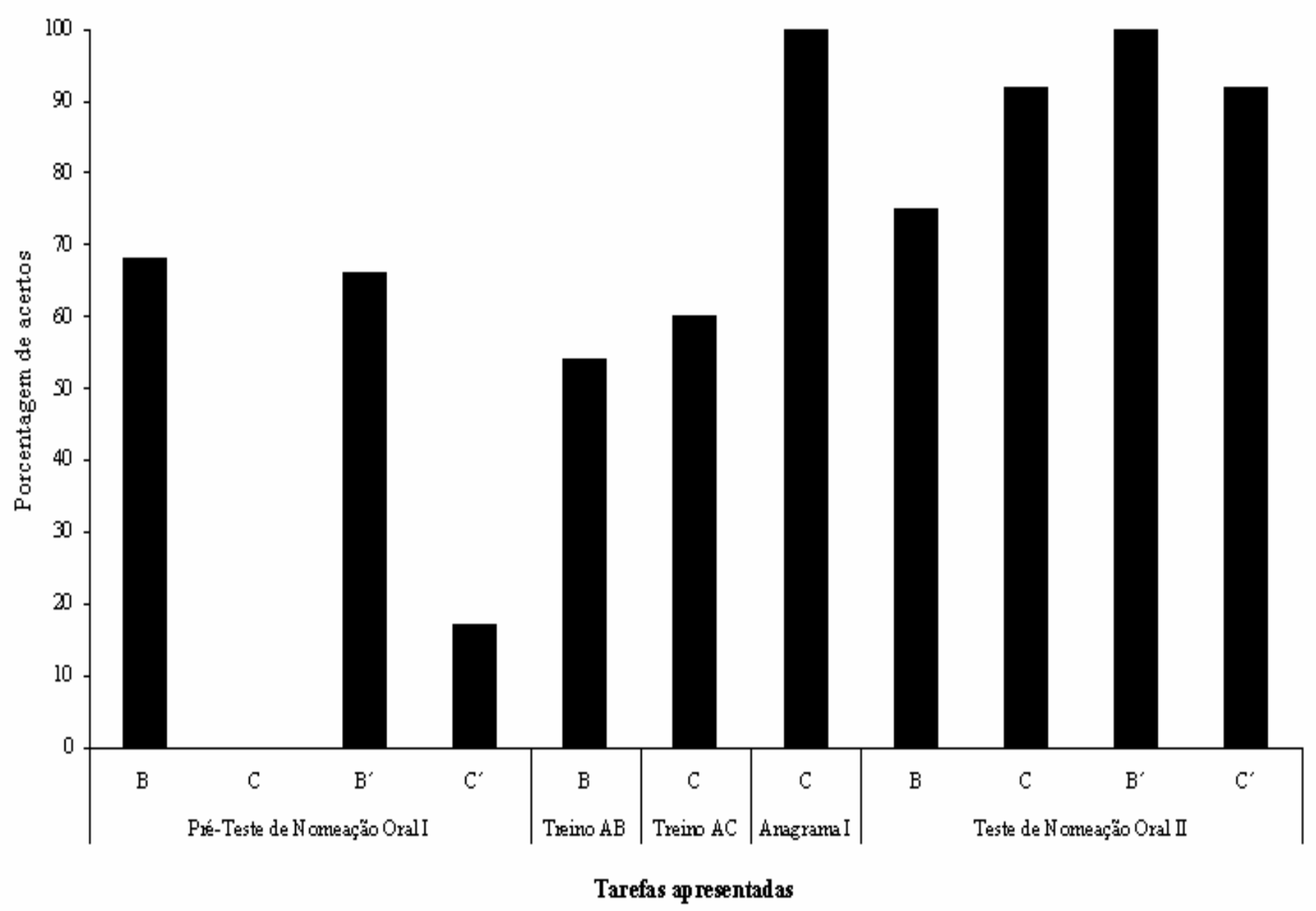

Figura 17. Distrbuição das porcentagers de acertos da Participarte 4, nas diferentes fases do programapara dois coryuntos de estínulos diferentes.

comportamento textual. Este dado é muito relevante e importante já que, como já destacado anteriormente, no Teste de Nomeação Oral I, P4 nomeou apenas a palavra impressa: COCA em duas de três tentativas e, quando as outras palavras eram apresentadas, a participante não emitia nenhuma resposta.

O destaque à emergência do repertório textual é muito significativo para P4, principalmente considerando a restrição do comportamento verbal vocal da participante, que praticamente é restrito ao operante verbal ecóico. Um exemplo desta dificuldade e restrição pôde ser encontrada e analisada durante a coleta de dados desse trabalho; na fase de Teste de Nomeação Oral I, em que um dos objetivos é ensinar o participante a nomear as figuras do programa, $\mathrm{P} 4$ acumulou 68 erros em uma total de 164 tentativas 
(41\% de erros), sendo que os participantes típicos do Estudo 1 (P1, P2 e P3) não emitiram nenhuma resposta incorreta nessa fase, para a nomeação de figuras.

Assim, como ressaltado, os repertórios de controle por unidades mínimas verbais e emergência de comportamento textual emergiram. Entretanto, para a participante se manter e continuar no programa atingindo os critérios de avanços de $100 \%$ préprogramados, em contextos de tentativas de MTS e de nomeação (aprendizagem de figuras), foram necessários alguns procedimentos específicos, planejados individualmente frente às dificuldades de $\mathrm{P} 4$, durante a coleta nas fases de Teste de Nomeação Oral I, Treino AB e Treino AC; a indicação do momento de inserção destes procedimentos está na Tabela 13 e sua descrição na seção de Método, deste estudo.

A Figura 18 apresenta o número de erros e acertos acumulados, pela Participante 4, durante a coleta de dados com o programa EQUIVIUM; como pode ser verificado nesta figura, na fase de Teste de Nomeação Oral I, a Participante 4, frente a três figuras do primeiro e segundo conjunto de estímulos (lobo, cabo e caco) não emitia resposta de nomeação e o procedimento padrão era a disponibilização do modelo oral da experimentadora após o erro da participante; como P4 não respondia a algumas figuras, foi introduzido, já na segunda sessão desta fase, um procedimento de disponibilização de dica verbal (apenas para as tentativas com estas figuras) com atraso de cinco segundos após a apresentação da mesma e este tempo foi aumentando, gradualmente, para dez segundos (prompt delay). Como pode ser verificado na Figura 18, este procedimento mostrou-se eficaz para P4, já que a mesma aprendeu a nomear as palavras sem a dica ecóica da experimentadora na sessão 4.

No Treino $A B$ (iniciado na sessão 5) foram necessários quatro procedimentos específicos para P4 alcançar o critério de 100\% de respostas corretas para avançar no programa $\mathrm{Na}$ sessão 6, foi introduzida a ajuda física para uma resposta de observação, 


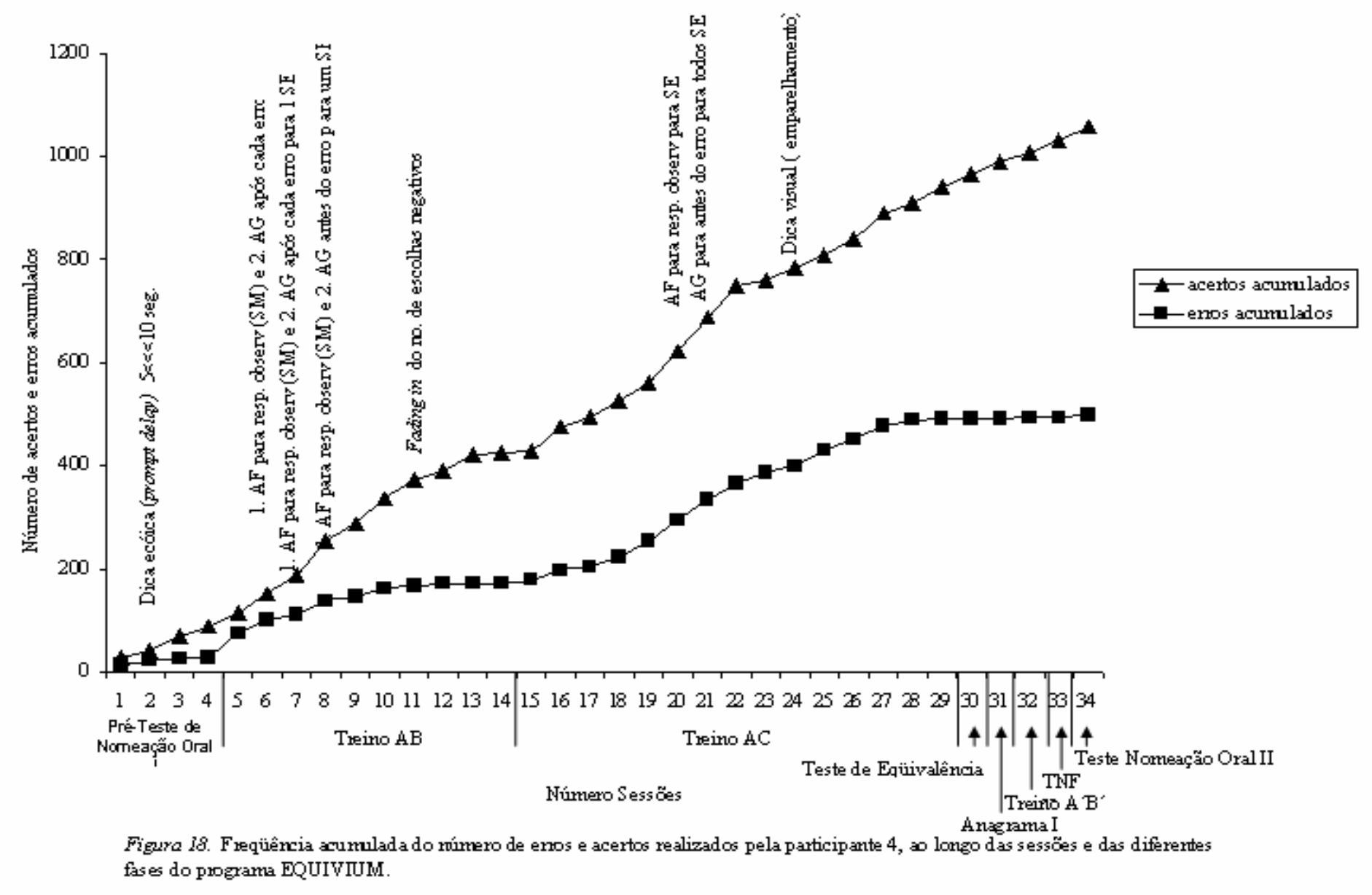

ou seja, manter a resposta de P4 de apontar para o quadrado inferior em branco na tela (que seria o relativo ao estímulo modelo- SM) com o objetivo de diminuir uma resposta de P4, que vinha ocorrendo, que era a de tocar todos os estímulos na tela durante as tentativas de MTS. Além disso, foi oferecido o modelo de resposta (ajuda gestual ${ }^{32}$ após cada tentativa na qual ocorria erro); vale ressaltar que o procedimento de correção padrão era a disponibilização do modelo após três erros consecutivos ou cinco erros não-consecutivos. Como P4 estava mostrando uma dificuldade na tarefa de MTS, foi introduzido este procedimento específico que auxiliou na diminuição de erros e na aprendizagem da tarefa de discriminação condicional.

Como foi destacado na seção de Método, deste estudo, P4 não foi submetida à fase de Pré-Treino de Cores, o qual tem como objetivo maior preparar o participante para as tarefas que serão apresentadas no programa, mais especificamente as tarefas de

\footnotetext{
${ }^{32} \mathrm{Na}$ ajuda gestual foi disponibilizado apenas o gesto, da experimentadora, de apontar para a tela como uma dica para a resposta de seleção a ser realizada pela participante.
} 
MTS; provavelmente, a não realização deste treino pode ter afetado o desempenho da mesma e, o efeito, estaria relacionado ao grande número de erros nestas tarefas e por conseguinte a necessidade da introdução de vários procedimentos de correção específicos.

Na sessão 7, ainda no Treino $\mathrm{AB}$, a Participante 4 passou a demonstrar dificuldade com apenas uma resposta de seleção: diante do estímulo modelo oral "lobo", ela selecionava bolo; frente a esta dificuldade mais específica, a ajuda física para a resposta de observação continuou e a ajuda gestual continuou apenas para a correção, após a resposta incorreta de seleção, diante do modelo auditivo "lobo". Na sessão 8, como foi observado pela experimentadora, P4 continuou sob controle restrito de estímulos durante as tentativas entre os pares de estímulos "lobo"/lobo, ou seja, diante do estímulo auditivo "lobo", P4 sempre selecionava a figura de bolo; assim, para evitar o erro, foi disponibilizado a ajuda gestual de forma mais intrusiva, antes do erro acontecer. Mas os erros em relação a este par de estímulos ocorriam, sobretudo quando a experimentadora aumentava, em um segundo, o tempo para emitir a ajuda gestual. Essa dificuldade em retirar a ajuda gestual foi observada durante as sessões 9 e 10 .

Para a sessão 11, foi introduzido o procedimento de fading in do número de estímulos de escolhas negativos, tal como planejado para o Treino AC, inclusive com a manutenção do mesmo critério de avanço: 100\% de respostas corretas em cada passo deste tipo de fading; como é possível observar na Figura 18. Com este procedimento de introdução passos, que é padrão do EQUIVIUM, e que foi introduzido já nesta fase de Treino $\mathrm{AB}$ (anterior à fase de Treino $\mathrm{AC}$, na qual este procedimento é utilizado), a Participante 4 atingiu todos os critérios de avanço, sem ocorrência de erros.

Na sessão 15 foi iniciado o Treino AC, com o procedimento padrão de fading in do número de escolhas negativos, já planejados para a esta fase. Até a sessão 19, P4 
atingiu o critério de avanço no passo 1 de fading, com apenas um estímulo de escolha positivo, mas não conseguiu atingir o critério de avanço para o passo 2 (no qual as tentativas eram realizadas com dois estímulos de escolha, um positivo e um negativo), já que a participante passou a selecionar os estímulos de escolha sob controle restrito de estímulos em relação à posição direita dos estímulos, na tela de computador. Na sessão seguinte (sessão 20), a experimentadora disponibilizou um procedimento especifico de correção para bloquear este padrão de seleção no lado direito da tela do computador: ajuda gestual para todos os estímulos de escolha, na tela, antes da resposta de seleção. O efeito do procedimento não foi eficaz em bloquear o padrão de seleção sob controle da posição porque P4 continuou a emitir erros, como pode ser verificado na Figura 18.

Frente a este desempenho, a experimentadora, na sessão 21 , disponibilizou ajuda gestual antes da resposta de seleção. Nas sessões 22 e 23, a experimentadora tentou aumentar o tempo com que a ajuda gestual era disponibilizada para um segundo, mas P4 direcionava a resposta de apontar para o lado direito da tela e, assim, o acúmulo de erros continuava a ocorrer. Por fim, na sessão 24, foi requerida de P4 uma nova topografia de resposta nas tentativas de MTS: a cada tentativa, foram dispostos na mesa, em frente ao computador, os quatro estímulos de escolha impressos em papel (com o mesmo tamanho e forma dos estímulos apresentados na tela e P4 deveria: 1. após a liberação do estímulo auditivo no computador, pegar a palavra impressa relacionada que estava na mesa e emparelhar este estímulo visual (em papel) com o estímulo de escolha relacionado na tela do computador.

No início deste procedimento, foi disponibilizado o modelo (ajuda gestual para pegar a palavra impressa da mesa e para emparelhar com o estímulo relacionado na tela); a partir da sessão 26, a experimentadora aumentou o tempo entre a liberação do estímulo auditivo pelo computador e a ajuda gestual para pegar a palavra impressa 
relacionada e emparelhar com o estímulo na tela (de 1 para 5 segundos). Os resultados mostraram-se satisfatórios; a partir da sessão 28, P4 não realizou mais erros, alcançando os critérios de avanço no programa de $100 \%$ de acertos para as fases de Treino AC com o último procedimento de correção descrito. Em seguida, a Participante 4 realizou o Teste de Equivalência I e Anagrama I (para o primeiro conjunto de estímulos) e finalizou o programa com o Teste de Novas Formas Verbais I (com o segundo conjunto de estímulos) e o Teste de Nomeação Oral II (com os primeiro e segundo conjunto de estímulos). Vale ainda ressaltar que P4 finalizou o programa com os procedimentos padrão, descritos neste estudo, do EQUIVIUM, sem a necessidade de introdução de novos procedimentos específicos.

Como foi descrito, para a adequação e continuidade da Participante 4 no programa, foi necessária a introdução de vários procedimentos específicos de correção que, com certeza, não precisaram ser manejados com os Participantes 1, 2 e 3; além disso a participante exibiu um número de erros consideravelmente maior do que os participantes com desenvolvimento típico. A falta de coerência entre a Topografia de Controle de Estímulos planejada para a emergência dos repertórios e a apresentada pela participante mostrou-se importante, o que exigiu que a experimentadora delineasse novas estratégias de adequação do programa às necessidades de $\mathrm{P} 4$, além daquelas dos arranjos experimentais que têm sido planejados e revisados constantemente (Matos et al., 2002) e, também, daquelas elaboradas anteriormente à coleta de dados (proposta descrita na seção de Método, deste estudo, referente à adaptação do programa EQUIVIUM para uma participante com autismo); a preocupação principal era aumentar a coerência entre a Topografia de Controle de Estímulos demonstrada por P4 e aquela planejada no programa (McIlvane \& Dube, 1992; McIlvane, Serna, Dube \& Stromer, 2000). 
Embora essa diferença entre os desempenhos de P4 e dos participantes analisados no Estudo 1 seja substancial, também é importante destacar que após a revisão constante dos arranjos experimentais do programa, diante das dificuldades da participante, a mesma passou a ter um desempenho semelhante aos desempenhos de P1, P2 e P3, ou seja, alcançou a aquisição do controle por unidades verbais mínimas e a emergência do comportamento textual.

Vale destacar que P4 ainda mostrou maior acurácia nos testes de recombinação (Testes de Novas Formas Verbais II) que P2, por exemplo. Além disso, adquiriu a aquisição do controle por unidades verbais mínimas, em etapas anteriores do programa, em relação à $\mathrm{P} 3$. $\mathrm{O}$ desempenho de $\mathrm{P} 4$ teve maior similaridade com o demonstrado por P1, ou seja, após um acúmulo maior de erros no Treino AC, seguiram acertando nas situações de teste; outra similaridade entre os desempenhos de P4 e P1 é em relação à preponderância de erros derivados da combinação entre pares de estímulos com diferenças críticas, com duas sílabas em comum, em posição invertida.

Em relação aos seis participantes do Estudo de Hübner et al. (2007), P4 também demonstrou um padrão semelhante de aquisição do controle por unidades mínimas durante o treino de discriminações condicionais, já que alcançou a fase de Testes de Novas Formas Verbais com altos índices de acertos. Este padrão de aquisição também foi similar aos descritos para P1, P2 e P3. Tais dados levam à suposição de que o controle por unidades mínimas, seja para crianças com desenvolvimento típico ou com autismo, é adquirido durante os treinos e não durante os testes.

Ainda é importante salientar que foi bem sucedida a replicação sistemática (Sidman, 1960) de Matos et al., (2002), com P4, que é diagnosticada com autismo e que, como foi amplamente discutido neste trabalho, pode exibir uma tendência a demonstrar controle restrito de estímulos durante a aprendizagem de discriminação de 
estímulos compostos (Lovass \& Schreibman, 1971; Lovaas e cols., 1971; Koegel \& Wilhelm, 1973 e Allen \& Fuqua, 1985); assim, a possibilidade de aplicação deste procedimento e a possibilidade de aquisição do controle por unidades verbais mínimas demonstradas neste trabalho, com a Participante 4, apresenta possibilidades de novas pesquisas na área, inclusive para buscar a generalização e extensão dos dados aqui obtidos. 


\section{Considerações Finais}

Conforme os dados apresentados e discutidos, neste trabalho, foi observado que todos os participantes atingiram a emergência do controle por unidades verbais mínimas, a partir de um treino de discriminações condicionais pré-requisitos, que vem sido amplamente revisto por meio de procedimentos experimentais e controlados, com o objetivo de promover a leitura generalizada ou recombinativa (Hübner, 1990; Matos \& Hübner, 1992; Matos et al., 1997 e Matos et al., 2002). É importante ressaltar que tanto os participantes com desenvolvimento típico (P1, P2 e P3) quanto a participante com desenvolvimento atípico (P4) beneficiaram-se dos procedimentos padrões aqui apresentados.

Além de uma análise geral, em relação à emergência do controle por unidades mínimas verbais, neste trabalho também foi proposta uma análise detalhada, molecular, dos erros, de cada participante, que ocorreram em variadas etapas do programa; um recorte para a análise dos erros foram as combinações entre os estímulos envolvidos nas respostas dos participantes e os estímulos apresentados aos mesmos, em cada tentativa, como modelos. O objetivo era identificar padrões de escolha relacionados ao grau de semelhança entre os pares de estímulos, como proposto e analisado por Hübner et al. (2007) e uma possível relação com o repertório de emergência do controle por unidades mínimas.

Para auxiliar nesta categorização, foi utilizada a nomenclatura utilizada por Allen e Fuqua, 1985 e Birnie-Selwin e Guerin, 1997, na qual os autores denominam a combinação de pares de estímulos com muitos elementos em comum e/ou na mesma posição como contendo diferenças críticas. A combinação de pares de estímulos com poucos elementos e posição não coincidentes como contendo Diferenças Múltiplas. 
A hipótese principal dos autores é que um treino de discriminações condicionais com os estímulos que tenham diferenças críticas aumenta a probabilidade de uma discriminação mais acurada dos elementos dos estímulos compostos e, assim, diminui a probabilidade de ocorrência de controle restrito de estímulos. O que foi observado no presente trabalho é a existência de alguns padrões existentes durante a aquisição do controle por unidades mínimas, mas que variam inter-sujeitos (Malheiros, 2002; Matos et al, 2002; Gomes, 2007; Leite, 2008); na análise de erros dos participantes, variados controles de estímulos foram interpretados em termos de probabilidade, uma noção intrínseca ao comportamento operante, que demonstra a funcionalidade de um determinado padrão de resposta: ou seja, se há manutenção da freqüência de uma resposta é porque ela está sendo reforçada, em graus variados de probabilidades.

Neste sentido, a identificação de alguns padrões de controles de estímulos que não estejam facilitando o processo de aquisição do repertório esperado, mas que continuam a ocorrer com uma determinada freqüência, é relevante, pois o analista do comportamento, no ambiente experimental ou aplicado, deve planejar estratégias individualizadas para o desenvolvimento de outros padrões de respostas que sejam compatíveis com o processo de aquisição de repertórios esperados. Este também acabou por ser parte integrante deste trabalho: propor procedimentos de correção específicos e individualizados, estabelecidos sob controle do comportamento do participante, emitido no momento da coleta de dados, nas sessões.

Em relação ao Participante 1, foi discutido que o mesmo tenha possivelmente demonstrado inicialmente um controle restrito pela sílaba 'bo', independente da posição em que a mesma ocupava nos estímulos nas tentativas de erro ocorridas, no início do programa; além disso, tais escolhas estavam relacionadas, em sua maioria, a combinações de pares de estímulos com diferenças múltiplas e, foi discutido que as 
contingências já planejadas no programa foram suficientes para diminuir esta dificuldade e o participante atingir o repertório esperado, com $100 \%$ de acurácia.

O Participante 2 acumulou erros em todo o programa, mas sem a identificação de um padrão específico que o instrumento de análise aqui apresentado pudesse detectar; mas os erros deste participante estavam relacionados ao que foi denominado como diferenças múltiplas; discussões sobre a entrada de procedimentos de correção específicos foi discutida, já que o mesmo atingiu o controle por unidades verbais mínimas, mas com índices em torno de $90 \%$ de acertos.

O Participante 3 demonstrou uma padrão de respostas, principalmente durante os testes em que as sílabas anteriormente treinadas e sílabas recombinadas eram apresentadas, com preponderância de erros para estímulos com diferenças críticas, com três de quatro elementos dos compostos em comum e na mesma posição; o participante alcançou o repertório esperado, com $100 \%$ de acertos com a exposição a mais um conjunto de estímulos; discutiu-se que procedimentos de correção específicos nas fases iniciais do programa poderiam maximizar a rapidez na aquisição do controle por unidades verbais mínimas.

Também foi objetivo do presente trabalho estender a aplicação do programa ao qual os Participantes 1, 2 e 3 foram submetidos e estender a análise de identificação de padrões de controles de estímulos aqui apresentada para um participante com desenvolvimento atípico, mais especificamente, com um participante diagnosticado como autista. Tais objetivos foram alcançados com a coleta de dados com P4 e com análise posterior desses dados; P4 exibiu um número de erros consideravelmente maior do que os participantes com desenvolvimento típico e, também demonstrou que a preponderância de seus erros estava relacionada a uma combinação entre pares de estímulos com diferenças críticas, mas não similar àquela demonstrada pelo Participante 
3. A Participante 4 realizou erros preponderantes com pares de estímulos nos quais havia duas sílabas em comum e em posição invertidas em relação às do estímulo modelo (4LC/2SC em PI). Para a Participante 4 foram propostos e realizados alguns procedimentos de correção específicos que auxiliaram tanto na quebra de padrões de controle restrito de estímulos, quanto na aprendizagem das tarefas de discriminações condicionais, para as quais ela mostrou muita dificuldade, especificamente com a apresentação das mesmas em computador. Essa alteração de padrão de controle restrito é relevante, pois tem sido amplamente discutido que indivíduos com o diagnóstico de autismo demonstram, com freqüência, controle restrito de estímulos durante a aprendizagem de discriminação de estímulos compostos (Lovass \& Schreibman, 1971; Lovaas e cols., 1971; Koegel \& Wilhelm, 1973 e Allen \& Fuqua, 1985). A presença de padrões de controle restrito, durante o aprendizado de repertórios de leitura, pode afetar e impedir o estabelecimento de um repertório adaptativo do ponto de vista social, principalmente para uma população que tem como um dos principais déficits, a dificuldade no desenvolvimento do repertório verbal.

Recentemente, alguns estudos têm procurado identificar e corrigir controle restrito de estímulos relacionados ao repertório de leitura, com portadores de autismo (Walpole, Roscoe, \& Dube, 2007; Da Hora \& Benvenuti, 200); tais estudos têm em comum o fato de utilizarem o procedimento de DOR (resposta de observação diferencial) proposto por Dube e McIlvane (1999) para corrigir padrões de controle restrito apresentados em tarefas de MTS, com estímulos compostos (palavras escritas) formados por letras e sílabas.

Em relação, ainda, à importância de identificar minuciosamente padrões de controle de estímulos, é possível supor que uma análise desenvolvida com este objetivo (como a apresentada neste trabalho) poderia, em alguma medida, ser beneficiada pelo 
uso de um aparato tecnológico, como o eye scan, que pode rastrear os movimentos oculares do participante e, assim, auxiliar na identificação de quais elementos e em que posição os mesmos ocupam no estímulo composto, durante a resposta do participante. De qualquer forma, a análise apresentada neste trabalho foi realizada com todos os recursos observacionais oferecidos pelos conceitos e procedimentos da Análise do Comportamento, o que, como ressaltado anteriormente, está de acordo com a lógica do determinismo probabilístico. Tais recursos permitiram identificar, de maneira geral, que os quatro participantes atingiram o controle por unidades verbais mínimas, mas como foi descrito, com variação nos controles de estímulos estabelecidos durante a aquisição.

Uma outra questão que pode ser suscitada com o presente trabalho diz respeito ao momento de aquisição do controle por unidades mínimas na leitura: se durante os treinos das discriminações condicionais pré- requisitos ou durante os testes de novas formas verbais. Hübner et al. (2007) apontaram que, possivelmente, durante os treinos tal habilidade é adquirida, já que a maioria dos participantes analisados naquele estudo revelaram $100 \%$ de acertos já nas primeiras tentativas dos testes. No presente estudo a aquisição do controle por unidades mínimas parece ter sido adquirida durante os treinos para todos os participantes.

A variabilidade comportamental é outro aspecto que pode ser discutido a partir do presente estudo. Ela tem sido relacionada a uma falta de coerência entre a topografia de controle de estímulos que o experimentador programou e a topografia de controle de estímulos exibida pelo participante (McIlvane \& Dube, 1992; McIlvane, Serna, Dube \& Stromer, 2000). A busca por procedimentos experimentais que sejam eficientes para a aprendizagem é fundamental e necessária e este comportamento do cientista é evidenciado pelos arranjos oferecidos e planejados previamente a um processo de coleta de dados; neste trabalho, esses arranjos que vem sido analisados e revistos (Matos et al., 
2002) foi utilizado e, além disso, foram realizadas alterações prévias neste arranjo para a coleta de dados com uma participante diagnosticada com autismo. Todo esse processo foi realizado com o objetivo de diminuir a falta de coerência entre os controles planejados pelo experimentador e a topografia de controle de estímulos revelada pelo participante durante o processo de aquisição do controle por unidades mínimas. Porém, os arranjos prévios não foram suficientes para P4 e padrões de controle restrito de estímulos apareceram e, como também era objetivo deste trabalho corrigir possíveis controles deste tipo, foram propostos, continuamente, procedimentos de correção específicos e individualizados.

A variabilidade ocorre e é constantemente relatada por pesquisadores da área (Page \& Neuringer, 1985; Hunziker \& Moreno, 2000), como destacado anteriormente. E, nesta perspectiva, discussões relativas sobre qual o método mais eficiente de ensino para a leitura, traduzida pela dicotomia entre método global e silábico, tornam-se inócuas, s se o comportamento do pesquisador estiver sob controle do desempenho do participante. Quando isto ocorre, os procedimentos podem ser constantemente revistos, modificados e individualizados (Keller, 1979/1983), já que o comportamento do pesquisador não está sob controle de regras pré-desenvolvidas e mantidas a despeito do comportamento que é (ou deveria ser) seu objeto de análise.

Finalmente, vale apontar que pesquisas na Análise do Comportamento, com indivíduos com autismo e relacionadas ao estabelecimento ou ampliação do comportamento verbal, têm sido conduzidas preferencialmente com respostas baseadas na topografia, mais do que com respostas baseadas na seleção (Sundberg \& Partington, J. W. (1998). Nesse contexto, presente trabalho também pretende contribuir para o desenvolvimento de pesquisas que tenham como objetivo promover a aquisição do controle por unidades verbais mínimas e, por conseguinte, o ensino o comportamento de 
ler, via MTS, com indivíduos com desenvolvimento atípico, mais especificamente o autismo, com respostas baseadas na seleção de estímulos. 


\section{REFERÊNCIAS BIBLIOGRÁFICAS}

Alessi, G. (1987). Generative strategies and teaching for generalization. The Analysis of Verbal Behavior, 5, 15-27.

Allen, K. D., \& Fuqua, R. W. (1985). Eliminating selective stimulus control: A comparison of two procedures for teaching mentally retarded children to respond to compound stimuli. Journal of Experimental Psychology, 39, 55-71.

Andréa, V. \& Micheletto, N. (2005). Efeitos do treino de leitura na escrita de crianças. In: M. M. C. Hubner; M. Marinotti (org). (Org.). Análise do comportamento para a educação: contribuições recentes. Santo André: ESETec, p. 159-76.

Baldani, Diego M. e Piccolo, Gino C. C. (2008). EQUIVIUM - Um Ambiente para Coleta e Análise de Dados da Pesquisa em Equivalência e Controle por Unidades Mínimas. Trabalho de Conclusão de Curso. Universidade Municipal de São Caetano do Sul (USCS).

Bagaiolo, L., \& Micheletto, N. (2004). Fading e exclusão: aquisição de discriminações condicionais e classes de estímulos equivalentes. Temas em Psicologia, 12, p. 168-85, 2004.

Birnie-Selwyn, B., \& Guerin, B. (1997). Teaching children to spell: decreasing consonant cluster errors by eliminating selective stimulus control. Journal of applied behavior analysis, 30, 69-91. 
CID 10 - Classificação Estatística Internacional de Doenças e Problemas Relacionados à Saúde $\left(10^{a}\right.$ revisão). Organização Mundial de Saúde. Centro Colaborador da OMS para Classificação de Doenças, em Português. São Paulo: EDUSP, vol. 1, 1994.

Cumming, W. W., \& Berryman, R. (1965). The complex discriminated operant: studies of MTS and related problems. Em: D. I. Mostofsky (Org.). Stimulus Generalization. Stanford, C. A.: Stanford University.

Da Hora, C. L., \& Benvenuti, M. F. (2007). Controle restrito em uma tarefa de matching-to-sample com palavras e sílabas: avaliação do desempenho de uma criança diagnosticada com autismo. Revista Brasileira de Análise do Comportamento, 3, 29-45.

de Rose, J. C.; de Souza, D. G.; Rossito, A. L., \& de Rose, T. M. (1989). Aquisição de leitura após história de fracasso escolar: equivalência de estímulos e generalização. Psicologia: Teoria e Pesquisa, 5, 325-46.

de Rose, J. C.; de Souza, D. G., \& Hanna, E. S. (1996). Teaching reading and spelling: exclusion and stimulus equivalence. Journal of applied behavior analysis, 27, 451-69.

de Souza, D. G, \& de Rose, J.C. (2006). Desenvolvendo programas individualizados para o ensino de leitura. Acta Comportamentalia, 14, 77-98. 
Domeniconi, C. (2002). Análise de controle restrito de estímulos na aprendizagem de leitura de palavras por indivíduos com Síndrome de Down. Tese de Mestrado apresentada ao Programa de Pós-Graduação em Educação Especial da Universidade Federal de São Carlos.

DSM-IV (1995). Manual diagnóstico e estatístico de transtornos mentais. Porto Alegre: Artes Médicas.

Dube, W. V., \& McIlvane, W. J. (1999). Reduction of stimulus overselectivity with nonverbal differential observing responses. Journal of Applied Behavior Analysis, $32,25-33$

Galvão, O. F., Calcagno, S., \& Sidman, M. (1992). Testing for emergent performances in extinction. Experimental Analysis of Human Behavior Bulletin, 10, 18-20.

Gomes, R. C. (2007). Controle por unidades mínimas e leitura recombinativa: solicitação de comportamento textual durante aquisição de pré-requisitos. Tese de mestrado apresentada no Instituto de Psicologia na Universidade de São Paulo.

Guilhardi, C. (2003). Potencial preditivo do teste ABLA na aquisição de treinos de discriminações condicionais auditivo-visuais e teste de outras discriminações condicionais. Tese de mestrado apresentada na Pontifícia Universidade Católica de São Paulo, São Paulo. 
Hunziker, M. H. L. \& Moreno, R. (2000). Análise da noção de variabilidade comportamental. Psicologia: Teoria e Pesquisa, 16 (2), 135-143.

Hübner, M. M. (1990). Estudos em relações de equivalência: uma contribuição à investigação do controle por unidades verbais mínimas na aprendizagem de leitura com pré-escolares. Tese de doutorado apresentada no Instituto de Psicologia na Universidade de São Paulo.

Hübner, M. M. (2006). Controle de estímulos e relações de equivalência. Revista Brasileira de Terapia Comportamental e Cognitiva, 1, 95-102.

Hübner, M. M., Faggiani, R., Leite, M., Coelho, A. \& Bagaiolo, L. (2007). Matrix of performance during tests of control by minimal units in reading: analysis of multiple stimulus classes. Programa da 4a. Conferência Internacional $d a$ Associação de Análise do Comportamento, 27-27. Sidney University.

Keller, F. (1983). Behaviorismo aplicado desde John Watson. Em Kerbauy, R. R. (org.). Fred Simmons Keller; Psicologia. São Paulo: Editora Ática (col. Grandes Cientistas Sociais, 41). Publicação Original (1979).

Kerr, N., Meyerson, L. e Flora, J. A. (1977). The measurement of motor, visual, and auditory discrimination skills. Rehabilition Psychology, 24 (Monography Issue), 95-112. 
Koegel, R. L., \& Schereibman, L. (1977). Teaching autistic children to respond to simultaneous multiple cues. Journal of Experimental Child Psychology, 24, 299311.

Lee, V. L., \& Pegler, A. M. (1982). Effects on spelling of training children to read. Journal of experimental analysis of behavior, 37, 311-322.

Leite, M. K. S. Controle por unidades mínimas na leitura: análise do desempenho de pré-escolares em treinos e testes de discriminações condicionais entre palavras ditadas e impressas. Tese de Mestrado. Universidade de São Paulo, São Paulo, 2008

Lovaas, O. I., \& Schereibman, L. (1971). Stimulus overselectivity of autistic children in a two stimulus situation. Behavior Research and Therapy, 9, 305-310.

Lovaas, O. I., Schreibman, L., Koegel, R., \& Rehm, R. (1971). Selective responding by autistic children to multiple sensory input. Journal of Abnormal Psychology, 77, $211-222$

Loovas, O. I., Koegel, R. L., \& Schreibman, L. (1979). Stimulus overselectivity in autism: a review of research. Psychological Bulletin, 86, 1236-1254.

Mackay, H. A., \& Sidman, M. (1984). Teaching new behavior via equivalence relations. In P. H. Brooke, S. Sperber \& C. McCauley (Eds.), Learning and cognition in the mentally retarded (pp. 493-513). Hillsdale, N.J.: Erlbaum. 
Malheiros, R. H. S. (2002). Equivalência de Estímulos e Recombinação Silábica:

Aquisição de Leitura após Redução de Treino de Linha de Base e Testes de Equivalência e Generalização. Dissertação de Mestrado, Universidade Federal do Pará, Programa de Pós-Graduação em Teoria e Pesquisa do Comportamento.

Matos, M. A., \& Hübner, M. M. (1992). Equivalence relations and reading. Em S. C. Hayes e L. J. Hayes (Eds). Understanding verbal relations (pp. 83-94). Reno, NV: Context Press.

Matos, M. A., Hübner, M. M., \& Peres, W. (1997). Leitura generalizada: procedimentos e resultados? Em Banaco, R. A. (org.), Sobre Comportamento e Cognição (vol. 1, pp. 470-487). São Paulo: ARBytes.

Matos, M. A., Hübner, M. M., Serra, V. R. B. P., Basaglia, A. E., \& Avanzi, A. L. (2002). Redes de relações condicionais e leitura recombinativa: pesquisando o ensinar a ler. Arquivos Brasileiros de Psicologia, 54, 284-303.

Matos, M. A., Avanzi, A. L., \& McIllvane W. J. (2006). Rudimentary Reading Repertoires via Stimulus Equivalence and Recombination of Minimal Verbal Units. The Analysis of Verbal Behavior, 22, 3-19.

McIlvane, W. J. \& Dube, W. V. (1992). Stimulus control shaping and stimulus control topographies. The Behavior Analyst, 15, 89-94. 
McIlvane, W. J., Serna, R. W., Dube, W. V. \& Stromer, R. (2000). Stimulus control topography coherence and stimulus equivalence: reconciling test outcomes with theory. In J. C. Leslie \& D. Blackman (Eds.), Experimental and applied analysis of human behavior (85-110). Reno, NV.

Page, S. \& Neuringer, A. (1985). Variability is na Operant. Animal Behavior Processes, 11(3), 429-452.

Pimentel, E. P. (1996). Desenvolvimento de um sistema para pesquisa em equivalência e unidades verbais menores utilizando estruturas de dados para textos e imagem. Tese de mestrado apresentada na Universidade Mackenzie, SP.

Pimentel, E. P., Hübner, M. M., \& Matos, M. A. (1997). Desenvolvimento de um sistema para pesquisa em equivalência e unidades verbais menores utilizando estruturas de dados para texto e imagem. Anais do VI Encontro da Associação Brasileira de Psicoterapia e Medicina Comportamental. Santos: ABPMC.

Reynolds, G. S. (1961). Attention in the pigeon. Journal of the Experimental Analysis of Behavior, 4, 203-208.

Saraiva, L. Z. (2000). Uma análise comparativa de resultados em testes de vocabulários, inteligência, equivalência e generalização de leitura. Dissertação de Mestrado, Universidade Presbiteriana Mackenzie, São Paulo.

Sidman, M. (1960). Tatics of scientific research. New York: Basic Books. 
Sidman, M. (1971). Reading and auditory-visual equivalences. Journal of Speech and Hearing Research, 14, 5-13.

Sidman, M., \& Tailby, W. (1982). Conditional discrimination vs. matching to sample: an expansion of the testing paradigm. Journal of experimental analysis of behavior, 37, 5-22.

Sidman, M. (1994). Equivalence relations and behavior: A research story. Boston: Authors Cooperative.

Sidman, M. (2000). Equivalence relations and the reinforcement contingency. Journal of the Experimental Analysis of Behavior, 74, 127-146.

Skinner, B. F. (1992). Verbal Behavior. Acton, Mass., Copley Publishing Group. Publicação Original (1957).

Skinner, B. F. (1998). Ciência e Comportamento Humano. Martins Fontes, SP. Publicação Original (1953).

Walpole, C. W, Roscoe, E. M. \& Dube, W. V. (2007). Use of a differencial observing response to expand restricted stimulus control. Journal of Applied Behavior Analysis, 40, 707-712. 
ANEXO 1 


\section{Anexo 1}

\begin{tabular}{|c|l|l|l|l||l|}
\hline \multicolumn{3}{|c|}{ SUMÁRIO DE PROCEDIMENTOS } \\
\hline \hline Passos & Natureza do Estímulo & $\begin{array}{l}\text { Número de } \\
\text { Tentativas }\end{array}$ & Tipo de Tentativas & Critério & $\begin{array}{l}\text { Probabilidade de } \\
\text { Reforçamento }\end{array}$ \\
\hline
\end{tabular}

FASE 1: Teste de Nomeação Oral I.

\begin{tabular}{|l|l|l||l|l||l|}
\hline & I FIGURA & 12 & 3BOCA-3BOLO-3LOBO-3CABO & $100 \%$ & 1.0 \\
\hline \hline 1 IMPRESSA & 12 & 3BOCA-3BOLO-3LOBO-3CABO & - & 0 \\
\hline \hline 1 FIGURA & 12 & 3BALA-3CACO-3BOLA-3COCA & $100 \%$ & 1.0 \\
\hline \hline & 1 IMPRESSA & 12 & 3BALA-3CACO-3BOLA-3COCA & - & 0 \\
\hline
\end{tabular}

FASE 2: Pré - Treino de Cores.

\begin{tabular}{|l|l||l|l||l|l|}
\hline $\mathbf{2}^{\mathbf{a}}$ & 1COR-1COR & 8 & 2amarelo-2azul-2verde-2vermelho & $100 \%$ & 1.0 \\
\hline \hline 2B & 1COR-2COR & 8 & 2amarelo-2azul-2verde-2vermelho & $100 \%$ & 1.0 \\
\hline \hline 2C & 1COR-3COR & 12 & 3amarelo-3azul-3verde-3vermelho & $100 \%$ & 1.0 \\
\hline \hline 2D & 1COR-4COR & 16 & 4amarelo-4azul-4verde-4vermelho & $100 \%$ & 1.0 \\
\hline \hline 2E & 1ORAL-4COR & 12 & 3amarelo-3azul-3verde-3vermelho & $100 \%$ & 1.0 \\
\hline
\end{tabular}

FASE $5^{33}$ : Treino da Relação Pré-Requisito AB para o $1^{\circ}$ Conjunto.

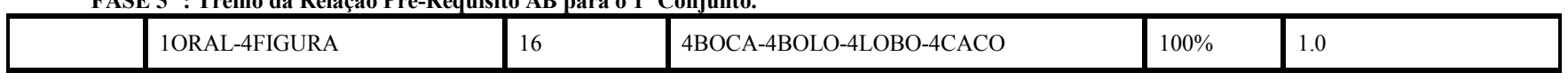

FASE 6: Treino da Relação Pré-Requisito AC para o $1^{\circ}$ Conjunto.

\begin{tabular}{|c|c|c|c|c|c|}
\hline $6^{\mathrm{a}}$ & 1ORAL-1IMPRESSA & 3 & 3BOCA & $100 \%$ & 1.0 \\
\hline $6 B$ & 1ORAL-2IMPRESSA & 6 & 3ВОСА-3LOBO & $100 \%$ & 1.0 \\
\hline $6 \mathrm{C}$ & 1ORAL-2IMPRESSA & 6 & 3BOCA-3BOLO & $100 \%$ & 1.0 \\
\hline 6D & 1ORAL-2IMPRESSA & 6 & 3BOLO-3CABO & $100 \%$ & 1.0 \\
\hline $6 E$ & 1ORAL-2IMPRESSA & 6 & 3LOBO-3CABO & $100 \%$ & 1.0 \\
\hline $6 \mathrm{~F}$ & 1ORAL-2IMPRESSA & 8 & 4BOCA-4CABO & $100 \%$ & 1.0 \\
\hline $6 G$ & 1ORAL-2IMPRESSA & 8 & 4BOLO-4LOBO & $100 \%$ & 1.0 \\
\hline $6 \mathrm{H}$ & 1ORAL-3IMPRESSA & 12 & 4BOCA-4CABO-4BOLO & $100 \%$ & 1.0 \\
\hline $6 I$ & 1ORAL-3IMPRESSA & 12 & 4BOLO-4LOBO-4BOCA & $100 \%$ & 1.0 \\
\hline $6 J$ & 1ORAL-3IMPRESSA & 12 & 4BOCA-4LOBO-4CABO & $100 \%$ & 1.0 \\
\hline $6 \mathrm{~L}$ & 1ORAL-3IMPRESSA & 12 & 4BOLO-4CABO-4LOBO & $100 \%$ & 1.0 \\
\hline $6 \mathrm{M}$ & 1ORAL-4IMPRESSA & 24 & 6BOCA-6BOLO-6LOBO-6CABO & $100 \%$ & 1.0 \\
\hline
\end{tabular}

Figura 19. Relação das fases pertencentes ao programa EQUIVIUM: passos, tipos de estímulos utilizados, número e tipo de tentativas previstas, critério de avanço e probabilidade de reforçamento utilizados para os Participantes 1,2 e 3.

33 Entre as Fases 2 e 5 não houve um seqüenciamento direto, pois as fases 3 e 4 foram canceladas ao longo do procedimento (Saraiva, 2000). 
FASE 7A: Treino AB e AC intercalados COM reforçamento para o $1^{\circ}$ Conjunto.

\begin{tabular}{|l|l|l||l||l||}
\hline \multirow{2}{*}{ 1ORAL-4FIGURA } & 12 & 3BOCA-3BOLO-3LOBO-3CABO & \\
\cline { 2 - 5 } & 1ORAL-4IMPRESSA & 12 & 3BOCA-3BOLO-3LOBO-3CABO & $100 \%$ \\
\hline
\end{tabular}

FASE 7B: Treino AB e AC intercalados SEM reforçamento para o $1^{\circ}$ Conjunto.

FASE 7B: Treino AB e AC intercalados SEM reforçamento para o 1 Conjunto.
\begin{tabular}{|l|l||l||l|}
\hline \multirow{2}{*}{ 1ORAL-4FIGURA } & 8 & 2BOCA-2BOLO-2LOBO-2CABO & - \\
\cline { 2 - 5 } & 1ORAL-4IMPRESSA & 8 & 2BOCA-2BOLO-2LOBO-2CABO \\
\hline
\end{tabular}

FASE 8A: Teste Combinado de Equivalência I para o $1^{\circ}$ Conjunto: $\mathrm{BC} / \mathrm{CB}$.

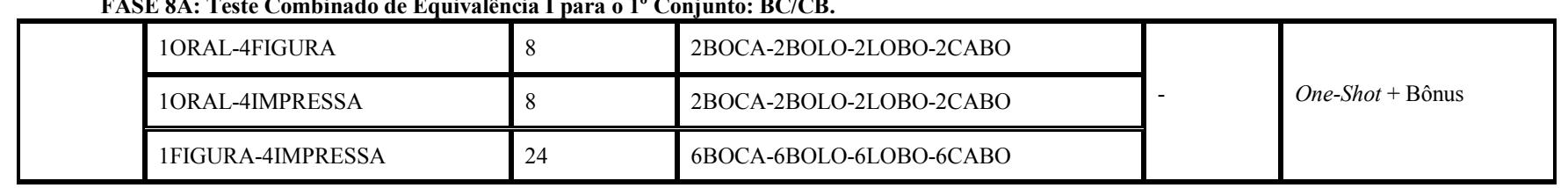

FASE 8B: Teste Combinado de Equivalência I para o $1^{\circ}$ Conjunto: CB.

\begin{tabular}{||l||l|l|l|||}
\hline \multicolumn{1}{||l||}{ 1ORAL-4FIGURA } & 8 & 2BOCA-2BOLO-2LOBO-2CABO \\
\cline { 2 - 5 } & 1ORAL-4IMPRESSA & 8 & 2BOCA-2BOLO-2LOBO-2CABO \\
\hline \hline 1IMPRESSA-4FIGURA & 24 & 6BOCA-6BOLO-6LOBO-6CABO & One-Shot + Bônus \\
\hline
\end{tabular}

FASE 8C: Teste Combinado de Equivalência I para o $1^{\circ}$ Conjunto: CB.

\begin{tabular}{|c|c|c|c|c|}
\hline 1ORAL-4FIGURA & 8 & 2BOCA-2BOLO-2LOBO-2CABO & & \multirow{4}{*}{ One-Shot + Bônus } \\
\hline 1ORAL-4IMPRESSA & 8 & 2BOCA-2BOLO-2LOBO-2CABO & & \\
\hline 1FIGURA-4IMPRESSA & 12 & 3BOCA-3BOLO-3LOBO-3CABO & & \\
\hline 1IMPRESSA-4FIGURA & 12 & 3BOCA-3BOLO-3LOBO-3CABO & & \\
\hline \multicolumn{5}{|l|}{ FASE 9: Anagrama I } \\
\hline 1 IMPRESSA & 12 & 3BOCA-3BOLO-3LOBO-3CABO & $100 \%$ & One-Shot + Bônus \\
\hline
\end{tabular}

FASE 10: Treino da Relação Pré-Requisito para o $2^{\circ}$ Conjunto: $A^{\prime} B^{\prime}$

\begin{tabular}{|c|c|c|c|c|}
\hline 1ORAL-4FIGURA & 16 & 4BALA-4CACO-4BOLA-4COCA & $100 \%$ & 1.0 \\
\hline \multicolumn{5}{|c|}{ FASE 11A: Teste das Novas Formas Verbais I para o $2^{\circ}$ Conjunto: $B^{\prime} C^{\prime}$. } \\
\hline 1ORAL-4FIGURA & 8 & 2BOCA-2BOLO-2LOBO-2CABO & \multirow{3}{*}{-} & \multirow{3}{*}{ One-Shot + Bônus } \\
\hline 1ORAL-4IMPRESSA & 8 & 2BOCA-2BOLO-2LOBO-2CABO & & \\
\hline 1FIGURA-4IMPRESSA & 24 & 6BALA-6CACO-6BOLA-6COCA & & \\
\hline
\end{tabular}

FASE 11B: Teste das Novas Formas Verbais I para o $2^{\circ}$ Conjunto: $C^{\prime} B^{\prime}$.

\begin{tabular}{||l||l|l|l|||}
\hline \hline \multicolumn{1}{||l|}{ 1ORAL-4FIGURA } & 8 & 2BOCA-2BOLO-2LOBO-2CABO \\
\cline { 2 - 5 } & 1ORAL-4IMPRESSA & 8 & 2BOCA-2BOLO-2LOBO-2CABO \\
\cline { 2 - 5 } & 1IMPRESSA-4FIGURA & 24 & 6BALA-6CACO-6BOLA-6COCA \\
\hline
\end{tabular}

FASE 12A: Reteste das Novas Formas Verbais I para o $2^{\circ}$ Conjunto: $B^{\prime} C^{\prime}$.

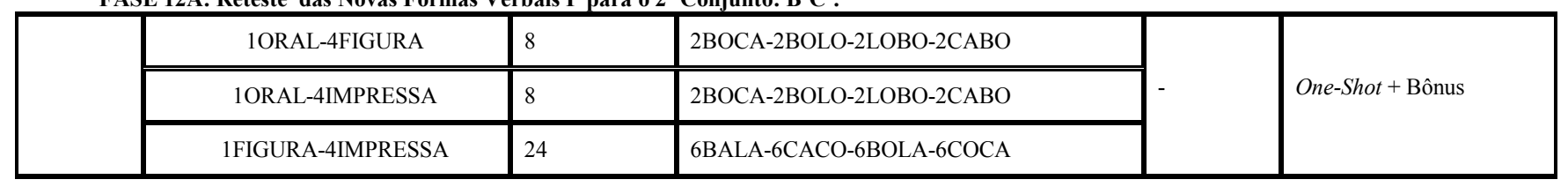

Figura 19 (continuação). Relação das fases pertencentes ao programa EQUIVIUM: passos, tipos de estímulos utilizados, número e tipo de tentativas previstas, critério de avanço e probabilidade de reforçamento utilizados para os Participantes 1, 2 e 3. 
FASE 12B: Reteste das Novas Formas Verbais I para o $2^{\circ}$ Conjunto: $C^{\prime} B$ '.

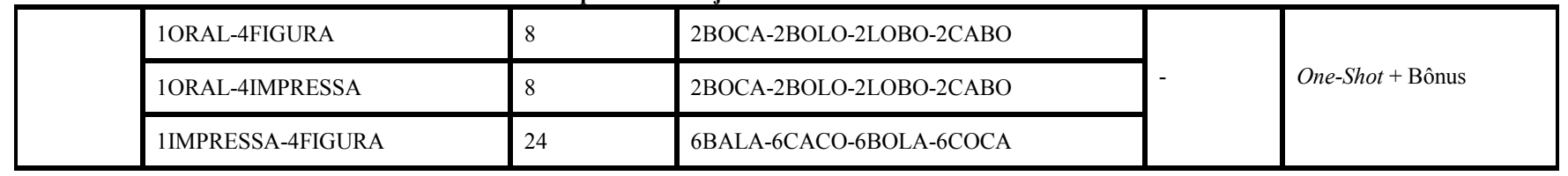

FASE 13: Teste de Nomeação Oral II.

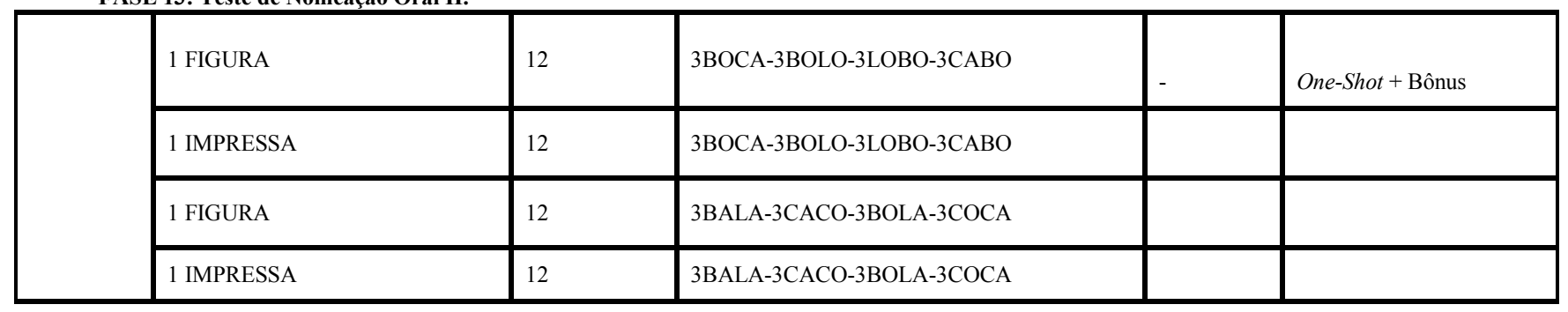

FASE 14: Treino da Relação Pré-Requisito $A^{\prime} C^{\prime}$ para o $2^{\circ}$ Conjunto.

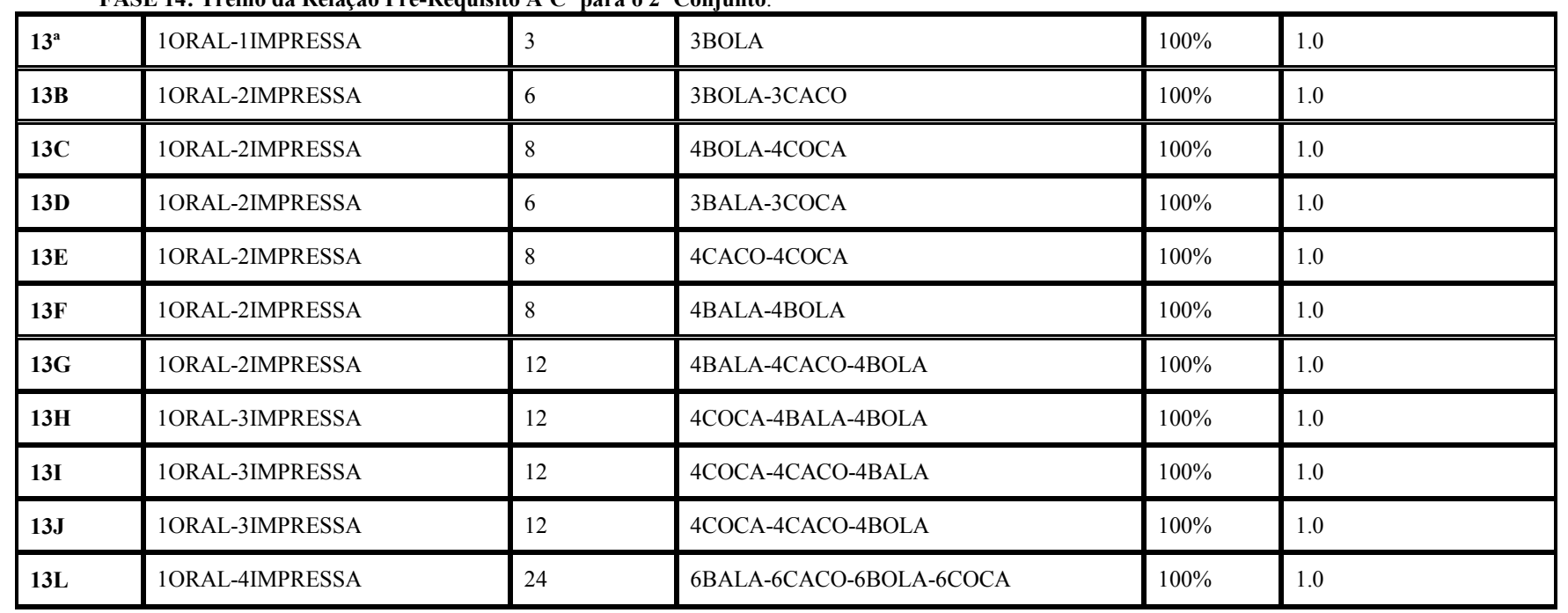

FASE 15A: Teste Combinado de Equivalência para o $2^{\circ}$ Conjunto: $B$ ' C'.

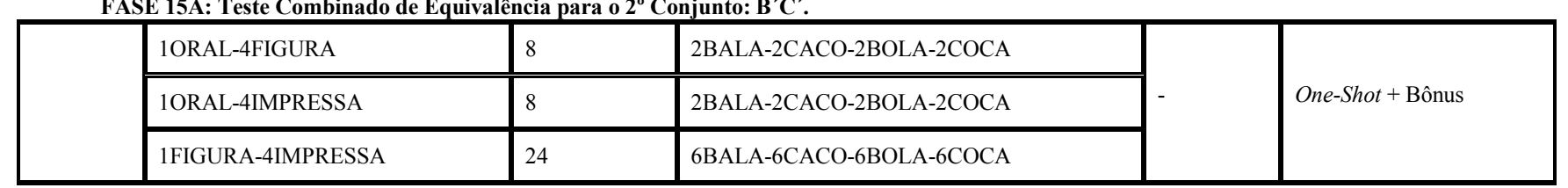

FASE 15B: Teste Combinado de Equivalência para o $2^{\circ}$ Conjunto: $C^{\prime} B$ '.

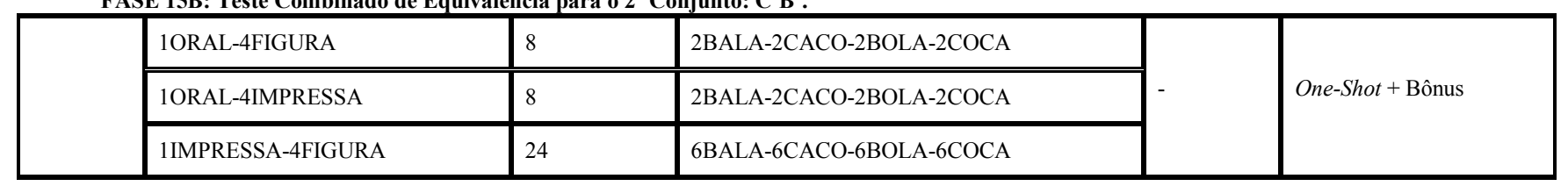

FASE 16: Anagrama II para o $2^{\circ}$ Conjunto $C^{\prime}$

\begin{tabular}{|l|l|l|l||l|l|l|}
\hline & 1 IMPRESSA & 12 & 3BALA- 3BOLA- 3COCA- 3CACO & $100 \%$ \\
\hline
\end{tabular}

Figura 19 (continuação). Relação das fases pertencentes ao programa EQUIVIUM: passos, tipos de estímulos utilizados, número e tipo de tentativas previstas, critério de avanço e probabilidade de reforçamento utilizados para os Participantes 1,2 e 3. 
FASE 17: Treino da Relação Pré-Requisito $A^{\prime \prime} B^{\prime \prime}$ para o $3^{\circ}$ Conjunto $^{34}$.

\begin{tabular}{|l|l|l|l||l|l|l|}
\hline & 1ORAL-4FIGURA & 16 & 4BOBO-4CALO-4LOCO-4LOLO & $100 \%$ \\
\hline
\end{tabular}

FASE 18A: Teste de Novas Formas Verbais II para o $3^{\circ}$ Conjunto: B" $\mathrm{C}^{\prime \prime}$.

\begin{tabular}{||l||l|l||l||}
\hline \multicolumn{1}{||}{ 1ORAL-4IMPRESSA } & 8 & 2LOBO-2CACO-2BOCA-2BOLO \\
\cline { 2 - 5 } & 1ORAL-4IMPRESSA & 8 & 2BALA-2CACO-2BOLA-2COCA \\
\cline { 2 - 5 } & 1FIGURA-4IMPRESSA & 24 & 6BOBO-6CALO-6LOCO-6LOLO \\
\hline
\end{tabular}

FASE 18 B: Teste de Novas Formas Verbais II para o $3^{\circ}$ Conjunto: $C^{\prime \prime} B^{\prime \prime}$.

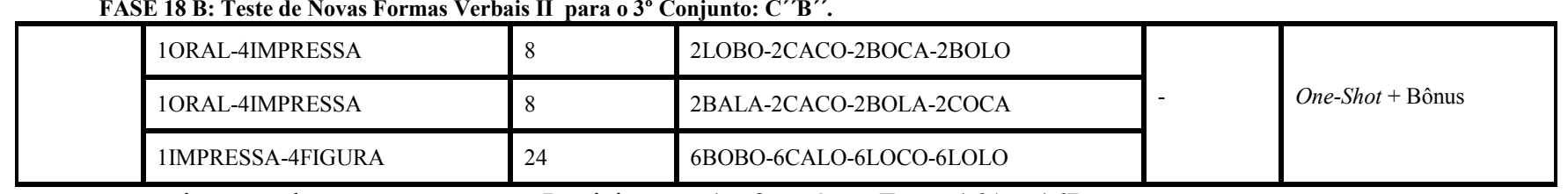

... continuação do programa para os Participantes 1 e 2, após as Fases 16A e 16B.

FASE 19: Teste de Nomeação Oral III ${ }^{35}$.

\begin{tabular}{|c|c|c|c|c|}
\hline 1 FIGURA & 8 & 2BOCA-2BOLO-2LOBO-2CABO & $100 \%$ & 1.0 \\
\hline 1 IMPRESSA & 8 & 2BOCA-2BOLO-2LOBO-2CABO & - & 0 \\
\hline 1 IMPRESSA & 8 & 2BALA-2CACO-2BOLA-2COCA & - & 0 \\
\hline 1 FIGURA & 8 & 2BOBO-2CALO-2LOCO-2LOLO & $100 \%$ & 1.0 \\
\hline 1 IMPRESSA & 8 & 2BOBO-2CALO-2LOCO-2LOLO & - & 0 \\
\hline
\end{tabular}

... continuação do programa para o Participante 3, após as Fases 16A e 16B

FASE 20: Treino da Relação Pré-Requisito $A^{\prime \prime} C^{\prime \prime}$ para o $3^{\circ}$ Conjunto.

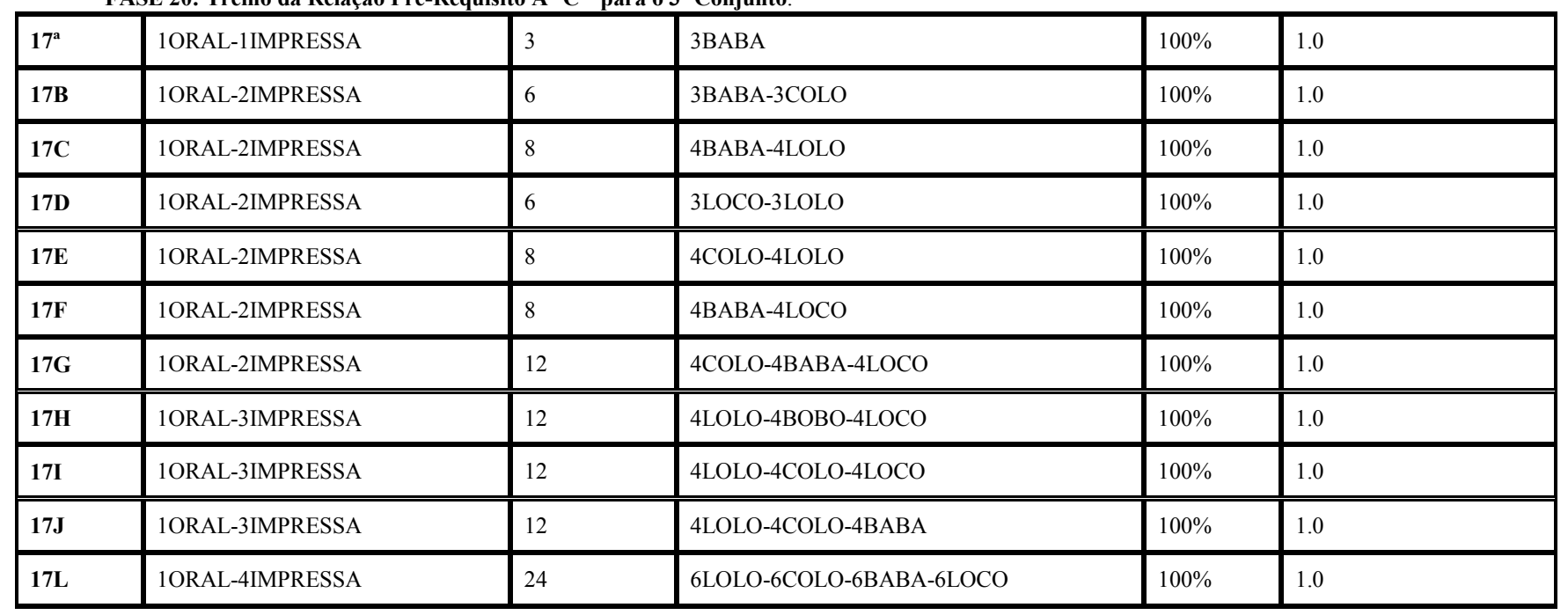

Figura 19 (continuação). Relação das fases pertencentes ao programa EQUIVIUM: passos, tipos de estímulos utilizados, número e tipo de tentativas previstas, critério de avanço e probabilidade de reforçamento utilizados para os Participantes 1,2 e 3 .

${ }^{34}$ Para o Participante 3, o terceiro conjunto de estímulos era diferente, como mencionado no Quadro 2. Os estímulos que envolviam palavras ditadas e as respectivas figuras e palavras impressas eram os seguintes: LOLO, BABA, COLO e LOCO.

${ }^{35}$ A Fase 17, como Teste de nomeação oral, III não aplicada ao Participante 3; este participante será exposto a esta etapa de teste em uma fase chamada como Fase 21. 
FASE 21A: Teste Combinado de Equivalência para o $3^{\circ}$ Conjunto: B" C"

\begin{tabular}{||l||l|l|l|||}
\hline 1ORAL-4FIGURA & 8 & 2BOBO-2LOCO-2CALO-2LOLO \\
\cline { 2 - 5 } & 1ORAL-4IMPRESSA & 8 & 2BOBO-2LOCO-2CALO-2LOLO \\
\cline { 2 - 5 } & 1FIGURA-4IMPRESSA & 24 & 6BOBO-6LOCO-6CALO-6LOLO \\
\hline
\end{tabular}

FASE 21B: Teste Combinado de Equivalência para o $3^{\circ}$ Conjunto: $C^{\prime \prime} B^{\prime \prime}$.

\begin{tabular}{||l||l|l|l|||}
\hline \hline \multirow{2}{*}{} & 1ORAL-4FIGURA & 8 & 2BOBO-2LOCO-2CALO-2LOLO \\
\cline { 2 - 5 } & 1ORAL-4IMPRESSA & 8 & 2BOBO-2LOCO-2CALO-2LOLO \\
\cline { 2 - 4 } & 1IMPRESSA-4FIGURA & 24 & 6BOBO-6LOCO-6CALO-6LOLO \\
\hline
\end{tabular}

FASE 22: Treino da Relação Pré-Requisito $A^{\prime \prime} B^{\prime \prime}$ para $04^{\circ}$ Conjunto ${ }^{36}$.

\begin{tabular}{|l||l|l|l||l|l|l|}
\hline \hline & 1ORAL-4FIGURA & 16 & 4BABO-4LOLA-4CACA-4COCO & $100 \%$ & 1.0 & \\
\hline
\end{tabular}

FASE 23A: Teste de Novas Formas Verbais III para o $4^{\circ}$ Conjunto: B"' $\mathrm{C}^{\prime \prime \prime}$.

\begin{tabular}{||l||l|l|l|||}
\hline \hline \multicolumn{1}{||l|}{ 1ORAL-4IMPRESSA } & 8 & 2BABO-2LOLA-2CACA-2COCO \\
\cline { 2 - 5 } & 1ORAL-4IMPRESSA & 8 & 2BABO-2LOLA-2CACA-2COCO \\
\cline { 2 - 5 } & 1FIGURA-4IMPRESSA & 24 & 6BABO-6LOLA-6CACA-6COCO One-Shot + Bônus \\
\hline
\end{tabular}

FASE 23B: Teste de Novas Formas Verbais III para o $4^{\circ}$ Conjunto: $C^{\prime \prime} B^{\prime \prime \prime}$.

\begin{tabular}{||l||l|l|l|||}
\hline \multicolumn{1}{||}{$\mid$ 1ORAL-4IMPRESSA } & 8 & 2BABO-2LOLA-2CACA-2COCO \\
\cline { 2 - 5 } & 1ORAL-4IMPRESSA & 8 & 2BABO-2LOLA-2CACA-2COCO \\
\cline { 2 - 5 } & 1IMPRESSA-4FIGURA & 24 & 6BABO-6LOLA-6CACA-6COCO \\
\hline
\end{tabular}

FASE 24: Teste de Nomeação Oral III.

\begin{tabular}{|l||l|l|l||}
\hline \hline $\mathbf{2 1}$ & 1 FIGURA & 16 & 4BOCA-4BOLO-4LOBO-4CABO \\
\hline \hline $\mathbf{2 1 B}$ & 1 IMPRESSA & 16 & 4BOCA-4BOLO-4LOBO-4CABO \\
\hline $\mathbf{2 1 C}$ & 1 FIGURA & 16 & 4BALA-4CACO-4BOLA-4COCA \\
\hline \hline $\mathbf{2 1 D}$ & 1 IMPRESSA & 16 & 4BALA-4CACO-4BOLA-4COCA \\
\hline \hline $\mathbf{2 1 E}$ & 1 FIGURA & 16 & 4LOLO-4BABA-4COLO-4LOCO \\
\hline \hline $\mathbf{2 1 F}$ & 1 IMPRESSA & 16 & 4 LOLO-4BABA-4COLO-4LOCO \\
\hline $\mathbf{2 1 G}$ & 1 FIGURA & 16 & 4BABO-4LOLA-4COCO-4CACA \\
\hline \hline $\mathbf{2 1 H}$ & 1 IMPRESSA & 16 & 4BABO-4LOLA-4COCO-4CACA \\
\hline
\end{tabular}

Figura 19 (continuação). Relação das fases pertencentes ao programa EQUIVIUM: passos, tipos de estímulos utilizados, número e tipo de tentativas previstas, critério de avanço e probabilidade de reforçamento utilizados para os Participantes 1,2 e 3.

\footnotetext{
${ }^{36}$ Apenas para o Participante 3.
} 
ANEXO 2 


\section{Anexo 2}

Com o objetivo de sistematizar os dados, foram criadas matrizes que foram denominadas como figuras e são relativas aos dados dos erros dos Participantes 1,2 e 3 , em diferentes Fases do programa:

- Treinos: 1. AC, $\mathrm{A}^{\prime} \mathrm{C}^{\prime}, \mathrm{A}^{\prime \prime} \mathrm{C}^{\prime \prime}$; este último apenas para o Participante 3.

. Treinos de Anagrama I e II.

- Testes: 1. Testes de Equivalência (testes $\mathrm{BC} / \mathrm{CB}^{37}$ e ${ }^{38}, \mathrm{~B}^{\prime} \mathrm{C}^{\prime} / \mathrm{C}^{\prime} \mathrm{B}^{\prime}$, $\mathrm{B}^{\prime \prime} \mathrm{C}^{\prime \prime} / \mathrm{C}^{\prime \prime} \mathrm{B}^{\prime \prime}$, realizados após o treino direto entre palavras ditadas e palavras impressas), 2. Testes de Novas Formas Verbais (testes $\mathrm{B}^{\prime} \mathrm{C}^{\prime} / \mathrm{C}^{\prime} \mathrm{B}^{\prime}, \mathrm{B}^{\prime \prime} \mathrm{C}^{\prime \prime} / \mathrm{C}^{\prime \prime} \mathrm{B}^{\prime \prime}$, $\mathrm{B}^{\prime \prime \prime} \mathrm{C}^{\prime \prime} / \mathrm{C}^{\prime \prime \prime} \mathrm{B}^{\prime \prime \prime}$-este último apenas para o Participante 3- realizados após o treino entre palavras ditadas e respectivas figuras, sem o treino direto entre palavras ditadas e palavras impressas) e 3. Testes de Nomeação das palavras impressas realizados em dois momentos diferentes do programa (na metade, aproximadamente e, no final); os erros ocorridos no primeiro Teste de Nomeação, que foi a primeira Fase do programa, não foram contabilizados aqui pois foram realizados a título de 'Pré-Teste' e foram comuns a todos os participantes.

Nas Fases de treino e teste nas quais não ocorreu nenhum erro não foi feita nenhuma matriz; todos os erros realizados durante o programa estão sistematizados, neste Anexo, nas Figuras 20 a 25 (relativas aos dados do Participante 1), nas Figuras 26

\footnotetext{
${ }^{37}$ No caso deste estudo, tentativas do tipo BC (tanto nos Testes de Equivalência quanto nos Testes de Novas Formas Verbais) são aquelas em que os estímulos modelos são formados por figuras e os estímulos escolha são formados por palavras impressas.

${ }^{38}$ Nas matrizes deste Anexo 2, as tentativas do tipo CB são destacadas com quadrados preenchidos com riscos oblíquos à direita e com o número de erros em negrito. Esses erros não serão contabilizados como contendo diferenças críticas ou não porque os estímulos de escolha positivos e negativos, formados por figuras, não tem uma divisão clara e uniforme dos elementos destes supostos estímulos compostos (figuras). Já, os estímulos compostos formados por palavras impressas, que compõe os estímulos escolha negativos e positivos em tentativas do tipo $\mathrm{AC}, \mathrm{BC}$ e, de certa forma, as tentativas de nomeação, são formados pelos elementos identificados neste trabalho como letras e sílabas e, portanto, podem ser comparados entre si, diferentemente das figuras.
} 
a 35 (relativas aos dados do Participante 2) e nas Figuras 36 a 41 (relativas aos dados do Participante 3). Nestas figuras, na parte vertical estão localizados os estímulos modelos (M) e na parte superior e horizontal estão localizados os estímulos de escolha (E) ou relacionados às respostas dos participantes (ex.: nomeação e construção), os números dentro de cada quadrado da matriz são relativos aos números de erros ocorridos durante as tentativas de treino ou teste que compreendiam os estímulos modelo e de escolha positivos e negativos relacionados; por exemplo, na Figura 20, nas tentativas de Treino AC em que o estímulo modelo "boca" foi apresentado, duas vezes o Participante 1 escolheu, erroneamente, o estímulo de escolha negativo LOBO, seis vezes BOLO e duas vezes CABO ao invés de escolher o estímulo de escolha positivo BOCA.

\section{Participante 1:}

Na Figura 20 estão os dados relativos à ocorrência de erros, do Participante 1, durante as tarefas de MTS relativas ao Treino AC (para o primeiro conjunto de estímulos); os estímulos modelo são palavras ditadas e os estímulos de escolha positivos e negativos são palavras impressas.

Na Figura 20 é possível observar que nas tentativas em que o estímulo modelo auditivo, a palavra ditada "boca", foi apresentado ao Participante 1, ocorreram dez erros:

$\mathrm{M}=$ modelo $-\mathrm{E}=$ escolha

\begin{tabular}{|c|c|c|c|c|}
\hline M/E & boca & lobo & bolo & cabo \\
\hline boca & - & 2 & 6 & 2 \\
\hline lobo & - & - & 1 & - \\
\hline bolo & 6 & 2 & - & 5 \\
\hline cabo & 4 & 2 & 1 & - \\
\hline
\end{tabular}

Figura 20. Matriz com erros do Participante 1, nas tentativas do Treino AC, para o primeiro conjunto de estímulos. 
duas vezes ele escolheu como estímulos de escolha negativos a palavra impressa LOBO e a palavra impressa $\mathrm{CABO}$ e, seis vezes escolheu a palavra impressa BOLO, em detrimento da escolha do estímulo de escolha positivo, a palavra impressa BOCA.

Durante as tentativas em que o estímulo modelo auditivo "lobo" foi apresentado, o Participante 1 realizou apenas um erro escolhendo o seguinte estímulo de escolha: a palavra impressa BOLO. Quando o estímulo modelo "bolo" foi apresentado ocorreram treze erros: seis vezes o participante escolheu os estímulos de escolha negativos representados, respectivamente, pelas palavras impressas BOCA e CABO (cinco vezes); também perante a palavra ditada "bolo" (estímulo modelo auditivo) o Participante 1 escolheu novamente duas vezes a palavra impressa LOBO (estímulo de escolha negativo), realizando dois erros.

Finalmente, ainda durante o Treino AC, durante as tentativas de apresentação do estímulo modelo auditivo formado pela palavra ditada "cabo", o Participante 1 escolheu quatro vezes a palavra impressa BOCA; escolheu também uma vez o estímulo de escolha negativo LOBO e BOLO (este em duas tentativas).

Como indica a Figura 21, o Participante 1 realizou dois erros durante o Treino de Anagrama I, nas tentativas de construção da palavra BOLO, construiu erroneamente a palavra impressa BOLO, invertendo as sílabas, selecionando LO como primeira sílaba e BO como segunda sílaba, formando o estímulo negativo: palavra impressa LOBO. Para esta fase, também eram expostos estímulos sobressalentes aqueles que estavam sendo treinados (MA e TA). 
$\mathrm{M}=$ modelo $-\mathrm{C}=$ construção

\begin{tabular}{|c|c|c|c|c|}
\hline $\mathbf{M} / \mathrm{C}$ & bo & lo & ca & $\mathbf{m a} / \mathbf{t a}$ \\
\hline boca & - & - & - & - \\
\hline lobo & - & - & - & - \\
\hline bolo & 1 & 1 & - & - \\
\hline cabo & - & - & - & - \\
\hline
\end{tabular}

Figura 21. Matriz com erros do Participante 1, nas tentativas de Treino de Construção (Anagrama I), para o primeiro conjunto de estímulos.

O Participante 1 não realizou nenhum erro durante o Teste de Equivalência I, para o primeiro conjunto de estímulos. Porém, durante o Teste de Novas Formas Verbais I $\left(\mathrm{B}^{\prime} \mathrm{C}^{\prime} / \mathrm{C}^{\prime} \mathrm{B}^{\prime}\right)$, que ocorreu após o treino entre palavras ditadas e as figuras do segundo conjunto de estímulos (Treino A'B'), sem o treino direto entre palavras ditadas e impressas (Treino $\mathrm{A}^{\prime} \mathrm{C}^{\prime}$ ), foi observada a ocorrência de erros, como pode ser observada na Figura 21. Perante uma das tentativas do tipo BC com o estímulo modelo formado pela figura de caco, o Participante 1 escolheu uma vez o estímulo de escolha negativo formado pela palavra impressa BALA.

Como pode ser visualizado na Figura 22, houve uma tentativa do tipo CB na qual o estímulo modelo era formado pela palavra impressa BOLA e este participante escolheu o estímulo de escolha negativo formado pela figura de bala; erros advindos de tentativas do tipo $\mathrm{CB}$ não foram passíveis de serem contabilizados, como contendo diferenças críticas ou diferenças múltiplas, por conta da característica dos estímulos de escolha e são marcados nas figuras deste anexo por meio do quadrado com riscos oblíquos e em negrito ou com asteriscos quando os pares de estímulos foram coincidentes com tentativas $\mathrm{BC}$, que foram categorizados posteriormente como contendo diferenças críticas ou múltiplas. 
$\mathrm{M}=$ modelo $-\mathrm{E}=$ escolha

\begin{tabular}{|c|c|c|c|c|}
\hline $\mathbf{M} / \mathbf{E}$ & caco & bala & coca & bola \\
\hline caco & - & 1 & - & - \\
\hline bala & - & - & - & - \\
\hline coca & - & - & - & - \\
\hline bola & - & TIIII & - & - \\
\hline
\end{tabular}

Figura 22. Matriz com erros do Participante 1, nas tentativas de Teste de Novas Formas Verbais I (BC/CB), para o segundo conjunto de estímulos.

O Participante 1 não apresentou erros durante o Teste de Nomeação Oral II (realizado após o Teste de Novas Formas Verbais $\mathrm{I}-\mathrm{B}^{\prime} \mathrm{C}^{\prime} / \mathrm{C}^{\prime} \mathrm{B}^{\prime}$ ) das palavras impressas relativas aos primeiro e segundo conjuntos de estímulos'.

Durante o segundo treino de discriminações condicionais entre palavras ditadas e palavras impressas para o segundo conjunto de estímulos (Treino $\mathrm{A}^{\prime} \mathrm{C}^{\prime}$ ) foi observada a ocorrência de um erro, como pode ser observado na Figura 23. Perante a tentativa com o estímulo modelo formado pela palavra ditada "caco", o Participante 1 escolheu o estímulo de escolha negativo formado pela palavra impressa BOLA.

$\mathrm{M}=$ modelo $-\mathrm{C}=$ escolha

\begin{tabular}{|c|c|c|c|c|}
\hline $\mathbf{M} / \mathbf{C}$ & caco & bala & coca & bola \\
\hline caco & - & - & - & 1 \\
\hline bala & - & - & - & - \\
\hline coca & - & - & - & - \\
\hline bola & - & - & - & - \\
\hline
\end{tabular}

Figura 23. Matriz com erros do Participante 1, nas tentativas de Treino $\mathrm{A}^{\prime} \mathrm{C}^{\prime}$, para o segundo conjunto de estímulos.

Durante o Teste de Equivalência II $\left(\mathrm{B}^{\prime} \mathrm{C}^{\prime} / \mathrm{C}^{\prime} \mathrm{B}^{\prime}\right)$, realizado após o Treino $\mathrm{A}^{\prime} \mathrm{C}^{\prime}$, também foi observada a ocorrência de erros, como pode ser observada na Figura 24. Perante uma tentativa, do tipo BC, com o estímulo modelo formado pela figura de caco, 
o Participante 1 escolheu uma vez o estímulo de escolha negativo formado pela palavra impressa BOLA.

Também pode ser observado na Figura que o Participante 1 realizou um erro perante uma tentativa $\mathrm{CB}$, que não foi contabilizado como contendo diferenças críticas ou múltiplas; perante o estímulo modelo formado pela palavra impressa BOLA, este participante escolheu o estímulo de escolha negativo formado pela figura de coca, este erro está destacado na Figura 24 por meio do quadrado com riscos oblíquos e em negrito.

$\mathrm{M}=$ modelo $-\mathrm{E}=$ escolha

\begin{tabular}{|c|c|c|c|c|}
\hline $\mathbf{M} / \mathbf{E}$ & caco & bala & coca & bola \\
\hline caco & - & - & - & 1 \\
\hline bala & - & - & - & - \\
\hline coca & - & - & - & - \\
\hline bola & - & - & TII & - \\
\hline
\end{tabular}

Figura 24. Matriz com erros do Participante 1, nas tentativas do Teste de Equivalência II ( $\left(\mathrm{B}^{\prime} \mathrm{C}^{\prime} / \mathrm{C}^{\prime} \mathrm{B}^{\prime}\right)$, para o segundo conjunto de estímulos.

Durante o Teste de Novas Formas Verbais II ( $\left.\mathrm{B}^{\prime} \mathrm{C}^{\prime} / \mathrm{C}^{\prime} \mathrm{B}^{\prime}\right)$ que ocorreu após o treino do terceiro entre palavras ditadas/figuras do conjunto de estímulos (Treino $\left.\mathrm{A}^{\prime \prime} \mathrm{B}^{\prime \prime}\right)$, sem o treino direto entre palavras ditadas e impressas, foi observada a ocorrência de apenas um erro, como pode ser observado na Figura 25. Perante a tentativas com o estímulo modelo formado pela figura de lolo, o Participante 1 escolheu o estímulo de escolha negativo formado pela palavra impressa LOCA. 
$\mathrm{M}=$ modelo $-\mathrm{E}=$ escolha

\begin{tabular}{|c|c|c|c|c|}
\hline M/E & bobo & calo & lolo & loca \\
\hline bobo & - & - & - & - \\
\hline calo & - & - & - & - \\
\hline lolo & - & - & - & 1 \\
\hline loca & - & - & - & - \\
\hline
\end{tabular}

Figura 25. Matriz com erros do Participante 1, nas tentativas do Teste de Novas Formas Verbais II $\left(\mathrm{B}^{\prime \prime} \mathrm{C}^{\prime \prime} / \mathrm{C}^{\prime \prime} \mathrm{B}^{\prime \prime}\right)$, para o terceiro conjunto de estímulos.

O Participante 1 também não apresentou erros durante o Teste de Nomeação Oral III (realizado após o Teste de Novas Formas Verbais II - $\mathrm{B}^{\prime \prime} \mathrm{C}^{\prime \prime} / \mathrm{C}^{\prime \prime} \mathrm{B}^{\prime \prime}$ ) das figuras e palavras impressas relativas aos primeiro, segundo e terceiro conjuntos de estímulos.

\section{Participante 2:}

Na Figura 26 estão os dados relativos à ocorrência de erros, do Participante 2, durante as tarefas de MTS relativas ao Treino AC, para o primeiro conjunto de estímulos. Na figura abaixo é possível observar a ocorrência de nove erros nas tentativas de Treino AC; quando o estímulo modelo auditivo, a palavra ditada "boca", foi apresentado ao Participante 2, ocorreram quatro erros pois ele escolheu como estímulo de escolha negativo a palavra impressa BOLO nestas tentativas e, inversamente, quando o estímulo modelo auditivo apresentado quatro vezes foi "bolo" os estímulos comparações negativos escolhidos foram BOCA, em detrimento da escolha dos respectivos estímulos de escolha positivos. 
$\mathrm{M}=$ modelo $-\mathrm{E}=$ escolha

\begin{tabular}{|c|c|c|c|c|}
\hline $\mathbf{M} / \mathbf{E}$ & boca & lobo & bolo & cabo \\
\hline boca & - & - & 4 & - \\
\hline lobo & - & - & 1 & - \\
\hline bolo & 4 & - & - & - \\
\hline cabo & - & - & - & - \\
\hline
\end{tabular}

Figura 26. Matriz com erros do Participante 2, nas tentativas de Treino AC, para o primeiro conjunto de estímulos.

O Participante 2 realizou cinco erros durante o Teste de Equivalência I (BC/CB) para o primeiro conjunto de estímulos, como pode ser observado na Figura 27. Perante uma tentativa do tipo $\mathrm{BC}$, com o estímulo modelo formado pela figura de boca, o Participante 2 escolheu o estímulo de escolha negativo formado pela palavra impressa CABO.

$\mathrm{M}=$ modelo $-\mathrm{E}=$ escolha

\begin{tabular}{|l|c|c|c|c|}
\hline M/E & boca & lobo & bolo & cabo \\
\hline boca & - & $1-\mathbf{1}^{*}$ & 1 & 1 \\
\hline lobo & - & - & - & - \\
\hline bolo & - & TIIII & - & - \\
\hline cabo & - & - & - & - \\
\hline
\end{tabular}

Figura 27. Matriz com erros do Participante 2, nas tentativas do Testes de Equivalência I (BC/CB), para o primeiro conjunto de estímulos.

Além desses erros, é possível observar na Figura 27 a ocorrência de dois erros, em tentativas do tipo BC, do Teste de Equivalência I; quando o estímulo modelo formado pela figura de boca, foi apresentado ao Participante 2, ocorreram erros pois ele escolheu uma vez, como estímulo de escolha negativo, a palavra impressa BOLO e escolheu uma vez a palavra impressa LOBO. 
Também pode ser observado na Figura 26 que o Participante 2 realizou erros perante duas tentativas, que também não foram contabilizados como contendo diferenças críticas ou múltiplas. Em uma das tentativas, perante o estímulo modelo formado pela palavra impressa BOLO, este participante escolheu o estímulo de escolha negativo formado pela figura de lobo. Este erro está destacado na Figura 27 por meio do quadrado com riscos oblíquos e em negrito.

Ainda houve outro erro realizado em uma tentativa do tipo CB: perante o estímulo modelo formado pela palavra impressa BOCA, este participante escolheu o estímulo de escolha negativo formado pela figura de lobo. Este erro está destacado na Figura 27 por meio de um asterisco, pois envolve os mesmos estímulos daquele erro que poderá ser categorizado como contendo diferenças críticas ou múltiplas, em tentativas do tipo BC.

No Teste de Novas Formas Verbais I $\left(\mathrm{B}^{\prime} \mathrm{C}^{\prime} / \mathrm{C}^{\prime} \mathrm{B}^{\prime}\right)$ que ocorreu após o treino entre palavras ditadas e as figuras do segundo conjunto de estímulos (Treino A'B'), sem o treino direto entre palavras ditadas e impressas (Treino $\mathrm{A}^{\prime} \mathrm{C}^{\prime}$ ), foi observada a ocorrência de nove erros, como pode ser observado na Figura 28.

$\mathrm{M}=$ modelo $-\mathrm{E}=$ escolha

\begin{tabular}{|c|c|c|c|c|}
\hline $\mathbf{M} / \mathbf{E}$ & caco & bala & coca & bola \\
\hline caco & - & 2 & - & - \\
\hline bala & - & - & 2 & पl! \\
\hline coca & - & 1 & - & 2 \\
\hline bola & - & - & 1 & - \\
\hline
\end{tabular}

Figura 28. Matriz com erros do Participante 2, nas tentativas de Testes de Novas Formas Verbais I $\left(\mathrm{B}^{\prime} \mathrm{C}^{\prime} / \mathrm{C}^{\prime} \mathrm{B}^{\prime}\right)$, para o segundo conjunto de estímulos.

Perante duas das tentativas do tipo $\mathrm{BC}$, com o estímulo modelo formado pela figura de bala, o Participante 2 escolheu os estímulos de escolha negativos formado 
pela palavra impressa COCA; em uma outra tentativa BC com o estímulo modelo formado pela figura de coca este participante escolheu o estímulo de escolha negativo BALA. Em outras duas tentativas BC com o estímulo modelo formado pela figura caco o participante escolheu o estímulo de escolha negativo BALA.

Outro erro ocorreu quando o estímulo modelo formado pela figura de bola foi apresentado a este participante, já que este escolheu o estímulo de escolha negativo formado pela palavra impressa COCA; em duas outras tentativas com o estímulo modelo formado pela figura de coca este participante escolheu o estímulo de escolha negativo BOLA.

Na Figura 28 pode ser observado que o Participante 2 realizou um erro em tentativas do tipo $\mathrm{CB}$ que, como ressaltado anteriormente, não foram contabilizados como passíveis de conter diferenças críticas ou múltiplas. Diante do estímulo modelo formado pela palavra impressa BALA, este participante escolheu o estímulo de escolha negativo formado pela figura de bola. Este erro está destacado na Figura 28 por meio do quadrado com riscos oblíquos e em negrito.

No Teste de Nomeação Oral II, (realizado após o Teste de Novas Formas Verbais $\left.\mathrm{I}-\mathrm{B}^{\prime} \mathrm{C}^{\prime} / \mathrm{C}^{\prime} \mathrm{B}^{\prime}\right)$, relativo às palavras impressas relacionadas aos primeiro e segundo conjuntos de estímulos, este participante errou a nomeação de quatro palavras impressas do segundo conjunto de estímulos com referências a palavras do primeiro conjunto de estímulos, como pode ser visualizado na Figura 29, a saber: 1. Quando foi apresentada a palavra impressa COCA, a resposta de nomeação foi "cabo", que é uma palavra do primeiro conjunto de estímulos e 2. Durante as três vezes em que a palavra impressa BOLA foi apresentada, o participante exibiu a resposta de nomeação "boca". 
$\mathrm{M}=$ modelo $-\mathrm{N}=$ Possíveis resposta de nomeação

\begin{tabular}{|c|c|c|c|c|}
\hline $\mathbf{M} / \mathbf{N}$ & caco & bala & coca & bola \\
\hline caco & - & - & - & - \\
\hline bala & - & - & - & - \\
\hline coca* & - & - & - & - \\
\hline bola** $^{*}$ & - & - & - & - \\
\hline
\end{tabular}

* O participante emitiu a resposta de nomeação "cabo".

** O participante emitiu, três vezes, a resposta de nomeação "boca".

Figura 29. Matriz com erros do Participante 2, nas tentativas do Teste de Nomeação Oral II (conjuntos C e $\left.\mathrm{C}^{\prime}\right)$.

Durante o segundo treino de discriminações condicionais entre palavras ditadas e palavras impressas para o segundo conjunto de estímulos (Treino $\mathrm{A}^{\prime} \mathrm{C}^{\prime}$ ) foi observada a ocorrência de dois erros, como pode ser observado na Figura 30. Perante a tentativa com o estímulo modelo auditivo formado pela palavra "bola", o Participante 2 escolheu o estímulo de escolha negativo formado pela palavra impressa BALA. O outro erro também ocorreu em uma tentativa com o estímulo modelo auditivo "bola": a escolha foi o estímulo de escolha negativo COCA.

$\mathrm{M}=$ modelo $-\mathrm{C}=$ escolha

\begin{tabular}{|c|c|c|c|c|}
\hline $\mathbf{M} / \mathbf{C}$ & caco & bala & coca & bola \\
\hline caco & - & - & - & - \\
\hline bala & - & - & - & - \\
\hline coca & - & - & - & - \\
\hline bola & - & 1 & 1 & - \\
\hline
\end{tabular}

Figura 30. Matriz com erros do Participante 2 nas tentativas de Treino A'C', para o segundo conjunto de estímulos.

Durante o Teste de Equivalência II ( $\left.\mathrm{B}^{\prime} \mathrm{C}^{\prime} / \mathrm{C}^{\prime} \mathrm{B}^{\prime}\right)$, realizado após o Treino $\mathrm{A}^{\prime} \mathrm{C}^{\prime}$, também foi observada a ocorrência de sete erros, como pode ser observada na Figura 
31. Um deles ocorreu quando o estímulo modelo era formado pela figura de coca e o Participante 2 escolheu o estímulo de escolha negativo formado pela palavra impressa CACO e, os outros dois erros ocorreram, em duas tentativas em que o estímulo modelo formado pela figura de bola foi apresentado e a escolha do Participante 2, ao invés de ser feita pelo estímulo de escolha positivo, foi feita para o estímulo de escolha negativo, a palavra impressa BALA.

Quanto à ocorrência dos três erros, em tentativas $\mathrm{BC}$, os mesmos ocorreram de formas diversas: 1. perante uma das tentativas com o estímulo modelo formado pela figura de bola, o Participante 2 escolheu o estímulo de escolha negativo formado pela palavra impressa CACO e 2. em outra tentativa com o estímulo modelo formado pela figura de bala este participante escolheu o estímulo de escolha negativo CACO e 3. perante uma das tentativas com o estímulo modelo coca, o participante escolheu o estímulo de escolha negativo BOLA, o que classifica esse erro como tendo 2LC, OSC, com as $2^{\mathrm{a}}$ e $4^{\mathrm{a}}$ letras situadas na mesma direção).

Na Figura 31 pode ser observado que o Participante 2 realizou um erro em tentativas do tipo $\mathrm{CB}$ que, como ressaltado anteriormente, não foram contabilizados como possíveis de serem categorizados como contendo diferenças críticas ou múltiplas. Diante do estímulo modelo formado pela palavra impressa CACO, este participante escolheu o estímulo de escolha negativo formado pela figura de bala. Este erro está destacado na Figura 31 por meio do quadrado com riscos oblíquos e em negrito. 
$\mathrm{M}=$ modelo $-\mathrm{E}=$ escolha

\begin{tabular}{|c|c|c|c|c|}
\hline $\mathbf{M} / \mathbf{E}$ & caco & bala & coca & bola \\
\hline caco & - & $\mathbf{T} \mathbf{T}$ & - & - \\
\hline bala & 1 & - & - & - \\
\hline coca & 1 & - & - & 1 \\
\hline bola & 1 & 2 & - & - \\
\hline
\end{tabular}

Figura 31. Matriz com erros do Participante 2, nas tentativas do Teste de Equivalência II ( $\left.\mathrm{B}^{\prime} \mathrm{C}^{\prime} / \mathrm{C}^{\prime} \mathrm{B}^{\prime}\right)$, para o segundo conjunto de palavras.

Na Figura 32 estão sistematizados os erros ocorridos durante o Teste de Novas Formas Verbais II ( $\left.\mathrm{B}^{\prime} \mathrm{C}^{\prime} / \mathrm{C}^{\prime} \mathrm{B}^{\prime}\right)$ que ocorreu após o segundo treino entre palavras ditadas e as figuras do terceiro conjunto de estímulos (Treino $\mathrm{A}^{\prime \prime} \mathrm{B}^{\prime \prime}$ ), sem o treino direto entre palavras ditadas e impressas. Foi observada a ocorrência de cinco erros; todas as tentativas em que ocorreram erros eram do tipo BC. Um deles ocorreu quando o estímulo modelo era formado pela figura de lolo e o Participante 2 escolheu o estímulo de escolha negativo formado pela palavra impressa BOBO e, o outro ocorreu em uma tentativa em que o estímulo modelo formado pela figura de loca foi apresentado e a escolha do Participante 2, ao invés de ser feita pelo estímulo de escolha positivo, foi feita para o estímulo de escolha negativo, a palavra impressa LOLO.

Quanto à ocorrência dos outros três erros, perante duas das tentativas com o estímulo modelo da figura loca, o participante escolheu o estímulo de escolha negativo CALO, o que também ocorreu inversamente: em outra tentativa com o estímulo modelo formado pela figura calo, o participante escolheu o estímulo de escolha negativo LOCA. 
$\mathrm{M}=$ modelo $-\mathrm{E}=$ escolha

\begin{tabular}{|c|c|c|c|c|}
\hline $\mathbf{M} / \mathbf{E}$ & bobo & calo & lolo & loca \\
\hline bobo & - & - & - & - \\
\hline calo & - & - & - & 1 \\
\hline lolo & 1 & - & - & - \\
\hline loca & - & 2 & 1 & - \\
\hline
\end{tabular}

Figura 32. Matriz com erros do Participante 2, nas tentativas do Testes de Novas Formas Verbais II $\left(\mathrm{B}^{\prime \prime} \mathrm{C}^{\prime \prime} / \mathrm{C}^{\prime \prime} \mathrm{B}^{\prime \prime}\right)$, para o terceiro conjunto de estímulos.

No Teste de Nomeação Oral III (realizado após o segundo Teste de Novas Formas Verbais $\left.\mathrm{B}^{\prime} \mathrm{C}^{\prime} / \mathrm{C}^{\prime} \mathrm{B}^{\prime}\right)$, o Participante 2 errou a nomeação de palavras impressas dos três conjuntos de estímulos. Em relação ao primeiro conjunto de estímulos (C), como pode ser visualizado na Figura 33, em uma das tentativas nas quais foi apresentada a palavra impressa BOLO, a resposta do Participante 2 foi 'Não sei', o que impede a posterior categorização deste erro como contendo diferença crítica ou múltipla.

$\mathrm{M}=$ modelo $-\mathrm{N}=$ Possíveis respostas de nomeação

\begin{tabular}{|l|c|c|c|c|}
\hline $\mathbf{M} / \mathbf{N}$ & boca & lobo & bolo & cabo \\
\hline boca & - & - & - & - \\
\hline lobo & - & - & - & - \\
\hline bolo* & - & - & - & - \\
\hline cabo & - & - & - & - \\
\hline
\end{tabular}

* O Participante 2 emitiu a resposta "Não sei” em uma das apresentações da palavra impressa BOLO.

Figura 33. Matriz com erros do Participante 2, nas tentativas do Teste de Nomeação Oral III (Conjunto C).

Como pode ser observado na Figura 34, em relação ao segundo conjunto de estímulos $\left(C^{\prime}\right)$ Teste de Nomeação III, em três tentativas nas quais foi apresentada a palavra impressa BOLA, a resposta do Participante 2 foi 'Não sei', o que também impediu a categorização destes erros como contendo diferença críticas ou múltiplas. 
Porém, em uma das tentativas de apresentação da palavra impressa BALA, a resposta de nomeação foi "bola".

$\mathrm{M}=$ modelo $-\mathrm{N}=$ Possíveis respostas de nomeação

\begin{tabular}{|c|c|c|c|c|}
\hline $\mathbf{M} / \mathbf{N}$ & caco & bala & coca & bola \\
\hline caco & - & - & - & - \\
\hline bala & - & - & - & 1 \\
\hline coca & - & - & - & - \\
\hline bola* & - & - & - & - \\
\hline
\end{tabular}

* O Participante 2 emitiu as respostas "Não sei" perante três apresentações da palavra impressa BOLA.

Figura 34. Matriz com erros do Participante 2, nas tentativas do Teste de Nomeação Oral III (Conjunto $\left.\mathrm{C}^{\prime}\right)$.

Como também pode ser observado na Figura 35, em relação ao terceiro conjunto de estímulos $\left(\mathrm{C}^{\prime \prime}\right)$ do Teste de Nomeação III, em uma tentativa na qual foi apresentada a palavra impressa BOBO, a resposta do Participante 2 foi 'Não sei', o que novamente impediu a posterior categorização destes erros como contendo diferença crítica ou múltipla; o mesmo ocorreu mediante a apresentação da palavra impressa CALO, o participante verbalizou 'Não sei' duas vezes. Porém, em uma das tentativas de apresentação da palavra impressa LOCA, a resposta de nomeação foi "loco", uma palavra que não está presente em nenhum dos três conjuntos de estímulos apresentados a este participante, mas que tem uma similaridade com LOCA. 
$\mathrm{M}=$ modelo $-\mathrm{N}=$ Possíveis respostas de nomeação

\begin{tabular}{|c|c|c|c|c|}
\hline $\mathbf{M} / \mathbf{N}$ & lolo & bobo & calo & loca \\
\hline lolo & - & - & - & - \\
\hline bobo* $^{*}$ & - & - & - & - \\
\hline calo** $^{*}$ & - & - & - & - \\
\hline loca*** $^{*}$ & - & - & - & - \\
\hline
\end{tabular}

* O Participante 2 emitiu as respostas "Não sei" perante uma apresentação da palavra impressa BOBO.

** O Participante 2 emitiu as respostas "Não sei" perante duas apresentações da palavra impressa CALO.

*** O Participante 2 emitiu a resposta de nomeação "loco" perante uma apresentação da palavra impressa LOCA.

Figura 35. Matriz com erros do Participante 2, nas tentativas do Teste de Nomeação Oral III (Conjunto $\left.\mathrm{C}^{\prime \prime}\right)$.

\section{Participante 3:}

O Participante 3 não realizou nenhum erro durante o Treino $\mathrm{AC}$ e, também, no Teste de Equivalência I. Já, no Teste de Novas Formas Verbais I, o Participante 3 emitiu erros em tentativas BC, como é possível observar na Figura 36; além disso, este participante também erros em tentativas do tipo CB que não foram passíveis de serem contabilizados como contendo diferenças críticos ou múltiplas, tais erros podem ser vistos na Figura 36 pelos quadrados preenchidos com traços oblíquos e, também, com os números seguidos de asteriscos.

Quanto aos erros do tipo BC, um deles ocorreu diante de uma tentativa de apresentação do estímulo modelo representado pela figura de coca, ao invés do Participante 3 escolher o estímulo de escolha positivo, o mesmo escolheu o estímulo de escolha negativo formado pela palavra impressa BOLA; inversamente, o mesmo ocorreu, perante o estímulo modelo com a figura bola, o participante escolheu a palavra impressa COCA. Houve outros erros que também podem ser visualizados na Figura 36, deste Anexo; quando o estímulo modelo formado pela figura de caco foi apresentado ao Participante 3, ocorreu um erro pois ele escolheu como estímulo de escolha negativo a 
palavra impressa BALA, em detrimento da escolha do respectivo estímulo de escolha positivo.

Em outras quatro tentativas nas quais o estímulo modelo formado pela figura de coca foi apresentado ao Participante 3, ele escolheu como estímulo de escolha negativo a palavra impressa BALA e, inversamente, quando o estímulo modelo formado pela figura de bala foi apresentado, o estímulo de escolha negativo escolhido foi COCA, em detrimento da escolha dos respectivos estímulos de escolha positivos.

$\mathrm{M}=$ modelo $-\mathrm{E}=$ escolha

\begin{tabular}{|c|c|c|c|c|}
\hline $\mathbf{M} / \mathbf{E}$ & caco & bala & coca & bola \\
\hline caco & - & 1 & $2-1 *$ & - \\
\hline bala & III & - & 1 & III \\
\hline coca & $1-2^{*}$ & 4 & - & 1 \\
\hline bola & - & $5-6^{*}$ & 1 & - \\
\hline
\end{tabular}

Figura 36. Matriz com erros do Participante 3, nas tentativas do Teste de Novas Formas Verbais I $\left(\mathrm{B}^{\prime} \mathrm{C}^{\prime} / \mathrm{C}^{\prime} \mathrm{B}^{\prime}\right)$, para o segundo conjunto de estímulos.

Outros erros envolvendo tentativas do tipo $\mathrm{BC}$ ocorreram da seguinte forma:

1. Perante duas apresentações do estímulo modelo formado pela figura de caco ao Participante 3, o mesmo escolheu como estímulo de escolha negativo a palavra impressa COCA e, inversamente, quando o estímulo modelo era formado pela figura de coca foi apresentado, em uma tentativa deste tipo, o estímulo de escolha negativo escolhido foi CACO, em detrimento da escolha do respectivo estímulo de escolha positivo.

2. Em cinco apresentações do estímulo modelo formado pela figura de bola ao Participante 3, como pode ser visualizado na Figura 36, o mesmo escolheu como estímulo de escolha negativo a palavra impressa BALA. 
Na Figura 36 pode ser observado que o Participante 3 realizou 15 erros em tentativas do tipo $\mathrm{CB}$ que, como ressaltado anteriormente, não foram contabilizados para serem categorizados como contendo diferenças críticas ou múltiplas. Diante de duas tentativas do estímulo modelo formado pela palavra impressa BALA, este participante escolheu o estímulo de escolha negativo formado pela figura de caco; também escolheu a figura de bola quatro vezes perante a apresentação do estímulo modelo formado pela palavra impressa BALA. Estes erros estão destacados na Figura 36 por meio dos quadrados com riscos oblíquos e em negrito.

Ainda em relação à ocorrência de tentativas $\mathrm{CB}$ : diante de seis tentativas do estímulo modelo formado pela palavra impressa BOLA, este participante escolheu o estímulo de escolha negativo formado pela figura de bala; também escolheu a figura de caco duas vezes perante a apresentação do estímulo modelo formado pela palavra impressa COCA. Além disso, perante o estímulo modelo formado pela palavra impressa CACO, o participante escolheu a figura de coca como estímulo de escolha negativo. Estes erros estão destacados na Figura 36 por meio de asteriscos, pois envolvem os mesmos estímulos daqueles erros relativos à tentativas do tipo $\mathrm{BC}$.

No Teste de Nomeação Oral II (realizado após o Teste de Novas Formas Verbais I - BC/CB), o Participante 3 errou a nomeação de palavras impressas dos dois conjuntos de estímulos de estímulos apresentados, totalizando cinco erros. Como pode ser visualizado na Figura 37, em relação ao primeiro conjunto de estímulos (C), em uma das tentativas na qual a palavra impressa BOCA foi apresentada, a resposta de nomeação do participante foi "cabo". Como também pode ser notado na Figura 37, por meio do asterisco que segue a palavra BOCA, em duas tentativas em que esta palavra foi apresentada na forma impressa, as duas respostas de nomeação foi "coca", que é uma palavra do segundo conjunto de estímulos. 
$\mathrm{M}=$ modelo $-\mathrm{N}=$ Possíveis respostas de nomeação

\begin{tabular}{|c|c|c|c|c|}
\hline $\mathbf{M} / \mathbf{N}$ & boca & lobo & bolo & cabo \\
\hline boca* & - & - & - & 1 \\
\hline lobo & - & - & - & - \\
\hline bolo & - & - & - & - \\
\hline cabo & - & - & - & - \\
\hline
\end{tabular}

* O Participante 3 emitiu a resposta de nomeação "coca" perante duas apresentações da palavra impressa BOCA.

Figura 37. Matriz com erros do Participante 3, nas tentativas do Teste de Nomeação Oral II (Conjunto C).

Em relação ao desempenho do Participante 3 no Teste de Nomeação II, para o segundo conjunto de estímulos $\left(\mathrm{C}^{\prime}\right)$, como pode ser visualizado na Figura 38, em uma das tentativas na qual a palavra impressa CACO foi apresentada, a resposta de nomeação do participante foi "coca". Além disso, também pode ser notado na Figura 38, por meio do asterisco que segue a palavra CACO, em uma das tentativas em esta palavra foi apresentada na forma impressa, a resposta de nomeação foi "cabo".

$\mathrm{M}=$ modelo $-\mathrm{N}=$ Possíveis respostas de nomeação

\begin{tabular}{|c|c|c|c|c|}
\hline $\mathbf{M} / \mathbf{N}$ & caco & bala & coca & bola \\
\hline caco* & - & - & 1 & - \\
\hline bala & - & - & - & - \\
\hline coca & - & - & - & - \\
\hline bola & - & - & - & - \\
\hline
\end{tabular}

* O Participante 3 emitiu a resposta de nomeação "coca" perante uma apresentação da palavra impressa CACO.

Figura 38. Matriz com erros do Participante 3, nas tentativas do Teste de Nomeação Oral II (Conjunto $\left.\mathrm{C}^{\prime}\right)$.

Durante o segundo treino de discriminações condicionais entre palavras ditadas e palavras impressas para o segundo conjunto de estímulos (Treino $\mathrm{A}^{\prime} \mathrm{C}^{\prime}$ ) foi observada a ocorrência de um erro, como pode ser observado na Figura 39. Perante a tentativa com 
o estímulo modelo formado pela palavra auditiva "bala", o Participante 3 escolheu o estímulo de escolha negativo formado pela palavra impressa BOLA.

$\mathrm{M}=$ modelo $-\mathrm{E}=$ escolha

\begin{tabular}{|c|c|c|c|c|}
\hline $\mathbf{M} / \mathbf{E}$ & caco & bala & coca & bola \\
\hline caco & - & - & - & - \\
\hline bala & - & - & - & 1 \\
\hline coca & - & - & - & - \\
\hline bola & - & - & - & - \\
\hline
\end{tabular}

Figura 39. Matriz com erros do Participante 3 nas tentativas de Treino A'C', para o segundo conjunto de palavras.

Durante o Teste de Equivalência II ( $\left(\mathrm{B}^{\prime} \mathrm{C}^{\prime} / \mathrm{C}^{\prime} \mathrm{B}{ }^{\prime}\right)$, realizado após o Treino $\mathrm{A}^{\prime} \mathrm{C}^{\prime}$, também foi observada a ocorrência de dois erros, como pode ser observado na Figura 40. Perante uma tentativa com o estímulo modelo formado pela figura bala, o Participante 3 escolheu o estímulo de escolha negativo formado pela palavra impressa BOLA, sendo que o inverso também ocorreu: em uma tentativa com a figura de bola, este participante escolheu o estímulo de escolha negativo formado pela palavra impressa BALA.

$\mathrm{M}=$ modelo $-\mathrm{E}=$ escolha

\begin{tabular}{|c|c|c|c|c|}
\hline $\mathbf{M} / \mathbf{E}$ & caco & bala & coca & bola \\
\hline caco & - & - & - & - \\
\hline bala & - & - & - & 1 \\
\hline coca & - & - & - & - \\
\hline bola & - & 1 & - & - \\
\hline
\end{tabular}

Figura 40. Matriz com erros do Participante 3, nas tentativas de Testes de Equivalência II (B' $\left.\mathrm{C}^{\prime} / \mathrm{C}^{\prime} \mathrm{B}^{\prime}\right)$, para o segundo conjunto de estímulos.

Na Figura 41 estão sistematizados os erros realizados pelo Participante 3 durante o Teste de Novas Formas Verbais II, novamente este participante demonstrou um 
número de erros considerável neste tipo de teste (28 erros); no Teste de Novas Formas Verbais II ele havia emitido 34 erros. Deste total de erros, quinze deles não foram passíveis de serem categorizados como contendo diferenças críticas ou múltiplas, já que ocorreram em tentativas do tipo $\mathrm{CB}$; tais erros podem ser vistos na Figura 41 pelos quadrados preenchidos com traços oblíquos e, também, com os números seguidos de asteriscos.

Quanto aos treze erros ocorridos durante as tentativas BC, um deles ocorreu diante de duas tentativas de apresentação do estímulo modelo representado pela figura de baba; ao invés do Participante 3 escolher o estímulo de escolha positivo, o mesmo escolheu o estímulo de escolha negativo formado pela palavra impressa COLO. Os outros onze erros também podem ser visualizados na Figura 41, deste Anexo, por exemplo, quando o estímulo modelo formado pela figura de lolo foi apresentado ao Participante 3, ocorreu um erro pois ele escolheu como estímulo de escolha negativo a palavra impressa BABA e, inversamente, quando o estímulo modelo formado pela figura de baba foi apresentado em uma das tentativas, o estímulo de escolha negativo escolhido foi 'lolo', em detrimento da escolha dos respectivos estímulos de escolha positivos.

$\mathrm{M}=$ modelo $-\mathrm{E}=$ escolha

\begin{tabular}{|c|c|c|c|c|}
\hline $\mathbf{M} / \mathbf{E}$ & baba & lolo & loco & colo \\
\hline baba & - & 1 & 3 & 2 \\
\hline lolo & $1-3^{*}$ & - & $2-3 *$ & 2 \\
\hline loco & - & $1-3^{*}$ & - & I \\
\hline colo & - & $4-3^{*}$ & I & - \\
\hline
\end{tabular}

Figura 41. Matriz com erros do Participante 3, nas tentativas do Teste de Novas Formas Verbais II $\left(\mathrm{B}^{\prime \prime} \mathrm{C}^{\prime \prime} / \mathrm{C}^{\prime \prime} \mathrm{B}^{\prime \prime}\right)$ para o terceiro conjunto de estímulos.

Quanto aos nove erros restantes do tipo BC: Perante quatro apresentações do estímulo modelo formado pela figura de colo ao Participante 3, o mesmo escolheu como 
estímulo de escolha negativo a palavra impressa LOLO e, inversamente, quando o estímulo modelo formado pela figura de lolo foi apresentado, em duas tentativas deste tipo, o estímulo de escolha negativo escolhido foi COLO.

Como também pode ser visualizado na Figura 41, em uma apresentação do estímulo modelo formado pela figura de loco, este participante escolheu como estímulo de escolha negativo a palavra impressa LOLO e, inversamente, quando o estímulo modelo formado pela figura de lolo foi apresentado, em duas tentativas deste tipo, o estímulo de escolha negativo escolhido foi LOCO, em detrimento da escolha dos respectivos estímulos de escolha positivos.

Na Figura 41 pode ser observado que o Participante 2 realizou quinze erros em tentativas do tipo $\mathrm{CB}$ que, como ressaltado anteriormente, não passíveis de serem foram contabilizadas como contendo diferenças críticas ou múltiplas. Diante de uma tentativa do estímulo modelo formado pela palavra impressa BABA, este participante escolheu o estímulo de escolha negativo formado pela figura de loco; também escolheu a figura de colo uma vez perante a apresentação do estímulo modelo formado pela palavra impressa LOCO. Além disso, escolheu a figura de loco, também uma vez, diante da apresentação do estímulo modelo formado pela palavra impressa COLO. Estes erros estão destacados na Figura 41 por meio dos quadrados com riscos oblíquos e em negrito.

Ainda em relação à ocorrência de tentativas $\mathrm{CB}$ : diante de três tentativas do estímulo modelo formado pela palavra impressa LOCO, este participante escolheu o estímulo de escolha negativo formado pela figura de lolo e, em outras três tentativas, diante do estímulo modelo formado pela palavra impressa LOLO escolheu a figura de loco; também escolheu a figura de $b a b a$ três vezes perante a apresentação do estímulo modelo formado pela palavra impressa LOLO. Estes erros estão destacados na Figura 
41 por meio de asteriscos, pois envolvem os mesmos estímulos daqueles que erros relacionados à tentativas do tipo $\mathrm{BC}$.

O Participante 3 não apresentou nenhum erro durante o Teste de Equivalência III, durante o Teste de Novas Formas Verbais III e, também, durante o último Teste de Nomeação Oral III relativo aos primeiro, segundo e terceiro conjuntos de estímulos formados pelas respectivas palavras impressas. 
ANEXO 3 
I - DADOS DE IDENTIFICAÇÃO DO PARTICIPANTE DA PESQUISA OU RESPONSÁVEL LEGAL

\section{NOME DO}

PARTICIPANTE:

DOCUMENTO DE IDENTIDADE $\mathrm{N}^{\circ}$ : SEXO: $\mathrm{M} \square \mathrm{F}$

DATA DE NASCIMENTO:.........................

ENDEREÇO: $\mathrm{N}^{\circ}$

APTO: BAIRRO: CIDADE:

CEP: TELEFONE: DDD ).

\section{RESPONSÁVEL}

LEGAL:.

NATUREZA (grau de parentesco):

DOCUMENTO DE IDENTIDADE $\mathrm{N}^{\circ}$ : SEXO: $\mathrm{M} \square \mathrm{F}$

DATA DE NASCIMENTO:.........................

ENDEREÇO: $\mathrm{N}^{\circ}$

APTO BAIRRO: CIDADE:

CEP. TELEFONE:DDD(....... ..).

II - DADOS SOBRE A PESQUISA CIENTÍFICA

1.TÍTULO DO PROTOCOLO DE PESQUISA: Padrões de aquisição de discriminação condicional durante a emergência do controle por unidades verbais mínimas em leitura em crianças com autismo e desenvolvimento típico.

2.PESQUISADORA: Leila Bagaiolo

3.CARGO/FUNÇÃO: Pesquisadora do Programa de Estudos Pós - Graduados em Psicologia Experimental: Análise do Comportamento da Universidade de São Paulo 
III - REGISTRO DAS EXPLICAÇÕES DO PESQUISADOR AO PARTICIPANTE DA PESQUISA OU SEU REPRESENTANTE LEGAL, CONSIGNANDO:

1. O objetivo do presente estudo foi investigar variáveis relevantes durante o ensino de leitura via o paradigma de equivalência, sobretudo na emergência do controle por unidades verbais mínimas na leitura recombinativa

2. Os procedimentos utilizados serão:

a) O participante será instruído a combinar palavras impressas em relação as respectivas palavras ditadas; além disso, aprenderá a formar palavras por meio de unidades mínimas(letras e/ou sílabas) e será testado se o mesmo aprendeu a recombinar tais unidades mínimas na leitura de palavras não ensinadas diretamente.

b) O participante será informado sobre os objetivos e métodos da pesquisa e deverá dar seu consentimento por escrito conforme os princípios éticos que norteiam a pesquisa com seres humanos. O participante poderá interromper a participação em qualquer Fase da pesquisa. As informações obtidas na presente pesquisa poderão ser divulgadas em congressos científicos e haverá garantia de anonimato e de sigilo. A identidade do participante não será revelada em nenhuma publicação ou exposição em congresso.

3. O participante não correrá nenhum risco.

\section{IV - ESCLARECIMENTOS DADOS PELO PESQUISADOR SOBRE GARANTIAS DO PARTICIPANTE DA PESQUISA:}

1. Acesso, a qualquer momento, às informações sobre procedimentos relacionados à pesquisa, inclusive para dirimir eventuais dúvidas.

2. Liberdade de retirar seu consentimento a qualquer momento e de deixar de participar do estudo. 
3. Salvaguarda da confidencialidade, sigilo e privacidade.

Data

1

Assinatura do Pesquisador(a)

ASSINATURA do RESPONSÁVEL LEGAL 
ANEXO 4 


\section{Folha de Registro da Avaliação de Preferência com}

\section{Múltiplos Estímulos}

(adaptada de DeLeon \& Iwata, 1996)

Participante:

Esperimentador(a):

Data:

Itens:

1.

2.

3.

4.

5.

6.

7.

\begin{tabular}{|c|c|}
\hline Circule a posição & Item selecionado \\
\hline x x x x x x x & \\
\hline x x x x x x & \\
\hline x x x x x & \\
\hline x x x x & \\
\hline x x x & \\
\hline x & \\
\hline
\end{tabular}


ANEXO 5 
2: Folhas de registro do ABLA teste (Traduzido e adaptado de DeWiele e Martin, 1998).

\section{Nível 1 (Imitação)}

Pergunta-se "Onde é que isto vai?"

Critério de aprovação definido por 8 respostas corretas consecutivas ( 4 com espuma + caixa; 4 com espuma + lata)
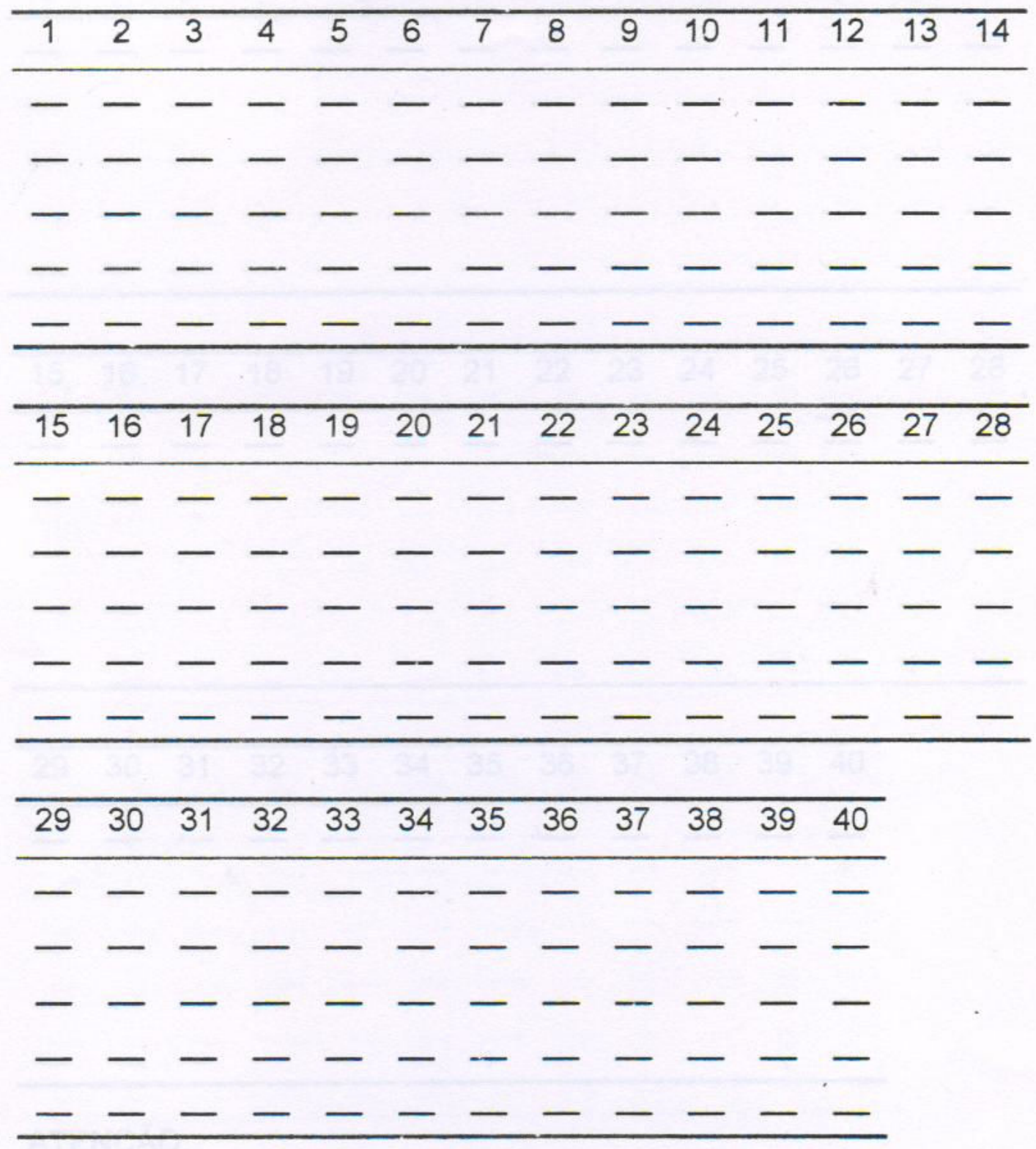

ATENÇÃO:

$\checkmark 8$ corretas consecutivas: contando apenas os números circulados e não os acertos nas tentativas de correção (acertos nas linhas). Vá para o próximo Nivel.

$\checkmark 8$ erradas consecutivas ou não: contatando erros nos números e erros nas tentativas de correção. Pare! Acabou a testagem. 


\section{Nível 2 (Discriminação de Posição)}

Lata e Caixa em posição fixa.

Pergunta-se "Onde è que isto vai?".

A resposta correta é colocar a espuma dentro da lata.

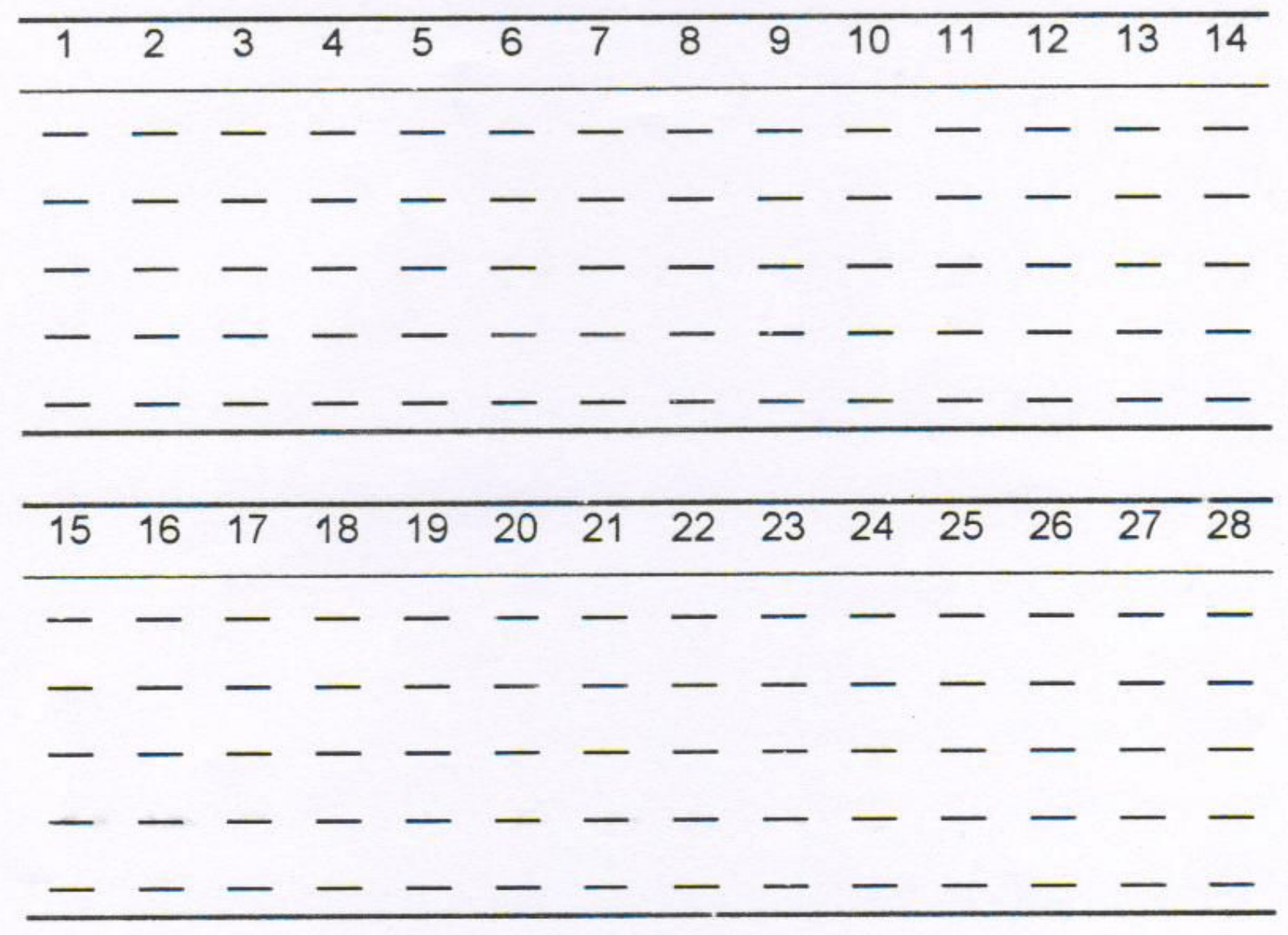

\begin{tabular}{llllllllllll}
\hline 29 & 30 & 31 & 32 & 33 & 34 & 35 & 36 & 37 & 38 & 39 & 40
\end{tabular}

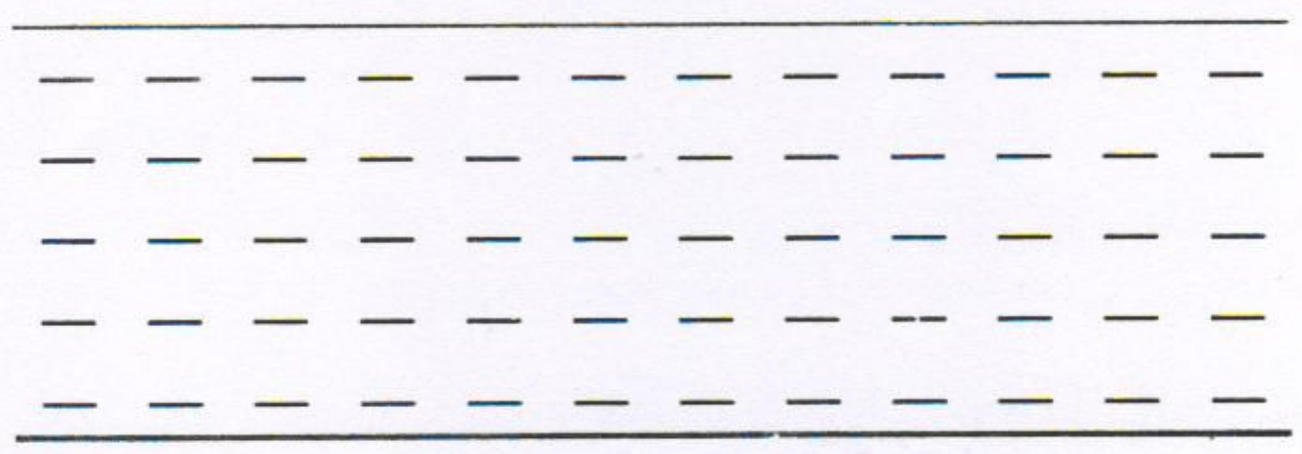

ATENÇÃO:

$\checkmark 8$ corretas consecutivas: contando apenas os números circulados e não os acertos nas tentativas de correção (acertos nas linhas). Vá para o próximo Nivel.

$\checkmark 8$ erradas consecutivas ou não: contatando erros nos números e erros nas tentativas de correção. Pare! Acabou a testagem. 


\section{Nível 3 (Discriminação Visual)}

"D" (direita) e "E" (esquerda) indicam as posições da lata em cada tentativa.

Pergunta-se "Onde é que isto vai?".

A resposta correta é colocar a espuma dentro da

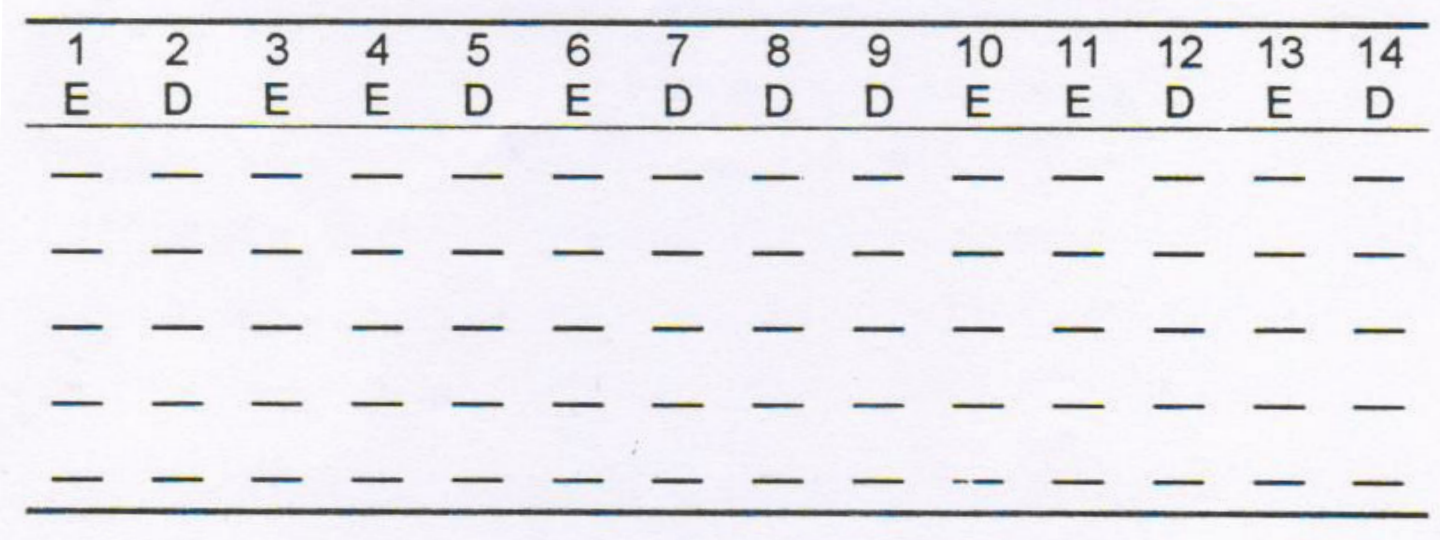

\begin{tabular}{llllllllllllll}
\hline 15 & 16 & 17 & 18 & 19 & 20 & 21 & 22 & 23 & 24 & 25 & 26 & 27 & 28 \\
$E$ & $E$ & $D$ & $E$ & $D$ & $D$ & $E$ & $D$ & $D$ & $D$ & $E$ & $D$ & $E$ & $E$ \\
\hline
\end{tabular}

\begin{tabular}{cccccccccccc}
\hline 29 & 30 & 31 & 32 & 33 & 34 & 35 & 36 & 37 & 38 & 39 & 40 \\
$E$ & $D$ & $D$ & $E$ & $D$ & $E$ & $E$ & $D$ & $E$ & $D$ & $D$ & $E$ \\
\hline
\end{tabular}

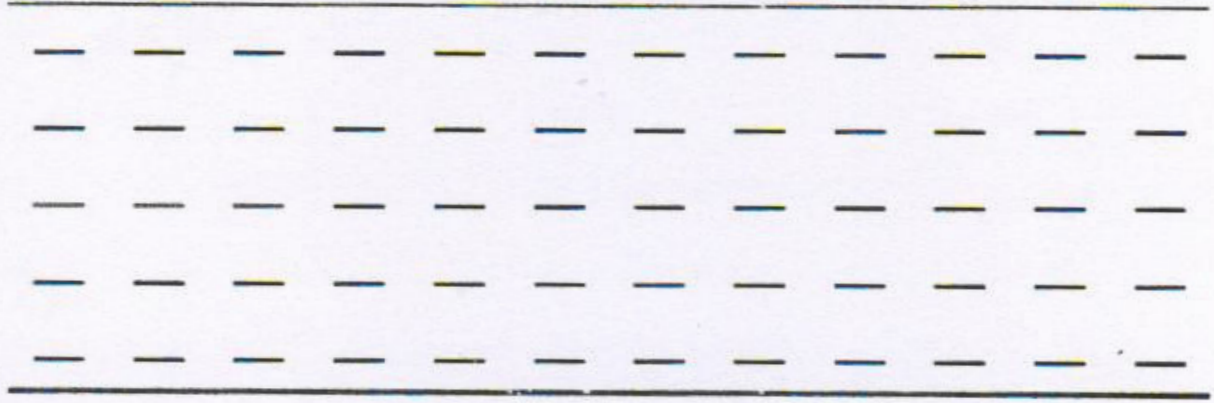

ATENÇÃO:

$\checkmark 8$ corretas consecutivas: contando apenas os números circulados e não os acertos nas tentativas de correção (acertos nas linhas). Vá para o próximo Nivel.

$\checkmark 8$ erradas consecutivas ou não: contatando erros nos números e erros nas tentativas de correção. Pare! Acabou a testagem. 


\section{Nivel 4 (Escolha de Acordo com o Modelo)}

"D" (direita) e "E" (esquerda) indicam as posições da lata em cada tentativa.

"b" indica que o pequeno cubo deverá ser apresentado.

" $c$ " indica que o cilindro deverá ser apresentado.

Pergunta-se "Onde é que isto vai?".

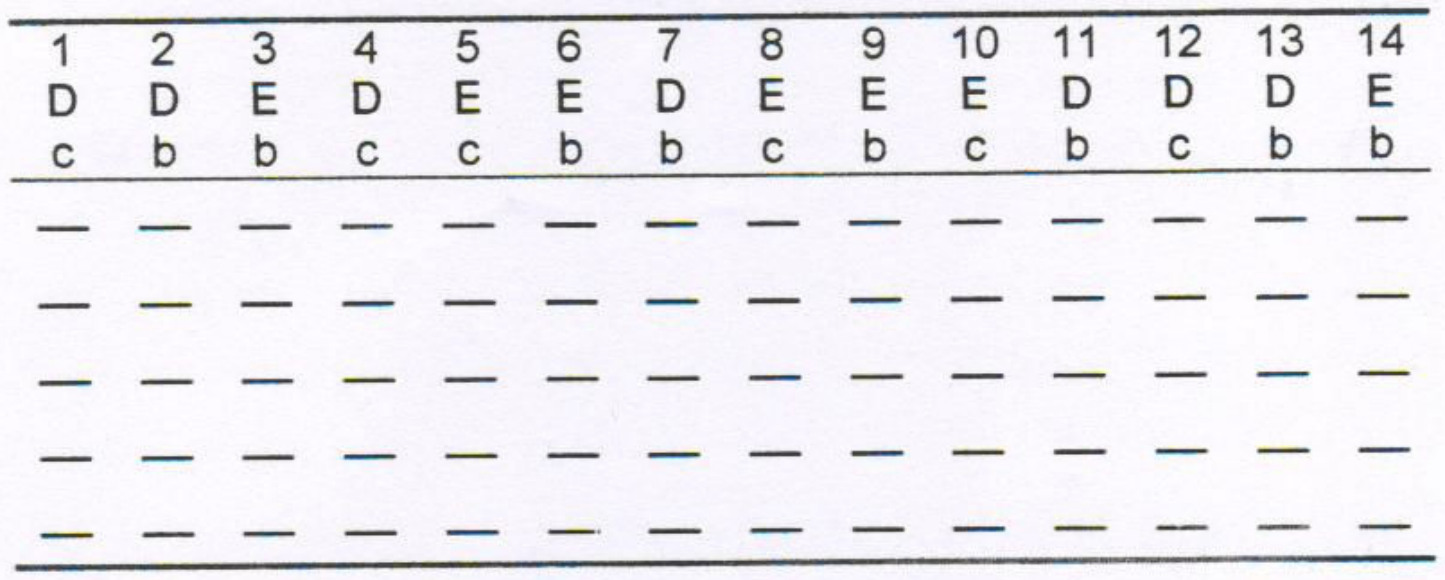

\begin{tabular}{lccccccccccccc}
\hline 15 & 16 & 17 & 18 & 19 & 20 & 21 & 22 & 23 & 24 & 25 & 26 & 27 & 28 \\
$\mathrm{E}$ & $\mathrm{E}$ & $\mathrm{D}$ & $\mathrm{E}$ & $\mathrm{D}$ & $\mathrm{D}$ & $\mathrm{E}$ & $\mathrm{D}$ & $\mathrm{E}$ & $\mathrm{D}$ & $\mathrm{E}$ & $\mathrm{E}$ & $\mathrm{D}$ & $\mathrm{D}$ \\
$\mathrm{b}$ & $\mathrm{C}$ & $\mathrm{C}$ & $\mathrm{C}$ & $\mathrm{b}$ & $\mathrm{C}$ & $\mathrm{b}$ & $\mathrm{b}$ & $\mathrm{b}$ & $\mathrm{b}$ & $\mathrm{c}$ & $\mathrm{C}$ & $\mathrm{C}$ & $\mathrm{b}$ \\
\hline- & - & - & - & - & - & - & - & - & - & - & - & - & - \\
- & - & - & - & - & - & - & - & - & - & - & - & - & - \\
- & - & - & - & - & - & - & - & - & - & - & - & - & - \\
- & - & - & - & - & - & - & - & - & - & - & - & - & -
\end{tabular}

\begin{tabular}{cccccccccccc}
\hline 29 & 30 & 31 & 32 & 33 & 34 & 35 & 36 & 37 & 38 & 39 & 40 \\
$E$ & $D$ & $E$ & $E$ & $D$ & $D$ & $E$ & $E$ & $E$ & $D$ & $E$ & $E$ \\
$b$ & $b$ & $c$ & $c$ & $c$ & $b$ & $b$ & $c$ & $c$ & $b$ & $b$ & $c$ \\
\hline
\end{tabular}

ATENÇÃO:

$\checkmark 8$ corretas consecutivas: contando apenas os números circulados e não os acertos nas tentativas de correção (acertos ras linhas). Vá para o próximo Nível.

$\checkmark 8$ erradas consecutivas ou não: contatando erros nos números e erros nas tentativas de correção. Pare! Acabou a testagem. 


\section{Nivel 6 (Pareamento Auditivo Visual)}

" $D$ " (direita) e "E" (esquerda) indicam as posições da lata em cada tentativa.

"CA" indica que o experimentador deve verbalizar "Caixa Vermelha".

"LA" indica que o experimentador deve verbalizar "Lata Amarela".
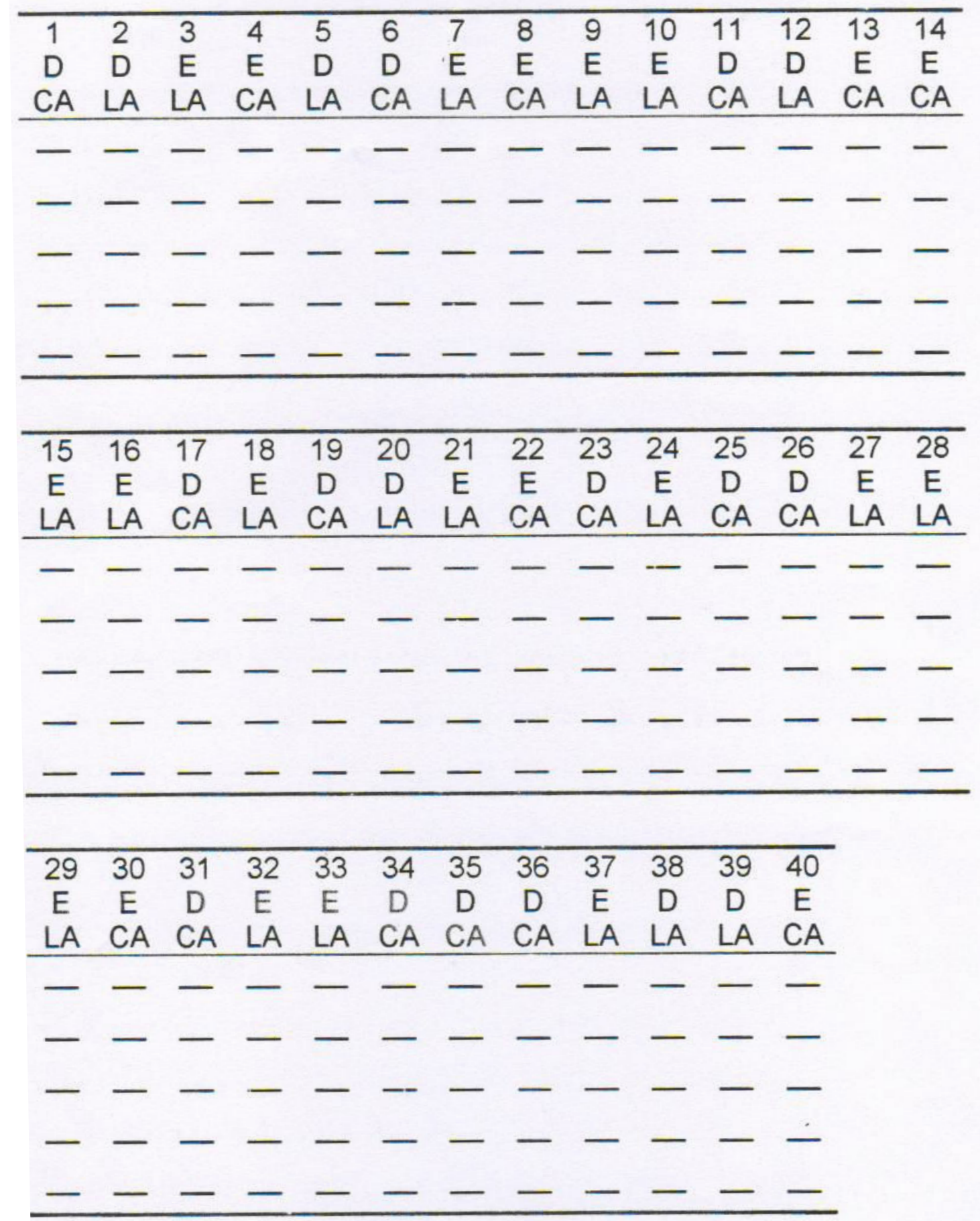

ATENÇÃO:

$\checkmark 8$ corretas consecutivas: contando apenas os números circulados e não os acertos nas tentativas de correção (acertos nas linhas). Vá para o próximo Nivel.

$\checkmark 8$ erradas consecutivas ou não: contatando erros nos números e erros nas tentativas de correção. Pare! Acabou a testagem. 
ANEXO 6 


\section{$\underline{\text { Participante } 4 \text { (Figura 42) }}$}

Na Figura 42 estão os dados relativos à ocorrência de erros, da Participante 4, durante as tarefas de MTS relativas ao Treino AC (para o primeiro conjunto de estímulos; os estímulos modelo são palavras ditadas e os estímulos de escolha positivos e negativos são palavras impressas.

$\mathrm{M}=$ modelo $-\mathrm{E}=$ escolha

\begin{tabular}{|c|c|c|c|c|}
\hline $\mathbf{M} / \mathbf{E}$ & boca & lobo & bolo & cabo \\
\hline boca & - & 29 & 6 & 18 \\
\hline lobo & 11 & - & 113 & - \\
\hline bolo & 3 & 88 & - & 12 \\
\hline cabo & 14 & 15 & 7 & - \\
\hline
\end{tabular}

Figura 42. Matriz com erros do Participante 4, nas tentativas do Treino AC, para o primeiro conjunto de estímulos.

Na Figura 42 é possível observar que nas tentativas em que o estímulo modelo auditivo, a palavra ditada "boca", foi apresentado ao Participante 4, ocorreram 53 erros: 29 vezes ele escolheu como estímulos de escolha negativos a palavra impressa LOBO, seis vezes escolheu a palavra impressa BOLO e, dezoito vezes ele escolheu a palavra impressa $\mathrm{CABO}$, em detrimento da escolha do estímulo de escolha positivo, a palavra impressa BOCA.

Durante as tentativas em que o estímulo modelo auditivo "lobo", ocorreram 124 erros, realizou onze erros escolhendo a palavra impressa BOCA, 113 erros escolhendo como estímulo escolha negativo a palavra impressa BOLO. Quando o estímulo modelo "bolo" foi apresentado ocorreram 103 erros: três vezes o participante escolheu o estímulo de escolha negativo pela palavra impressa BOCA, 88 vezes o estímulo negativo $\mathrm{LOBO}$ e, doze vezes o estímulos escolha negativo, a palavra impressa CABO.

Finalmente, ainda durante o Treino AC, durante as tentativas de apresentação do estímulo modelo auditivo formado pela palavra ditada "cabo", a Participante 4 escolheu 
quatorze vezes a palavra impressa BOCA; escolheu também quinze vezes, o estímulo de escolha negativo LOBO e, sete vezes a palavra impressa BOLO.

A Participante não realizou nenhum erro durante o Teste de Equivalência I (BC/CB), Anagrama I e Teste de Novas Formas Verbais I ( $\left.\mathrm{B}^{\prime} \mathrm{C}^{\prime} / \mathrm{C}^{\prime} \mathrm{B}^{\prime}\right)$. 